\title{
The institutional transformation of social transformation of social policy in East Central Europe : Poland and Hungary in comparative and historical perspective
}

Citation for published version (APA):

Polakowski, M. (2010). The institutional transformation of social transformation of social policy in East Central Europe : Poland and Hungary in comparative and historical perspective. [Doctoral Thesis, Maastricht University]. Boekenplan. https://doi.org/10.26481/dis.20101221mp

Document status and date:

Published: 01/01/2010

DOI:

10.26481/dis.20101221mp

Document Version:

Publisher's PDF, also known as Version of record

\section{Please check the document version of this publication:}

- A submitted manuscript is the version of the article upon submission and before peer-review. There can be important differences between the submitted version and the official published version of record. People interested in the research are advised to contact the author for the final version of the publication, or visit the DOI to the publisher's website.

- The final author version and the galley proof are versions of the publication after peer review.

- The final published version features the final layout of the paper including the volume, issue and page numbers.

Link to publication

\footnotetext{
General rights rights.

- You may freely distribute the URL identifying the publication in the public portal. please follow below link for the End User Agreement:

www.umlib.nl/taverne-license

Take down policy

If you believe that this document breaches copyright please contact us at:

repository@maastrichtuniversity.nl

providing details and we will investigate your claim.
}

Copyright and moral rights for the publications made accessible in the public portal are retained by the authors and/or other copyright owners and it is a condition of accessing publications that users recognise and abide by the legal requirements associated with these

- Users may download and print one copy of any publication from the public portal for the purpose of private study or research.

- You may not further distribute the material or use it for any profit-making activity or commercial gain

If the publication is distributed under the terms of Article $25 \mathrm{fa}$ of the Dutch Copyright Act, indicated by the "Taverne" license above, 


\section{THE INSTITUTIONAL TRANSFORMATION of SOCIAL POLICY IN EAST CENTRAL EUROPE:}

\section{POLAND AND HUNGARY IN COMPARATIVE AND HISTORICAL PERSPECTIVE}


(C) 2010 Michał Polakowski

Published by Boekenplan, Maastricht

ISBN 9789086661749

All rights reserved. No part of this publication may be reproduced, stored on a retrieval system, or transmitted in any form, or by any means, electronic, mechanical,

photocopying, recording or otherwise, without the prior permission in writing, from the author 


\section{THE INSTITUTIONAL TRANSFORMATION OF SOCIAL POLICY IN EAST CENTRAL EUROPE:}

\section{POLAND AND HUNGARY IN COMPARATIVE AND HISTORICAL PERSPECTIVE}

By

Michał Polakowski

\section{DISSERTATION}

to obtain the degree of Doctor at the Maastricht University, on the authority of the Rector Magnificus, Prof. dr. G. P. M. F. Mols, in accordance with the decision of the Board of Deans, to be defended in public on Tuesday 21 December 2010, at 14:00 hours 
Supervisor: Prof. Chris de Neubourg

Co-supervisor: Dr. Theodoros Papadopoulos, University of Bath, UK

Assessment committee:

Prof. Tannelie Blom (Chairman)

Prof. Thomas Christiansen

Dr. Maarten Vink

Prof. Jon Kvist, University of Southern Denmark, Denmark

Dr. Dorottya Szikra, Eötvös University, Hungary 


\section{ACKNOWLEDGMENTS}

Writing a PhD is never a one person project. It always involves a number of people who contribute to the final result. I would like to mention here those who have been important to me during these years.

Chris, Franziska and Mindel at the School provided me with a considerable degree of freedom, for which I am very grateful. I guess such freedom would be hardly possible in other places than the School. Susan and Celine patiently dealt with my requests and problems and definitely made my life in The Netherlands easier.

Theo continuously encouraged me to think about my own (as well as others') research critically. I will not forget our Bath meetings!

Along with my friends - especially Florian, Sonila, David, Paty and Britta - I suffered the never-ending year of courses and tests during our first year. After I left Maastricht we maintained our friendship. I guess without your support many things would not have been possible to achieve. Many thanks!

Gosta Esping-Andersen helped me to clarify my ideas at the beginning of my $\mathrm{PhD}$, especially regarding comparative social policy measurement.

Jon Kvist devoted a great deal of time to comment on my research and stimulated further development of my ideas during the visits to Copenhagen and Odense to which he invited me.

I have been lucky to spend a year at the European University Institute. At the EUI, the seminars of Laszlo Bruszt and Sven Steinmo proved very stimulating for my research. It was also in Florence I came to know Patryk - another great friend.

I need to mention the European Social Policy Analysis network - it created a unique platform for presenting and discussing social policy research. ESPAnet organized several workshops and conferences where I always received constructive comments on my work.

I would like to thank Fraser for his engagement in correcting my English.

My family has supported me throughout my PhD in so many ways that it is hard to list them here. Dziękuję! 
Big thanks to my friends: Adrian, Basia, Jarek, Iwonka, Kuba, Krzysiek and Łukasz for being there for me

Finally, my greatest gratitude goes to Dorota. We embarked on our PhD projects together and now this stage of life is over. She has had an amazing impact on my progress: we worked together on several ideas, but she challenged me intellectually as well. Thanks for your support, I would like to say that I am totally sure that without you my PhD would not have been possible. 


\section{TABLE OF CONTENTS}

$\begin{array}{ll}\text { LIST OF TABLES AND FIGURES } & 7\end{array}$

$\begin{array}{ll}\text { INTRODUCTION } & \overline{9}\end{array}$

CHAPTER 1: COMPARATIVE SOCIAL POLICY ANALYSIS AND EAST CENTRAL EUROPE: SETTING THE SCENE

INTRODUCTION

DiVERSE EVOLUTION OF SOCIAL POLICY IN EASTERN CENTRAL EUROPE IN A

CHANGING CONTEXT 21

METHODOLOGICAL ISSUES OF SOCIAL POLICY COMPARISONS IN EAST CENTRAL

EUROPE $\quad 23$

LITERATURE REVIEW: SOCIAL POLICY REFORM IN CEE

Economic situation and other structural factors $\quad \underline{33}$

Politics of social policy 38

International influence $\quad \underline{41}$

TOWARDS A HISTORICAL-INSTITUTIONAL EXPLANATION OF SOCIAL POLICY DIVERSITY

in CENTRAL EuROPE

CONCLUSIONS OF THE CHAPTER

CHAPTER 2: METHODOLOGY OF THE STUDY 51

INTRODUCTION

PUTTING THE TEMPORAL DIMENSION AT THE CENTRE OF ANALYSIS: HISTORICAL

INSTITUTIONALISM

$\begin{array}{ll}\text { INSTITUTIONALISM } & \frac{52}{54} \\ \text { TIME AND SOCIAL POLICY MEASUREMENT: FUZZY SETS IDEAL-TYPES APPROACH } & \frac{58}{58}\end{array}$

CHAPTER 3: INSTITUTIONAL FEATURES AND TRENDS OF SOCIAL POLICY IN CENTRAL AND EASTERN EUROPE - A FUZZY SETS APPROACH

INTRODUCTION

OLD-AGE PENSIONS

EMERGING PATTERNS OF OLD-AGE PENSIONS IN CEE

ANALYSIS OF UNEMPLOYMENT COMPENSATION 
UNEMPLOYMENT COMPENSATION IN CEE - EMERGING PATTERNS?

ANALYSIS OF CHILDCARE POLICY

PATTERNS OF CHILDCARE POLICY IN CEE

PENSIONS, CHILDCARE POLICY AND UNEMPLOYMENT COMPENSATION IN A

COMPARATIVE PERSPECTIVE

TOWARDS CASE SELECTION

CHAPTER 4: SOCIAL POLICY IN POLAND

INTRODUCTION

SOCIAL POLICY IN PARTITIONED POLAND (BEFORE 1918)

INTERWAR PERIOD

Social policy just after gaining independence: efforts towards sustaining inherited systems

Social policies in the era of relative stability (1924-1929)

Introduction

Social policy context

Old-age pensions

Consolidation of social policy in the context of economic hardship (1929-35)

Introduction

Organizational consolidation of social policy

$\overline{106}$

Unemployment compensation

107

Old-age pensions

108

Period from 1936 to 1939

110

Summary of the inter-war period

WORLD WAR II

THE SOCIALIST ERA

Introduction

The immediate post-war years

Social policy organization

Old-age pensions

Maternity benefits

Period 1950-67

Financing and organization of social policy

Old-age pensions

Period 1968 to 86

Social policy organization 
Old-age pensions

Maternity benefits

Period 1987-1989

Summary of the socialist period

TRANSITION

Transition: a new context for old-policy making

Period 1989-1991

Organisation and financing

Pension benefits

Discussion concerning reform and early proposals

The implementation of the "Security through Diversity" reform proposal.

Pension reform in Poland: conclusions

A CENTURY OF SOCIAL POLICY IN POLAND: A SUMMARY $\quad \overline{158}$

\section{CHAPTER 5: SOCIAL POLICY IN HUNGARY}

INTRODUCTION

HUNGARIAN SOCIAL POLICY BEFORE 1918

THE INTER-WAR PERIOD

The Bethlen era: introduction

Unemployment compensation

Old-age pensions

Childcare policy

The 1930s

Socio-economic conditions

Organization of social policy towards centralization

World War II

Summary of the pre-socialist period

THE POST-WAR PERIOD

From 1944/5 to 1956

Centralization of organization and financing

Pension benefits

1956 to 1975

Organizational structure of social policy

Old-age pensions

From the mid-1970 to 1989

Organizational issues

Old-age pensions 
Conclusions

TRANSITION

Organization and financing

Pension benefits

Debates and policy proposals

Post-reform developments (implementation)

Reformed PAYG tier

Development of MPPFs

Pension reform in Hungary: conclusions

SOCIAL POLICY IN HUNGARY IN THE $20^{\mathrm{TH}}$ CENTURY: SUMMARY

CHAPTER 6: TRANSFORMATION OF OLD-AGE PENSION SYSTEM IN POLAND AND IN HUNGARY COMPARED.

INTRODUCTION

DEVElOPMENT AND EVOLUTION OF SOCIAL POLICY IN POLAND AND HungaRY IN A COMPARATIVE CONTEXT.

Origins and the mid-war era.

Post-War social policy evolution: development, consolidation and crisis

POST-SOCIALIST SOCIAL POLICY REFORMS: RECOMBINATION OF INSTITUTIONAL FACTORS

Old-age pensions during early transition

Proposals, debates and reforms of old-age pension systems

CONCLUSIONS: CONTINUITY AND CHANGE IN OLD-AGE PENSIONS

236

CONCLUSIONS

APPENDIX 1: ADDITIONAL TABLES AND FIGURES.

REFERENCES

SAMENVATTING 


\section{LIST OF TABLES AND FIGURES}

\section{TABLES:}

TABle 1: VARIATION IN OlD-Age PENSIONS, Hungary AND POLAND, Year $2009 \quad \underline{18}$ TABLE 2: STRUCTURAL CHARACTERISTICS OF SOCIAL POLICY IN HUNGARY AND POLAND

(MID-1990 AND VARIOUS YEARS)

$\underline{36}$

TABLE 3: SPECIFICATION OF EMPIRICAL INDICATORS AND TRANSLATION OF DATA TO FUZZY SCORE RANGES AND VERBAL QUALIFIERS: OLD-AGE PENSIONS

TABLE 4: FUZZY MEMBERSHIP SCORES OF OLD-AGE PENSIONS IN IDEAL TYPES $\frac{65}{66}$

TABLE 5: UNEMPLOYMENT COMPENSATION: SPECIFICATION OF INDICATORS AND

TRANSLATION OF DATA TO FUZZY-SCORE RANGES AND VERBAL QUALIFIERS

TABLE 6: FUZZY MEMBERSHIP SCORES OF UNEMPLOYMENT COMPENSATION POLICY IN IDEAL TYPES

TABLE 7: SPECIFICATION OF EMPIRICAL INDICATORS AND TRANSLATION OF DATA TO FUZZY SCORE RANGES AND VERBAL QUALIFIERS: CHILDCARE POLICY

TABLE 8: FUZZY MEMBERSHIP SCORES OF CHILDCARE POLICY IN IDEAL TYPES

TABLE 9: EXPENDITURE OF THE SOCIAL INSURANCE Fund (FunDUSZ UbEZPIECZEŃ

SPOŁECZNYCH, FUS) AS A PERCENTAGE OF GDP IN THE 1990 s.

TABLE 10: PERCENT OF INSURED ACQUIRING ENTITLEMENT FOR PENSION AMONG ECONOMICALLY ACTIVE IN HUNGARY 1950-1990.

TABLE 11: PERCENT OF INDIVIDUALS RECEIVING PENSIONS TO THE GROUP OF PENSIONABLE AGE IN HUNGARY 1950-1990

TABLE 12: FUZZY MEMBERSHIP SCORES IN UNIVERSALITY OF THE OLD-AGE PENSIONS IN EIGHT POST-SOCIALIST COUNTRIES FOR YEARS 1989-2004

TABLE 13: FUZZY MEMBERSHIP SCORES IN GENEROSITY OF THE OLD-AGE PENSIONS IN EIGHT POST-SOCIALIST COUNTRIES FOR YEARS 1989-2004

TABLE 14: FUZZY MEMBERSHIP SCORES IN PRIVATE/PUBLIC MIX OF THE OLD-AGE PENSIONS IN EIGHT POST-SOCIALIST COUNTRIES FOR YEARS 1989-2004

TABLE 15: FUZZY MEMBERSHIP SCORES IN ACCESSIBILITY OF THE UNEMPLOYMENT COMPENSATION IN EIGHT POST-SOCIALIST COUNTRIES FOR YEARS 1989-2004

TABLE 16: FUZZY MEMBERSHIP SCORES IN GENEROSITY OF THE UNEMPLOYMENT COMPENSATION IN EIGHT POST-SOCIALIST COUNTRIES FOR YEARS 1989-2004

TABLE 17: FUZZY MEMBERSHIP SCORES IN DURATION OF THE UNEMPLOYMENT COMPENSATION IN EIGHT POST-SOCIALIST COUNTRIES FOR YEARS 1989-2004 
TABLE 18: FUZZY MEMBERSHIP SCORES IN OBLIGATION DIMENSION OF THE UNEMPLOYMENT COMPENSATION IN EIGHT POST-SOCIALIST COUNTRIES FOR YEARS 1989-2004

TABLE 19: EXTENSIVENESS OF CHILDCARE SERVICES: FUZZY-SET MEMBERSHIP SCORES FOR YEARS 1989-2004.

TABLE 20: QUALITY OF THE CHILDCARE SERVICES: FUZZY-SET MEMBERSHIP SCORES FOR YEARS 1989-2004.

TABLE 21: GENEROSITY OF PARENTAL LEAVE PROVISION: FUZZY-SET MEMBERSHIP SCORES FOR YEARS 1989-2004.

TABLE 22: UNIVERSALITY OF PARENTAL LEAVE PROVISION: FUZZY-SET MEMBERSHIP SCORES FOR YEARS 1989-2004.

TABle 23: ResPONSES TO WelFARE POLICY QUESTIONS, 1992-94 (PERCENT AGREE/STRONGLY AGREE).

TABLE 24: EMPLOYMENT RATES IN HUNGARY AND POLAND, 1992-2000, SELECTED YEARS

TABLE 25: PROPORTION OF NEWLY GRANTED PENSION/AVERAGE WAGE, PROPORTION OF RUNNING PENSION/AVERAGE WAGE, RELATION BETWEEN RUNNING AND NEWLY GRANTED PENSION IN POLAND, 1961-1978

TABLE 26: FARMERS' SCHEME: PENSIONERS, BENEFITS AND RELATIONS BETWEEN BENEFITS FROM FARMERS AND GENERAL SCHEME IN POLAND, 1963-81

\section{FIGURES:}

FIGURE 1: RELATION BETWEEN AVERAGE PENSION AND WAGES AND NEWLY GRANTED PENSION AND WAGES IN HUNGARY, 1970-1993 


\section{INTRODUCTION}

The collapse of state socialism and the centrally-planned economies of Eastern Central Europe was a shock to many scholars dealing with the political economy of socialist states. Soon however the transformation of these political economies attracted the attention of a number of social scientists who wanted to understand and explain the post-socialist transformations.

What has concerned many is the mechanism (or mechanisms) which drive social, economic and political change in the region. Are there differences between the countries sharing a seemingly similar state-socialist legacy? Is there one mode of transformation or are there many of them? Is the current institutional design of social policy in East Central European countries a result of domestic institutional evolution, is it a legacy shared among these countries, or rather is it that of external, unifying pressures? Finally, what is the extent of change that countries of the region have undergone, and how can we interpret it?

This research project deals with these questions concerning institutional evolution and policy diversity in East Central Europe with regard to social policy programmes. The dissertation is driven by a straightforward empirical puzzle: why is there such noticeably striking diversity of social policy between states in the region which seemingly not only share similar social, political and economic conditions, but also went through a period of state socialism together? To answer this question this dissertation focuses on the characteristics of social policy programmes, their dynamics over time, and the processes which contributed - and continue to contribute - to these policies' institutional development. In order to analyse these issues, the dissertation intends to answer the following key questions: what are the characteristics, the logic and the dynamics of social policy change after the collapse of communism; and what are the processes which have contributed to observed social policy features?

By exploring these questions, the dissertation intends to contribute to the understanding of welfare reform in East Central Europe on three fronts: in terms of policy analysis, methodology and social theory. In terms of policy analysis, the study will demonstrate that different social policy domains (such as old-age pensions, unemployment compensation and childcare) have varying dynamics, both with regard to inter- and intra-country comparisons. On the methodological front, a renewed focus on the temporal dimension of policymaking and its dynamics reveals the importance of sequencing in historical political and economic processes for understanding current policy developments. Finally, when it comes to the theoretical contribution of this study, the aim is to describe the mechanism - 
institutional reconfiguration - which stands behind social policy evolution in East Central Europe.

My argument is that what we observe in ECE is a diversity of social policy. I will demonstrate this diversity by looking at regulations concerning eligibility and the generosity of programmes in three social policy domains: old-age pensions, childcare and unemployment compensation. What is especially puzzling is the observation that in several instances the diversity already existed in the very early phase of transition. Such an observation leads one to conclude that these countries were already pursuing different social policies before 1989 and what we can observe currently is a snapshot of the unfolding of a long-term tendency.

I will go on to approach the explanation of the phenomenon of social policy diversity in East Central Europe in more analytical detail by examining the case of pension reform in two ostensibly similar countries - Poland and Hungary which introduced reforms with strikingly diverse redistributional consequences. I will argue that the choice of reform options which were available after 1989, the reform processes which were chosen and their implementation were all affected and shaped by the historically developed institutional logic of the two countries' welfare states. In light of - and informed by - historical institutionalism, I will analyse the development of the organization, financing and benefit characteristics in these two countries since their creation in early years of the $20^{\text {th }}$ century and observe how these historical factors created the power resources of the various actors involved in several reform attempts. With such an approach, I will present a mechanism of institutional evolution which focuses on reconfigurations of institutional factors. With an understanding of this mechanism of institutional reproduction it is possible to better understand the divergent paths of social policy reform in East Central Europe.

Apart from the important theoretical contributions raised above, there is also a unique lesson about the region to learn: of how the countries of Central and Eastern Europe have undergone significant changes in their economic, political and social systems since 1989. The introduction of various types of market economy as well as other changes such as the economic opening-up to the West, democratisation, the presence of multiparty systems, and changes in the levels of income and inequality are just few facets of these phenomena. As a consequence, several features of the communist system have been abandoned. In parallel, interest has been raised with respect to social policy in the region - of how such profound changes accompanied by new challenges (such as economic hardship and unemployment) as well as new actors shaping the agenda contributed to the paradigmatic change of social policy. While some changes are unquestionable 
(especially with respect to social services provided by state-owned companies), in many instances their magnitude in the literature seem overestimated.

Such an observation is of great theoretical importance. If the extent of change is limited and several features of the historically developed social policy are present in the post-socialist period, in spite of a variety of pressures, one may talk about the remarkable case of institutional continuity. On the other hand, the empirical analysis shows also cases of significant change. This research draws on this observation and outlines the conditions and a mechanism of relative change/stability. Such an approach focuses on process and sequencing of policy development. The pace of reforms and the complex nature of institutions were obstacles for research on social policy in the region because the results of such could not be robust as the situation was changing overnight. Hence the lack of comparative studies that could go beyond short-term description. Now, when the most important decisions concerning political, economic and social policy issues have been passed and can be analysed from some historical distance, it seems more legitimate to talk about the historically grounded alternatives, the choices and their consequences.

The historical analysis of this study aims at not only tracing back the origins of current social policy programmes, but also at understanding the context in which certain decisions were taken. In other words, historical analysis can provide us with a picture of the historically created set of vested interests and relations of power which informed actors in their decisions as well as giving us an understanding of the legacies of these policy decisions which, although reconfigured, continue to influence policies today.

The narrative presented in later parts of this dissertation can be understood in three complementary ways. On the first level, the economic and social histories of Poland and Hungary are presented with a special emphasis on the development and evolution of social policy in these two countries. On the second level, the analysis provides an explanation of conditions and processes contributing to the degree and kind of social policy retrenchment. Finally, on the most abstract level, this research can be read as the demonstration of the endogenous process of institutional evolution.

The empirical research consists of two parts. The first part deals with a broad comparison of three social policies (unemployment compensation, childcare policy and old-age pensions) in eight countries of the region from 1989 to 2004. The second part deals with the empirical puzzle of the disparity of old-age pension reform in two countries, namely Hungary and Poland. This part employs the 
historical-comparative approach and, in particular, the historical institutionalism to explore social, political and economic processes which have contributed to the striking difference between two seemingly similar cases.

This research project argues that the post-socialist social policies in different countries of the ECE area represent striking diversity in what they offered and continue to offer to their citizens. The measurement of the policies and a general analysis are conducted in part one of the volume. In order to do so, with a special emphasis on the cross-country diversity, the first part of the project answers the following sets of questions:

- What are the characteristics of the social policy programmes in the eight countries of the region between 1989 to 2004?

- What are the single-policy patterns among the countries in this period?

- What are the intra-country social policy patterns throughout the transition?

- Are there any cross-country trends?

The analysis concludes that there exists a variety of social policies in the region, but also that there were different styles of state welfare reforms. It is found that each policy had its own dynamics: childcare policy became stable and consolidated after some period, changes to unemployment compensation policy were made quite often but no big paradigmatic changes were introduced, and - in the case of pensions - almost all countries reformed their benefits but to differing degrees. The last point relating to the diversity of pension reform in the region is a point of departure for the analysis which aims at explaining this reform outcome.

The second part of the research draws on the institutional perspective. Unlike most of studies of this type, it argues that the post-socialist social policies are the result of the endogenous transformations (reconfigurations of legacies), rather than a response to exogenous factors, such as party politics, demographic demands or international influences.

The second part of the dissertation compares Hungary and Poland, two countries with quite similar structural characteristics but with very different policy designs after the reform. In order to understand the transformative nature of social policy developments relating to 1989, the analysis goes back to the formative moments in the countries old-age pension policies earlier in the twentieth century and follows the developments in each over time. The analysis also covers the evolution of the organizational and financing aspects of social security and changes in political, social and economic situation. Thanks to such a wide 
perspective, it is possible to identify crucial turning points concerning social policy development, and assess the importance of such for recent policy developments.

The work proceeds as follows. Chapter 1 outlines the discussion concerning social policy measurement. I argue that neither an analysis of social spending, nor the regime approach is suitable for analysing social policy in the region of Central and Eastern Europe. While the former provides a very simplified overview which is not capable of grasping the issues of change and stability, the latter's theoretical assumptions (exaggerated stability of regimes and sequential nature of rights) stand in contrast with the social policy developments in the region. Instead, an innovative approach to studying social policy is proposed: the ideal-types fuzzy sets approach. I argue that this approach is capable of presenting the complex social policy dimensions regarding the redistribution of wealth and its dynamics covering several cases in a concise and straightforward way. This innovative approach is signature to the overall arc of this thesis: analysing the dynamics of change of social policy. The remainder of the chapter describes the basic features of the approach and techniques used when applying it to studying social policy.

Chapter 2 employs ideal-types fuzzy sets approach to the analysis of three social policies: childcare policy, unemployment compensation and old-age pensions in the eight countries which joined the EU in 2004. The period covered is 1989-2004. This chapter finds a great variety in the rationales underlying social policy programmes, over time and across countries. The analysis is conducted on different levels of aggregation. It starts with single policy dimensions (generosity of benefits, for example), next it analyses social policy programmes as configurations of dimensions. Finally, the most general analysis is conducted in which the countries' social policy profiles are discussed. This chapter finds a variety of policy dynamics.

Chapter 3 discusses the most popular explanations for social policy developments in Central and Eastern Europe against the background of two cases used in the later empirical analysis. First, it focuses on the role of the short term explanations: economic and demographic factors, party politics and international agents. This group of factors is critically assessed against the empirical arguments, and their logical validity is discussed. Not only are the social policy developments in some instances contradictory to those predicted by the theories, but also the assumptions regarding the rationality of actors and the perceived possibility of change seem unrealistic. The approach proposed here focuses on the role of past developments and their unintended consequences for the development in social 
policy in the two countries. It is argued that reforms (or the lack of them) and their direction followed logics which had been developed over decades.

Chapters 4 and 5 comprise the theoretically-informed empirical analysis of social policy developments in Poland and Hungary respectively. They draw on a number of historical sources and outline main policy developments in the $20^{\text {th }}$ century. The analysis points out the main structural features of welfare states and the rules guiding social policy programmes. The role of these chapters is to describe and explain the direction of developments preceding the transition to capitalism. To this end, the wider social, political and economic conditions are taken into account. Understanding the rationale underlying these developments allows, in turn, for an explanation of the continuity or change in policy and its direction during the transition. As mentioned above, one of the key arguments of this thesis is that post-socialist welfare states are the reconfigurations of legacies of earlier social policies. This theoretical argument will provide the basis for understanding the institutional evolution of social policy in CEE. The exposition of this mechanism is essential: institutional evolution does not happen randomly and incidentally, and takes place through the actions of actors involved in the social policy domain. The operations of actors are not only constrained, but also enabled, by institutional legacies. The reworking and reconfiguring these legacies by actors contributes to overall institutional evolution.

The final chapter combines the findings from the country chapters (chapters 4 and 5) and draws more general conclusions regarding the causes of social policy developments in the region of Central and Eastern Europe. Considering the previous analyses, I argue that these studies which focused on old-age pensions tended to overestimate the degree of change. The reason for this is as follows. First, many scholars tend to overestimate the direct impact a spillover effect from a change in one field of the socio-economic system has on other fields; namely, now economic changes have an impact on social security and policy. Second, very little attention was paid to the comparative characteristics of the reformed social policy programmes, especially pensions. Finally, conclusions concerning the development of welfare states in the region were often drawn from a single policy, hence running the risk of unjustified generalisations.

Finally, the chapter synthesises the empirical, methodological and theoretical contribution of the thesis. It summarizes the almost century-long histories of old-age pension policies in Hungary and Poland as well as drawing out similarities and differences in their development against social, economic and political conditions. Methodologically, the chapter shows that the focus on the process of social policy-making requires a historical view. Finally, it is argued that 
differing social policy settings and characteristics (legacies) will lead to separate paths of institutional evolution even under conditions of similar economic and social pressures. 


\section{CHAPTER 1: COMPARATIVE SOCIAL POLICY ANALYSIS AND EAST CENTRAL EUROPE: SETTING THE SCENE}

\section{INTRODUCTION}

The transition in Central and Eastern Europe resulted in a number of adhoc decisions in some policy areas, combined with rather stable institutions inherited from the socialist past in others. The outcome was, therefore, a hybridization of social policy. Beside the substantive interest in studying the social policy field, there is also theoretical significance to this choice. First, on the most general level, this chapter deals with the debate concerning the nature of institutional change/stability. Until recently, analyses of social policy, driven by the concept of path dependency, emphasized institutional stability (Pierson 2001).

As mentioned in the Introduction, the starting point of this dissertation is the puzzle of why there should be such a diversity of social policy arrangements in the context of such an ostensibly economically, socially, and geographically unified region. This situation became even more puzzling in the late 1990s, after a period of strong and potentially unifying international pressures. Table 1 highlights this incongruity by focusing on old-age pension provision in two similar countries, Hungary and Poland, which are often bundled together in terms of socio-political and economic situation (Bohle and Greskovits 2007). 


\begin{tabular}{|l|l|l|}
\hline Dimension of variation & Hungary & Poland \\
\hline $\begin{array}{l}\text { Financing and organizational } \\
\text { principle 1st tier }\end{array}$ & PAYG & NDC \\
\hline $\begin{array}{l}\text { Financing and organizational } \\
\text { principle 2nd tier }\end{array}$ & Funded & Funded \\
\hline $\begin{array}{l}\text { Financing and organizational } \\
\text { principle 3rd tier }\end{array}$ & Funded & Funded \\
\hline $\begin{array}{l}\text { Retirement age men/women (if } \\
\text { applies) }\end{array}$ & 62 & $65 / 60$ \\
\hline $\begin{array}{l}\text { Current net replacement rate (old } \\
\text { system) }\end{array}$ & $86.9 / 79.3$ & $76 / 70$ \\
\hline $\begin{array}{l}\text { Expected net replacement rate men } \\
\text { (new system) }\end{array}$ & 96.5 & 74.8 \\
\hline $\begin{array}{l}\text { Expected replacement rate women } \\
\text { (new system) }\end{array}$ & 96.5 & 55.3 \\
\hline Return guarantees & $\begin{array}{l}\text { Minimum } \\
\text { amount }\end{array}$ & $\begin{array}{l}\text { Internal sector } \\
\text { return rate }\end{array}$ \\
\hline After-reform system structure & $\begin{array}{l}\text { Unified (one } \\
\text { for all) }\end{array}$ & Fragmented \\
\hline Main problems & $\begin{array}{l}\text { Financial } \\
\text { sustainability }\end{array}$ & $\begin{array}{l}\text { Poverty of } \\
\text { pensioners }\end{array}$ \\
\hline
\end{tabular}

Source: (Holzmann and Guven 2009; Organisation for Economic Co-operation and Development. 2009), own elaboration.

A quick look at the table reveals striking differences between the reformed old-age pension systems in two countries. Without going into technicalities, one could argue that even though both countries reformed their pension systems into multitier solutions with funded components, their expected outcomes differ a lot. In Hungary, it retains several features of the classic PAYG (extensive redistribution) system, not only due to the fact that the first tier is already a slightly modified PAYG solution but also because the second pillar, which is in principle funded (which assumes saving in private accounts with very limited redistribution), actually mimics several redistributional features of classical PAYG systems due to extensive regulation by the state. As a result, what one can observe 
in the Hungarian case is the limited impact of the reform on the quality of pensions (replacement rates), especially in case of women who more often than men interrupt their careers. In addition, the level of pensions, including private funds, is secured by the state.

In Poland on the other hand, the reform has changed the old-age pension system more profoundly. The reform has abandoned a PAYG system completely, replacing it with a solution which from a redistribution perspective mimics funded pension systems (individual saving accounts, marginal redistribution). The first tier is coupled with a second tier which offers no redistribution, as the pension savings are located in individual accounts. Such construction of a pension system will, as empirical data clearly demonstrates, contribute to the drop in the level of pensions and which will be especially severe for women (Bridgen and Mayer 2007; Organisation for Economic Co-operation and Development. 2009). This drop can be even more severe, as the return from the second tier is not guaranteed in terms of inflation or GDP growth adjustment.

Therefore, what one can see with the examples of Poland and Hungary is a combination of stability and change in terms of not only the principles guiding benefits and the involvement of the state in social policy regulation, but also organizational cohesion. When looking at the relative levels of benefits, Hungarian pensions are higher than Polish ones, and this difference is expected to increase even further, especially in the case of women. The overall structure of the social security systems is different as well: in Hungary, it is a unified system covering the whole of the population, while in Poland it is fragmented, including separate schemes for workers, farmers and a number of the so-called privileges for groups such as miners. Finally, it is worth noting that the main problems which are often presented as direct causes of pension reform remain important issues in the two countries.

What this case study of old-age pensions in Poland and Hungary shows us is the complexity of social policy reform in the region. However, the discussion does not stop here and is not limited to one social policy field. A careful comparison of social policies of CEE may serve as the basis for a more nuanced analysis: which policies change, how, in what direction, whether policy change is radical or evolutionary and whether one can talk about some intra-country (or policy) logic. The results of the comparison crucially contribute to the debate on European social policy and the position of the region in international analyses, as it will assess the 'one post-socialist social policy regime' thesis (that is, all postsocialist countries belong to one regime). 
The aim of this chapter is to present and discuss a number of issues which arise when analysing changes of social policy in the region. First, the chapter deals with a specific theoretical case, namely, the evolution of social policy in East Central Europe. The question to be addressed concerns the changing co-evolution of social policy inherited from the state socialist past in the conditions following the introduction market economies, pluralist democratic political systems as well as the emergence of civil society and widening interest representation. How and to what extent has social policy or any given welfare state reacted to this overwhelming contextual change? What was the role of institutional innovation in these processes?

The second part of the chapter will be devoted to specifying research tools, which could be capable of assessing the kind and the degree of change. An innovative research method will be introduced and explained: fuzzy sets idealtypes analysis. I will argue that thanks to its unique properties, this method is able to provide an analysis that is sensitive to the essential features of social policy cash benefit programs. As will be detailed more in the following chapters and only sketched here, social policy programs differed in many important respects. While all the countries analysed in this dissertation went through a period of state socialism, their benefits differed in a number of ways, such as in terms of their generosity and eligibility. It is worth reiterating here that these differences were already evident in the late phase of the state socialism period. Also, the relative importance of social policy programmes differed among countries. In light of these facts, I will argue that the configurational view of social policy programmes offered by the methodological approach I employ provides the necessary analytical leverage for studying such developments as its sensitivity to policy content and process dynamics matches closely with the overall methodological approach of this research project.

The last section of the chapter moves from the comparative-analytical perspective to comparative-explanatory perspective. The discussion focuses on old-age pensions and other social policy programs which are the biggest spending position in most welfare states, and which consume an especially large proportion of spending in CEE. Also, pension reform was treated in all countries of the region as particularly important, being a part of more general trend of departing from the socialist past (Mueller 1999). Given the arguments presented in the two previous sections, and the empirical data presented that suggest a lack of viability of 'snapshot' analytical explanations, the section invokes the need to go beyond these and to adapt to an approach which provides us with more of a historical institutionalist understanding in order to explain the striking difference in the 
parameters of pension systems in Hungary and Poland. As will be shown, the different pension systems reforms can hardly be explained by a set of factors usually considered in the literature (socio-economic situation, international pressures or party politics). These factors are carefully considered and scrutinized in light of empirical material, and as a result, discarded. Instead, historical institutionalism is brought into the picture, for its sensitivity to historical factors which, although distant in time, are as important as contemporary ones. In addition, the section outlines the concepts and factors behind the endurance of policy. The chapter concludes with a summary of the discussion.

\section{DIVERSE EVOLUTION OF SOCIAL POLICY IN EASTERN CENTRAL EUROPE IN A CHANGING CONTEXT}

The political and economic transformation in East Central Europe itself poses significant theoretical challenge to students of political economy. Unlike in the case presented by Polanyi (1957), in East Central Europe socialist markets were replaced by some forms of market economy (Neale 1991) for the first time in history. This tough task by itself was coupled with the introduction of a variant of liberal democracy.

This challenge seems even greater when the evolution of post-socialist social policy is concerned. The reason for this difficulty lies in the locus that modern welfare state occupies: it a cross-section of politics and economy embedded in a wider international context. In order to understand this complexity, one has to refer to the debate on the issues of institutional stability, change and evolution. The challenge here is twofold: first, one should understand the roots of difference between countries' social policies and second, one should be able to explain possible continuities (or lack of them).

Generally, when it comes to political and especially economic order, several scholars (and policy makers) believed in the possibility of mimicking an ideal-typical institutional design. This assumed the existence of a desired institutional order to be achieved, and a functionalist logic in achieving this aim regardless of existing institutions. The role model was often depicted in the concept of the 'Washington Consensus', emphasizing deregulation, liberalization and the role of free markets (Williamson 1990). The background assumption of such thinking was that individuals are market entrepreneurs and consequently, 
will complete this task. Such a model and target-oriented approach had been promoted by several economists and reformers, but also international organizations such as the World Bank (Deacon, Hulse et al. 1997). As Keune (2006) rightly argues, such approach shares several features of functionalism: an emphasis on automatism of action, the move from inferior (state socialism) to optimal (market economy) system and finally, the assumption of convergence. Also, it has a lot in common with functionalist Marxist approach, with its inevitable transition to 'better' or more 'advanced' stage of development (in Marxism communism, while here capitalism) (Stark and Bruszt 1998).

In the social policy field such an approach was envisioned by the World Bank, which, in the 1990s promoted a 'one size fits all' policy, especially with regard to old-age pensions (with its 'Averting the Old Age Crisis...' publication) (World Bank. 1994). In more general terms, social policy development in transition is seen as a residual of economic policy, rather than development based on its own logic (Ksiezopolski 1999). As a consequence, given the point raised above, postsocialist social policy was perceived by the key reformers and many scholars as being that which should converge to one specified model.

Another approach to the political economy of transformation focuses on the past developments as constraints to policy innovation. Here it is the past system, state socialism, which determines specific kind of developments. Such a teleological approach leaves aside the possibility of interaction with current environment. Michael Burrawoy calls this phenomenon involution, a process in which a chronic and persistent regression takes place (mostly in economic sphere) (cf. Stark and Bruszt 1998). The sources of involution lie in the conditions postsocialism has found itself: the legacy of socialist economic order which still influences the markets and hence, distorts them. Second, Burrawoy finds the introduction of liberal democracy and the collapse of the party state as a constraint in reforming economies (Stark and Bruszt 1998). In terms of social policy, the features of socialist welfare states would strongly determine the shape of the postsocialist model and developments thereof, and involution would mean disintegration and degeneration of welfare state inherited from the socialist period.

The discussion presented above is essential for understanding social policy developments in post-socialist Europe as it deals with two most intuitive but also prominent approaches that could determine these developments. How could one analyse such developments with a more dynamic framework such as one developed by Karl Polanyi mentioned above? The analysis should be based on a thorough historical and interactional view of economic and societal development, so that the formation and evolution of a distinct political economy could be grasped (Streeck 2009). However, before engaging in the discussion concerning how to explain post-socialist social policy, one has to decide what social policies 
should be compared and with which instruments. The issue of comparison is not merely a technical one: the comparative analysis will deliver several conclusions regarding similarities and differences which underlie the evolution of social policy in Central and Eastern Europe. This, in turn, will help understand the role of actors and the processes which shape social policy.

\section{METHODOLOGICAL ISSUES OF SOCIAL POLICY COMPARISONS IN EAST CENTRAL EUROPE}

This section aims to outline the requirements that a comparative-analytical approach has to meet in order to be successful in grasping the developments that took place in East Central Europe so that they can be meaningfully interpreted. In principle, the section is devoted to comparing social policy in ECE; however, several points raised are of general importance. This section will discuss the two most popular approaches, social spending analysis and regime approaches used widely in social policy comparisons. Both are found to be limited in their potential to grasp changes in policy characteristics. Thus, the final paragraphs are devoted to the solution to weaknesses raised by adopting an innovative comparative method, the fuzzy sets ideal-type approach.

Harold Wilensky (1975) was one of the first social scientists to engage in systematic comparative social policy analysis. This task was made possible thanks to the development of public spending datasets which held data on expenditures related to the activity of a welfare state. In his study, Wilensky analysed 64 countries from different regions of the world by looking at their social security effort in the mid-1960s. The conclusion was that there is a one-dimensional distribution of welfare states, depending on their social spending, determined, in turn, by structural factors, such as economic and demographic development.

The social spending approach is a straightforward measure of a welfare state 'effort'. It seems informative, allows for fast comparisons and interpretation and is often the only available and easily quantifiable data on this topic. These are exactly the reasons why has been employed so many times in comparative analysis, especially the ones focusing on a bigger number of countries. However, the strength of this approach is also, simultaneously, its weakness. First, Wilensky and his followers were able to demonstrate the absolute expansion of the welfare state by pointing to the increase of social spending. Nevertheless, this can be easily questioned, especially in the light of demographic changes or shifts in the 
magnitude of social problems (unemployment, for example) that can affect levels of spending. An attempt to overcome this drawback has been the proposal to study 'need-adjusted' spending by contrasting the spending with the 'size' of social problem, demographic structure and so forth (Castles 2004). This attempt, being a step forward (as it allows for more meaningful comparisons), does not create a solution to the main problem of this approach. While social spending describes the welfare effort, the structural and general feature of the welfare states, it is not capable of describing the content of policies, they way they are governed and so on. Even though disaggregated to single social policy programs and acknowledging the public/private provision distinction, social spending, as a proxy of welfare state effort, is detached from the social, political and economic context, and as a result, far from the description of the content of welfare state itself. Also, this highly aggregated measure offers no way to account for redistributional effects of social policy. In other words, it is a linear way of measuring social policy and its development, which takes into account neither redistributional effects nor differences in ways of provision.

Nonetheless, social spending has been widely used in the description and explanation of social policy. This has been the case of Central and Eastern Europe as well. The World Bank, the OECD and the IMF, which were the main data providers for the region for a long time (especially in the early phase of the transition) had their analyses based on this very simple dimension (Milanović and World Bank. Development Research Group. 1995).The other issue is that the agenda of these organizations has not valued comparative research that much, focusing more on contrasting big spenders to modest ones and from this observation drawing policy conclusions regarding the public finances discipline.

In fact, for all of the improvements which have been made to the social spending approach, one cannot learn a lot about social policy, about its development, stagnation or retrenchment (Pierson 1994). This conclusion is even more striking if one considers explanatory research endeavours that go beyond a simple functionalist approach and bring political and ideological components to the analysis. As Gosta Esping-Andersen put it famously in the light of the call for more sophisticated tools for understanding social policy in the macro perspective, 'nobody struggles for social spending per se' (Esping-Andersen 1990).

It is exactly the introduction of politics and its complex effects into the explanatory mechanism which requires another analytical strategy that can satisfy the requirements of a theoretical model focusing on policy processes. 
In addition to that of Wilensky's, another major contribution to comparative welfare state analysis is the regime approach, proposed by Gosta Esping-Andersen. By breaking away from the one-dimensional measurement of policies and embedding them in historical and political context, Esping-Andersen considerably boosted the debate concerning the question how to measure and compare welfare states.

The author's proposal was to redefine welfare state in two main respects: in terms of the decommodification of labour and in terms of the system of stratification (i.e. of how social welfare affects social stratification). Unlike the previous account, the regime approach has been embedded in the literature emphasizing the importance of not only politics and ideology, but also the historical context for understanding the nature of social policy in a comparative perspective. Accordingly, Esping-Andersen draws on three, partially overlapping intellectual traditions. First, he refers to the work of T.H. Marshall (Marshall 1950) concerning the sequential development of rights (civic - political - social) and their importance for fulfilling human needs. Second, the author applies the Polanyian view on the nature of relations between individuals, state and market, with the emphasis on the ways in which the market can be adjusted to meet socially desirable aims. Finally, Esping-Andersen, following Richard Titmuss, recognizes the variety of social effects different social policy models (designs) can have with respect to stratification.

These theoretical assumptions found their empirical expression in two dimensions constitutive for the welfare state: decommodification and social stratification. Decommodification, Esping-Andersen states, is an indicator of social rights present in a given society. If its level is high it means that the individual does not have to rely on income from her labour: in a situation where social risk occurs (for example, the inability to work, loss of job, sickness), she may leave the labour market, and to a significant degree sustain her standard of living. In words of the author, '...citizens can freely, and without potential loss of job, income, or general welfare, opt out of work when they themselves consider it necessary' (ibid., 23). The index of decommodification is based on analyses of such cash benefits as old-age pensions, unemployment and sickness insurance (ibid., 54).

The second dimension, social stratification, shows how various social policy solutions present in each of the regimes shape the social structure (ibid., 69). Thus, some of the social policy programmes can consolidate class hierarchies and potentially limit movement on the 'social ladder', while others (thanks to their design) create opportunities for changing social position. The index of social stratification covers privileges related to various benefits such as special pension 
schemes for selected groups, the role of means-testing and private expenditures on social purposes (ibid., 78).

By demonstrating different combinations of the decommodification of labour and the stratifying effects of regime paradigms on social structure, EspingAndersen broke away from the tradition of quantification, which assumes a linearity of welfare state development and argued that there might be diverse and distinct regimes of the welfare states. Unlike the approaches described previously which assume the linearity of development (either in terms of social spending or the extent of social citizenship) - Esping-Andersen argued that the differences between social policies are not only of a degree but also of a kind. It is exactly the historically and politically determined interplay of individuals, state and market concerning their duties and rights which creates different forms of welfare state, as expressed in their impact to the decommodification of labour and how they affect social stratification. These combinations, in turn, result in qualitatively different types of welfare regime. In other words, the author states that one can observe qualitatively different welfare states, each of which has its own underlying values, its own approach to the way social problems are solved, and a different balance between the market and the state (or in Robert Goodin's terms: politics, social policy and economics) (cf. Goodin et al. 1999). For comparative purposes, Goodin created ideal types of these relations and compared the existing welfare states against them. As he showed, the 'real' welfare states to some extent resemble the ideal-typical constellations of the variables mentioned above (Esping-Andersen 1990, 1999). In effect, Esping Andersen distinguished between three regimes: liberal, corporatist/conservative and social democratic.

As stated above, these three regimes types have distinguishable features. The liberal regime is based on the liberal doctrine (Esping-Andersen 1990). Accordingly, the state should be neutral in the relations between society and market; that is to say, let market forces determine the shape of this relationship (Goodin et al. 1999). With respect to social policy solutions, the leading role is reserved for means-testing and modest universal or social insurance benefits. These measures are aimed mainly at the poorest strata of the population which are not able to provide means through performance on the labour market. These measures are, therefore, highly selective. The liberal doctrine also has other consequences: the transfers the state makes to the needy are modest, as the labour market is perceived as the main channel of the wealth distribution, or they are provided by private institutions operating on the commercial basis (EspingAndersen 1990:29). 
The conservative/corporatist regime is less devoted to the pure rules of a free market. Instead, it assumes that the harmful effects of the market should be reduced. Nevertheless, the response to the ineffectiveness of the market is strongly related to the social position of the individual. Thus, compensatory measures are dependent on the labour market position of the individual. This is done by linking the level of social transfers with previous income, which is something typical of insurance-based solutions (Esping-Andersen 1990). As this regime is influenced by Catholic social thought, certain social policy measures aim at preserving traditional family structure and roles (the role of crèches, kindergartens and institutional care of elderly is marginal). The position of men as breadwinners and women as carers is reinforced by the fact that mainly the former are granted benefits (as it is they who perform on the labour market) (Esping-Andersen 1990, 1999; Goodin 1999). In this way, social policies reinforce the existing social structure, by the preservation of achieved or traditional positions within it.

Finally, there is the social democratic regime. Here, as Esping-Andersen argues, the dominating ideology is social democracy. Following this doctrine, the state is strongly involved in market-society relations. This entails the commitment to full employment on the one hand, and to compensation of income in cases of social risk on the other. The underlying idea of this regime is to provide equal welfare conditions for all individuals, without relating it to the individual's condition of work or previous contributions. Thus, the level of benefits and availability of services is high and accessibility is characterised by far fewer conditions compared to other regimes (Esping-Andersen 1990). Therefore, this regime is equalising both with respect to social and gender relations. Here the role of redistribution is significant, as the provision is based on public funds (taxes) and strongly reflects the value of social solidarity (Goodin 1999).

The regime approach has gained considerable attention and became the benchmark for comparative social policy analysis. At the same time, it has received much criticism from different angles. In the following paragraphs I will briefly outline a number of the key reservations which have been made with regard to the approach in general, while in subsequent paragraphs some points will be raised with respect to its potential applicability in the context of Central and Eastern Europe.

When it comes to a general critique of Esping-Andersen's approach, one may distinguish at least three general standpoints. The first one refers to the placement of countries in certain clusters and/or the omission of some countries in the analysis. For instance, it has been noted that in Esping-Andersen's initial categorization the Netherlands belonged to the social-democratic regime, while it 
displayed more features of the corporatist one (Kersbergen and Becker 2001). Similar criticism was raised in the case of Switzerland (Castles and Mitchell 1993; Ragin 1994). Other group of authors (Leibfried 1992; Castles and Mitchell 1993; Ferrera 1996; Arts and Gelissen 2002) raised the point concerning theoretical sufficiency of three-type typology. Accordingly, they have argued for adoption of more types: Mediterranean, Latin rim, Southern (for the countries of Southern Europe), and marginal/radical for the Australia and New Zealand.

The second general criticism emphasizes the lack of sufficient acknowledgment of the different social roles of men and women. The regime approach, it is argued, is male-centred, and as such, does not reflect gender differentiation in the society. This argument, pursued by feminist scholars, criticizes the theoretical foundations of the approach, especially in relation to social-citizenship and the decommodification perspective. Both perspectives adopted the male norm for society as a whole; logically, to assume some form of decommodification requires previous commodification in the labour market, not necessarily being the case for women who, in some societies, were predominantly occupied with childcare and homework. Similarly, while in some countries women gained full political rights, the fulfilment of social rights depended on the position of men in the labour market.

Third, the regime approach displays some deficiencies when it comes to studying social policy changes, such as retrenchment or restructuring. The challenge lies in the very nature of the concept of regime itself. As defined by Esping-Andersen,

'the concept of welfare-state regimes denotes the institutional
arrangements, rules and understandings that guide and shape concurrent
social-policy decisions, expenditure developments, problem definitions
and even the response-and-demand structure [of] citizens and welfare
consumers (...) that are relatively historically stable' (Esping-Andersen
1990).

In other words, the notion of regime assumes some continuity of welfare arrangements, thanks to the existence of historically structured institutional complementarities (cf. Hall and Soskice 2001). This assumption, in turn, may lead to the over-deterministic vision of regimes, as self-perpetuating institutional entities with a marginal propensity to change, especially in the absence of an exogenous shock. While the latter might be the case, many scholars observe slow 
evolution of social policy arrangements, leading in all probably to significant alterations of the regimes beyond the short-term perspective (cf. Streeck and Thelen 2005).

While the regime approach was developed for the affluent industrialized democratic states of the West, its application to other regions of the World seems problematic. This caveat applies to Central and Eastern Europe as well. It will be shortly outlined below (and more thoroughly developed later in the part dealing with explanatory factors) how the theoretical embeddedness of this approach in the Western context makes it difficult to apply it to CEE.

What seems central for the regime approach is the assumption the regimes are founded on ideological and political premises. In effect, at least theoretically, they should rather closely relate to the values their choices display. As EspingAndersen convincingly argues, this is the case of the countries he analysed (developed OECD members). The ideology-policy congruency in the case of Western countries is, in other words, the effect of following the pattern presented by both Marshall and Polanyi: the sequential development of rights accompanied by varying degree of decommodification. However, the following question should immediately be raised: what about the countries that did not follow this pattern? The states of East and Central Europe did not encounter the logic of this sequential development, with the biggest interruption being the state-socialist period. As a result, under state socialism there was a notable gap between declared (socialist) values and policy practice (Deacon 1992b). Accordingly, while the state announced egalitarianism, many social groups and policies were treated in an opposite way (leaving country differences aside). If one recognises some degree continuity of social policy context before and throughout the transition (and this study does), this legacy of the socialist era combined with the chaotic changes which occurred during the transition makes the application of a regime approach highly questionable.

Next, on more of a conceptual note, the regime approach tends to treat social policies on the aggregate level. As mentioned, it is the degree of decommodification and type of social stratification which constitute the analytical space in which the regimes are located. The reason for such conceptualization has been presented above and stems from the assumption of the priority of regime continuity and consistency of a given ideology over policy changes. In the case of CEE, as the following chapters show, one may observe a variety of social policy solutions in many respects: in one country, across countries, over time and so on. This is why the study of post-communist social policies requires a more 
disaggregated approach, so that it is capable of capturing potential policy changes and/or continuities.

What is proposed here for studying social policy following the collapse of the state socialism is an analysis of social policy in terms of its institutional features, notably citizens' eligibility to benefits, the generosity of such benefits and the duration of payments. In the case of childcare policy, the analysis of institutional features of cash benefits will be combined with the analysis of services available to parents with small children. The institutional features will be analysed for each of three policies (unemployment compensation, childcare and old age pensions) separately, so that one is able to follow their developments. To some extent the institutional features approach resembles the idea of the decommodification index, but avoids the high level of data aggregation and does not carry that much context-specific load. In addition - and what is especially important for later parts of this work dealing with historical developments in Poland and Hungary - the institutional features are more relevant categories of social policy analysis. In the end, it is the generosity of benefits or duration of their payment that belong to the domain of public discussion concerning policies and not the abstract categories such as decommodification. This emphasis is necessary because, as demonstrated by students of welfare state retrenchment (Pierson 1994; Hacker 2002; Starke 2008), social policy change is often a multifaceted phenomenon which involves shifts in such parameters as eligibility, generosity and coverage.

The following paragraphs will introduce the approach that I will use for studying social policies in eight countries of Central and Eastern Europe from 1989 to 2004. Specifically, it will devote attention to the issues of diversity, configurational perception of policies, and technical rules guiding this approach.

As demonstrated by some scholars (Janoski and Hicks 1994; Rihoux and Grimm 2006), a fruitful comparative research on welfare state policies should be sensitive to the variation among cases and driven by clear conceptual and theoretical guidelines. Usually, this means a case-oriented approach, emphasizing the analytical complexity of policy (Ragin 1987). However, meeting this requirement usually means reducing the number of cases at hand as there exist limited possibilities of application of 'thick', comprehensive description to an extended number of cases. These limitations exist because it is impossible to analyse and compare large quantities of data concerning multidimensional phenomena. 
Another important question that is related to the issue of measurement is the relevance of concepts driving selection of policy dimension. As mentioned already, this research project suggests that policy is dynamic, contested and can take various forms and shapes, depending on the historic, institutional and relational context. What stems from this is that policy is subject to the games actors play in a given institutional context, allowing them to mobilize their resources, both for shaping and maintaining certain policy solutions (Streeck and Thelen 2005). Thus, the subject of actors' games must be relevant to the games themselves. This is somehow the repetition of Esping-Andersen critique of social spending approach, which does however go further in the disaggregation of policy features (or dimensions).

This is why I suggest focusing on what I call institutional features of social policy which are complemented by organizational and financial dimensions. The organizational dimension, often in the shadow of debates on social policy change, constitutes an important conceptual element of welfare state change. As SeeleibKaiser argues, changes in the organization and regulation of welfare states might impact the overall social policy change as much as shifts in benefits (Seeleib-Kaiser 2008). At the same time, however, the regulatory framework can stabilise social policy in spite of changed organisation. Also, following Pierson (1994; Pierson 2004), the very organization of welfare benefits and services and their feedback effects are important inputs for social policy making.

Such an approach meets the 'policy content' and is also in line with the view of policy as contested in political process. However, the social policy conceptualisation presented above is difficult to measure, because it entails a variety of features that differ depending on their configuration.

One of the successful ways of minimizing this problem, the fuzzy set theory, has been proposed by Charles Ragin (2000). This work utilizes the extension of this approach, namely fuzzy set ideal-types analysis. Based on fuzzyset theory it allows for a comparison of a bigger number of cases without losing an emphasis on the complexity of social policy. As shown by Jon Kvist (1999; 2006), this type of comparative analysis can be successfully used for studying both the diversity and change of social policy. The most straightforward benefit of using this method is that it allows for more nuanced accounts of change, which is of a great relevance, especially given the unstable context of policy-making in CEE. In addition, this approach allows for measurement of features of social policy that meet the methodological requirements raised in previous paragraphs: it is capable of translating various types of data concerning complex social policy phenomena into concise categories. To sum up, the fuzzy set ideal types approach offers great 
advantages when studying social policy. It allows for transparent and systematic measurement of policy, driven by clear conceptual and theoretical guidelines. When applied to many points of time (in this study, eight), it gives a strong basis for describing trends. Finally, used in a cross-country comparison, it allows for clustering countries. I use all three features of this approach in this study.

\section{LITERATURE REVIEW: SOCIAL POLICY REFORM IN CEE}

The sections presented above maintained that there should be a link between the specificity of empirical cases, method and theoretical approach. The current section focuses on the last point - the theoretical approach - and presents a literature review of research conducted on social policy reform in the countries of East Central Europe. The review will critically discuss the most important works on this topic. As will be argued, these works have several shortcomings. The criticism does not only come from theoretical presumptions; also, empirical evidence, while confronted with several approaches used in the literature, shows their weakness. Therefore, this section will serve as a theoretical discussion, outlining the main strands of arguments used so far.

With regard to eight countries of CEE in the period 1989 to 2004, I will go on to demonstrate in Chapter 3 that the multifaceted diversity of the three social policy programs (i.e. unemployment compensation, childcare and old age pensions) can be observed. In Chapter 3 and elsewhere I identify the variety of intra-country designs (especially as expressed by the rules governing accessibility, generosity and durations of benefits), both just before the transition and thereafter (the phenomenon of hybridization). Second, cross-country differences are found. These findings suggest the existence of separate country logics of social policy development, logics which are deeply rooted in the past. The aim of this chapter is to present these issues in the context of the discussion on the changes of social policy under the transition. It covers the problem of explaining social policy developments during the transition with special emphasis on the diversity of cases and hybridisation. As the explanatory part of this dissertation will include the oldage pension policies of Poland and Hungary, these two countries will serve as empirical counterparts against which the viability of theoretical propositions will be assessed. The discussion starts with the presentation of more 'proximate' type of explanations: economic capacity combined with structural social pressure, party politics, and influence of international actors. The second part of the chapter deals with more 'remote' explanations referring to the importance of history and social 
policy developments in past. It focuses on the issues of institutional reproduction and reconfiguration and points to the comparative historical analysis as the tool capable of dealing with shortcomings of approaches presented in the previous section such as short-termism and the full rationality (or lack thereof) of political actors.

In the comparative literature related to social policy change in CEE, the greatest attention has been paid to old-age pensions, pointing out a variety of exogenous factors leading to its reform. The focus on old-age pensions has shifted the discourse on social policy under transition to that of a 'revolutionary' or 'paradigmatic' change (Mueller 1999; Orenstein 2008; Orenstein, Bloom et al. 2008). The 'exogenous factors' branch of arguments narrows the debate in a twofold way. On the one hand, it tends to overstate the degree of change, especially when the depended variable, old-age benefits system, is defined in an oversimplified way. On the other hand, the abovementioned focus on pensions overshadows other policy fields, in terms of both the degree of their change and possible explanations. Such superficial treatment tends to overstate change, but also crowds out other, endogenous factors contributing to post-socialist social policy evolution. This chapter stresses the role of historical legacies for understanding the two main dimensions of social policy in Hungary and Poland. First, it explains relative characteristics of social policy in the countries, including well-established pillars of welfare provision (childcare and old-age pensions) and others, such as unemployment compensation, which were more recently introduced. Second, the historical legacies can explain the direction of undertaken reforms (especially pensions). The following part of this chapter presents the most common explanations of social policy outputs after 1989, while the final section outlines the argument of this dissertation in more detail.

\section{ECONOMIC SITUATION AND OTHER STRUCTURAL FACTORS}

The explanations referring to economic and other structural factors belong to a wider theoretical approach, functionalism. While explaining welfare state expansion, the approach referred to structural factors regarding societies and economics, such as economic growth (Wilensky 1975). Therefore, it linked the growth of economies and accompanying social processes, such as industrialisation, with a growing need for catering for the social needs of growing numbers of workers. In this view, the expansion of welfare state was a straightforward response to the growing need for it. Similar logic was presented by Flora and Alber (Flora and Alber 1981), who argued that the development of the welfare state is the result of modernization and growing complexity of industrialized societies. 
While in the case of retrenchment, the drivers are not anymore economic growth or industrialization, the basic mechanism of social (economic) needresponse remains. The arguments concerning welfare state retrenchment maintain that the shifts in structure of economy (increasing role of services, employment of women, deindustrialisation), international economic relations (increased international competition), higher levels of inflation and social structure (ageing population) create pressures on rolling back social policy (Pierson 2001; Schwartz 2001). In nutshell, such logic underlines the 'new social risk' approach, which in principle is the newer version of the structural approach: the unfavourable structural conditions force governments to seek cuts by setting ineligibility criteria and reducing the level of generosity and the general level of social spending (Bonoli, George et al. 2000; Taylor-Gooby 2004).

The case of East Central Europe is rather extreme in this respect: while in the West the shifts were taking place over longer period of time, in CEE these phenomena were 'frozen' during the socialist period and some of them exploded at the beginning of the transition. This argument especially concerns the economic situation in the region: international trade, the situation in labour markets and overall fiscal stability (in various magnitudes for different countries, however) (Roland 2000). One of the most important changes which framed the post-socialist states debate on economic sustainability was the shift from the so-called soft budget constraint to the hard budget constraint. According to Janos Kornai (Kornai 1980), the economies of socialist countries were characterised by permanent budgetary imbalance due to excessive spending, whose scale and growth was not matched by revenues. The hard budget constraint changed this situation and imposed strict rules regarding budget spending. This, in turn, made the items of social expenditures the main targets of retrenchment. The paragraphs below discuss how these structural factors could explain the diversity of social policies in Hungary and Poland in terms of the outcomes of their old-age pension reforms.

Let us start with the simplest explanation of the social policy reform diversity in the two countries which stresses the importance of the economic situation (not only the level of economic development, but also macroeconomic instability-output decline, high level of unemployment etc) and other structural pressures such as an ageing population. It might be the economic hardship (or transformational recession, to use the term coined by Janos Kornai (Kornai 1992)) it is argued which creates a constraint on policy makers and forces them to introduce stricter rules concerning the access to benefits, their generosity etc. The logic is as follows: because of the structural problems such as a drop of GDP, industrial production output falls, there is a rise in unemployment combined with a difficult 
social situation, and so there emerges a negative macroeconomic situation. In a short-term this situation usually presents itself as a fiscal crisis. In order to overcome it, two solutions (which are sometimes combined) are possible: increasing the fiscal revenue or cutting public spending (Barr 1994).

The second facet of the structural situation is demographic pressure. This factor relates to an unfavourable demographic situation, namely ageing. Social ageing is the result of a low fertility rate combined with an increase in the number of elderly in society. From point of view of different policies, the problem may have some variants. Usually (but not always) for family policy, a low fertility rate can be a driver for expanding its scope. In case of old-age pensions, the flow from the labour market to retirement which is not balanced by the flow from schooling to the labour market may be seen as the reason for a reform.

Table 1 summarizes the data on structural conditions in Hungary and Poland. It presents the indicators with respect to the initial severity of the transition (the GDP decline, industrial output fall and speed of recovery), combined with the level of social spending and other indicators relating to the three policies analysed. Each dimension will be discussed below shortly. 
TABLE 2: STRUCTURAL CHARACTERISTICS OF SOCIAL POLICY IN HUNGARY AND POLAND (MID-1990 AND VARIOUS YEARS)

\begin{tabular}{|c|c|c|}
\hline Indicator & Hungary & Poland \\
\hline \multicolumn{3}{|l|}{ General economic situation } \\
\hline \multicolumn{3}{|l|}{ GDP per capita } \\
\hline GDP change (1995) & 1.5 & 7 \\
\hline Year of recovery & 2000 & 1996 \\
\hline General government balance (1995/2000) & -5.0 & -3.3 \\
\hline Annual inflation rate (1995) & 28.2 & 27.8 \\
\hline General government expenditure (1995) & 52.2 & 49.2 \\
\hline Public social spending as \% of GDP (1994) & 34 & 35.4 \\
\hline \multicolumn{3}{|l|}{ Pensions: mid 1990s } \\
\hline System dependency rate & 78.1 & 53.7 \\
\hline Old age dependency rate & 35.7 & 29.4 \\
\hline Pensioners as percentage of population & 27.5 & 18.2 \\
\hline Coverage rate & 77 & 68 \\
\hline Replacement rate & 61.9 & 60.9 \\
\hline Support burden ratio, year 2000 & 1.509 & 1.412 \\
\hline \multicolumn{3}{|l|}{ Current Demographic situation } \\
\hline Total Fertility Rate in 1995 & 1.58 & 1.61 \\
\hline $\begin{array}{l}\text { Life expectancy at birth, males/females, } \\
2000\end{array}$ & $65.6 / 78$ & $70.8 / 79.4$ \\
\hline \multicolumn{3}{|l|}{ Demographic situation: year 2050} \\
\hline Share of $60+(\%)$ & $35.8 / 34.3$ & $36.9 / 35.3$ \\
\hline Old-age dependency ratio & 0.79 & 0.83 \\
\hline Support burden ratio & 1.910 & 1.788 \\
\hline \multicolumn{3}{|l|}{ Unemployment } \\
\hline Unemployment rate (1995) & 10.4 & 15.2 \\
\hline Employment ratio (1995) & 59.4 & 63.8 \\
\hline
\end{tabular}

Sources: Gal 2008. 
When it comes to the transformation recession, the data are compared to the breakthrough year 1989/90. Starting with the GDP decline recovery, one may observe that Poland recovered faster than Hungary (as measured by the return to the pre-transition level. Also, the cumulative GDP fall was deeper in the latter case. The slower recovery in the case of Hungary was accompanied by smaller growth rates throughout the decade.

Moving to the fiscal situation, in the mid-1990s Poland had a significantly lower budget deficit as compared with Hungary (-3.3 vs. -5.0$)$. This trend was also present during the 1990s. When it came to inflation, its level was comparable in the two countries, and decreased sharply around the new Millennium. To summarize the general economic situation, it was worse in Hungary than in Poland, especially when the discussion regarding reform of many social policy programs was accelerated. Such conditions, according to the theoretical predictions, should result in more severe social policy retrenchment in the country with the economy performing comparatively worse. This, however, was not the case.

Moving to a more current demographic potentially affecting the pension systems, the total fertility rate was higher in Poland than Hungary. This situation may have manifold impact on the possibility of social policy reform and therefore must be analysed jointly with the proportion of the elderly in the respective societies and their longevity. The parameters relevant for the condition of the system were less favourable in Hungary in terms of the system sustainability. Such a situation was reflected by a higher system dependency rate, old age dependency rate and proportion of pensioners in the population in Hungary than in Poland in the wake of pension reforms. In terms of generosity and coverage, the two systems were in similar situation.

One could argue, however, that what is more important than the current situation is the expectation concerning the functioning of pension systems in the future. Such arguments have been especially strong among World Bank employees who presented them as the main reason underlying the necessity for social policy reform (Deacon 2000). The simulations, presented by Gál and colleagues (Gál. Róbert, Iwasaki et al. 2008) demonstrate that the pressures in the year 2050 will be similar in two countries. This, according to the structural pressure argument, should lead to similar policy reform, which did not and has not happened.

Finally, with respect to the labour market, in Poland the situation was more severe than in Hungary. The unemployment rates vary according to the method of the measurement, but generally, one may argue that the share of 
unemployed in Polish economy was much higher than in Hungary (Golinowska 1999).

How can all of these indicators explain the outcome in social policy terms observed around 2004? Given all comparative data (excluding the unemployment rate which significantly declined in both countries in the end of the decade), it was Hungary rather than Poland that was in a position to introduce some retrenchment measures. However, beside some short-lived solutions, the social policy of Hungary has not changed drastically. Overall, Hungarian social policy is much more comprehensive and generous. If compared in very general terms, Hungary locates somewhere between social democratic and conservative model of social policy, while Poland is mainly liberal with some conservative elements. The structural situation of the two countries can hardly explain their social policies, but maybe it is possible to do it using political factors. The next section deals with the impact of political actors on policy developments.

\section{POLITICS OF SOCIAL POLICY}

The second prominent theoretical approach in explaining social policy has been concerned with the impact of politics on social policy making. This approach has developed several branches, focusing on various areas of the political scene (such as parliament, corporatist institutions), and actors involved on policy making (political parties, trade unions, employers, etc). However, what the various branches of this approach have in common is the conflict over social policy issues (its values, redistributional effects etc) among actors representing social interests, classes, etc. This section outlines the main features of the approach and presents how it has been applied for explaining social policy developments in CEE.

The oldest and most straightforward branch of the 'politics' approach concerns the impact of political actors (political parties) on social policy making in a process of a democratic and pluralist struggle over social policy expansion. Such arguments focused especially on the role of social democratic parties in shaping Scandinavian welfare states. It was argued that with the increasing industrialisation, the growing working class became represented by social democratic parties against the interests of capital (Korpi 1980; Esping-Andersen 1985). A more sophisticated, but similar argument has been put forward by proponents of the power resources approach. Here, the emphasis has been put on the growing relative power of the labour movement compared to that of capital. While capital's advantage focused one financial resources, the resource of labour lied in numbers: it was at the ballot box where the advantage of labour over capital 
could be realized in the electoral game (Korpi 1989; Palme 1990). In other words, the transformation of the labour-capital conflict takes place through democratic institutions, where the interests of labour can be achieved.

The party politics approach did not focus only on the parties of left. Esping-Andersen (Esping-Andersen 1990) focused on class-coalitions as one of the main explanatory factors of certain welfare state configurations (the ideological underpinning of the parties in coalition led to specific policy output, reflecting cross-coalitional redistribution alliance and including the middle classes). Later, van Kersbergen (Kersbergen 1995) documented the role of Christian democratic parties in the development of welfare states pursuing a conservative policy type.

However, as Starke (Starke 2006) rightly points out, explaining retrenchment in terms of party politics is not as straightforward as explaining welfare state development. It is partially the result of the empirical complexity of welfare state retrenchment, but also the fact that, following Pierson (Pierson 1994), one deals with the 'new politics' of the welfare state. In the nutshell, the new situation is characterised by the fact that social policy programmes are well entrenched, have high social support and parties attempting retrenchment are predominantly occupied with the logic of blame avoidance. Moreover, social programs not only enjoy the popular support, but are also defended by organized actors: trade unions, beneficiaries' organizations etc. Such context makes retrenchment a hard and difficult political project for political parties.

The application of the party thesis to both development and retrenchment of social policy in Central and Eastern Europe seems an uneasy task. The region, as mentioned above, has only a limited record of democratic policy-making - that of the mid-war era and the period since 1989. In the period when Western welfare states were maturing and going through the first phases of crisis (late 1970s and 1980s) the CEE region was characterised by a monopoly of state-imposed socialist parties and trade unions (with Poland being a notable exception). Thus, the logic of welfare state development was completely different, and social policy development was seen as the achievement of the socialist state. Thus, the forces of social policy development were quite 'impersonal' and no link between political parties or social movements and welfare achievements could be made. Accordingly, very few parties after 1989 identified with these achievements.

Another important point to emphasise and focus on is the ideological orientation of parties established after 1989. The political programs and actions of several of them do not follow the Western distinction between left and right wing. Finally, for several years, the issues of social policy did not occupy an important 
position on the agenda of political parties and was a function of economic policy rather than a separate item.

The main idea behind this approach is that political parties are significant drivers of social policy change. In principle, it is the political agenda of a party which is translated into policy proposals and then implemented as a social policy solution (Hasselmann 2006; Vanhuysse 2006). Conventionally, it is assumed that a link exists between parties' ideological positions and certain shapes of social policy (Castles 2004). Esping-Andersen, for example, demonstrates the link between leftwing parties being in power and a decrease in the importance of means-testing. Other authors stress the impact of socialist/social-democratic parties on increases in social spending. Therefore, one would expect differences in social policy outputs in Hungary and Poland as the result of political struggle and consequently, electoral victories (Cook, Orenstein et al. 1999; Lipsmeyer 2000).

However, if one looks at the policy developments, it is quite clear the relationship between party's ideological orientation and social policy reform (or lack of it) is rather weak. In Poland, it was the coalition of the post-communist and agrarian parties (both considered as sitting on the left of the political scene) which introduced the retrenchment measures in unemployment compensation and maternity-related benefits. The same situation took place in Hungary, when a wave of income-testing occurred under the rule of a left-wing led coalition.

One could ask: what about corporatist structures in CEE? What about the tradition of the Polish Solidarność trade union movement, which had 10 million members at the beginning of the 1980s? The result of several studies focusing on corporatism in the West point to the importance of organized labour and mediation structures in shaping social policy (Schmitter and Lehmbruch 1979; Huber and Stephens 2001). Surprisingly, the role of trade unions in shaping the social policy agenda CEE is very small. Several authors dealing with the nature of corporatism in the region emphasise the lack of engagement of organized labour movements in the public sphere as observed in the West (Crowley 2004; Ost 2005). This situation is even more striking given that in the not too distant past the states labelled themselves 'workers states'.

Finally, the fact that trade unions function as the base for social democratic or Christian democratic parties cannot be ignored. Such a relationship in Western, industrialised countries allowed for the formulation of policy proposals by unions and transferring them by political parties to parliamentary and governmental bodies. Such an important role of trade unions is marginal in the CEE region in 
spite of the strong engagement of unions in left-wing parties in both Hungary and Poland and the Christian democratic Solidarność centre-right party in Poland.

According to David Ost, the reason for the lack of engagement in social policy formulations lies in the reverse logic of proposal transfer. It is the government and the parties that support it which form policy proposals and impose support for these proposals on trade unions. In other words, it is not political parties which are unionized, but trade unions which are politicised. Such logic prevents the unions from having their own policy formulation and, if such actions take place, those responsible within the union enjoy less support from the union because a part of it remains loyal to the government. The mechanism holds for trade unions related to parties in opposition as well. The logic of ruling party contestation hijacks the actions of trade unions that are relevant from union's point of view, but threaten the position of the party it is related to.

\section{INTERNATIONAL INFLUENCE}

Another strand of literature associates directions of social policy change with the influence of external actors, mainly multilateral agencies such as the World Bank, the International Monetary Fund, the Organization for Economic Cooperation and Development and the European Union. The region of Central Europe after 1989 was a playground for these organizations, especially when it came to economic policy. The dire economic situation and the will to open their economies to world trade after the collapse of COMECON were the reasons why the countries so openly welcomed the assistance from international organizations. This assistance included technical support, expertise (management consultancy), training of staff, and infrastructural and financial support (meaning both cancelling debts from the 1970s and 80s, and lending new money on projects).

On of the most often invoked features of the instruments used by the organizations, especially the World Bank and the IMF, was that of conditionality. This meant lending money to the countries of the region on the condition of fulfilling special requests (with more of an emphasis on the social sector in the case of the World Bank, and on the economic sector in the case of the IMF). With these instruments, the organisations were able to exercise their ideological agenda of the free market in the social sphere too (Deacon, Hulse et al. 1997). Interestingly, both the IMF and the WB were very active in those countries (in Hungary, for example, the WB had already been active from the beginning of 1980s) which were biggest loan-takers in the region. This activity went beyond offering loans - in both 
countries the World Bank missions were present and actively involved in social policy reforms. Also, the links between the governments and the World Bank went well beyond organizational protocols and had a personal dimension: Lajos Bokros in Hungary and Michal Rutkowski in Poland (Orenstein 2008), both central figures in the pension reform in their respective countries. According to the external influence thesis, the policy blueprints, implementation, and outcomes should be strongly influenced by and somehow conform to the tokens imposed by the organization. And yet Hungary, despite being a bigger loan-receiver than Poland, conformed to the WB and IMF blueprints less.

As mentioned above, their reformed pension systems follow the general advice of the WB (having a multi-tier construction, a funded component), but when one looks at the detailed features, they differ. The difference lies in the philosophy of the first tier (NDC in Poland, DB in Hungary), the expected replacement rates, guarantees to individuals with atypical work, issues of regulation, such as the return rate of the funded tier etc. Other organizations such as the ILO, despite their presence in the region, were not successful in pursuing their goals.

Another line of argument concerns the role of the European Union in the agenda-setting in the candidate countries. Accession to the EU is conditional upon the incorporation of the acquis communaitre into the national legal system of the candidate country. This way, it is argued, the component of the UE legal system concerning social policy becomes the binding law in the new member states.

However, the problem is that the regulations included in the EU 'hard law' cover such issues as work safety or gender equality, which are the fundaments of any European welfare state. When it comes to the social policy programs this work deals with, especially pensions, they remain the domain of national legal regulation. As such, no direct effects of enlargement can be seen immediately (Sissenich 2007). The issues of social inclusion and social policy are regulated through the 'soft' mechanism of the Open Method of Coordination, which so far has not been proven successful in changing this policy. In fact, the only relevant impact the EU might have on social policy (in the future, however) can be attributed to the compliance to the Maastricht criteria (Rhodes and Keune 2006). This concerns the level of public debt, including that induced by public pension schemes. As in the case of others explanations outlined above, the role of international agencies can hardly explain the diversity of social policy in ECE. 


\section{TOWARDS A HISTORICAL-INSTITUTIONAL EXPLANATION OF SOCIAL POLICY DIVERSITY IN CENTRAL EUROPE}

Few points arise from the presentation of the short-term explanations. First the discussion suggests that the logic of social policy change during the transition can hardly be explained by the arguments related to the context of transition itself. The short-term perspective - looking at political, economic and social determinants - is not able to explain the diversity in CEE for more a general reason, outlined below.

First, the transition is often treated as the tabula rasa. Accordingly, the political and economic institutions associated with the old regime cease to exist and the new ones arise. It is possible to model the new, blank social reality without bigger restraints according to some vision of a new order. The new institutional design is the result of such purposeful action, reaching an established aim. There are no mediating factors which can seriously modify the implementation of the plan.

The next, related problem refers to the rationality of the actors: it is assumed that political actors are rational, that they can meaningfully choose from a portfolio of policy options, and that they know how to implement and are aware of the effects any given policy will have (cf. Vanhuysse 2006). All these issues are taken into account when the choice of policy option is being made.

Finally, a general problem with the type of explanations presented above is a so-called functionalist fallacy. This is especially the case of those explanations focusing on structural, economic and social pressures, directly coming from the functionalist approach. The problem of functionalist explanations is that they tend to infer the cause of something from its result: here a certain social policy characteristic is to be explained by the need for it. For example, keeping others factors constant, the level of economic development can explain the generosity of social programmes. Clearly, this is not the case in a complex social world, where there exist several mediating factors.

From this brief discussion, an important conclusion arises: in order to understand the diversity of social policy programmes, one has to go beyond shortterm explanations and understand the context of logic of policy development in the past. It is exactly the persistent institutional logics which can explain the different trajectories of Poland and Hungary with respect to social policy. To reveal these 
logics, one has to go back in time to the formative moments of policies and from there, follow them over time. I will now go on to develop this argument further.

The literature on Western welfare state development is quite extensive. Starting from the seminal works of Gaston Rimlinger (1971) and Hugh Heclo (1974), a wave of comparative research studies on the origins of social policies and their development has followed. Later, the works of Esping-Andersen (1990), Skocpol (1992), Orloff (1993), Steinmo (1993) and Pierson (Pierson 1994; Pierson 2001) have expanded this agenda by focusing on the role of institutional and historical factors which can shape current social policy pathways.

The central contribution of these studies, especially of the latter group of authors, is that policies (or social systems, more generally) display a striking level of resilience to change. More precisely, institutional continuity is explained by the mechanisms of increasing returns and positive feedback in the welfare states of industrialised countries (cf. Pierson 2000).

The region of East-Central Europe has been a subject of analyses departing from the institutionalist perspective; however, the number of such analyses especially comparative analyses - is considerably smaller. Most of them dealt with pensions (Mueller 1999; Nelson 2001; Guardiancich 2009) with notable exceptions (Inglot 2008).

The work of Mueller focuses on the relations between policy-makers involved in the process of policy-making and the context in which they operate. The approach, labelled 'actor-based institutionalism' allows Mueller to account for relative imbalances of power among various experts (both governmental and external) and demonstrate the mechanism of policy transfer from international actors (mainly in the World Bank). Additionally, the general economic situation (level of external indebtedness), institutional legacies (existing institutional structures) and design of political institutions provide the context for policy transfer in the field of pensions (Mueller 1999: 55). Mueller focuses on three countries - Hungary, Poland and the Czech Republic - and argues that while in the previous two a radical pension reform took place due to favourable conditions, the Czech Republic resisted such change. By radical reform, Mueller means the introduction of a pension system following the World Bank prescription (i.e. multitier organization combined with at least partial privatisation). Such a classification may raise doubt on several grounds. First, for obvious reasons, Mueller missed the phase of implementation (which, as Nelson and Guardiancich argue might alter the system in the early phase of its existence, and which indeed did alter the system). Second, focusing more on the policy drafting process, Mueller 
optimistically assumes that the policy blueprint is not 'distorted' by the domestic factors. In fact, although the pension systems of the two countries may appear similar, as the following chapters demonstrate the detailed solutions implemented in each country add to the differences between the two countries (financing, organization, preferential treatment of some groups, etc). Finally, Mueller attaches little attention to the history of the countries under study, assuming they share similar legacy which, as mentioned above, is another misleading simplification. These arguments, taken together, lead to an overstatement concerning change of pension systems in Poland and Hungary, but also the influence of international actors.

Guardiancich (2009) focuses precisely on the phase of implementation and argues that original designs may be changed during this phase. Building on the approach of Streck and Thelen, Guardiancich demonstrates how the existing institutional legacies and context created by the reform itself give the actors who are involved in the process the ability to alter the outcome of the reforms. In other words, in order to implement a reform according to its blueprints, it is necessary to support it actively. Otherwise, it is possible that a reformed system 'degenerates' (Guardiancich 2007). The author finds the roots of this process in the contamination of a reformed institutional design: the blend of new and old structures, the short-term perspective of political agents and the continuation of their mode of operation can all contribute to the degeneration of the new system. Consequently, the process of implementation can contradict the aims of reform (be it the alleviation of poverty, more equity in the system or fiscal sustainability). Guardiancich's focus on implementation brings an important element to our understanding of the success or failure of a social policy reform, as it can point to the factors which can facilitate or obstruct this process. In addition, on a theoretical level, the author demonstrates that reform blueprints are not stable in themselves; rather, they need to be actively sustained, otherwise they can be altered. Guardiancich's work, with its focus on the late phase of reform, pays less attention to the question how and why socialist and post-socialist social policy has been historically developed and contextualised after implementation.

The questions mentioned above are the core of the work by Inglot (Inglot 2008). The study, the most comprehensive to date both in terms of time span and country coverage, analyses the emergence, developments and reversals of social policy in three countries: Hungary, Poland and Czechoslovakia (later the Czech republic and Slovakia) between 1919 and 2004. Inglot makes a number of important findings. First, he argues that East Central European welfare states faced different dynamics as compared to their Western counterparts: while in the West, 
welfare states faced retrenchment after a long phase of development, the countries under study underwent several stages of expansion and retrenchment. A second crucial point is that these countries had differing dynamics of these processes, which were linked (not necessarily directly) to political, economic and social developments. Inglot discerns in this way a thesis on the unified character of Eastern Europe. Third, the author presents the striking resistance of these countries when it comes to external influences, both during socialist era (Soviet influence) and transition (various international organizations). The development of East Central European welfare states is rather a path-dependent evolution of historically developed country tradition, concerning social policy institutions, organization and rules, rather than a number of rupture changes. Finally, beside the institutional legacies mentioned above, Inglot demonstrates the replication of a certain policy-making styles and government actions in different periods.

The study by Inglot provides the most exhaustive analysis concerning the establishment and continuing differences between the welfare states in the region. However, his analysis stops short when it comes to analysing and explaining pension reforms that took place in the last years of the 1990s. It is perhaps due to the extensive time-, space- and policy-field scope of his study, but also a social policy measurement issue (social spending).

It seems that in the light of the abovementioned examples there exists a niche, as each extant study displays some deficiencies. A study that could in some way overcome these issues would then focus not only on the issues of historical development but also should be able to acknowledge the early phase of reform development, the debate surrounding reform, and its implementation in a consistent methodological and theoretical manner. I propose such an approach for studying pension reform in East Central Europe in the remainder of this chapter.

Clearly, social policy systems should be treated as institutional regimes (cf. Hacker 2002) as they comprise a variety of rules which are enforced by third parties. The selection of cases and the context of Central and Eastern Europe provide an interesting opportunity to assess the viability of the approach just described. The discussion presented above suggests that exogenous factors such as the overall political, economic and social changes and new international actors have rather limited explanatory power, and played a role of inhibitors at most. This conclusion suggests that the direction and extent of social policy institutional evolution in CEE has been of an endogenous character. The following paragraphs discuss these issues in more detail. 
In this context, the problem of transition poses interesting challenges. Should one see, as argued in the sections above, the change of pension systems in Poland and Hungary as contingent on the transition? Or is it the transition, which induced the genuine pension crisis, which provided the blueprint for the reform? As Laszlo Bruszt has argued, 'a deeper analysis of transformative politics must examine differences in the structural and institutional legacies of these regimes; linking the modalities in the transformative politics to the differences in the paths taken before and during the transition (...)' (Bruszt 1993). This research argues that the pathways of reform depend on the historically developed institutional patterns.

Another crucial issue is the recognition of differences among the countries in various historical periods. Is the meaning of the pre-war period for social policy the same thing in Hungary and Poland? What about World War II: how was social policy operated in years 1939 -1944(5)? Finally, what about the socialist era? Was the 'socialist' social policy the same across the region? The following chapters answer these questions and emphasize that difference existed during each period.

Two important remarks should be raised here. First, as I argue in chapter 2, in contrast to many authors dealing with historical legacies (see for example Barany and Völgyes 1995), the communist legacy is not treated in this dissertation as a set of consistent rules generalised across countries. Elsewhere, the communist period and its legacy have been seen as homogenous among the countries of the region. A similar approach has been applied to the pre-war and World War II periods (cf. Mueller 1999). Although this homogenising assumption makes the analysis easier, it also misleads when it comes to a detailed assessment of the impact of the past on the current situation.

Clearly, there have existed many similarities between Hungarian and Polish social policy systems, but as the detailed description shows in the following chapters, there existed significant differences. These differences concerned social security organization, as well as the relative importance of its various components. This, in turn, is a consequence of different paths of development from the initial moments of social policy existence, conditioning further choices.

Second, we need to discuss the perception of the social policy reform in Hungary and Poland. The two countries are often presented as cases of a paradigmatic change and retrenchment, especially when it comes to their pension systems. Comparative studies (Mueller 1999) argue that the introduction of a funded component was the watershed which, being less redistributive, has brought about the drop in the welfare state standards and changed the roles of the actors who participate in the management and provision of such systems. At closer 
inspection later in this project, I raise doubts whether such generalisations are correct and my argument is that it depends on the institutional configuration and path taken to date. In Hungary, the coherence of the system was present well before the transition and resulted in sustaining and even the expansion of the social policy. In Poland, the complexity and fragmentation of the system has led to the partial retrenchment.

The social policy systems are the reconfigurations of the old systems and present both institutional continuity and change simultaneously. In other words it is argued here that the (relative) characteristics of Polish and Hungarian social policies are the consequence of reconfigurations of institutional factors (cf. Stark and Bruszt 1998), rather than those of pure policy innovations or stability. It should be noted that the institutional reconfigurations Stark and Bruszt talk about do not take place only during the post-socialist era. As will be demonstrated in further chapters, reconfigurations can occur not only as political and economic systems undergo radical change, but also within seemingly stable regimes.

This chapter outlines the argument for the presence (or lack) of welfare state reform in the two countries during the transition. My argument is that the current shape of (reformed) social policy can be explained after analysing the underlying logic of welfare state development in Poland and Hungary. Accordingly, what one actually observes is the outcome of the gradual endogenous transformation processes operating within social security system. Several processes that were found as problem-generating during the transition are not caused by the introduction of market economies and democracy, but are somehow independent and displaying inertia already from the communist period or even earlier. Therefore, I argue that what matters most in the light of common challenges that Hungary and Poland faced with respect to reform of social policy is the historically developed logic (historical legacy) expressed in terms of the quality and accessibility of benefits but also the organization of the system. The latter point covers aspects such as financing, provision and regulation.

The historical legacies are not perceived as constraints concerning social change; they can serve as enabling factors as well. It is in this light the historical legacies can be utilised for explaining the occurrence of social policy in the region. The logic of welfare states developed can have a multifaceted impact on recent attempts of reform as the actions taken in the past may have both intended and unintended consequences. The potential for opposition to the reform is entrenched in society, which if divided by different institutional welfare state settings, can bring about a power struggle of a relational character. 


\section{CONCLUSIONS OF THE CHAPTER}

The main argument of this work is that the diversity of social policy developments taking place during the transition in Central and Eastern Europe is a case of country-specific institutional evolution.

These institutional factors are divided into two groups:

- institutional features of social policy programmes (eligibility, generosity etc.)

- organizational characteristics of social security (financing, autonomy, cohesion)

Thus, the post-socialist welfare states are the result of the reconfiguration of historical legacies, seen not only as constraints but also, in some cases, enabling factors. The old-age pensions provide the starkest example of this argument. The development of their organizational structure and financing mechanisms strongly determined the context of the social policy-making during the transition.

Accordingly, Poland entered the transition with a fragmented pension system having separate schemes for workers and farmers (with strong support from the constituency of the latter) and a weak financial structure (especially the farmers' scheme, running into deficit). The fragmented structure of this social policy program made it prone to a selective change: the workers scheme (with no support from future beneficiaries for the existing scheme because of the overall poor quality of benefits) was comparatively radically changed, while the farmers' scheme remained intact, having the strong backing of this group. In contrast, over decades Hungary has developed a unified system covering all social groups with strong financial structure (offering high and increasing benefits). This resulted in the comparatively modest overall change. The conventional, 'snapshot' approaches are not able to explain these outcomes.

Such observations lead to the following theoretical conclusions. First, the transformation of the welfare states is an endogenous process and depends on the inherited conditions. Second and related, the impact of exogenous factors often highlighted in the literature, such as the international actors mentioned above, should not be exaggerated. Finally, the transformation of social policy takes place gradually over the years.

Thanks to an analysis of these factors since the establishment of the three social policy programs (old-age pensions, unemployment compensation and 
childcare policy) it is possible to trace the evolution of the three social policy programmes and factors which have contributed to their diversity. The empirical chapters that follow present the empirical evidence for the argument raised above. 


\section{CHAPTER 2: METHODOLOGY OF THE STUDY}

\section{INTRODUCTION}

This chapter deals with the methodology used for studying the transformation of social policy in Central and Eastern Europe after the breakthrough of 1989. The introduction of market economies and the democratization process in Central Europe has been accompanied by changes in social policy programmes. The transformation has brought about risks typical for market economies (such as unemployment) that had stood in contrast with an institutional framework inherited from the socialist past (or lack of it at all). Therefore, the potential scope of social policy has been expanded. Also, the transition significantly changed the structure (by reducing the role of state-owned enterprises) and logic (the introduction of mechanisms meant to fit the requirements of a market economy) of social policy provision. Exposed to various factors, both domestic and external (foreign advisors, EU membership), the countries of the region, even though commonly perceived as a monolith, adapted differently to this situation.

This issue raises a number of questions: of how social policies changed since 1989, whether one may distinguish some patterns of this change (evolutionary or rapid, divergence or convergence), and whether there has been a consolidation of social policies in the region. As it is presented below, the temporal dimension is not merely a measurement issue, but encompasses problems of methodological importance. The methodological position, which involves studying the dynamics of social policy, is inspired by the historical institutionalism. However, as will be argued, the method used in this study - a fuzzy sets idealtypes analysis - and historical institutionalism complement each other and provide added value to the study of post-socialist social policy. Accordingly, methodologically, the fuzzy sets approach is sensitive to various types of change, and as such is capable of revealing different social policy reform strategies (Polakowski and Szelewa 2008). From the methodological point of view, historical institutionalism aims at understanding policy developments by looking at the interplay of historically developed legacies and actors whose actions are either constrained or enabled by them. What is central here is the reform strategy applied by actors, given the institutional context. Such strategies can involve policy sequencing, the creation of strategic alliances and so on. (Palier and Martin 2007). 
This chapter aims at aligning these two research components into a coherent research strategy. What brings the fuzzy sets ideal types approach as applied in this research (i.e. a cross-sectional analysis) and historical institutionalism (comparative case studies) together is the issue of time in policymaking. As argued by scholars dealing with issues of policy change (GreenPedersen 2004; Leitner and Lessenich 2005; Howlett and Cashore 2009 ) these two components - one dealing with dependent variables and the other with explanatory factors - are two sides of the same coin and hence should not be studied separately. Also, in the field of comparative welfare state analysis the question of proper measurement of a welfare state dynamics became one of its central topics (cf. Clasen and Siegel 2007), especially given recent theoretical developments pointing to endogenous factors in policy evolution.

Such an approach, which mixes research methods and applies complementary research tools, is close to the approach that Lieberman (2005) calls 'nested research'. As he argues, nested research assumes an interest in both the exploration of general relationships and explanations and the specific explanations of individual cases and groups of cases. In the first stage of my research, I intend to identify basic relationships in post-socialist social policy, while in the second I want to understand the mechanisms which purport to be processes of institutional reproduction with respect to social policy. These two stages are not foreign to each other; on the contrary, I argue they have a common backbone which is the focus on policy sequencing, dynamics and the temporal dimension. This relationship is described in the following paragraphs.

\section{PUTTING THE TEMPORAL DIMENSION AT THE CENTRE OF}

\section{ANALYSIS: HISTORICAL INSTITUTIONALISM}

In his influential book Politics in Time (Pierson 2004), Paul Pierson focuses on the ways in which considering the time factor has already constructed - or has a potential for constructing - analytical, explanatory frameworks that are more informed and resistant to critique. Pierson argues that both institutional causes and outcomes might have different time-horizons, and often these processes take time. This calls into question the majority of the works in the social sciences that have been focused on the immediate causes of more rapid outcomes. According to the author, events are generated through the conjuncture of different processes. These processes might have a different pace, which itself might also be different in time some processes are developing, or unfolding into events after a gradual, systematic 
development of new elements, but sometimes even after a sudden change it is still not enough to lead to the conversion of institution. A small event might then be of crucial importance, but without embedding it into the whole process of which it is a part, the researcher will not get the full picture of the causes and outcomes. Thus it is not usual that changes come suddenly, but that they are already happening, and this constant transformation already in place is the basis for a more profound development: the meaning of 'immediate' causes should be interpreted through this vision of incremental development.

As Thelen argues (2004) in the literature on new institutionalism, one may observe two tendencies with respect to the concept of path-dependence: the pattern is characterised as either 1) that of marginal change and continuity, or 2) that of significant change and discontinuity. This differentiation stems from two different visions of change. Position 1 refers to the significance of past legacies for future choices, as supposedly they create constraints for change. Position 2 derives from a different vision: disruptive change (punctuated equilibrium) followed by the reproduction of a newly established equilibrium. Here, the change is exogenously induced. As a result, Thelen stresses, one has to deal with either incremental, endogenous continuity or abrupt, exogenously induced change. Either of these positions can grasp a transformative but significant change which is endogenous to the system.

The argument applied in this research project follows neatly the view concerning institutional evolution as developed by Thelen and Streeck (Thelen 2004; Streeck and Thelen 2005). As mentioned, the key issue here is endogeneity of change, depending on the features of a social system itself. While the authors of Beyond Continuity (2005) focus primarily on the modes of change, the question of the institutional mechanism which drives change remains in shadow. However, this research gives important hints as to where to look for the sources of change.

The starting point of Thelen and Streeck is that, in spite of quite stable economic political and social situation, there has been ongoing liberalisation (multifaceted process of flexibilisation, loosened protection for various groups etc). In other words, in spite of the continuously stable environment (i.e. a lack of significant disruption), there have been changes taking place, changes following different patterns and pathways. This observation led them to conclude that this change 'unfolds by and large incrementally' (Streeck and Thelen 2005: 5) and that thus it is neither a case of disruptive institutional change nor that of pathdependence. 
To deal with such a problem of a more sophisticated conceptualisation of institutional dynamics, Streeck and Thelen refer to the notion of social regime. This allows them to see institutions as rules that are enforced by a third party -in this way rules become embedded and legitimised. A social regime is a conceptualisation of an institutional setting which is dynamic and which involves a number of actors (rule makers and rule takers). The emphasis on actors is essential, as it is actors who influence the rules (by setting, implementing and challenging them) and, moreover, give leverage when it comes to empirical research requiring identification of the relevant players. Finally, the focus on social regime makes it possible to distinct between the rules and their implementation, which in turn allows for identifying gaps between the two. It is exactly the discrepancy that may arise from imperfect implementation or enactment which can create space for strategic action of actors and, in turn, endogenous change (ibid).

The imperfection of implementation is rooted in the complexity of the social world: while the abstract rule mirrors some ideal social patterns that which are necessarily simplified, the implementation deals with more complex, real patterns. Such imperfection makes institutions subject to challenge by various actors. Also, the rules themselves cannot be unambiguous - social life is characterised to varying degrees by uncertainty and the rules must take account for this. Again, this leaves some freedom to interpret them, and possibly to challenge them. Finally, it is these very rule-makers who, given a changing environment, define the rules so that they can be changed (adjusted) in the future. Therefore, as Streeck and Thelen conclude, control over the creation and functioning of social institutions cannot be perfect. The degree of this imperfection, which grows with the complexity of social institutions, drives their very own change.

\section{TIME AND SOCIAL POLICY MEASUREMENT: FUZZY SETS IDEAL-}

\section{TYPES APPROACH}

This section outlines the method used for the comparison of the main institutional characteristics of three social policy areas: unemployment benefits, family policy (maternity and parental leave benefits, childcare) and pensions in the group of eight countries which joined the European Union in 2004: the Czech Republic, Estonia, Hungary, Latvia, Lithuania, Poland, Slovakia and Slovenia. The inclusion of such a period allows for observation of how the policies evolved, how they were created (or rather, how they were being created in process) and how this evolution unfolded in the light of significant political and economic transformations taking place in the region. 
Such analysis can provide one with hints concerning the presence of social policy institutional logic in the region. This dissertation looks at the relation between institutional logics of social policy programmes expressed by the principles guiding eligibility, generosity and quality or relations among state and market. If one underlying logic would be applied, it might mean one 'postcommunist' model of social policy exists, as suggested by the 'monolith' thesis. If this is not the case, and the region of Central Europe is characterised by internal divergence of policies, then the analysis should go beyond the 'common experience' approach and focus more on the specific country developments and reasons which stand behind them.

More on the methodological note, the possible diversity among such a number of countries has never been studied before to such an extent, and case (or small $n$ comparisons) studies have been dominating the research agenda for many years. Others focused solely on social spending, without analysing the content of social policies. Thus, comparative research on the welfare state in Central and Eastern Europe still seems rather undeveloped, as there are only very few comparative studies with a scope broader than four countries.

Finally, in order to overcome the problem of instability of the policy outputs, the analysis attempts to present synchronic and diachronic perspectives simultaneously. Thus, it is possible to present the dynamics of change, policy trends and the diversity among the countries. By using the fuzzy-set method I am making a systematic comparison, and in doing so specifying the differences more precisely. In other words, great emphasis is placed on the method of comparison and the temporal dimension of social policy change.

First, the approach introduces the notion of fuzzy sets (Ragin 2008). A fuzzy set is a representation of an empirical phenomenon, which is guided by rules stemming from theoretical and substantive knowledge. Therefore, fuzzy sets should not be seen as conventional variables: they are neither binary variables, nor any other type, as they comprise qualitative anchors (defining boundaries of a set), which affect the membership assessment. Thus, fuzzy sets are simultaneously qualitative and quantitative, as they include the qualitative boundaries and quantitative variation within them (usually the value of a fuzzy set ranges from 0 to 1 and these values - with 0.5 as a cross-over point - constitute qualitative boundaries) (Ragin 2000). The qualitative anchors are established in the process of calibration. For example, a theoretical concept of unemployment compensation generosity quality is operationalised by the replacement rate of a benefit. The set of generosity is then calibrated according to some theoretical premises (concerning the financial needs of the unemployed, etc) and empirical knowledge (some 
systems of unemployment compensation identified previously as being generous). In this sense, fuzzy sets may have different degrees of membership - therefore, one can talk about different fuzzy set values. In effect, every case is viewed as belonging to pre-defined aspects (and varying with respect to this membership).

Second, the fundamental assumption of the fuzzy set approach is that empirical phenomena have a complex character. This configurational character stems from the presumption that theoretical constructs can rarely be described by one aspect (characteristic), and only multidimensional treatment of cases can provide their sufficient reflection in a process of research (Ragin 2008). For example, when comparing unemployment compensation, one should at least take into account eligibility criteria defining access to a benefit and its generosity. These two dimensions represent the constituting aspects of a given phenomenon (here: unemployment compensation), i.e. a fuzzy set. This is why in order to catch this complexity it is reasonable to point out their constituting aspects and to think about them as configurations (set intersections) (Ragin 2000). In effect, every case is viewed as belonging to pre-defined aspects (and varying in the respect to this membership).

Finally, the fuzzy set approach puts emphasis on the importance of the interplay of ideas (theory) and evidence. This centrality of theoretical and substantive knowledge results in precise definition of relevant aspects (sets), their calibration and also the reduction of a set's variation (as not all variation is meaningful from a theoretical point of view).

The importance of the fuzzy set theory here is at least twofold. As already mentioned the approach is sensitive to the qualitative (difference in kind) and quantitative (difference in degree) character of analysed phenomena simultaneously, which in turn might be a first step towards creating typologies (ibid). Second, the fuzzy sets approach can be successfully used for assessing conformity of cases to ideal types. If one treats boundaries of combinations of sets (so-called crisply defined property-space locations) as the ideal types, the operations on sets can be used for establishing a relation between cases and theoretically constructed ideal types (Kvist 2006; Szelewa and Polakowski 2008). These two aspects, combined with methodological and conceptual transparency, create the background for comparative analysis, satisfying requirements of both the measurement validity (Adcock and Collier 2001) and precise location of cases in conceptual space defined by the researcher.

There are some rules which govern fuzzy sets and their interpretation. The operations used in this analysis are: negation and logical and. As far as the 
negation is concerned, the point is that the fuzzy membership of a case in set not-A is equal to 1- set $A$ (or in a more formal form: an=1- An; where small a stands for the negation of the set $A, A$ for the set and $n$ is the $\underline{n}$ th case) (Ragin 2000: 172). The negation this way shows that thinking in bipolar categories strongly constrains the analysis. At the same time, the negation is a very useful tool, as it allows for conclusion that, for example, if some childcare policy membership in the set of generosity is 0.6 , than this case scores 0.4 in the set of non-generosity (cf. Kvist 1999).

Logical and is used when two or more sets are intersected. It is the minimum rule which governs this operation in the case of fuzzy sets. It means that the membership value of such sets is equal to the lowest score achieved by any of them. Thus, if one has sets $\mathrm{A}^{*} \mathrm{~B}$ (the sign ${ }^{*}$ stands for and), and the case scores 0.6 and 0.8 respectively, the membership of this case in sets $A^{*} B$ is 0.6 (Ragin 2000: 173).

These operations on fuzzy sets allow for proper and fast assessment of the cases' membership assessment in a complex combination of sets. This is done by the evaluation of a membership degree in the crisply defined property-space locations; that is, logically possible combinations of full membership and nonmembership in the sets which create the property space. Logically, the number of crisply defined property-space locations equals to $2^{\mathrm{k}}$ where $k$ stands for a number of dimensions.

The idea of a comparison is to contrast empirical evidence with each combination representing an ideal type and find the instance with the highest membership. The analogy between configurational analysis, proposed by Lazarsfeld (1937) and developed by Ragin and the way Weberian ideal types are constructed, is striking. Accordingly, the ideas of viewing different instances (types) of the same phenomenon as configurations of attributes constituting this and constructing ideal types as constellations of elements defining this phenomenon (Bürger 1987) falls in the same category of understanding empirical reality. These two characteristics combined together to offer a great analytical opportunity: we can measure empirical reality more precisely, we can compare it, and thus we can understand it better.

These properties of the approach offer a great advantage when studying the dynamics of social policy change: one studies the conformity of policies to a variety of ideal types repeatedly in subsequent points of time. In this way, one may trace changes both within one type of policy, and shifts from one policy type to another. 
Drawing the benefits of the fuzzy set ideal types approach together, it can be seen that it offers great advantages when studying social policy. It allows for transparent and systematic measurement of policy, driven by clear conceptual and theoretical guidelines. When applied to many points of time (in this study, eight) it gives a strong basis for describing trends. Finally, used in a cross-country comparison, it allows for clustering countries. All three features of this approach are used in this study.

To sum up, this study pays as much attention as possible to the conceptualisation of social policy in the changing context of post-socialist transition. The measurement of post-socialist social policy will give a general picture of variation among countries and policies, but also trends, such as convergence or divergence. The results of the first step of the analysis are the starting point for the second step, which is a historical comparative analysis. The first step of the research is not only a case selection tool, but the results are also fed in to the second step of analysis, where the extensiveness of analysis is being replaced by its depth (Adcock and Collier 2001). Such a procedure is legitimate because, as several authors mentioned as cited above, and especially Pierson argue, in a comparative historical analysis, the results in terms of policy outputs became the inputs for a next step in policy-making. By continually following policies since their establishment, one is able to understand the conditions which influenced given policy output and how past events and policy outputs contributed to reworking social policy. Special emphasis is made on the sequencing of policies: the sequences of social policy development in East Central Europe are hardly random; rather there is a historical logic in them (Rayner 2009). This important conclusion applies to both analyses carried out in this dissertation: the policy dynamics and direction it follows captured in a wider comparison can only be explained by looking at the historical development of this policy since its inception.

\section{DATA SOURCES AND RESEARCH LIMITATIONS}

This dissertation utilizes a variety of data sources. The first part of the study covers the period 1989-2004, which poses serious problems as far as the information concerning social policy changes is concerned. It uses the US Social Security Administration's Social Security Programs Throughout the World publications from various years as this is the only source which contains the information concerning the chosen eight countries for such a long period. Certainly, the data coming from the Social Security Administration have limitations: even though it covers the whole period, one may encounter the vague information included there (Clegg and Clasen 2003). This is why the data also 
come from the International Labour Organization, the European Union, the Organization for Economic Cooperation and Development, the Council of Europe and World Bank publications as they allow for some degree of comparability. Whenever possible, the data are supported by the information coming from other sources, such as the Mutual Information System on Social Protection in the Central and Eastern European Countries, the Mutual Information System on Social Protection in the Member States of the European Union and the Mutual Information System on Social Protection of the Council of Europe. Importantly, several national primary sources of data have been consulted: reports from ministries dealing with social policy (welfare, finances, etc), statistical yearbooks, analyses provided by independent research institutions. Additionally, a number of secondary sources (articles and books) have also been used.

In the second part of the research, dealing with the historical evolution of social policy in Hungary and Poland, the challenge concerning obtaining data has been even bigger. The chapters dealing with Polish and Hungarian social policy are based on a number of primary and secondary data sources. It involves official national statistics, unofficial and classified statistics, expert reports presenting genuine data which used to be partially available only to a small circle of policy makers and experts. The secondary sources include a number of scientific books, articles, stakeholders' publications and analyses. It should be noted that due to the existence of propaganda during state socialist period several sources had to be cross-checked for the validity of the data presented. For the purposes of the historical comparison I utilize unique data sources, classified in the socialist period. Especially demanding was the comparison of policies between countries: the reason for this was the incompatibility of statistical data conceptualisation, collection and processing. Also, Poland and Hungary differed in terms of statistical data research and some social programmes were not researched at all. 


\section{CHAPTER 3: INSTITUTIONAL FEATURES AND TRENDS OF SOCIAL POLICY IN CENTRAL AND EASTERN}

EUROPE - A FUZZY SETS APPROACH

\section{INTRODUCTION}

This chapter looks at the main institutional characteristics of three social policy areas: unemployment benefits, family policy (maternity and parental leave benefits, childcare) and pensions in the group of eight countries which joined the European Union in 2004: the Czech Republic, Estonia, Hungary, Latvia, Lithuania, Poland, Slovakia and Slovenia. The inclusion of such a period allows us to observe how the policies were being created, evolved and changed in the light of significant political and economic transformation taking place in the region.

Beside the substantive interest in studying the three social policy areas, there is also an analytical significance to this choice. First, on the most general level, this chapter refers to the debate concerning the nature of institutional change/stability. Up until recently, analyses of social policy, driven by the concept of path dependency, emphasized institutional stability (Pierson 2001). A careful comparison of the social policies within the CEE region may serve as the basis for a more nuanced analysis which is capable of showing which policies change, how, and in what direction; whether policy change is radical or evolutionary; and whether one can talk about some intra-country (or policy) logic. This chapter demonstrates that, in the context of unprecedented political and economic change, some policies have changed significantly while others represent cases of stability.

In addition, such an analysis can provide one with hints concerning the presence of one or different social policy institutional logics in the region. This chapter looks at the relation between institutional logics of social policy programmes expressed by the principles guiding eligibility, generosity and quality, from which we can deduct the relations between state, market and family in welfare provision. If one underlying logic would be the case, it might mean there exists one 'post-communist' model of social policy, as suggested by the 'one Eastern European regime' thesis. If this would not be the case, and the region of Central Europe is characterised by internal divergence of policies, then the analysis should go beyond the 'common experience' approach and focus more on the specific country developments and reasons which stand behind them. 
More on the methodological note, the possible diversity among such a number of countries has never been studied before to such an extent. Case (or small $n$ comparisons) studies have dominated the research agenda. Others focused solely on social spending, without analysing the content of social policies. Thus, comparative research on the welfare state in Central and Eastern Europe still seems rather undeveloped as there are only very few comparative studies with a scope broader than four countries.

Finally, in order to overcome the problem of instability of the policy outputs, the analysis attempts to present synchronic and diachronic perspectives simultaneously. Thus, it is possible to present the dynamics of change, policy trends and the diversity among the countries. Thus by using the fuzzy-set method, comparisons are made systematically, and so can specify differences more precisely. In other words, great emphasis is placed on the method of comparison.

The chapter proceeds as follows: the next three sections are devoted to the analysis of three social policy areas in turn: pensions, unemployment compensation and childcare policy. The chapter then describes these social policy trends in comparison before drawing the discussion of the study's methodology to a conclusion.

\section{OLD-AGE PENSIONS}

Old age pensions constitute the first social policy programme to be analysed in this chapter. Stanislawa Golinowska stresses that ' $[\mathrm{t}]$ he pension debate became a major issue in the transformation countries of Central and Eastern Europe' (Golinowska 1999: 172). As Joan Nelson adds, these reforms consisted of at least two steps: first, pension systems were adjusted to changing economic and social conditions; and second, there were attempts to conduct more profound reforms (Ksiezopolski 1999; Mueller 1999; Nelson 2001). This section examines these changes.

For the purpose of the comparison, the following dimensions of postsocialist pension systems are proposed: universality, generosity and the role of private schemes.

Generosity of the pension benefits shows how the relation between received pension and the prior salary is designed. If pensions are generous, it means that the average level of the pension received during the retirement period (whether this is after the period of work or childbearing is the subject of another dimension) is high compared to the average salary level. This aspect is brought up 
in almost every discussion on comparative welfare state research. For the purpose of this project, the replacement rate is used as an indicator of generosity. The replacement rate reflects an average percentage of the previous income compared with the median salary in the economy.

One crucial aspect of social policy reform analysis is the time dimension for many reasons the effects of reform are usually delayed. This seems especially crucial in the case of pension reform, where a new scheme (institutional structure) is already in place, but the payment of benefits is a matter for the future. Nevertheless, as Pierson (1994) suggests, this situation should not imply that the change did not occur. To account for this problem, this research treats the reform as it had been implemented fully. In this particular case it means that the replacement rate will represent a simulated value for the new system for a person with a standardised earnings career.

The qualitative anchors are established as follows. The lower position is established at the level of 40 percent. This level is connected with the poverty line measured as the percentage of average salary (the World Bank and OECD). While it is assumed that the presented level lies below the poverty line, at the same time one has to take into consideration the fact that the elderly do not have to finance their dependants so extensively (Golinowska 1997). Thus, this lower level seems justified as this level of benefit is taken to be the minimum standard by the International Labour Organisation and other international bodies (Fultz 2002). As far as the cross-over point is concerned, it is established at the level of 60 percent of average earnings. Finally, the upper level is established at the level of 75 percent of the previous salary (Cerami 2003). These two points were recognised as important qualitative indicators of the situation of the elderly in Central and Eastern Europe (ibid.).

The universality of the old-age pensions relates to the way benefits are targeted. It takes into account whether the whole population is covered by the provision or if pensions are aimed at some special groups (e.g. those who pay contributions or fulfil special criteria). One might say that if access to such benefits does not require special conditions, then the programme is fully universal. However, this situation is purely theoretical, because even in Scandinavian countries which are often perceived as being the most universal (in the scope of social rights), one has to meet the criterion of residence or citizenship (EspingAndersen 1990). Nevertheless, the condition of citizenship or residence should still be perceived as an emanation of universal provision. In the literature there is talk about the universality of provision: it is said that both the liberal and social democratic regimes provide universal pensions (Clasen and van-Oorshot 2002; 
Clegg and Clasen 2003). However, this applies only to the general rule: in both regimes basic pensions are financed through taxes, but the eligibility criteria are significantly different. While in the case of liberal regimes there is the condition of passing an incomes means-test, in social democratic regimes the only requirement is proof of citizenship or residence.

A similar approach is proposed here: it takes into account the coverage and the conditions that have to be met by a person in order to be eligible for the benefit as the basis of universality assessment. In other words, which social groups are eligible for the old-age benefit and which situations are taken into account when assessing eligibility are taken as the basis of the entitlement it this study. The upper qualitative point is set for the situation where every citizen is entitled to some basic benefit and where access to it is not conditional (for example, a basic pension financed through taxes). The lower cut-off point is characterised by benefits which are provided by the state, but which are only provided after means-testing. Finally, the cross-over point should reflect the situation where there is a clear link between the minimum pension and an individual's contribution. Thus in effect one has a triad of welfare provision: it can be universal (fully-in), contributory (cross-over) and finally selective (fully-out) (cf. Kvist 1999). These three clusters were divided into smaller parts in order to allow for more of a fine-grained analysis (there are two subdivisions for selectivity and two for universality).

The final element of the old-age pensions analysed here is the publicprivate mix. It focuses on the locus of pensions provision, whether it is done by the state or market (private companies). The market provided, funded element of a pension system reduces government expenditures related to the programme in the long run (Atkinson 1999). But at the same time it reduces the possibility of the state's involvement with respect to redistribution (Baldwin 1990). Such a change is of fundamental importance, because as Fultz puts it this arrangement effectively shifts risk from society at large to individual workers and shifts the role of government from that of benefit provider to that of regulator vis-à-vis the firms that make up the private tier (Fultz 2006).

Usually, the private component of old-age pensions is measured as the share of private pensions in total social expenditure. While this type of measure has some merits, one of its biggest drawbacks lies in the fact current spending does not reflect any reform whose effects are, as should be expected, delayed. To solve this problem, the chapter proposes to measure the role of private provision as a share of a future pensioners' contribution, which is transferred to private funds. This approach should allow for catching the shift (even partial) in the public/private mix. The qualitative anchors are established as follows: the lower 
point at 3 percent of contribution going to the private scheme, the cross-over at 15 , the upper marker at 50 percent. Table 1 below presents the aspects of the comparison and their translation into indicators, fuzzy score ranges and verbal qualifiers.

TABLE 3: SPECIFICATION OF EMPIRICAL INDICATORS AND TRANSLATION OF DATA TO FUZZY SCORE RANGES AND VERBAL QUALIFIERS: OLD-AGE PENSIONS

\begin{tabular}{|c|c|c|c|c|c|c|c|}
\hline $\begin{array}{l}\text { Empirical } \\
\text { indicator }\end{array}$ & $\begin{array}{l}\text { Fully } \\
\text { out }\end{array}$ & $\begin{array}{l}\text { Mostly } \\
\text { but not } \\
\text { full out } \\
.01-.24\end{array}$ & $\begin{array}{l}. \text { More } \\
\text { or less } \\
\text { fully } \\
\text { out } \\
.25- \\
.49 \\
\end{array}$ & $\begin{array}{l}\text { Neither in } \\
\text { nor out } \\
0.5\end{array}$ & $\begin{array}{l}\text { More or } \\
\text { less in } \\
.51-75\end{array}$ & $\begin{array}{l}\text { Mostly } \\
\text { but not } \\
\text { fully in } \\
.76-.99\end{array}$ & Fully in \\
\hline $\begin{array}{l}\text { Universality of the } \\
\text { minimum old-age } \\
\text { benefits measured } \\
\text { by the rules } \\
\text { guiding access }\end{array}$ & \multicolumn{3}{|c|}{ Selectivity } & $\begin{array}{l}\text { Contribu } \\
\text { tion rule }\end{array}$ & \multicolumn{3}{|c|}{ Universality } \\
\hline $\begin{array}{l}\text { Generosity } \\
\text { measured as } \\
\text { replacement rate }\end{array}$ & $<40 \%$ & $40.1-50$ & $\begin{array}{l}50.1- \\
59.9\end{array}$ & $60 \%$ & $60.1-68$ & $68.1-74.9$ & $75 \%$ \\
\hline $\begin{array}{l}\text { Private provision of } \\
\text { benefits measured } \\
\text { as the percentage } \\
\text { of the contribution } \\
\text { devoted to private } \\
\text { mandatory } \\
\text { scheme }\end{array}$ & $<3 \%$ & $3.1-7$ & $\begin{array}{l}7.1- \\
14.9\end{array}$ & $15 \%$ & $15.1-20$ & $20.1-50$ & $>50.1 \%$ \\
\hline
\end{tabular}

\section{EMERGING PATTERNS OF OLD-AGE PENSIONS IN CEE}

Analysing changes with regard to particular dimensions of comparison is helpful for grasping the practical side of reforms. However, the main goal of this chapter is the configurational analysis. To this end the three dimensions of the oldage pensions policy are taken into account. This gives 8 possible combinations. Membership of each combination of sets is assessed and the highest value is chosen. ${ }^{i}$ The table below presents only the highest scores of the pensions dimensions for each country in selected years. It should be noticed that whenever the chapter refers to Estonia, Lithuania and Latvia (period 1989-91) these countries were still republics of the Soviet Union. The same applies to the Czech Republic 
and Slovakia (Czechoslovakia 1989-1993), as well as to Slovenia (Yugoslavia 19891991). Beneath is the summary of the findings concerning old-age pension policy. As mentioned above, the results of simulations are used for reforms delayed in time. The combinations of dimensions including such simulations are presented in italics.

Generally, in the analysed period (1989-2004), pension policy in Central and Eastern Europe was marked by many changes of various nature. Some countries opted for a change of system parameters without changing fundamental institutional structures. Other countries decided to shift to a completely different system. The countries which only reformed their PAYG systems are: the Czech Republic, Lithuania, Slovakia and Slovenia. The second group reformed their pensions more profoundly by shifting to a multi-tier system with the PAYG system either reformed or replaced as the first tier and which accompanied this with a mandatory funded second tier. The characteristics of pensions and their changes are presented in the table below.

TABLE 4: FUZZY MEMBERSHIP SCORES OF OLD-AGE PENSIONS IN IDEAL TYPES1

\begin{tabular}{|c|c|c|c|c|c|c|c|c|}
\hline Country/ & & & & & & & & \\
\hline Year & 1989 & 1991 & 1993 & 1995 & 1997 & 1999 & 2002 & 2004 \\
\hline Czech Rep. & $\begin{array}{c}u \cdot G \cdot p \\
(0.55)\end{array}$ & $\begin{array}{c}\mathrm{u} \cdot \mathrm{G} \cdot \mathrm{p} \\
(0.7)\end{array}$ & $\begin{array}{l}\mathrm{u} \cdot \mathrm{g} \cdot \mathrm{p} \\
(0.58)\end{array}$ & $\begin{array}{l}\mathrm{u} \cdot \mathrm{g} \cdot \mathrm{p} \\
(0.58)\end{array}$ & $\begin{array}{l}u \cdot g \cdot p \\
(0.53)\end{array}$ & $\begin{array}{l}u \cdot g \cdot p \\
(0.53)\end{array}$ & $\begin{array}{c}\mathrm{U} \cdot \mathrm{g} \cdot \mathrm{p} \\
(0.6)\end{array}$ & $\begin{array}{l}\mathrm{U} \cdot \mathrm{g} \cdot \mathrm{p} \\
(0.6)\end{array}$ \\
\hline Estonia & $\begin{array}{c}\mathrm{U} \cdot \mathrm{g} \cdot \mathrm{p} \\
(0.5) \\
\end{array}$ & $\begin{array}{c}\text { U.g.p } \\
(0.7) \\
\end{array}$ & $\begin{array}{c}\mathrm{U} \cdot \mathrm{g} \cdot \mathrm{p} \\
(0.7) \\
\end{array}$ & $\begin{array}{l}\text { U.g.p } \\
(0.7)\end{array}$ & $\begin{array}{r}\text { U.g.p } \\
(0.7) \\
\end{array}$ & $\begin{array}{c}\text { U.g.p } \\
(0.7) \\
\end{array}$ & $\begin{array}{r}\mathrm{U} \cdot \mathrm{g} \cdot \mathrm{p} \\
(0.7) \\
\end{array}$ & $\begin{array}{l}u \cdot g \cdot P \\
(0.65) \\
\end{array}$ \\
\hline Hungary & $\begin{array}{c}\text { U.G.p } \\
(0.7)\end{array}$ & $\begin{array}{c}\text { U.G.p } \\
(0.6)\end{array}$ & $\begin{array}{c}\text { U.G.p } \\
(0.6)\end{array}$ & $\begin{array}{l}U \cdot G \cdot p \\
(0.53)\end{array}$ & $\begin{array}{c}\mathrm{U} \cdot \mathrm{G} \cdot \mathrm{p} \\
(0.5)\end{array}$ & $\begin{array}{l}\text { U.g.p } \\
(0.52)\end{array}$ & $\begin{array}{l}u \cdot G \cdot P \\
(0.75)\end{array}$ & $\begin{array}{c}u \cdot G \cdot P \\
(0.75) \\
\end{array}$ \\
\hline Latvia & $\begin{array}{r}\mathrm{u} \cdot \mathrm{g} \cdot \mathrm{p} \\
(0.5)\end{array}$ & $\begin{array}{r}\mathrm{u} \cdot \mathrm{g} \cdot \mathrm{p} \\
(0.6)\end{array}$ & $\begin{array}{l}\mathrm{u} \cdot \mathrm{g} \cdot \mathrm{p} \\
(0.75)\end{array}$ & $\begin{array}{l}u \cdot g \cdot p \\
(0.75)\end{array}$ & $\begin{array}{l}\mathrm{u} \cdot \mathrm{g} \cdot \mathrm{p} \\
(0.72)\end{array}$ & $\begin{array}{l}u \cdot g \cdot p \\
(0.55)\end{array}$ & $\begin{array}{l}\mathrm{u} \cdot \mathrm{g} \cdot \mathrm{p} \\
(0.75)\end{array}$ & $\begin{array}{l}u \cdot g \cdot P \\
(0.75)\end{array}$ \\
\hline Lithuania & $\begin{array}{r}U \cdot g \cdot p \\
(0.6) \\
\end{array}$ & $\begin{array}{r}U \cdot g \cdot p \\
(0.6) \\
\end{array}$ & $\begin{array}{c}U \cdot g \cdot p \\
(0.6) \\
\end{array}$ & $\begin{array}{l}U \cdot g \cdot p \\
(0.6) \\
\end{array}$ & $\begin{array}{l}\text { U.g.p } \\
(0.75) \\
\end{array}$ & $\begin{array}{l}U \cdot g \cdot p \\
(0.75) \\
\end{array}$ & $\begin{array}{l}U \cdot g \cdot p \\
(0.75) \\
\end{array}$ & $\begin{array}{r}\mathrm{u} \cdot \mathrm{g} \cdot \mathrm{p} \\
(0.6) \\
\end{array}$ \\
\hline Poland & $\begin{array}{l}\mathrm{U} \cdot \mathrm{g} \cdot \mathrm{p} \\
(0.55)\end{array}$ & $\begin{array}{c}U \cdot G \cdot p \\
(0.6) \\
\end{array}$ & $\begin{array}{c}U \cdot G \cdot p \\
(0.6)\end{array}$ & $\begin{array}{c}\cdot G \cdot p \\
(0.6) \\
\end{array}$ & $\begin{array}{c}U \cdot G \cdot p \\
(0.6) \\
\end{array}$ & $\begin{array}{l}U \cdot g \cdot p \\
(0.58) \\
\end{array}$ & $\begin{array}{l}u \cdot g \cdot P \\
(0.75) \\
\end{array}$ & $\begin{array}{l}u \cdot g \cdot P \\
(0.75) \\
\end{array}$ \\
\hline Slovakia & $\begin{array}{c}u \cdot G \cdot p \\
(0.55) \\
\end{array}$ & $\begin{array}{c}\mathrm{u} \cdot G \cdot \mathrm{p} \\
(0.7) \\
\end{array}$ & $\begin{array}{l}\text { U.g.p } \\
(0.53) \\
\end{array}$ & $\begin{array}{l}\text { U.g.p } \\
(0.54) \\
\end{array}$ & $\begin{array}{l}\text { U.G.p } \\
(0.51)\end{array}$ & $\begin{array}{l}\text { U.g.p } \\
(0.51)\end{array}$ & $\begin{array}{c}\text { U.g.p } \\
(0.6)\end{array}$ & $\begin{array}{r}\mathrm{U} \cdot \mathrm{g} \cdot \mathrm{p} \\
(0.6) \\
\end{array}$ \\
\hline Slovenia & $\begin{array}{c}\text { U.G.p } \\
(0.6)\end{array}$ & $\begin{array}{c}\text { U.G.p } \\
(0.6)\end{array}$ & $\begin{array}{c}\text { U.G.p } \\
(0.6)\end{array}$ & $\begin{array}{c}U \cdot G \cdot p \\
(0.6)\end{array}$ & $\begin{array}{c}\text { U.G.p } \\
(0.6)\end{array}$ & $\begin{array}{c}\text { U.G.p } \\
(0.6)\end{array}$ & $\begin{array}{c}\text { U.G.p } \\
(0.6)\end{array}$ & $\begin{array}{c}U \cdot G \cdot p \\
(0.6)\end{array}$ \\
\hline
\end{tabular}

${ }^{1}$ The fuzzy-set memebership scores for each dimension of old-age pension policy are presented in Appendix 1 in tables 12-14 
The table should be read as follows. Combinations of letters illustrate the policy type, while the number in parentheses describe conformity to the ideal type (the higher the number, the closer the combination is to the ideal type). For example, Hungarian policy in 1989 belonged to the type U.G.p, which, in plain English, means that the policy was characterized by high universality (U) and generosity $(G)$ of pensions without involvement of private sector $(p)$. The high number reflects close conformity of the policy to this ideal type. As mentioned above, the fuzzy sets approach is sensitive to two modes of change - from one type to another (difference in kind), and change in the conformity to the ideal type (difference in degree). The latter can be illustrated by the change of score for the same combination while the previous takes place when policy shifts to a different type (as represented by another combination). From the methodological and theoretical point of view, a shift in one dimension (from low to high universality) results in a change of policy type.

As far as the Czech old pensions are concerned, several incremental but small changes took place, but generally a fundamental shift did not occur. In the initial period, the benefits were moderately accessible, quite generous and managed and controlled by the state $(u \cdot G \cdot p)$. The generosity of benefits declined in the following period, which resulted in the change to another combination $(u \cdot g \cdot p)$. The final years before joining the EU were characterized by more accessible benefits, but they were still not generous. The private provision of benefits was absent for the whole period and it was the state which took care of system management. It is worth noting that the shifts recorded up until 2002 result from ambiguous scores of generosity. Therefore it seems legitimate to label the pensions as moderately generous and universal and then from 2002 as moderately generous and accessible.

Lithuania is the second country which pursued a rather stable policy in the analysed period. Except for 2004, the system was characterised by high universality of minimum pensions, low generosity and a lack of involvement of a private sector in the mandatory system (U.g.p). In 2004 the access to a minimum pension became stricter and thus there was a shift to $u \cdot g \cdot p$.

Another country with a relatively stable old-age pension system over this period is Slovakia. From 1989 to 1991 the policy was the same as in the Czech Republic (moderately accessible, quite generous and managed and controlled by the state, $u \cdot G \cdot p)$. From 1993 on (except for 1997), Slovakia followed its own path with an easily accessible minimum benefit, not generous average pensions and a lack of private sector involvement (U.G.p). As was the case of the Czech Republic, the scores of generosity revolve around the cross-over point which affects the 
overall score of the policy. Taking this ambiguity into account, the pension policy of Slovakia can be characterised as being highly universal, moderately generous, and with no state involvement.

The last country in the group of 'modest' reformers is Slovenia. Interestingly, the pension policy of Slovenia remained stable in the whole period (U.G.p). The minimum pensions were quite accessible, the benefits were generous and no private sector was involved.

Estonia is an example of a more profound reform. At the beginning of the transformation, the pension system inherited from the Soviet Union was slightly changed by loosening access to a minimum benefit. The system of accessible and generous pensions (U.G.p) continues to exist. However, reform has been introduced. The analysis shows that the reform will result in significantly restricting access to minimum pensions, the generosity will drop even further and part of a benefit will be provided by private insurance companies (u.g.P). In analytical categories it means a serious departure from the previous system: partial withdrawal of the state, individualisation of responsibility and an increased role for the market solutions in the pension system.

Hungarian pension policy is another case where encompassing change can be seen as well. While the policy remained quite stable from 1989 to 1999, the introduction of a multi-tier system marked a clear break. In the first period, the policy features were those of high accessibility, moderate generosity and lack of mandatory private pension (U.G.p). The reform made the rules of access stricter and introduced a private, mandatory component of pensions. The level of generosity, according to simulations, is expected to rise. Therefore, the policy reflects the combination (u.G.P).

The third Baltic country, Latvia, took its own path. From the very beginning minimum pensions were barely accessible, the level of an average benefit was low and no private sector was involved in the mandatory system (u.g.p). This situation lasted until the reform, when a new, multi-tier system will be introduced. After the reform, pensions will still be barely accessible, even less generous and partially delivered by a private sector $(\mathrm{u} \cdot \mathrm{g} \cdot \mathrm{P})$. As is the case for other countries which opted out for the multi-tier system, this reform should be considered as a significant change.

Finally with regard to Poland, the features of the pension system are as follows. First, the pensions were easily accessible, moderately generous and without involvement of a private sector in 1989 (U.g.p). This situation lasted until 
1999, when a new, multi-tier system was introduced. The new system will have stricter rules concerning accessibility, the simulated replacement rates suggest low generosity, and the contributions are managed partially by private insurance companies (u.g.P). Such a change, therefore, is a departure from the system which was present in the 1990s.

To conclude this part of the analysis, some more general remarks need to be aired. First, the diversity of paths is striking. There was no one leading pattern of pension stability/change in the region. Generally, in the first phase of the transformation, the changes were not encompassing; rather, they were only modifications of single parameters. Later on, some countries decided the change the system within already existing frames by the further parametric changes. It usually meant changes in the PAYG systems, concerning the rules of accessibility and benefits' generosity. Other countries decided to replace their systems with a new structure. This took place at the end of the 1990s and later.

It should be noted that pension systems in the 1990s demonstrated a variety of types. Similar patterns may be observed in the cases of the Czech Republic and Latvia (u.g.p); Estonia, Lithuania and Slovakia (U.g.p); and Hungary, Poland and Slovenia (U.G.p). However, within the analysed timeframes, Latvia, Estonia, Hungary and Poland went for a partial privatisation of their mandatory programmes, accompanied by decreasing generosity of benefits (as indicated by the simulations) and stricter access to minimum pensions.

The inclusion of the simulated future replacement rates and focusing on the contributions' public/private split allows for a more long-term interpretation. In this way, it is possible to demonstrate the delayed effects of the reforms which otherwise would be omitted, as at the moment new pensions are being phased in. The approach used here shows a great shift in the features of the systems and suggests that in the cases of Latvia, Estonia, Hungary and Poland one should not talk anymore about the stability of their pension policies. These four countries are going in a similar direction of partial privatisation, individualisation and marketisation. These changes are accompanied by a partial withdrawal of the state from the management and provision of pensions and a move towards a more residual function of control.

This analysis suggests there were two phases to the reform of pension programmes. The first one involved parametric adjustments in all the countries, without changing fundamental features of pension systems. In the second phase some countries continued parametric change, while others opted for more 
profound, paradigmatic changes. Therefore, one should talk about the variety of emerging pension systems in the region, characterised by both continuity and change.

\section{ANALYSIS OF UNEMPLOYMENT COMPENSATION ${ }^{2}$}

The aim of this section is to provide an overview of unemployment compensation in Central and Eastern Europe. For this purpose, it presents institutional dimensions of this policy. Then it goes on to demonstrate how these dimensions are operationalised and their empirical values are transformed into fuzzy scores. The final part deals with a configurational analysis of the policy: it shows to which ideal policy types unemployment compensation belonged, and how this membership changed over time and across countries. This, in turn, allows for studying diversity, convergence/divergence and consolidation of unemployment compensation policy.

For the purpose of the comparison, four dimensions of labour market policy are taken into account. These aspects of unemployment compensation policy are: accessibility to, and generosity of, unemployment compensation, the duration that unemployment compensation is provided and the obligations concerning the claimants of such compensation. It should be noted that this selection does not leave aside important conceptual trade-offs. Such issues as functional equivalence and the existence of programmes which follow the basic unemployment compensation are the subject of necessary simplification. However, this chapter aims more at describing (changing) patterns, reflecting the policy choices of states, rather than detailed accounts of the content of each single policy. For this purpose, the selected dimensions seem most appropriate. As they will be transformed into sets and then analysed configurationally, they are briefly outlined below.

The accessibility is operationalised through the ratio of time necessary to qualify to the period of reference (Clasen 2001; Kvist 2003). The inclusion of groups other than workers will move the score towards a higher level of accessibility. Thus, as more groups are made eligible for the unemployment benefit and as more of the conditions of previous work are loosened, the more unemployment compensation becomes accessible. The cross-over point is established for the ratio

2 This part is based on Polakowski and Szelewa 2007 
0.5 (for example 6 months of work within 12 months or 2 years within 4 years of reference period). The higher qualitative point refers to the situation where there ratio equals to 0.25 . The lower qualitative point is established when the ratio equals 1. The scores are modified when other activities besides work are sufficient to qualify (when military service, child care and attending school are taken into account). Table 4 below shows approximate distribution of the categories.

As far as the generosity of compensation is concerned, the lower cut-off point (fully-out)is set at the level of 30 percent. It has been argued that the level of salaries in the region is generally low. For example in the case of Poland the relation between the survival minimum (based on the basket of minimum needs) and the average salary is approximately $25 \%$ and the relation between the survival minimum and socially desirable needs - the social minimum - is around $50 \%$ (Kurowski 2002). For others countries of the region, these ratios vary although the relation is rather robust (ILO 1995; Vaughan-Whitehead 1995; Cerami 2003). Therefore, this qualitative anchor takes a middle ground. When it comes to two other qualitative anchors, the cross-over (neither in, nor out) point is established at $45 \%$ of the average income, while the higher cut-off point (fully-in) is set at $60 \%$ of the average wage.

The calibration of the duration set is done as follows. The cross-over point is set for the period of 9 months. This level refers approximately to the duration of benefit in the OECD countries pursuing a modest policy in this respect. The lower cut-off point is for 3 months while the higher qualitative anchor is for a period of 18 months. Comparatively, the previous value is typical for residual policy types, while the latter for those more comprehensive policy types in the OECD (Riboud, Sánchez-Páramo et al. 2002). Table 1 presents in more detail the way the dimension of duration is translated into fuzzy set value ranges.

The final dimension of analysis covers the obligations of unemployed persons who receive a benefit. This section studies the severity of sanctions stated in formal rules governing suspension of a benefit in case of a job offer and/or training refusal. The severity of benefit suspension is based on the number of refusals leading to it. This is accompanied by the possibility of renewal of benefit eligibility. For example, the sanctions are more acute in the case of one refusal than one refusal with the renewal.

By combining these two dimensions (the number of refusals acceptable and the possibility of being re-granted the right to benefit) the three qualitative anchors are established at the following levels. The lower cut-off point (no obligation, fully-out) represents a situation, when receivers of the benefit are not 
punished at all for refusing a job offer. Consequently, the upper cut-off point (fully-in) is reached by countries where any job refusal leads to automatic suspension of the benefit without the right to re-apply for it. As decided after analysing different combinations of policies including those in the Western Europe (Esping-Andersen, Regini et al. 2000), the cross-over point characterizes a relatively moderate version of sanctions - with suspension of the benefit without the perspective for re-gaining it but only after two refusals of job offers. The scores between these three critical points will be evaluated according to the further sanctioning power of the arrangements. Thus, for instance, less strict (than the cross-over level) versions of policies - with more rejections of a job offers needed for withdrawing the right to benefit, or shorter breaks in receiving the benefit - are the basis for intermediary points. The same applies for the stricter arrangements. Where appropriate, the sanctioning power of the given solution is softened in the (very rare) cases of the benefit reduction, instead of their total suspension. Table 4 summarises this section and gives a starting point for the empirical analysis. 
TABLE 5: UNEMPLOYMENT COMPENSATION: SPECIFICATION OF INDICATORS AND TRANSLATION OF DATA TO FUZZY-SCORE RANGES AND VERBAL QUALIFIERS

\begin{tabular}{|c|c|c|c|c|c|c|c|}
\hline Empirical indicator & $\begin{array}{c}\text { Fully- } \\
\text { out } \\
\\
0\end{array}$ & $\begin{array}{c}\text { Mostl } \\
\text { y but } \\
\text { not } \\
\text { full } \\
\text { out } \\
0.01- \\
.24\end{array}$ & $\begin{array}{c}\text { More or } \\
\text { less fully } \\
\text { out } \\
\text { 0.25-0.49 }\end{array}$ & $\begin{array}{c}\text { Neither } \\
\text { in nor } \\
\text { out } \\
0.5\end{array}$ & $\begin{array}{c}\text { More or } \\
\text { less in }\end{array}$ & $\begin{array}{l}\text { Mostly } \\
\text { but not } \\
\text { fully in } \\
0.76-0.99\end{array}$ & $\begin{array}{c}\text { Fully-in } \\
1\end{array}$ \\
\hline $\begin{array}{c}\text { Accessibility to } \\
\text { unemployment } \\
\text { compensation based } \\
\text { on work } \\
\text { requirements (ratio } \\
\text { of work } \\
\text { requirement to } \\
\text { period of reference) } \\
\text { and scope of } \\
\text { eligibility }\end{array}$ & $\begin{array}{c}1 \\
\text { (Res) }\end{array}$ & $.99-.75$ & $.74-.51$ & $\begin{array}{c}.5 \\
(\text { Sel) }\end{array}$ & $.49-.38$ & $.37-.26$ & $\begin{array}{c}<.25 \\
\text { (Univ) }\end{array}$ \\
\hline $\begin{array}{c}\text { Generosity measured } \\
\text { as the replacement } \\
\text { rate }\end{array}$ & $<30$ & $\begin{array}{l}30.1- \\
37.4\end{array}$ & $37.5-44.9$ & $45 \%$ & $45.1-52.4$ & $52.4-59.9$ & $>60 \%$ \\
\hline $\begin{array}{l}\text { Duration of the } \\
\text { unemployment } \\
\text { compensation in } \\
\text { weeks }\end{array}$ & $<12$ & $13-25$ & $26-37$ & 38 & $39-59$ & $60-77$ & $>78$ \\
\hline $\begin{array}{l}\text { Obligations of the } \\
\text { unemployed } \\
\text { measured by the } \\
\text { number of negative } \\
\text { sanctions plus } \\
\text { possibility of re- } \\
\text { establishment of } \\
\text { benefits }\end{array}$ & $\begin{array}{c}\text { No } \\
\text { obligat } \\
\text { ions }\end{array}$ & & & $\begin{array}{c}2 \\
\text { refusals, } \\
\text { no } \\
\text { possibili } \\
\text { ty }\end{array}$ & & & $\begin{array}{c}\text { After 1st } \\
\text { refusal }\end{array}$ \\
\hline
\end{tabular}




\section{UNEMPLOYMENT COMPENSATION IN CEE - EMERGING}

\section{PATTERNS?}

Analysing changes with regard to particular dimensions of comparison is helpful for grasping the practical side of reforms. However, the main goal of this chapter is the configurational analysis. To this end the four dimensions of the unemployment compensation policy - a claimant's accessibility to compensation (A), the generosity of payments $(\mathrm{G})$, the duration of such payments (D) and the level of obligation burden for the claimant $(\mathrm{O})$ - are taken into account. This gives 16 possible combinations. The table below presents only the highest scores of the unemployment compensation policy dimensions for each country in selected years.

TABLE 6: FUZZY MEMBERSHIP SCORES OF UNEMPLOYMENT COMPENSATION POLICY IN IDEAL TYPES ${ }^{3}$

\begin{tabular}{|c|c|c|c|c|c|c|c|c|}
\hline $\begin{array}{l}\text { Country/ } \\
\text { Year }\end{array}$ & 1989 & 1991 & 1993 & 1995 & 1997 & 1999 & 2002 & 2004 \\
\hline $\begin{array}{l}\text { Czech } \\
\text { Rep. }\end{array}$ & NS & $\begin{array}{c}A \cdot G \cdot D \cdot O \\
0.67\end{array}$ & $\begin{array}{c}\mathrm{A} \cdot \mathrm{G} \cdot \mathrm{d} \cdot \mathrm{O} \\
0.7\end{array}$ & $\begin{array}{c}A \cdot G \cdot d \cdot O \\
0.7\end{array}$ & $\begin{array}{c}A \cdot G \cdot d \cdot O \\
0.7\end{array}$ & $\begin{array}{l}A \cdot g \cdot d \cdot O / \\
A \cdot G \cdot d \cdot O\end{array}$ & $\begin{array}{l}A \cdot g \cdot d \cdot O / \\
A \cdot G \cdot d \cdot O\end{array}$ & $\begin{array}{l}A \cdot g \cdot d \cdot O / \\
A \cdot G \cdot d \cdot O\end{array}$ \\
\hline Estonia & NS & $\begin{array}{c}A \cdot G \cdot d \\
0.67\end{array}$ & $\begin{array}{c}\text { A.G.d.o } \\
0.6\end{array}$ & $\begin{array}{c}\mathrm{A} \cdot \mathrm{g} \cdot \mathrm{d} \cdot \mathrm{O} \\
0.6\end{array}$ & $\begin{array}{c}\mathrm{A} \cdot \mathrm{g} \cdot \mathrm{d} \cdot \mathrm{O} \\
0.6\end{array}$ & $\begin{array}{c}\mathrm{A} \cdot \mathrm{g} \cdot \mathrm{d} \cdot \mathrm{O} \\
0.7\end{array}$ & $\begin{array}{c}A \cdot G \cdot d \cdot o / \\
A \cdot g \cdot d \cdot o\end{array}$ & $\begin{array}{c}A \cdot G \cdot d \cdot o / \\
A \cdot g \cdot d \cdot o\end{array}$ \\
\hline Hungary & $\begin{array}{c}A \cdot G \cdot D \cdot O \\
0.6\end{array}$ & $\begin{array}{c}A \cdot G \cdot D \cdot O \\
0.6\end{array}$ & $\begin{array}{c}A \cdot G \cdot D \cdot O \\
0.6\end{array}$ & $\begin{array}{c}A \cdot G \cdot D \cdot O \\
0.6\end{array}$ & $\begin{array}{c}\text { A.G.D.O } \\
\mathbf{0 . 6 7} \\
\end{array}$ & $\begin{array}{c}\text { A.G.D.O } \\
0.67\end{array}$ & $\begin{array}{c}A \cdot G \cdot D \cdot O / \\
A \cdot G \cdot d \cdot O\end{array}$ & $\begin{array}{l}\text { A.G.D.O, } \\
\text { A.G.d.O }\end{array}$ \\
\hline Latvia & NS & $\begin{array}{c}A \cdot G \cdot d \\
0.67 \\
\end{array}$ & $\begin{array}{l}a \cdot g \cdot d \\
0.73 \\
\end{array}$ & $\begin{array}{l}a \cdot g \cdot d \\
0.73 \\
\end{array}$ & $\begin{array}{l}a \cdot G \cdot d / \\
a \cdot G \cdot D \\
\end{array}$ & $\begin{array}{l}a \cdot G \cdot d / \\
a \cdot G \cdot D\end{array}$ & $\begin{array}{l}a \cdot G \cdot d \cdot o / \\
a \cdot G \cdot D \cdot o\end{array}$ & $\begin{array}{l}\text { a.G.d.o/ } \\
\text { a.G.D.o }\end{array}$ \\
\hline Lithuania & NS & $\begin{array}{c}A \cdot G \cdot d \\
0.67\end{array}$ & $\begin{array}{c}a \cdot G \cdot d \cdot o \\
0.66\end{array}$ & $\begin{array}{c}a \cdot G \cdot d \cdot o \\
0.66\end{array}$ & $\begin{array}{c}\mathrm{A} \cdot g \cdot d \cdot \mathrm{O} \\
0.6\end{array}$ & $\begin{array}{c}\mathrm{A} \cdot g \cdot d \cdot \mathrm{O} \\
0.6\end{array}$ & $\begin{array}{c}\mathrm{A} \cdot g \cdot d \cdot \mathrm{O} \\
0.6\end{array}$ & $\begin{array}{c}\mathrm{A} \cdot \mathrm{g} \cdot \mathrm{d} \cdot \mathrm{O} \\
0.6\end{array}$ \\
\hline Poland & NS & $\begin{array}{c}A \cdot G \cdot D \cdot O \\
0.65\end{array}$ & $\begin{array}{l}A \cdot g \cdot D \cdot o / \\
A \cdot g \cdot D \cdot O\end{array}$ & $\begin{array}{c}\mathrm{a} \cdot \mathrm{g} \cdot \mathrm{D} \cdot \mathrm{o} \\
0.67\end{array}$ & $\begin{array}{c}a \cdot g \cdot D \cdot o \\
0.67\end{array}$ & $\begin{array}{c}a \cdot g \cdot D \cdot o \\
0.67\end{array}$ & $\begin{array}{c}a \cdot g \cdot D \cdot o \\
0.67\end{array}$ & $\begin{array}{c}a \cdot g \cdot D \cdot o \\
0.67\end{array}$ \\
\hline Slovakia & NS & $\begin{array}{c}A \cdot G \cdot D \cdot O \\
0.67\end{array}$ & $\begin{array}{c}\text { A.G.d.O } \\
0.7\end{array}$ & $\begin{array}{c}\text { A.G.d.o } \\
0.67\end{array}$ & $\begin{array}{c}\mathrm{A} \cdot G \cdot d \cdot \mathrm{O} \\
0.54\end{array}$ & $\begin{array}{c}\mathrm{A} \cdot G \cdot \mathrm{d} \cdot \mathrm{O} \\
0.67\end{array}$ & $\begin{array}{l}\mathrm{a} \cdot \mathrm{g} \cdot \mathrm{d} \cdot \mathrm{o} / \\
\mathrm{a} \cdot \mathrm{G} \cdot \mathrm{d} \cdot \mathrm{O}\end{array}$ & $\begin{array}{c}\mathrm{a} \cdot \mathrm{G} \cdot \mathrm{d} \cdot \mathrm{o} / \\
0.67\end{array}$ \\
\hline Slovenia & $\begin{array}{c}a \cdot G \cdot D \cdot O \\
0.6\end{array}$ & $\begin{array}{c}a \cdot G \cdot D \cdot O \\
0.6\end{array}$ & $\begin{array}{c}a \cdot G \cdot d \cdot O \\
0.6\end{array}$ & $\begin{array}{c}\mathrm{a} \cdot \mathrm{G} \cdot \mathrm{d} \cdot \mathrm{O} \\
0.6\end{array}$ & $\begin{array}{c}a \cdot G \cdot d \cdot O \\
0.6\end{array}$ & $\begin{array}{c}a \cdot G \cdot d \cdot O \\
0.6\end{array}$ & $\begin{array}{c}\mathrm{a} \cdot \mathrm{G} \cdot \mathrm{d} \cdot \mathrm{O} \\
0.6\end{array}$ & $\begin{array}{c}a \cdot G \cdot d \cdot O \\
0.6\end{array}$ \\
\hline
\end{tabular}

${ }^{3}$ The fuzzy-set memebership scores for each dimension of unemployment compensation policy are presented in Appendix 1 in tables 15-18 
The specific developments of each country are as follows. The policy of the Czech Republic in the initial phase of the transformation was characterised by easily accessible benefits of high generosity. Unemployment compensation was paid for, relatively speaking, in the long term. However, it was coupled with strong obligations for the beneficiary (A.G.D.O). Later on, the period of payment was shortened and the generosity reduced, which resulted in the policy of high accessibility, moderate generosity, short duration of a benefit payment and extensive obligations for an unemployed person $(\mathrm{A} \cdot \mathrm{g} \cdot \mathrm{d} \cdot \mathrm{O})$.

Estonia, just after the introduction of unemployment compensation, made the programme easily accessible and generous, but it was paid only for a short time (A.G.d). Then, the level of benefits was decreased and was rather moderate until the end of the analysed period. At the same time, the obligations was kept minimal $(\mathrm{A} \cdot \mathrm{g} \cdot \mathrm{d} \cdot \mathrm{o})$.

Hungary introduced unemployment compensation even before the collapse of the socialist regime. The policy in this country was rather stable, characterised by high accessibility to the compensation which was generous and paid for a long time. At the same time, the obligations of unemployed were high (A.G.D.O).

The second Baltic country, Latvia, at the very beginning of this period pursued a rather universal and generous policy. Later, however, entry conditions became stricter and the level of benefit dropped. In the second half of the 1990s, the level of benefit was increased, but the duration of payment was moderate. The obligations were minimal $(a \cdot G \cdot d \cdot o)$.

The last country from the group of former Soviet republics, Lithuania, pursued a policy which was different from both Estonia and Latvia. At the very beginning, access to compensation was easy and generous, but in the following years the rules became stricter. In the second half of the 1990s, looser rules of access were restored and the role of obligation grew. From then the policy was characterised by high accessibility, low generosity and short duration of payment, but at the same time, the unemployed were made subject to more serious obligations (A.g.d.O).

At the beginning of this period Poland introduced a policy which was easily accessible, generous and imposing obligations on the unemployed. In the following years these were changed: the rules of access were made stricter and the benefits were not so generous anymore. With the reduced obligations imposed, the type of policy became a.g.D.o. 
Slovakia, after the dissolution of Czechoslovakia, pursued a policy which did not resemble the developments in the Czech Republic. Thus, in the initial period, the policy was similar (A.G.D.O), but afterwards the role of obligations was reduced $(\mathrm{a} \cdot \mathrm{G} \cdot \mathrm{d} \cdot \mathrm{o})$. In the final part of the analysed period, another change took place: the policy became less accessible, of a moderate generosity, of a short duration and with marginal obligations.

Finally, Slovenian unemployment policy was marked by only one slight change. Until the mid-1990s unemployment compensation was barely accessible and the obligations were high, but it was generous for those fortunate enough to receive it (a.G.D.O). Later, the duration of benefits payment was cut and became moderate and, therefore, the policy moved to the combination A.G.d.O.

As noticed above, the analysis of unemployment compensation policy in the post-communist countries is especially interesting due to the fact that in most of these countries this kind of policy did not exist during the state-socialist period.

One of the first observations here is that at the beginning of transformation the reformers created quite open and generous systems of income support, though rights to unemployment benefits were also connected with relatively high levels of obligation. In most of these countries, therefore, people who registered as unemployed were automatically entitled to the benefit. In Poland, for example, the first version of the regulations related to unemployment allowed people to receive benefits with no formal constraint concerning its duration. Yet after the first signs of unemployment, reformers in most of these countries started to introduce restrictions. In the Czech Republic and in Slovakia the duration of the period of payment was shortened by half. In Poland, on the other hand, the qualifying criteria were restricted by introducing income-testing, and the level of benefit was established as a flat-rate payment that was not generous. For the Czech Republic this resulted in shifting from conforming to the ideal-typical combination with all the dimensions scoring high (A.G.D.O) to the one with low score on duration (A.G.d.O). Poland underwent the most dramatic changes - from conforming to the same 'AGDO' ideal-type as the Czech Republic in 1991, Poland's unemployment compensation policy stabilised in the cluster scoring low in all but one dimension, scoring high only in its long period of payment $(a \cdot g \cdot D \cdot o)$.

Second, while some countries experienced more changes, others were relatively stable. Interestingly, the cases of stability and resistance to change are the two countries where the unemployment compensation programmes were already in place. Slovenia represents an example of a stable unemployment compensation policy - the characteristic combination for this country ensures generous level of 
benefit but which is not paid for a very long period of time and only after meeting quite demanding qualifying criteria $(a \cdot G \cdot d \cdot O)$. Similarly, in Hungary a generous and accessible version of unemployment insurance prevailed for most of the time (A.G.D.O). On the contrary, policy developments in other countries, especially those which were liberated later, were undergoing more reforms. An interesting case for comparison here is that of Czech Republic and Slovakia which took two different paths after starting from similar positions. The Czech Republic sustained a form of compensation characterised by rather strict obligations throughout this period. Only at the end of the 1990s did the level of generosity start to be undermined. In Slovakia, the reformers did not decide to enhance the sanctions. However, more recent changes include more demanding qualifying criteria. The latter fact resulted in this Slovakia's shift from having a policy bundle with accessible and generous benefits paid for a comparatively short period and with no serious obligations attached $(A \cdot G \cdot d \cdot o)$ to one with restricted accessibility $(a \cdot G \cdot d \cdot o)$.

Third, contrary to expectations, not all the policies were equal in introducing restrictions. In Estonia, where the level of benefits has traditionally been the lowest in the region, an element of more generous benefits can be seen being introduced in the last two points of time under analysis. As this change is not radical, it results in distinguishing two combinations with ambiguous meanings on generosity dimension. Lithuania, representing again a more stable case, increased accessibility to benefits, but this was accompanied by more clearly defined obligations for the unemployed. Additionally, it also shifted to a combination with a low generosity score and consequently changed its ideal-type class membership from the combination $a \cdot G \cdot d \cdot o$ to $A \cdot g \cdot d \cdot O$.

Fourth, while these reforms could be observed as time went by, they rarely proceeded in different, erratic directions in any given country. In other words, no 'trial and error' phase of frequent policy shifts 'back and forward' took place, as could be observed, for example, with regard to childcare policy (Szelewa and Polakowski 2006). Instead, the policies took rather divergent paths and the changes were introduced in a more incremental manner. Therefore, shifting from one combination to another was hardly ever revolutionary - usually it involved reforming only one element out of four constitutive dimensions and involved delicate changes within this dimension. One of the consequences of such developments in policies are ambiguous results for the last two to three years, where two - instead of one - combinations are dominant. This problem is also discussed in the next section.

Finally, the reforming tools were very divergent. In the Czech Republic and in Estonia unemployment compensation policies were reformed through 
changes in generosity, in Lithuania and in Slovakia transformation of the system was channelled through reforming the rules of accessibility, and in Latvia and in Hungary a changing duration was the element of reforms. Interestingly, in each of these three pairs of cases developments went in opposite directions.

In short, one cannot talk about consolidation of the policies in this region. After initial similarities, these countries took divergent paths of development, reforming their policies with different tools and in different directions. Still, the changes have a more evolutionary than revolutionary character.

\section{ANALYSIS OF CHILDCARE POLICY ${ }^{4}$}

This section deals with development of policy aimed at families with small children. The structure of this part is similar to the previous one. First, it introduces the dimensions of comparison. Next, it operationalizes them and presents the translation of empirical indicators into fuzzy scores. The section concludes with a discussion concerning observed patterns.

This chapter deals with two components of the policy: public childcare arrangements and parental leave policies. More precisely it looks at four dimensions: extensiveness (E) and quality (Q) of the publicly provided childcare, and generosity (G) and the universality (U) of parental leave. The operationalization of each dimension is presented below.

The extensiveness of the childcare is operationalised through the net enrolment rate in a pre-primary education. The choice of the net rate allows for a proper assessment of children's attendance, as it relates the number of children of official school age who are enrolled in educational institutions to the population of the corresponding official school age. In this way, one may infer about the capacity of state-run institutions to accommodate specific social needs concerning institutional childcare (Rostgaard 2000a).

The upper cut-off point (fully in the set) is established at the level of 80 percent (Hantrais 2004). This level is found as satisfying for a Scandinavian, universalist type of childcare policy, characterized by almost full coverage of children of pre-primary education age (3-6) (Kvist 1999). Further, as Linda Hantrais

4 This part is based on Szelewa and Polakowski 2006 
argues, such a high level is justified when a significant percentage of women are active in the labour market. As this was the case also in Central and Eastern Europe during the (early post-) socialist period (Deacon and Szalai 1990; Ferge 1995; Haney 2002), this qualitative anchor seems reasonable. As far as the crossover point is concerned, it has been set at around 50 percent of the net enrolment rate. Comparative studies indicate that levels similar to this reflect modest coverage (Daly and Rake 2004). Finally, the lower qualitative breakpoint for extensiveness is set at the level of $20 \%$ of children enrolled in the public preprimary education. This level refers to very marginal engagement of public authorities in the childcare policies (Gornick and Meyers 2003).

The lower cut-off point for the generosity of childcare provision is established at the level of 16 weeks duration and 0.3 of the average net wage. As compared to the Western countries this threshold seems to be a bit high for set membership: still, this seems to be more relevant for the character of pro-natalist and overall more generous and maternalist policies. Establishing the level of financial support was inspired by the variety of solutions in the Western world such as those which are wage-related (as in the Nordic countries), or flat-rate (in the continental Europe) benefits plus the observations concerning the levels of average net replacement rates in the post-communist countries. The cross-over point corresponds to the moderate state's support discussed by Gornick and Meyers, i.e. one year with the lower support ( 0.3 of the average net wage) accompanied by the system of generous maternity leave provision (26 weeks and full wage replacement). This also seems reasonable for the eight of the new EU member-states, as high standards are the characteristics of the period shortly before and shortly after the child's birth.

Then the extended period of the leave usually reaches 3 years, but there exists a variety of financial support, usually in the form of the flat-rate payments. In the Western world parental leave was not introduced at the same time and families in many countries still do not have the right to such a long period of child care leave. Simultaneously, the communist countries were the pioneers in introducing paid parental leave as early as in the late 1960s and 1970s (Szikra 2005). For these reasons the upper cut-off point for the analysis, as expressing the most generous possible combination of the parental leave provision, is set at a long period of maternity leave (51 weeks paid in full) plus three-year parental leave with the flat-rate payment at the level of 0.3 of the average net wage. All these provisions are also available to a different degree. This is tackled by the dimension of universality. 
When considering universality or availability of childcare support, the following approach is proposed. One should take into account the coverage and the conditions that are to be met by the person eligible for the benefit and use this as the basis of the universality dimension. In other words, it is analysed which social groups are eligible for the parenthood-related benefits and which situations are taken into account as the basis for the entitlement. The upper qualitative point is set for the situation where every citizen is entitled to some basic benefit and the access to it is not conditional. ${ }^{5}$

The lower cut-off point is characterised by benefits which are provided by the state, but which are means-(income) tested. Finally, the cross-over point should reflect the situation where there is a clear link between the level of a benefit and a contribution. Thus, as with old-age pension provision there is in effect a triad of welfare provision: it can be universal (fully-in), contributory (cross-over) and finally selective (fully-out). These three broad clusters were divided into smaller parts in order to allow for more fine-grained analysis, encompassing the combinations of principles and taking into account the different scopes of application within each cluster.

The specification of empirical indicators and translation of data to fuzzy score ranges and verbal qualifiers for all four dimensions are presented in Table 7.

\footnotetext{
${ }^{5}$ One might say that if the access to the benefits does not require special conditions, then the programme is fully universal. However, this situation is purely theoretical because even in Scandinavian countries, perceived as the most universal, one has to meet the criterion of residence or citizenship (Esping-Andersen 1990). Nevertheless, the condition of citizenship or residence still should be perceived as emanating from universal provision. In the literature there is a discussion about a dual nature of universality: it is said that both the liberal and social democratic regimes provide universal benefits (Clegg and Clasen 2003; Clasen and van Oorshot 2002). However, this applies only to the general rule: in both regimes the benefits are financed through taxes, but the eligibility criteria are significantly different. While in the case of liberal regime there is the condition of passing the means(income) test, in the social democratic regime the only requirement is of citizenship or residence.
} 
TABLE 7: SPECIFICATION OF EMPIRICAL INDICATORS AND TRANSLATION OF DATA TO FUZZY SCORE RANGES AND VERBAL QUALIFIERS: CHILDCARE POLICY

\begin{tabular}{|c|c|c|c|c|c|c|c|}
\hline Empirical indicator & $\begin{array}{l}\text { Fully } \\
\text { out } \\
0\end{array}$ & $\begin{array}{l}\text { Mostly } \\
\text { but not } \\
\text { full out } \\
.01-.24\end{array}$ & $\begin{array}{l}\text { More or } \\
\text { less } \\
\text { fully } \\
\text { out } \\
.25-.49\end{array}$ & $\begin{array}{l}\text { Neither } \\
\text { in nor } \\
\text { out } \\
0.5\end{array}$ & $\begin{array}{l}\text { More or } \\
\text { less in } \\
.51-75\end{array}$ & $\begin{array}{l}\text { Mostly } \\
\text { but not } \\
\text { fully in } \\
.76-.99\end{array}$ & $\begin{array}{l}\text { Fully in } \\
1\end{array}$ \\
\hline $\begin{array}{l}\text { Extensiveness of } \\
\text { family policy } \\
\text { measured as the } \\
\text { enrolment rate of } \\
\text { children in the } \\
\text { kindergartens }\end{array}$ & $<20 \%$ & $20.1-35$ & $35.1-49.9$ & $50 \%$ & $50.1-65$ & $65.1-79.9$ & $>80 \%$ \\
\hline $\begin{array}{l}\text { Quality of family } \\
\text { policy measured as } \\
\text { child } \leftrightarrow \text { staff ratio in } \\
\text { the kindergartens }\end{array}$ & $<12$ & $\begin{array}{l}10.51- \\
11.99\end{array}$ & $9.1-10.5$ & 9 & 7.51-8.99 & $6.1-7.5$ & $>6$ \\
\hline $\begin{array}{l}\text { Generosity of } \\
\text { maternity-related } \\
\text { benefits measured } \\
\text { by the index based } \\
\text { on weighted } \\
\text { replacement rate } \\
\text { and duration of } \\
\text { benefits* }\end{array}$ & $<4.2$ & $4.3-21.5$ & $21.6-41.5$ & 41.6 & $41.7-69.5$ & $69.6-98.7$ & $>98.8$ \\
\hline $\begin{array}{l}\text { Universality of } \\
\text { parenthood-related } \\
\text { benefits( maternity } \\
\text { and parental } \\
\text { benefits) measured } \\
\text { as the combination } \\
\text { of principles } \\
\text { guiding the access } \\
\text { (residual, selective } \\
\text { and universal) }\end{array}$ & $\begin{array}{l}\text { Means } \\
\text {-test, } \\
\text { Means } \\
\text {-test** }\end{array}$ & $\begin{array}{l}\text { Insuran } \\
\text { ce, } \\
\text { Means- } \\
\text { test }\end{array}$ & $\begin{array}{l}\text { Insuran } \\
\text { ce, } \\
\text { Insuran } \\
\text { ce }\end{array}$ & $\begin{array}{l}\text { Insuran } \\
\text { ce, } \\
\text { Insuran } \\
\text { ce (no } \\
\text { conditio } \\
\text { ns) }\end{array}$ & $\begin{array}{l}\text { Univers } \\
\text { al, } \\
\text { Means- } \\
\text { test }\end{array}$ & $\begin{array}{l}\text { Univers } \\
\text { al, } \\
\text { Insuran } \\
\text { ce }\end{array}$ & $\begin{array}{l}\text { Univers } \\
\text { al, } \\
\text { Univers } \\
\text { al }\end{array}$ \\
\hline
\end{tabular}

${ }^{*}$ calculated according to the formula given in the text: the number of weeks paid maternity leave times the replacement rate plus the same but in relation to the extended leave (child-care leave, etc.)

** first: maternity leave, second: parental leave (extended, childcare, etc.) 


\section{PATTERNS OF CHILDCARE POLICY IN CEE}

This section aims at assessing the membership of childcare policies in fuzzy set combinations as defined by the aspects analysed above. It should be recalled that it is not enough to take into account one dimension of policy to understand its location in a given cluster because, as showed, they might be very similar in all but one respect. This, in turn, can be decisive for constituting another kind of childcare policy. Therefore, the policies should be analysed as the configurations of aspects.

In this thesis four dimensions of childcare policy are taken into account. This gives 16 possible combinations. A membership of each combination of sets is assessed and the highest value is chosen. The table below (Table 7) presents only the highest scores of the childcare policy dimensions for each country in selected years. As far as the highest scores are concerned, the policies conformed to thirteen ideal types.

TABLE 8: FUZZY MEMBERSHIP SCORES OF CHILDCARE POLICY IN IDEAL TYPES ${ }^{6}$

\begin{tabular}{|c|c|c|c|c|c|c|c|c|}
\hline Year & 1989 & 1991 & 1993 & 1995 & 1997 & 1999 & 2002 & 2004 \\
\hline Czech & $\begin{array}{c}E \cdot q \cdot G \cdot u \\
(.6)\end{array}$ & $\begin{array}{c}E \cdot q \cdot G \cdot u \\
(.6)\end{array}$ & $\begin{array}{c}\mathrm{E} \cdot \mathrm{q} \cdot G \cdot \mathrm{u} \\
(.57)\end{array}$ & $\begin{array}{c}E \cdot q \cdot G \cdot u \\
(.6)\end{array}$ & $\begin{array}{c}\text { E.q.G.U } \\
(.79)\end{array}$ & $\begin{array}{c}E \cdot q \cdot G \cdot U \\
(.7)\end{array}$ & $\begin{array}{c}\text { E.q.G.U } \\
(.78)\end{array}$ & $\begin{array}{c}\mathrm{E} \cdot \mathrm{q} \cdot G \cdot U \\
(.87)\end{array}$ \\
\hline Estonia & $\begin{array}{c}E \cdot Q \cdot g \cdot u \\
(.56)\end{array}$ & $\begin{array}{c}E \cdot Q \cdot G \cdot U \\
(.52)\end{array}$ & $\begin{array}{c}\mathrm{e} \cdot \mathrm{Q} \cdot \mathrm{g} \cdot \mathrm{U} \\
(.53)\end{array}$ & $\begin{array}{c}\mathrm{E} \cdot \mathrm{Q} \cdot \mathrm{g} \cdot \mathrm{U} \\
(.62)\end{array}$ & $\begin{array}{c}\mathrm{E} \cdot \mathrm{Q} \cdot \mathrm{g} \cdot \mathrm{U} \\
(.65)\end{array}$ & $\begin{array}{c}E \cdot Q \cdot g \cdot U \\
(.58)\end{array}$ & $\begin{array}{c}E \cdot Q \cdot g \cdot U \\
(.57)\end{array}$ & $\begin{array}{c}E \cdot Q \cdot g \cdot U \\
(.59)\end{array}$ \\
\hline Hungary & $\begin{array}{c}\mathrm{E} \cdot \mathrm{q} \cdot G \cdot U \\
(.85)\end{array}$ & $\begin{array}{c}E \cdot q \cdot G \cdot U \\
(.88)\end{array}$ & $\begin{array}{c}\text { E.q.G.U } \\
(.87)\end{array}$ & $\begin{array}{c}E \cdot q \cdot G \cdot U \\
(.87)\end{array}$ & $\begin{array}{c}E \cdot q \cdot G \cdot u \\
(.7)\end{array}$ & $\begin{array}{c}E \cdot q \cdot G \cdot U \\
\text { (1) }\end{array}$ & $\begin{array}{c}\mathrm{E} \cdot \mathrm{q} \cdot G \cdot \mathrm{U} \\
(.51)\end{array}$ & $\begin{array}{c}E \cdot q \cdot G \cdot U \\
(.51)\end{array}$ \\
\hline Latvia & $\begin{array}{c}\mathrm{e} \cdot \mathrm{Q} \cdot \mathrm{g} \cdot \mathrm{u} \\
(.66)\end{array}$ & $\begin{array}{c}\mathrm{e} \cdot \mathrm{Q} \cdot \mathrm{g} \cdot \mathrm{u} \\
(.56)\end{array}$ & $\begin{array}{c}\mathrm{e} \cdot \mathrm{Q} \cdot \mathrm{G} \cdot \mathrm{U} \\
(.82)\end{array}$ & $\begin{array}{c}\mathrm{e} \cdot \mathrm{Q} \cdot \mathrm{g} \cdot \mathrm{U} \\
(.59)\end{array}$ & $\begin{array}{c}\mathrm{e} \cdot \mathrm{Q} \cdot \mathrm{g} \cdot \mathrm{U} \\
(.63)\end{array}$ & $\begin{array}{c}E \cdot Q \cdot g \cdot U \\
(.56)\end{array}$ & $\begin{array}{c}E \cdot Q \cdot g \cdot U \\
(.61)\end{array}$ & $\begin{array}{c}E \cdot q \cdot g \cdot U \\
(.7)\end{array}$ \\
\hline Lithuania & $\begin{array}{c}\mathrm{e} \cdot \mathrm{Q} \cdot \mathrm{g} \cdot \mathrm{u} \\
(.71)\end{array}$ & $\begin{array}{c}\mathrm{e} \cdot \mathrm{Q} \cdot \mathrm{G} \cdot \mathrm{u} \\
(.54)\end{array}$ & $\begin{array}{c}e \cdot Q \cdot G \cdot u \\
(.6)\end{array}$ & $\begin{array}{c}\mathrm{e} \cdot \mathrm{Q} \cdot \mathrm{G} \cdot \mathrm{U} \\
(.67)\end{array}$ & $\begin{array}{c}\mathrm{e} \cdot \mathrm{Q} \cdot \mathrm{G} \cdot \mathrm{U} \\
(.72)\end{array}$ & $\begin{array}{c}\mathrm{e} \cdot \mathrm{Q} \cdot \mathrm{G} \cdot \mathrm{U} \\
(.7)\end{array}$ & $\begin{array}{c}\mathrm{e} \cdot \mathrm{Q} \cdot \mathrm{G} \cdot \mathrm{U} \\
(.68)\end{array}$ & $\begin{array}{c}E \cdot Q \cdot G \cdot U \\
(.58)\end{array}$ \\
\hline Poland & $\begin{array}{c}\mathrm{e} \cdot \mathrm{q} \cdot \mathrm{g} \cdot \mathrm{u} \\
(.74)\end{array}$ & $\begin{array}{c}\mathrm{e} \cdot \mathrm{q} \cdot \mathrm{g} \cdot \mathrm{u} \\
(.51)\end{array}$ & $\begin{array}{c}\mathrm{e} \cdot \mathrm{q} \cdot \mathrm{g} \cdot \mathrm{u} \\
(.52)\end{array}$ & $\begin{array}{c}\mathrm{e} \cdot \mathrm{q} \cdot \mathrm{g} \cdot \mathrm{u} \\
(.57)\end{array}$ & $\begin{array}{c}\mathrm{e} \cdot \mathrm{q} \cdot \mathrm{g} \cdot \mathrm{u} \\
(.54)\end{array}$ & $\begin{array}{c}\mathrm{e} \cdot \mathrm{q} \cdot \mathrm{g} \cdot \mathrm{u} \\
(.51)\end{array}$ & $\begin{array}{c}\mathrm{e} \cdot \mathrm{q} \cdot \mathrm{g} \cdot \mathrm{u} \\
(.51)\end{array}$ & $\begin{array}{c}\mathrm{e} \cdot \mathrm{q} \cdot \mathrm{G} \cdot \mathrm{u} \\
(.58)\end{array}$ \\
\hline Slovakia & $\begin{array}{c}E \cdot q \cdot G \cdot u \\
(.6)\end{array}$ & $\begin{array}{c}E \cdot q \cdot G \cdot u \\
(.6) \\
\end{array}$ & $\begin{array}{c}E \cdot Q \cdot G \cdot u \\
\text { (.6) }\end{array}$ & $\begin{array}{c}\mathrm{e} \cdot \mathrm{q} \cdot G \cdot \mathrm{u} \\
(.55)\end{array}$ & $\begin{array}{c}E \cdot q \cdot G \cdot U \\
(.63)\end{array}$ & $\begin{array}{c}E \cdot q \cdot G \cdot U \\
(.52) \\
\end{array}$ & $\begin{array}{c}\text { E.q.G.U } \\
(.52) \\
\end{array}$ & $\begin{array}{c}E \cdot q \cdot G \cdot U \\
(.6) \\
\end{array}$ \\
\hline Slovenia & $\begin{array}{c}\mathrm{e} \cdot \mathrm{Q} \cdot \mathrm{g} \cdot \mathrm{u} \\
(.55)\end{array}$ & $\begin{array}{c}\mathrm{e} \cdot \mathrm{q} \cdot \mathrm{g} \cdot \mathrm{u} \\
(.54)\end{array}$ & $\begin{array}{c}E \cdot q \cdot G \cdot U \\
(.52)\end{array}$ & $\begin{array}{c}E \cdot q \cdot G \cdot U \\
(.63)\end{array}$ & $\begin{array}{c}E \cdot Q \cdot G \cdot U \\
(.52)\end{array}$ & $\begin{array}{c}E \cdot q \cdot G \cdot U \\
(.74)\end{array}$ & $\begin{array}{c}E \cdot q \cdot G \cdot U \\
(.61)\end{array}$ & $\begin{array}{c}E \cdot q \cdot G \cdot U \\
(.54)\end{array}$ \\
\hline
\end{tabular}

${ }^{6}$ The fuzzy-set memebership scores for each dimension of childcare policy are presented in Appendix 1 in tables 19-22 
The table reveals the development of childcare policy in CEE. Main trends for each country will be described.

As far as the Czech Republic is concerned, the policy was rather stable and only one change occurred. In the first half of the 1990s Czech childcare policy was characterized by high extensiveness and low quality with benefits being generous but not universal $(\mathrm{E} \cdot \mathrm{q} \cdot \mathrm{G} \cdot \mathrm{u})$. In the remaining period the policy resembled the type of high extensiveness, low quality of kindergartens and universal and generous benefits.

Estonian childcare policy fluctuated a lot in the first half of the 1990s and then stabilized. The policy type in the later period involved high extensiveness and quality of the institutional childcare accompanied by universal, but not generous benefits $(\mathrm{E} \cdot \mathrm{Q} \cdot \mathrm{g} \cdot \mathrm{U})$.

Hungary pursued one type of policy for the whole period. Public care was extensive but of low quality, while the benefits were generous and universal $(E \cdot q \cdot G \cdot U)$.

The policy of a second Baltic country, Latvia, was changing quite often. First, it represented the e.Q.g.u dynamic. After the reform, the benefits became more generous and universal; however, soon their level dropped. Finally, childcare became more extensive which resulted in the policy shift to a E.Q.g.U dynamic.

Lithuanian childcare policy did not follow the pattern of other Baltic countries. While fluctuating in the first part of the analysed period, it stabilized afterwards. It resembled the policy type of low extensiveness and high quality of public childcare and easily accessible benefits of high generosity $(e \cdot Q \cdot G \cdot U)$.

For almost whole period Poland had one model of policy. It scored low on all the dimensions $(e \cdot q \cdot g \cdot u)$.

Slovakia, after some changes in the beginning of transformation, pursued exactly the same type of policy $(E \cdot q \cdot G \cdot U)$ as the Czech Republic.

Finally Slovenia, after the collapse of Yugoslavia, faced some changes in its childcare policy. The 1990s saw fluctuations in the mixes of policies to end up with a model of high extensiveness and low quality of public kindergartens coupled with generous and universal benefits.

Generally, two conclusions arise. First, one may distinguish four clusters of policies in CEE. The first combination, which almost only ever happened to be the 
case in Poland, has a low score in all the four dimensions $(e \cdot q \cdot g \cdot u)$. Here we find low extensiveness and quality of publicly-provided childcare combined with neither generous nor universal leave. Another, quite considerable group of countries (notably the Czech Republic and Hungary in some periods, but also Slovenia and Slovakia) seemed to pursue the policies characterized by high extensiveness and low quality of childcare with parental leave of considerable generosity and universality. The third group of cases comprise the countries with low generosity of parental leave provision with the rest of the dimensions scoring high (E.Q.g.U). Finally, when all the dimensions approach the full set membership (E.Q.G.U), the family is reaching support both in terms of leave and childcare infrastructure.

To draw towards a more general conclusion, the policies are marked by many qualitative and quantitative shifts. This is especially visible in the case of the newly emerging countries (especially in the case of the Baltic republics). The initial period of transition can be characterised by many policy shifts resulting from various adjustments (mainly concerning labour markets changes) and 'trial and error' strategies (Offe and Preuss 1998). For the later stage of transition, one may talk about the consolidation of policies which did not change their characteristics so significantly. Therefore, it makes sense to talk about two policy stages: one of a trial and error and later, one of consolidation toward model types in the second part of transition.

\section{PENSIONS, CHILDCARE POLICY AND UNEMPLOYMENT COMPENSATION IN A COMPARATIVE PERSPECTIVE}

So far, the analysis has focused on single policy developments. This section aims at a brief comparison of transformation of pensions, family and unemployment compensation policy together. First it focuses on the situation around 2004 and then analyses developments over time.

The social policies of the Czech Republic around 2004 were of a mixed character. The pensions were moderately generous and universal, with no involvement of the private sector. Unemployment compensation was easily accessible, moderately generous, with short duration of benefit payment and a high level of obligations. Childcare policy consisted of extensive childcare of poor quality combined with generous and universal benefits. It seems that in the case of 
the Czech Republic the role of the market was rather residual and the state supported its citizens, albeit in a modest way.

Focusing on Estonia's social policy at the end of analysed period, it can be seen that pensions underwent a reform which in consequence is expected to lead to compensation that is barely accessible, not generous and partially provided for by the private sector. Before this reform unemployment compensation was easy to access, guaranteeing a modest level of benefits paid for only a short time, but without obligations. The childcare policy was extensive, universal, of high quality but not so generous. Taking these aspects of social policy in Estonia together, one can see clearly some signs of the individualisation of responsibility and privatisation in the pensions field, whereas other fields remain in the domain of public provision, characterised by guaranteeing sufficient standards.

Hungary also introduced significant reform to its pensions, but childcare and unemployment compensation policy show signs of continuity. The pension system involves some elements of funding, is supposed to be less accessible but at the same time, generous. Unemployment compensation is accessible and generous, both in terms of the level of benefits and the length of payment, but imposes some obligations on benefit recipients. The childcare policy is characterized by extensive care of poor quality combined with generous and universal benefits. Again, in the case of pensions there are signs of individualisation and privatisation, but otherwise the standards of the system are rather high.

The Latvian pension system on the other hand underwent radical reforms, heading in the direction of restricted access, a low level of benefits and involvement of private sector. Unemployment compensation is restricted to most needy, is generous, of modest duration and has no obligations. Childcare is quite extensive, but of low quality and is combined with benefits which are not so generous, although easy to obtain. As with the majority of reformed systems in the region, there is a tendency towards individualisation and restricted access, which is also the case of unemployment benefits. On the other hand, the state provides extensive services to individuals with small children.

Lithuania is the country which, within the timeframes of this analysis, did not introduce a radical pension reform. The pensions remained the sole responsibility of public authorities, however their level was low and accessibility was restricted. Unemployment compensation was universal, but not generous. Finally, childcare policy was characterised by its extensiveness and the quality of institutional childcare, while the benefits were accessible and universal. The case of Lithuania is therefore ambiguous: childcare policy had high standards, but the 
levels of pensions and unemployment benefits were low. To sum up, the main provider of social policy was the state, but its involvement varied.

The policies of the biggest country of the region, Poland, followed quite the same pattern. The pension system was significantly reformed, which in consequence is expected to lead to a low level of benefits and restricted access to them. The system contains some private, funded elements. With regard to unemployment compensation, it was also rather rudimental, aimed at the very needy, but without too many obligations however. At the end of the period childcare is seen to be restricted and of poor quality although the level of benefits is rather generous, albeit focused on a very narrow group. The social policy of Poland can be seen as an example of one which is characterised by quite a marginal involvement of the state, and with the marketisation and individualisation of responsibility. Examples of such policies are those of the new pension system and also unemployment compensation. Childcare remains almost the exclusive responsibility of a family, as the market alternative is not available.

In the analysed period Slovakia did not reform its pension system which remained highly universal, not generous, and with no involvement of a private sector. Unemployment compensation remained restricted to the most needy, with a high level of benefits and no obligations. Public childcare was extensive and of low quality, while the benefits we generous and universal. The policy of this country is based on the involvement of the state, with some restrictions concerning unemployment benefits.

Finally, Slovenia also has the mixed social policy. At the end of the period old-age pensions are highly universal and generous, without a private component. Unemployment compensation is aimed at those in difficult financial situations: it is generous but paid for only a short time and combined with many obligations. Childcare policy is extensive, but of low quality and combined with generous and universal payments.

\section{TOWARDS CASE SELECTION}

The comparison conducted above shows a wide spectrum of policy mixes. It seems hard to find single underlying logic for each policy and combinations of them. Rather, there are different logics which underlie each specific policy mix. As mentioned in the previous chapter, such an observation is of crucial importance when explaining this striking variation of social policy in Central and Eastern Europe, and points to the existence of historically developed transformation pathways. In this section I will attempt to synthesise the transformation pathways 
observed in the period 1989-2004 and lay down the fundamentals for further analysis which will focus on the factors which affected one particular social policy programme: old-age pensions. In other words, this section outlines the conditions guiding the choice of two countries whose old-age pension systems will be compared in chapters 4 and 5: Hungary and Poland. The two countries share a number of political, economic and social characteristics but underwent pension reforms which, in some instances, make their pension systems different.

At the beginning of transition, all three policies areas were characterized by some variation across countries (to a different extent, of course). This observation leads to two conclusions. First, that the policies inherited from the socialist past were already varying. If one assumes some degree of continuity and stability, it means that family policies already had different shapes in the pretransition era. This argument goes against the assumption of communist social policy as a single regime. Second, the variation in unemployment compensation points to the existence of multiple designs already in the early phase of this policy development. Finally, the countries which conducted radical reforms to their pension systems did not necessarily implement the same type reform in other fields of social policy. This diversity leads to the idea that the transformation of social policy has been a multiple process from the very beginning and there did not exist one template of the policy design and implementation.

The emphasis on multiple transformations of social policy ought to be even stronger when one considers the development over the whole period. The changes (and consolidation) took place at a different pace and in a different order in each social policy area. The lack of one general pattern resembles the point Bruszt and Stark made about multiple pathways of transition. According to them, the plurality of transition has a double meaning. First, it relates to the variety of transition strategies in the countries of the region. Moreover, the transition should be seen as an inconsistent phenomenon when looked at country to county, involving processes in the economy, polity and society, each with a different timing and temporality (Stark and Bruszt 1998).

The issue of diversity of policies and their multiple transformations lead to more general remarks. The analysis presented above pointed out that in many instances the transformation of social policy was gradual and involved a change in one dimension of a programme rather than abandoning the old one and introducing completely new solution. A change in one dimension does not necessarily involve its reform either - the change may be the result of non-action as well (Hacker 2005). Such different forms of transformation call for more thorough analysis of social policy in the region, which should be sensitive to the modes of 
institutional change like drift, layering and conversion (Streeck and Thelen 2005). This analysis may signal these sorts of change, especially when one considers the situation of 'hybridisation' of social policy programmes.

Finally, this analysis may serve as a tool of case selection for further exploration. A general conclusion stemming from the debate above is that while the countries had a shared general context (economic, social, political), they have followed different routes expressed by institutional characteristics of social policy programmes. Such an observation calls for a more thorough exploration, which will be the subject of the following chapters. The choice of two countries, Hungary and Poland, will be discussed shortly below. As the economic, social and political situation in the two countries was presented in Chapter 1, the discussion focuses on characteristics related to social policy, such as the expected level of benefits, qualification criteria, redistribution characteristics, the role of the private sector in providing benefits and its structure. The remainder of the dissertation will focus on old-age pensions in Hungary and Poland. The focus on this particular social policy program stems from their importance in national social policy systems (the biggest single category in social spending) and political salience of pension reforms. Additionally, the relative importance of state and markets in pension provision, and the role of state in regulation of such relationship can reveal a lot about political economy of a given country.

As previously mentioned, since 1989 Hungary has pursued a policy of quite encompassing and generous benefits combined with extensive social services. During the period under the study, pensions remained comparatively generous, with moderate access. Ultimately, the Hungarian pension system was reformed by adding a funded tier operated by commercial private companies which collect mandatory contributions, invest them and finally transform them into annuities. Such a solution often means a significant drop in the redistribution between high and low-earners, and an increase in the level of uncertainty regarding levels of future benefits (as in the pure insurance solution, benefits are a function of contributions paid and return or loss from their investment) (Whiteside 2003; Bridgen and Mayer 2007). However, the expected negative impact of the reform on the level and accessibility of benefits is smaller than in other countries of the region (Holzmann and Guven 2009). As such, Hungary remains the only country in the region with benefits remaining virtually untouched. Hungarian childcare policy was one of the most generous and encompassing in the region. The benefits were generous and easily accessible throughout the whole period. On the services side, the extensiveness of childcare provision was combined with growing quality. Unemployment compensation in the 1990s was characterized by easy access to 
benefits, which were generous and paid for a long period. This generous provision was coupled, however, with a high level of obligations for the unemployed person. This situation remained rather stable, with a slow move towards cutting the length of payment.

Polish pensions were rather accessible and generous in the first period of the transitions. At the end of the decade, the reform pension provisions by way of the introduction of a multi-tier system was announced, which strongly restricts the access to pensions and limits their generosity. Comparatively, the reform is one of most profound in the region (Holzmann and Guven 2009). When it comes to childcare policy, the involvement of the state is rather residual. The extensiveness and quality of services is low and is coupled with benefits that are hard to access and not generous. Finally, unemployment compensation was not accessible and if paid at all, with small replacement rate. The payment of benefits was conditional upon fulfilling a number of obligations.

From this short presentation one may conclude that the two countries have pursued quite different policy models. Hungary presents the case of a more generous, encompassing policy with extensive involvement of the state. While the old-age pension reform marks a change in the latter respect, due to the extensive state regulation, it does not imply such severe cuts of benefits as in other countries. Poland, on the other hand, moves towards residual solutions fulfilling minimal needs. Cuts in social services, and the lack of adjustment of generosity of some benefits stand in stark contrast with Hungary. It is worth noticing that the two countries faced roughly similar pressures and stood in a similar structural position at the very beginning of transition. Generally, they had a similar level of social spending, demographic structure and political system (see Table 2 in Chapter 1). However, the old-age pension reform output differs greatly between the two countries.

This raises the question about what can explain the nature of such policy diversity. The following chapters, dealing with the evolution of social policy in Hungary and Poland, attempt to outline the answer to this question. 


\section{CHAPTER 4: SOCIAL POLICY IN POLAND}

\section{INTRODUCTION}

The aim of this chapter is to present the developments in old-age pension programmes in Poland since their establishment. As argued in Chapters 1 and 2, such a long-term perspective is necessary not only in order to grasp the emergence of institutional logic underlying social security, but also the mechanisms and actors who reproduced and reshaped this logic. Special attention will be paid to the following features: accessibility to social policy programmes (eligibility criteria); generosity (the replacement rate), financing (the size of the contributions \& how these are split between employers and employees), the budgetary autonomy of social policy programmes (i.e. whether the social policy programmes have separate funds from the state budget) and the administrative cohesion of social policy management (whether different social groups have separate programmes or if there is just one and whether social policy programmes are managed by the same institution).

The chapter follows a chronological order. Each section starts with the basic social, political and economic context or period which is relevant to understanding the process of social policy-making. Next, the organizational and financial aspects of the social policy programmes for that context are dealt with. The core of each section consists of a description of social policy developments and an analysis of how they link with the contextual factors and the regulations that were in place at that time. The aim of structuring the narrative in such a way is to emphasize how various policy initiatives overlap and mix, and further, to account for the distinctive country-specific logic of social policy. This country-specific logic of social policy is dealt with in detail in the part of the chapter which focuses on social policy developments during the transition and how the scope and extent of such reform was heavily dependent on historical legacies structured in the past. The analysis deals with old-age pensions, but makes links to other social policy fields that can be seen as important country innovations or specificities.

The chapter presents the history of social policy structuration in a possibly exhaustive way. It begins with the pre-World War I period, when the Polish state did not exist. Nonetheless, some foundations for social policy which continued to have an influence in the coming decades were laid down at that time. The preWorld War I period was characterised by the development of three parallel systems of social policy in the three partitioned territories of Poland [sic]. It is essential to highlight that these systems were developed separately, independently 
of one another. Such differences were the source of several inconsistencies in the following period. When it came to the inter-war social policy, much effort was aimed at reducing the differences which had come about as a result of this differentiation. In spite of the dire situation which the state was in (political and fiscal instability, capital-labour conflict and several other problems), some very modern \& progressive social policies (at least on the regional scale) were introduced. Accordingly the 1920s and 30s saw - among other things - an extension of retirement rights to the working class as well as the introduction of unemployment compensation, sickness and maternity insurance.

The state-socialist era was a period of simultaneous continuities, inconsistencies and policy reversals. Under the conditions of central planning and constrained political liberties, the pre-war system was reconfigured both in terms of organisation and financing. This reconfiguration took place in the context of a shift from financial autonomy to state-dependence. At the same time, the expansion in several policy fields took place which, by the end of the 1970s, led to almost full coverage of social risks. By the end of the state-socialist era the system was mature, but there were also some attempts towards gaining autonomy from the state budget. Simultaneously, throughout the whole period, several ad-hoc adjustments took place which made the system rather complex and organizationally incoherent. From a comparative point of view, social security policy became structurally divided, with two main components operating: one for salaried workers and another for farmers, accompanied by a number of smaller schemes covering such groups as the military and state militia. The generosity of the system was rather low especially with regard to private farmers, but given the small size of the contributions they were obliged to pay to the system, pensions became an important source of income for the elderly from this group. In the 1980s, the system became more accessible so that the ruling party could re-gain social legitimacy after major political upheaval accompanying the emergence of a major opposition actor, the Solidarność trade union movement. The measures taken (mainly related to lowering the retirement age) were first directed at specific groups (e.g. branch privileges for those working in heavy industry) but soon the privileges were extended to several other groups. Such extensive privileges were a time bomb with the potential to detonate a huge increase in pension spending. Moreover, in the late 1980s the system was not able to deliver due to the worsening economic crisis. As a consequence, the real value of benefits dropped markedly and this became a significant issue among policy analysts. These developments provided the policy context for the transition to a market economy. 
After 1989, several measures were undertaken to solve the problems which had not only come about since the beginning of the decade (i.e. the declining levels of benefits), but which were also rooted in that period. The starkest example of such a delayed effect was extensive early retirement in the early 1990s, when hundreds of thousands of Poles reached the stipulated retirement age. This, combined with unusual inflationary pressure on the level of benefits, caused an immense increase in the spending side of the pension system. On the contribution side, a collapse of several state-owned companies, contribution evasion (especially extensive at the beginning of the period), and the introduction of benefit taxation without offsetting this from the state budget put the social security finances in a difficult situation. It was this situation (being caused by short-term factors in several aspects) that fuelled the debate on the long-term sustainability of the system.

As pension reform rose to the top of the political agenda (which was in part brought about by international organizations), the policy makers faced a situation where no big opposition towards the reform was displayed by the majority of salaried workers, but where protest from private farmers and interest groups such as miners was a constant. It was the condition of the salaried workers scheme which led to the reform, and the defence of the loss-generating agricultural system which contributed to the depth of reform. In addition, those who had been privileged in the previous system successfully mobilized themselves in the defence of their rights. Hence, the reform carried a lot of continuities, in spite of the initial revolutionary nature of the proposal. The policy-makers acted in an inherited context that had been under development for decades and which had not only constrained their actions at times but had at other times allowed them to defend against retrenchment. The main social insurance institution, ZUS (Zakład Ubezpieczeń Społecznych), supported the reform because it was run by government nominees (a tradition which went back to interwar era). Additionally, organizational continuities existed with the main split into two systems: one for salaried workers and another for farmers. The role of ZUS, the public institution which had and still remained in charge of the management of the funds, saw its responsibly increase. As such, the reform of 1998 should be seen as another stage of institutional evolution, part of the long term process in which distant, historical events have a complex, but profound impact on current social policy making. The sections below demonstrate this mechanism in detail. 


\section{SOCIAL POLICY IN PARTITIONED POLAND (BEFORE 1918)}

Until 1918, Poland had been partitioned and its territory was divided among, and incorporated into, three countries: Prussia, Russia and the AustroHungarian Empire. During this period, Poland was not recognized by other states and did not have an independent legal system. As such, before 1918 the territory of Poland was divided between three different legal, economic and political systems, each with its own particular regulations concerning social policy. Moreover, the status of different lands belonging to each country was not equal (especially in the case of the territories under Russian control). The reason for this was that for political and strategic reasons some of them were economically and legally closer to the 'core' of the governing country, while others were virtually abandoned and controlled rather by military than civil governors. To complicate the picture even more, during World War I, the Polish territories [sic] were in the middle of the battlefield and moving from one set of hands to another, which meant that the regulations concerning social policy were amended according to the legal framework of the current occupant. As a result, after 1918 Poland entered a period of independence having had three completely different frameworks for social policy provision, management and scope as well as having endured significantly war losses that amounted to some $10 \%$ of the national wealth (Landau 1992). All of these factors influenced policy making in the following period. The sections below aim at providing the background for understanding pre-1918 social policy systems. Generally, one may argue that among the three occupying countries, Prussia had developed its social policy most, both in terms of risk coverage and compensation; Austro-Hungary was in second place, while social policy was very rudimental in the territory controlled by Russia.

When it came to the social policy solutions, Prussia was a leader in terms of the timing of the introduction of social security programmes as well as risk coverage and scope. Before 1919 provision was already in place for sickness insurance (1883), work injury insurance (1884) and disability and old-age benefits (1889) although this was different for manual workers and white-collar workers. The schemes were mandatory and covered the whole working population, including family members. The schemes were run by associations of employers (regional or branch-based) (Rimlinger 1971; Bleses and Seeleib-Kaiser 2004).

In Austria, as mentioned, social policy was less developed than in Germany, partially due to the underdevelopment of this country (Austria at that time not belonging to the 'core' of the most economically developed countries) (Pronobis 1996). Insurance provision covered risks such as work injury (1887), sickness (1888) and disability. However, mandatory, encompassing disability and 
old-age insurance did not exist before 1918. The only groups favoured in this respect consisted of those from state and military apparatus (1866) and coal miners, run by mutual miners' associations (1889). Interestingly, it was in Lwów in 1889 that the first Polish-speaking and Polish-staffed Social Insurance Institution for Work Injury was established (ZUS 2005).

Finally, in Russia, social policy provision was marginal (Orlowski 1912). The provision of old-age benefits was restricted to state employees (MPiOS 1923). The regulations concerning industrial accidents (1903) put the obligation of assistance on employers; however, it was mandatory only for big industrial enterprises and, even here, the rights of workers were rarely executed (Rimlinger 1971). Other types of benefits were provided by a very limited number of voluntary mutual associations (Landau 1991).

This brief presentation demonstrates the extent of the complexity of social policy provision which Poland had to face after gaining independence. Different systems of financing and the sources thereof (employers, employees, state), the levels of benefits, where the responsibility for the provision of social policy lay (companies of certain sectors, mutual association, state) not to mention the extreme differentiation of scope combined with different degrees of political and economic development were all part of the mix. Interestingly enough, out of the three policies which are of interest in this study, only old-age provision in its different forms was present. Maternity benefits and unemployment compensation were yet to be introduced following the aftermath of the World War I in all three partitioning countries. In addition, the fact that the biggest part of partitioned Poland belonged to Russia, which until the Bolshevik revolution had very scarce social policy, meant that a majority of Poles had in most instances no rights to social policy programmes at all. This was the legacy of the pre-war era that newlyestablished Polish governments had to work with in order to build the sustainable system. The challenge was even bigger because such a system had to cover all the territories in a consistent manner. This grand task will be described in the section below.

\section{INTERWAR PERIOD}

SOCIAL POLICY JUST AFTER GAINING INDEPENDENCE: EFFORTS TOWARDS SUSTAINING INHERITED SYSTEMS

In the second half of 1918, the territory which was to become independent Poland was in the hands of the so-called Central Powers (Prussia and the Austro- 
Hungarian Empire). The key members of the Triple Entente (England, France and Russia) gained advantage in the war and were, at least in principle, together in their support of an independence movement in Central Europe. The removal of the Central Powers would almost lead directly to independence. The international situation coincided with a domestic independence movement. It was November 1918 that members of the independence movement started military action and also assigned Józef Piłsudski, a central figure of this movement, to create basic state institutions (Albert 1989). This task proved hard, as only a part of Polish territory was independent. Faced with such significant territorial difficulties and spatial inequalities, Piłsudski appointed a socialist government because he saw it as the only chance to mitigate the situation. One of the first actions of the post-war government led by Jędrzej Moraczewski was to regulate the labour market, introduce social policy measures and empower trade unions (Pronobis 1996).

Apart from building domestic state institutions, in the first years following independence in 1918 Poland was struggling to consolidate its territory in which strong centrifugal tendencies existed. This meant that the country was involved in a number of international conflicts, but also supported the independence movement especially in the western territories, where Germans still resided).

The first elections conducted in 1919 saw quite a balanced division of votes: around a third of which were won by left (30.3\%), 30.8\% by the centre and $34.2 \%$ by right wing parties. Importantly, the communist party did not participate in the elections (Roszkowski 2003).

The borders of country were established: Poland's neighbours were Germany, Czechoslovakia, Romania, and the Soviet Republic. According to the 1921 census, the population of Poland was 27.2 million and ethnically heterogeneous. Poles were the majority, making up $69 \%$ of the population, $14 \%$ of the population were Ukrainians, $8 \%$ Jews, $4 \%$ Belarusians and $4 \%$ were Germans. When it came to the social structure, it clearly reflected the relative underdevelopment of the economy. As many as $63.9 \%$ of citizens were active in agriculture. Together mining and industry were the second biggest sector at $17.2 \%$, while other sectors were significantly less important $(6.2 \%$ in trade and insurance, $3.4 \%$ working in transport and 3.7\% in the public sector) (Roszkowski 2003). In terms of social strata, $55 \%$ of the population were farmers (many of them without any land), $27 \%$ were industrial workers, $11 \%$ were petit bourgeois, $5.5 \%$ belonged to the intelligentsia, $1 \%$ were bourgeois while big landowners constituted less than $0.5 \%$. 
The economy was (slowly) recovering, and some sort of (fragile) political consensus was emerging, especially after the first years of 1920s when political polarisation arose following several bomb attacks by communist groups and which culminated in the assassination of President Narutowicz (who had sympathised with left). The political and economic tensions reached a peak at the end of 1923 when several strikes - including a general strike - broke out. The inflation crisis was immediate and the social tensions immense.

Poland entered into independence in November 1918 with the heritage of complex and inconsistent social policy programmes. The problem of consolidation was not, obviously, restricted to social policy: at both a central and a local level it included the public administration of taxation, currency, customs and the military. Thus the early years of the independence were devoted to the process of building a modern coherent state. In January 1918 the Ministry of Social Care and Labour Protection (Ministerstwo Opieki Spolecznej i Ochrony Pracy) was established, responsible among other things for health care and social welfare legislation. Soon afterwards in October of the same year, two separate ministries were created due to the overwhelming extent of the responsibility involved: Public Health and Labour Protection (Bornstein-Łychowska 1928).

While political reconstruction was a difficult aim to achieve, economic integration proved to be even more difficult. On the one hand there were signs of social unrest, especially in the eastern areas formerly occupied by Russians (Landau 1992) and on the other there was a separatist movement, visible especially in the western part of Poland. In the east the war damage was so extensive that in 1919 only 13\% of those employed in 1913 were working (Landau 1991). Food shortages were common. This dramatic situation was amplified by migration movements, both international (such as war prisoners of various countries, repatriates) and domestic (inflow to big cities, mainly Warsaw) requiring immediate government action. When it came to the stance of political parties' with regard to the development of social policy, all but those related to the workers' movement had their reservations. The proposals to include some regulation regarding the social problems in the Constitution of 1921 were rejected (Simon 1928). In fact, the demands of workers to adjust their salaries were seen by the some government representatives as the source rather than a result of the economic problems. To sum up, the immediate post-World War I years were characterised by high levels of social need combined with scarce resources and no support from the political sphere.

In this context, it was rather impossible to replace already existing social policy systems with brand new ones which would cover the whole territory. In 
fact, the only social risk which was covered extensively was sickness (following the decree of January 11 1919). The institutional solutions were borrowed from the German system and led to the introduction of regional sickness funds which were either governed by employees (two thirds) or employers (one third). The decree was replaced in the following year (May 19th 1920) and covered the whole area of the country, excluding Gorny Slask (Upper Silesia). The introduction of his new solution both organized and also significantly reduced the number of sickness funds in the former Prussian and Austrian zones. In principle, every salaried worker (including agricultural workers) was covered by the insurance. The scheme was financed by contributions $(6.5 \%$ of a person's salary, with an employer/employee split).

The regulations concerning sickness insurance offered some provision to mothers with very small children. This included a birth allowance paid at the level of $100 \%$ of previous salary for a maximum 8 weeks, of which 6 weeks were directly after the labour. For breastfeeding mothers the regulation provided this support in cash or in nature, based on the equivalent of milk prices.

With regard to unemployment compensation, the government's actions were of a temporary and charitable character. Some compensation was delivered in the form of food aid, but in 1920 even this residual form was suspended.

One of the first regulations in the field of old-age pensions concerned the military and state apparatus. As early as 1921 provision for military staff was introduced. Two years later, state employees received a similar provision. This system had some peculiar characteristics. There was no age limit as a qualifying condition for receiving a benefit. The only criteria were a record of work in an enlisted branch of state apparatus or state-owned company and proof of the length of employment. When it came to the first condition, all employees of state agencies were entitled to the benefit. The length of employment in the state sector was set at 10 years (later 15 years). Interestingly, any service accrued in other states (Russia, Prussia and Austro-Hungary) was included in the record and other activities multiplied the years taken into account. The level of benefits was exceptionally high, reaching $100 \%$ of the replacement rate in the case of those with 35 years in the state service. The system was financed from the state budget and/or funds run by public enterprises. Subsequently, other groups of employees (notably the railways employees) were covered by branch-based pension systems (Jackowiak 1991).

The efforts of the authorities just after the end of the World War I were focused on establishing the operations of a fully-functioning, independent state, with social policy being a second order issue. Therefore, in the immediate post-war 
years the policy makers were concerned more with preventing the out-and-out destitution of groups within society rather than with building a consistent and modern social policy system. The only serious development took place within the health insurance, which became a universal right. Apart from this, no successful attempts at unifying the three social policy systems were attempted as there were too many differences existed in terms of the organization, scope and generosity of benefits and services. The only exception from this general rule concerned those groups especially important to the state in the aftermath of war and in the reconstruction of its vital functions: the military and state bureaucracy.

\section{SOCIAL POLICIES IN THE ERA OF RELATIVE STABILITY (1924-1929)}

\section{INTRODUCTION}

The years immediately following the gain of national independence in 1918 were focused mainly on the creation of basic state institutions and securing their existence. These efforts to improve the domestic situation of the country were severely threatened by external factors, namely the war with Bolshevik Russia. After this very unstable period, the second half of the 1920s was seen as the relatively stable period.

The early 1920s was a period in which social tensions and economic problems (mounting inflation and unemployment) coincided with a very unstable political situation. This instability was caused by communists supported by Russia and also by domestic actors from the left concerned with the scale of social problems. In light of such instability the political scene mobilised itself and a proposal for a 'cabinet of experts' was put forward. This idea was quickly realised and a new cabinet reflecting a wide political spectrum with no links to previous governments was approved. The Prime minister, Władysław Grabski, was simultaneously the Treasure Minister which meant he had a strong personal involvement in matters relating to the budget. The government started with a package of cuts (involving closing down the Ministry of Health and Ministry of Public Works) and by increasing several taxes and charges. These measures, combined with stricter monetary policy, brought about the stability to Polish currency in a short period of time. In terms of state organization, the economic improvement led to the establishment of a central bank and the introduction of a new Polish currency: the zloty. The reserves of the banks were boosted by donations from society which was increasingly supportive of Grabski's plan (Roszkowski 2003). 
However, the increases in the standard of living came at the cost of employers, who demanded lowering salaries and extending working hours, and in general lessening the burden the state was putting on their shoulders. As very few of these demands were accepted by the government, the holders of capital became disappointed and distrustful. As the following paragraphs will show, the hostile attitude of private capital was to continue until World War II and would hamper several attempts to introduce progressive social measures.

The Grabski cabinet was successful in stabilizing the economic situation. However, its position soon started to deteriorate due to both domestic and international reasons (notably the continuing conflict with Germany over the import of coal which was an essential raw material for Polish manufacturing). After a relatively stable period for the Grabski government, the political scene became polarised. Piłsudski successfully weakened his enemies within a fragmented parliament, and gained the popular support of a big part of society who saw him as the only person able to overcome the difficulties (Pronobis 1996).

The situation grew more dire once again as, in spite of increased exports, the value of real wages dropped. Piłsudski continued his criticism of the existing political climate, and more and more called for political renewal. This was realised with the coup d'état Piłsudski inspired in May 1926. The coup led to a concentration of power in his hands which, according to his followers, was aimed at Sanacja (Restoration). After of a series of manoeuvres, Piłsudski was elected president. However, he did not accept this position and instead became Minister of Military Affairs.

In principle, the rule under the Sanacja government coincided with economic prosperity: economic growth, a rise in the quality of living (especially in the rural areas) and industrial investment lasted for three years. Poland in this period was one of the fastest developing countries. For example, comparing 1929 to1926 the growth in industrial production was $41 \%$ in Poland, while in Czechoslovakia it was $36 \%$, in Germany $25 \%$, while in the US the figure was $10 \%$. In the same period industrial employment went up by $37 \%$, salaries in real terms grew by $30 \%$ and unemployment declined to one third of the initial level (Roszkowski 2003).

In these conditions, the state aimed at more profound reforms, which would establish a consistent system of social policy instead of the ad-hoc approach to solving particular problems. Several important systemic regulations were introduced and concerned such things as Labour Inspection, safety in the 
workplace, labour courts and regulation of job contracts. This following section describes these policy innovations and traces the main trends of the period.

\section{SOCIAL POLICY CONTEXT}

On July 18 1924, the unified system of unemployment compensation for workers was introduced. The system covered Polish citizens above 18 years of age, being employed by industrial companies, including those operating for non-profit with more than five workers. The rules governing this system were as follows. First, the benefit was offered to insured unemployed individuals who fulfilled the contribution criteria of being able to work and for whom 'proper' job offers (in terms of physical capacity, education and work experience) were not available. Additionally, to meet the benefit criteria an individual's unemployment status should not have been caused by the employee himself, or (relating to seasonal workers) a specific reason associated with cyclical changes in the labour market. The definitions of the ability to work and seasonal workers, however, were subject to possible change by the Minister of Labour and Social Assistance.

The scheme was financed by a contribution of $2 \%$ of a salary, out of which $25 \%$ was paid by the employee combined with the State budget subsidy equal to $50 \%$ of all contributions. These resources were managed by a separate legal entity, the Unemployment Fund which fell under the auspices of the Ministry of Labour and Social Assistance and not the Social Insurance Institution (Rozniewicz 1931).

The eligibility criterion in terms of work requirement was 20 weeks of work during 1 year prior to the period of unemployment. The benefit was paid for up to 13 weeks, and only under circumstances of severe unemployment could this period be extended up to 17 weeks by the Minister. The level of benefit depended on the average daily salary within the last 13 weeks prior to unemployment and the number of dependants (generally, children and parents and grandparents) in the family. Accordingly, the replacement rate was 30\% of previous daily salary for a single person (35\% for up to 2 dependants, $40 \%$ from 3 to 5 and $50 \%$ for more than 5 dependants). The level of the reference wage was capped and could not exceed 5 zloty per day. This last element combined with the scheme's narrow scope (as it excluded small family firms, farmers etc) and the short period of payment were seen as significant inadequacies (Jackowiak 1991).

The concerns regarding the inadequacy of the benefits triggered a series of adjustments aimed at reducing the problem. In the following years seasonal workers were included in the system on equal footing with regular workers. Also, those falling into the category of the partially unemployed received the full rights to the benefit. The amount of the reference wage level of the benefit was raised in 
steps, to achieve 10 zloty in 1929 . This change was accompanied by increasing the level of benefits by $10 \%$ while simultaneously decreasing the contribution by $10 \%$ and lowering the qualifying age to 16 .

Until 1929, the workers' unemployment compensation system was in fairly good financial condition. The amount of contributions exceeded the spending on benefits and the scheme never faced a financial deficit.

Just after the establishment of unemployment compensation for workers, the state introduced a scheme for white-collar workers. On October 28 1925, the workers' scheme had been expanded on the latter group. However, even under the joint system there were some differences concerning the two occupational groups. The main difference was a contribution split $(60 \% / 40 \%$ for employers/employees) and the rule of self-financing. Nevertheless, this solution was treated as temporary and preparations concerning a separate, encompassing scheme for white collars were under way.

A separate scheme for the white collars had been introduced by Presidential decree on November 24 1927. The scheme covered all white collars with only minor exceptions. Compared to that for manual workers, the newly introduced unemployment compensation scheme was characterized by more favourable treatment, although at the price of a longer contributory period. Accordingly, an individual earned the right to the benefit after 6 months of contributing, but the length of payment varied from 6 to 9 months. The basic length of payment was 6 months, increasing with contributions and number of children. Nine months of payment was available to those older than 60 and contributing for more than 30 months (Pilichowska 1931).

The construction of benefit level was similar to the one described above. The basic amount equalled to $30 \%$ for a single person and $40 \%$ in case of dependants. The definition of the latter was quite liberal and included persons under 24 years of age in university education (a regulation absent in the manual workers' scheme). Even more importantly, the level of benefit was not capped.

The scheme was financed exclusively from contributions and, as such, was included in the social security organization (unlike to workers' programme) and was managed by ZUS. The scheme had financial autonomy and contributions were channelled to the Unemployment Fund for the Non-Manual workers (Pasternak 1926). Until the Great Crisis, the financial situation of the scheme was relatively good and stable. 


\section{OLD-AGE PENSIONS}

With regard to old-age pensions, since 1919 there had been several efforts to introduce a unified system. However, due to the weakness of Polish state (both economically and politically) they all failed. The only progress in this matter was included in the Polish Constitution of March 171921 in the passage stating that 'every Citizen has the right to protection regarding work, and the case of its loss, sickness, accident and disability, the right to social protection, stipulated in a separate legal act' (Piatkowski 1991). Developments in the provision of old-age pensions followed a different path, focusing on specific social groups. Accordingly, in 1921 the scheme for war veterans was introduced parallel to one for the army members. Subsequently in 1923, the scheme for the military was expanded to state civil servants.

The beginning to the mid-1920s saw similar developments. Even though it was a period of relative economic prosperity, the government withdrew its own bill from Sejm (the lower parliament chamber) when the Ministry of Labour and Social Assistance attempted to introduce a universal, highly subsidized and workers-governed system in 1927. Instead, the government introduced a scheme for white collars which reflected the principles of the withdrawn universal scheme bill. The features of the white collar scheme were as follows. The decree introduced a favourable and (in terms its geographical reach, excluding only Upper Silesia) unitary social insurance plan which was based on German and Austrian solutions. The definition of white collar was based on a list of work activities, rather than occupations. Some groups of individuals were excluded from the scheme: those already insured in state-run schemes, individuals unable to work or older than 60 and without previous insurance history, and those for whom activities defining the white collar status were not their main source of income - priests, members of religious groups, foreigners as well as students of secondary schools and certain universities. At the same time, while some occupations (e.g. lawyers.) had the right to quit the scheme, Ministers of Labour and Social Assistance could extend the coverage to other occupational groups. The latter was the case for civil aviation pilots and navigators (in 1934) (Piatkowski 1991)

The system was territorially decentralized, with four insurance offices. The benefits were financed through the contributions at a level of $8 \%$ of salary, operated and invested by the insurance funds. Interestingly, the unified white collars insurance significantly improved the standards of provision, mostly in the former Russian district. The contribution period was counted in months, irrespective of factual days worked. Generally, the minimum contribution period was 60 months and non-contributory periods were excluded. In order to qualify for 
the old-age pension, a person had to meet the minimum contribution period and the retirement age ( 65 for men and 60 for women). Alternatively, the retirement age could be lowered by five years by having 40 years of contribution for men and 35 for women. An additional condition was the lack of disruption between the contribution period and the beginning of the benefit claim of no longer than 18 months (excluding parliamentary and military service, sickness and documented unemployment).

The level of benefits was determined by two factors: a base amount and a dynamic component. The base amount equalled $40 \%$ of an average individual's salary for the whole period of contribution collection. The dynamic component grew proportionally with the number of years contributions were paid, and could reach $60 \%$ of an average salary in the case of 40 years of contributions. In this extreme situation, the level of benefit was $100 \%$ of a person's average salary.

Comparatively, the construction of the scheme was rather generous in international perspective. Also, the white collars scheme was generous compared to the workers' schemes (given they existed at all, as was the case of the former Prussian lands).

The end of the first half of the 1920s was marked by significant economic problems which had continued from the early years of independence. This economic situation influenced social conditions: unemployment was widespread and contributed to the destitution of urban population, while the low prices of agricultural products combined with low production levels and continuing large numbers in the landless rural population were sources of poverty in the countryside. On the top this there was the political conflict over the modernization path Poland should follow and the position it should take on the international scene. The efforts to 'depoliticise' government and steer the country towards recovery proved short-lived. However, their unintended effect was the mounting protest of private capital against progressive social measures. This increasing political conflict culminated in the coup d'état, led by one of the most prominent political actors, Piłsudski. The coup concentrated power in his hands, but equally important, coincided with exceptional economic growth.

Under such conditions, social policy making in the second half of the 1920s was quite peculiar. 


\section{CONSOLIDATION OF SOCIAL POLICY IN THE CONTEXT OF ECONOMIC}

HARDSHIP (1929-35)

\section{INTRODUCTION}

In the second half of the 1920s the economic and political situation was rather stable. Poland had its own currency, the economy was growing (although keeping in mind it did not reach its pre-World War I level at all before WWII) while after the shock created by the assassination of President Nar utowicz in 1922, the political situation became less tense.

This period of comparatively successful development ended with signs of international economic crisis. The number of unemployed started rising while the economy encountered a period of what was at first stagnation and then decline. The effects of this were soon seen in an extensive growth of unemployment and drop in industrial production. These factors were accompanied by others of more political importance (the Sanacja movement and the growing importance and strength of proponents of capital).

The political conflict between the ruling power led by Pilsudski (Sanacja) and the opposition erupted at the end of the 1920s. The elections to be held in 1930 did not guarantee Sanacja victory anymore, as the opposition consolidated. However, the leaders of opposition were arrested under false accusations before they managed to engage in any serious opposition activity, while others were afraid to act against the government. In addition, state bureaucracy was actively involved in supporting the ruling coalition, BBWR (Bezpartyjny Blok Współpracy z Rządem - The Non-Affiliated Bloc in Cooperation with the Government). In such a climate, serious political coalition was hampered, and the elections confirmed the superiority of BBWR once again. This meant that Polish political system headed towards if not dictatorship then at least authoritarian rule (Pronobis 1996).

At the end of the 1920s, the effects of the Great Crisis became visible in Poland. Agriculture was hit by the decline in the price of foodstuffs, which was accompanied by a growth in production. Due to decreasing demand, the decline in prices was so huge that agricultural producers received only one third of the previous price, which in turn led to more oversupply and a further decline in prices. Another important factor at work was the growing disparity between the price of products necessary for cultivating land and the value of those products sold by farmers: the price of the former in 1934 equalled $71 \%$ of the 1928 level, while for the foodstuffs it equalled only 34\% (Roszkowski 2003). This situation contributed to the extensive poverty of the rural population. 
In industry, the Great Crisis affected the level of production which dropped by a third between 1929 and 1932 (ibid.) and was accompanied by the decline in employment on a comparable scale. Poverty became widespread, and this was only partially alleviated by unemployment benefits and social assistance. The real income of the citizenship was also affected by monopolist practices in several branches of the economy.

The reaction of the state at the beginning of the Great Crisis was rather slow and marginal. As late as at the end of 1932 the government proposed a plan to fight the crisis by regulating the prices imposed by cartels, reappraising how public works were organised and the nationalisation of some factories (which increased state ownership to $15 \%$ in the Polish economy). The dire situation of the economy lasted until 1935; however, some signs of recovery had already appeared in 1933 due to the involvement of state in industrial production and the labour market.

What followed from the situation as outlined above was that the trend which had appeared in domestic politics of increasing the role of the state was reinforced by the occurrence of the crisis. This superiority of the state was boldly confirmed in the constitution introduced in $23^{\text {rd }}$ April 1935.

\section{ORGANIZATIONAL CONSOLIDATION OF SOCIAL POLICY}

Poland entered the 1930s with the burden of economic crisis and mounting unemployment. This situation required immediate action. At the same time, work on the consolidation and unification of the social security system continued. There were at least two underlying reasons for these efforts. First, the more proximate reason was how the economic system as such could provide inadequate support to the needy. The second, linked reason was that the existing fragmentation of the system (as a consequence of the partitioning) was problematic both in terms of different benefit standards and organizational management. This section describes the policy changes introduced during the most severe years of the Great Crisis. There were rather marginal changes at the beginning of the period, followed by the most significant reform of social policy in the mid-war period. Therefore, special emphasis is placed on the law of 1933, which to a great extent made the system more transparent and consistent but which also, given the economic and political context, altered the rules governing the programmes.

As mentioned, the Polish social policy system was fragmented when it came to its financing, its organization and beneficiaries' rights. The system as such was not only hard to steer from the ministerial level but also from the level and perspective of Polish companies. When it came to calculating contributions for 
different occupational groups, companies were faced with great complexities. This issue was even more problematic given territorial variations in the programs. For similar reasons, workers' knowledge of their rights was rather limited. Finally, a large section of the population - manual workers - did not have consistent protection against the risk of old-age. These were, generally, the motivations which stood behind the consolidation efforts. The first serious attempt to consolidate the system was made in 1929. However, being afraid of empowering workers' representatives in the insurance councils, the government withdrew the proposal from parliament. A (partial) consolidation of the social security system was carried out in 1933 which left, however, unemployment outside the new organizational structure. Most notably, the reform introduced an old-age pension scheme for manual workers. This and changes in other programs are described below.

\section{UNEMPLOYMENT COMPENSATION}

In the context of a deteriorating economic situation, the government saw it as a priority to deal with the protection of the unemployed, at least in the shortterm. After years of relative economic prosperity (low numbers of individuals receiving benefits) and of having built up the financial resources of the Unemployment Fund (a large number of contributions), the schemes for both manual and non-manual workers entered a period of financial strain.

By 1929 the Unemployment Fund for manual workers was already having problems balancing revenues and expenditures. In order to change this situation, the Fund borrowed from the state budget. However, these actions did not bring long-lasting results. In 1930 the contributions and state subsidy covered just two thirds of expenses and in the following years this deficit grew. In order to sustain the system, some policy reversals were introduced. Accordingly, the contributions and benefits were restored to the initial level from 1927. These changes also did not stabilize the situation, so on March 17th 1932 more severe changes were introduced. The reform of March 1932 increased the length of the contribution period after which an individual was eligible for the benefit (from 20 to 26 weeks). In addition, the generosity of benefits was reduced further by paying them just for working weekdays (instead of 7 days a week) and by restoring the cap on the reference period (maximum 6 zloty). The total length of payment was restricted to 17 weeks and the right of a minister to extend this period was constrained. Finally, the contribution of seasonal workers was doubled with the introduction of a 50/50 split. 
With regard to the non-manual workers system, the changes were also profound. As the number of persons withdrawing this benefit grew especially fast at the beginning of the Great Crisis and the stream of contributions narrowed significantly, this system too faced financial instability. In order to stabilize it, at least in the short-term, loans from the pension fund were taken. However, the structural problems of the system had not been solved and two further significant changes were introduced.

First, on March 22nd 1933, the rules concerning eligibility were modified. The new law excluded persons receiving old-age pensions from the right to such benefits and suspended benefit payments to seasonal workers while extending the contributory period to 12 months within 24 months preceding the loss of work. On June $17^{\text {th }} 1933$ the second legal act raised the level of contribution from $2 \%$ to $2.8 \%$ as well as the percentage of contribution paid by employees.

\section{OLD-AGE PENSIONS}

The first half of the 1930s marked an important change in the provision of old-age pensions. As mentioned above, from 1929 the situation of working masses deteriorated significantly. As a result of the economic crisis, both employment and real wages dropped (the latter by $21 \%$ in 1939 as compared to the level from 1928). The situation was severe for those who lost their jobs, including a large group of working class, elderly people. To recall, only in the former Prussian district were manual workers entitled to this benefit; however, due to the dire financial situation, the level of benefits was seen as inadequate even there. In other parts of Poland, it was mainly miners (rather a small group) who had some protection against old age. At this time and under the conditions of the Great Crisis, tension was building between the organised labour actors who were voicing their demands more and more loudly and those representing the interests of capital who pointed to the excessive and complex burden financing social security presented.

Under this pressure, the government drafted a law in 1929 to consolidate the social insurance system. It was, however, withdrawn from the Parliament due to obstructions laid down by conservative parties. However, pressure for reform from the most interested actors - the employers and employees - continued until, in 1933, another bill was submitted. There were five basic principles underlying the reformed system: a reduction in the financial burden for employers; the equalization of the burden in different parts of the country; the harmonization of the legal system across the country; the introduction of old-age pensions for manual workers; and the organizational consolidation of the system, with the leading role of the state in its management (p. 36). The law was passed on March 
$28^{\text {th }} 1933$ and it generally followed all the principles described above. It encompassed almost all areas of social policy, except for the two systems of unemployment compensation, the pension system for white collars, and specific regulations concerning Gorny Slask (Upper Silesia).What is important here in this chapter is the impact of the ustawa scaleniowa (the consolidation bill) on old-age pensions and maternity benefits. These problems are described below.

From the perspective of the Polish working class the introduction of such old-age provision was a big step towards building an encompassing social security system. As the consolidation bill did not simply extend the regulations concerning white collars scheme to the rest of the working population, the new system will now be described in more detail. Generally, the standards of the provision were not as high as for the white collars. First of all, the regulations did not directly point out that old-age was a risk requiring income replacement, as in the white collars scheme. A person of 65 years of age or more was seen as disabled and this disability requirement was seen as the basic condition. Therefore, in fact, the elderly were receiving a disability pension.

The minimum contributory period was 200 weeks (based on at least one working day a week). However, the contributory week was only counted when a contribution was paid or at least calculated. Information regarding insurance contributions was reported by the employer. In principle, every worker was covered; however, cases of contribution evasion were quite frequent.

When it came to the level of benefits, it depended on several factors. A benefit consisted of two parts: a general and an individual component. The general component was defined by the Council of Minsters as the flat rate amount for all those who received the right to the benefit in a given calendar year. The amount resembled the actual risk occurrence among the insured and the average salary of a person in the group who had received the right to benefits in the previous year. On average, the amount of the flat rate component ranged from 10 to $16 \%$ of the salary. The individual component depended on the length of contributory period and level of a person's salary. This part of the benefit referred to the level of income during the complete contributory period and so it became relatively higher within that period. For example, for a person contributing for eight years, the amount was around $10 \%$ of the salary and could increase up to $40 \%$ after 36 years of contributions. In general, the replacement rate could not exceed $80 \%$ of previous income.

The rules of the scheme were quite strict and it was clear from the very beginning that very few workers would benefit from it. The new scheme was a 
continuation of an existing scheme only for those workers from what had been the Prussian partition and whose previous contributions were transferred to the Workers Pension Fund. In all remaining cases, given the lack of any previous contributions (especially in the former Austrian and Russian parts where there had been no pension scheme), the earliest benefit could only be received in 1938 . However, the problem of the deteriorating financial conditions of elderly workers persisted. This is why the government introduced a special regulation in the consolidation law which could ease the situation of those who did not qualify for the benefit. The conditions relating to this regulation were as follows: a person had to be 65 years of age, have no source of income and have at least four years of paid work since 1920. The level of benefits was defined by the Minister of Social Affairs and it was financed from the Workers Pension Fund, which in practice meant only the contributions of workers formerly covered by the Prussian system.

The consolidation bill regulated the issue of other benefits as well. One of them was the provision aimed at persons with small children. The law from 1920 was quite significantly changed. The level birth allowance was reduced from 100 to $50 \%$ of a previous salary. The coverage was changed as well, and excluded a significant group of agricultural workers. The length of payment remained the same, as well as the support for breastfeeding mothers (either one litre of milk per day or its financial equivalent).

Under conditions of economic crisis and with growing state control over various fields of life, Poland introduced one of the most crucial reforms to its social policy system. The change concerned the harmonisation of social policy organization and the rules governing benefits in regions of Poland which used to belong to different countries before 1918 .

\section{PERIOD FROM 1936 TO 1939}

The last years before the war were marked by a further concentration of power in the hands of the executive branch of the government. After the death of Piłsudski in May of 1935, this ideological stance was continued by his close collaborators. The elections which followed Piłsudski's death were of limited democratic character, and in principle openly promoted the parties in power. The election turnout, however, demonstrated popular disappointment with the measures that restricted democratic rights: only $45.9 \%$ of Poles went to the polls, around $30 \%$ less than before. 
A wave of strikes hit the country again in the spring of 1936. At the same time, a popular agrarian opposition movement grew in power. Strikes and demonstrations often ended up with violent clashes with police and military. In several instances, right wing ideology turned into nationalist actions.

Considering the economic problems of the time, the post-crisis recovery was not as fast as expected. In 1936 production equalled only 94\% of the 1928 level, while employment stood at only $88 \%$ of the 1928 benchmark. In parallel and as a result of the post-war baby boom, there was growing unemployment which the labour market could not absorb. The government saw a solution to this problem in long-term planning which would involve heavy investment by the state (the socalled Kwiatkowski plan) and last for at least four years. Independent measures were undertaken by those in military circles concerned with the international situation, especially the demands of Hitler's Germany. Here, the army proposed its own plan for development which would last 6 years. The investment plans, with the flagship initiative, COP (Centralny Okręg Przemysłowy - the Central Industrial Region initiative), were financed mainly by the state, as foreign capital abstained from investing in such a volatile country, and domestic capital was scarce.

The investment efforts made by the state also enhanced private investment and, under relatively good economic conditions, translated into the growth of industrial production. The real income of workers grew, but for the reasons mentioned above the decline in unemployment was proportionally smaller. The statistics concerning industrial investment clearly show that in the late 1930s Poland pursued an economic model of state-led industrialisation.

When it came to population growth trends, Poland was a European leader in terms of birth rate and was located at the top end of demographic growth. However, the society was growing older. In terms of migration, the interwar period saw a net outflow of more than a million Poles, a movement which was especially visible during the Great Crisis. At the same time, the growing role of cities was seen: whereas in 1921 24.6\% of citizens lived in cities, in 1938 it was more than $30 \%$. And with regard to the structure of the economy, an outflow from the agricultural sector took place: in 1921 approximately 64\% of Poles worked in agriculture, while 17 years later it was less than $60 \%$.

It should be noted that in spite of urbanisation and industrialisation, Poland remained mainly an agricultural country. Besides the fact that agricultural plots of land were small and fragmented, there was a growing number of landless inhabitants in rural areas (approximately 12\% in 1938). 
The second half of the 1930s did not see any major changes in the three social policy programmes. All of them were functioning although the scale of operations did vary. Looking at the overall context, the importance of those representing the interests of capital was growing as their voices and arguments could be heard more and more calling for a reduction in the financial burden related to social policy. At this time no new major provision was introduced, no significant retrenchment took place. Instead, only minor, parametric changes took place.

Those representing the interests of capital fought for a reduction in social insurance contributions and in fact it was the major issue of the period. The state wanted to accommodate these demands to a certain extent and introduced a few regulations reducing the overall burden on capital. The first step was to reduce the volume of unpaid but standing contributions. This was done in 1935 and involved reducing interest rates, prolonging the period of payment and allowing partial cancellations. Secondly, in February 1936, the Minister of Social Affairs introduced a temporary reduction in the contributions level with regard to the old-age social insurance scheme (and later to the sickness scheme too) until the end of the following year. While the decrease in old-age social insurance contributions benefitted both the interests of labour and those of capital to some extent, the reduction of the burden in sickness insurance was felt by the capital only. These moves severely reduced the reserves of the social insurance funds, but such measures were treated as temporary solutions. However, they were to be prolonged in the coming years as well.

On the side of cash benefits, only a few relatively minor changes took place. The maximum reference amount for manual workers' pensions was raised in 1936 to 15 zloty (to be decreased later to the previous amount). The level of maternity benefit was $75 \%$ of a person's previous salary. Apart from this, social insurance was not consolidated completely and the differences inherited from the pre-1918 period were still affecting people's rights to benefits (Anderson, Hula et al. 1991). What was especially visible was the fast growth in the number of individuals being covered by the social insurance programmes.

\section{SUMMARY OF THE INTER-WAR PERIOD}

Poland entered its independence with the burden of a diversified level of economic, social and political development in its three partitions combined with the physical destruction resulting from the First World War. In this context, the 
basic tasks of the government were to secure its basic functions, and coordinate them over the whole territory. At the same time, the country was going through conflicts related to its integrity and economic crises. These circumstances allow us to understand why the introduction and reform of the Polish social security sector took so much time, why it was in fact unfinished in this time frame and did not cover more of the population than it did. On the other hand, the fact that some parts of Polish population (taking into account all the reservations just mentioned) were covered by some form of social insurance, the social policy programmes of this period should be seen as a success.

Stepping back a little, some more general remarks concerning this period are worth mentioning. First, it should be remembered that the consolidation of the social policy system took place between 1929 and 1935. This had quite profound implications as this period was to a large extent shaped by the depression. This was demonstrated in the specific treatment of unemployment benefits, which organizationally were outside the main system of funds. Second, maternity benefits were the only scheme covering the whole working population (with the exception of agricultural workers and those in the Gorny Slask region). Other benefits were aimed at selected groups of population: there were different old-age pension schemes for those who were part of the state apparatus, public employees, white collars and manual workers. Also, separate unemployment compensation schemes existed.

\section{WORLD WAR II}

The period of World War II is the most under-researched period in the activities of the Polish welfare state. Certainly, this is not because the period was not important for later developments in social policy in Poland. On the contrary, from the institutional perspective, the war years combined with the preceding period set the framework for understanding the developments in social policy making in the socialist, and most importantly, post-socialist era. As will be described below, the developments that took place in the years 1939-1945 significantly influenced the spectrum of policy options available afterwards. This section focuses on policy changes under the Nazi occupation, leaving aside the situation under the Soviet occupation, as there is virtually no information about the latter. As in the previous paragraphs, the content of the three policies and the organizational and financial features of social insurance will be considered. 
After the invasion of the Nazi Germany on September $1^{\text {st }} 1939$, the occupying forces set about removing every feature of the Polish state, including that of social insurance. As the official line of the Nazis was to view and to treat Poles as being inferior and of little or no value, the policy of the new order was aimed at reducing all available means for social and individual survival for those under occupation. Therefore, what remained of Polish social insurance did not last long (in fact, only until August 1942). As early as 1939, the Nazis introduced a system intended to supersede that which was in place. Poland was divided into two parts: the 'incorporated eastern lands' and the Generalne Gubernatorstwo (the 'General Government' territories seen as part of the idea of a 'Greater Germany'). Poles living in these two territories were treated differently.

When it came to the so-called 'incorporated eastern lands', the management of the insurance institutions was taken over by Germans. Special emphasis was paid to the collection of contributions, which followed the rules which were in place before the occupation. Some form of pension and sickness benefits were paid. Soon, however, such provision was forbidden to those with anti-German attitudes. Generally, the idea was to replace the old system with the German model and to restrict access only to Germans. This process followed in steps and was finished in 1941. The implementation of this logic resulted in a narrowing down of the scope of benefits and their generosity while simultaneously exacting the payment of contributions as under the German system. For example, birth allowances were reduced to $25 \%$ of the salary. With the decree of December 1941, the status of Poles decreased even further. This system was a mixture of social insurance (payment of contributions equal or even higher than for Germans) and social assistance (a very low level of benefits and with a high degree of discretion on the part of the German gatekeepers).

Social insurance in the territories under the Generalne Gubernatorstwo followed a slightly different path. However, the overall aims were the same as in the incorporated eastern lands. In principle, the organization of social insurance remained unchanged, with only the top positions being staffed by Germans. The policy the Germans followed focused on restricting access to benefits by blocking off access to financial resources. No financial operation was possible on existing resources as they had already been squeezed due to unfavourable exchange rates. In addition, the overall destruction of the war and occupation had played a significant role in limiting the financial resources available. However, thanks to a loan from the German Credit institution, the payment of pensions was possible. Later on, due to the policy of restricting access to social provisions but extending the contributions basis, social insurance had a financial surplus. 
In real terms, the spending on any one particular beneficiary decreased significantly. However, this might have had more to do with the benefits' quality and adequacy. The construction of benefits assumed the compliance of individuals with regard to specific rules established by the Nazis aimed at the exploitation of Poles. Consequently, this goes some way to explaining the marginal take-up of unemployment benefits. The benefits and services related to maternity were also severely restricted. In the later years of the war, the nominal value of benefits and their scope was raised incrementally. However, this should not lead one to any misperception concerning the real value of the benefits and overall situation.

In both parts of occupied Poland, the approach to social policy followed the same aims: maintaining of the manual labour force while at the same time dividing society along ethnic lines using the systems of social policy as a tool for the structural exclusion of certain groups. Significantly, the intelligentsia were also targeted in this way. Interestingly enough, some institutional solutions remained quite untouched, especially in the Generalna Gubernia territories, including staffing arrangements. Others were changed, and followed the German model closely.

When it came to the situation for the general population, things deteriorated significantly. A useful illustration might be a comparison of the level of the social security contributions and the cost of living in the four years of the occupation: the level of benefit contributions tripled, while the cost of living grew by nearly 50 times in Krakow and by 65 times in Warszawa.

As for the impact of the World War II on future developments in the Polish economy and social policy provision, the importance of this period is - needless to say - significant. More than $60 \%$ of the pre-war financial resources were gone and the already vulnerable pre-war institutional structure of social security was severely shaken.

Apart from the immediate and pressing problems related to the social security system following the war, the overall destruction was massive. Six million people had died or had been killed, there had been a huge migration from the east to the west, changes had been made to the country's territory and there had been an almost total destruction of the country's infrastructure. 


\section{THE SOCIALIST ERA}

\section{INTRODUCTION}

The immediate post-war years saw a struggle for political domination by the communist workers' party which was strongly supported by Moscow. This campaign was fought on many different fronts such as the defeat of independenceoriented guerrilla and the marginalization and takeover of other parties. Parallel efforts were directed at the reconstruction of the destroyed economy according to Soviet blueprints, which meant developing heavy industry while eradicating private enterprises. The situation changed when the socialist rule had been consolidated. However, at the same time signs of de-Stalinisation emerged. This had profound consequences: the system became less oppressive especially towards groups previously perceived 'the enemy' such as private farmers. Additionally, more consideration about the increasing level and standard of living came to the fore. Accordingly, the demographic coverage of the social security system was extended, with new occupational groups being included (although they were treated differently). The social security system became 'mature' around the mid1970s, at the peak of the period of economic prosperity. The expansion of the social security system to private farmers did not aim, however, at the long-term improvement of the position of this group; in fact, quite the contrary. Nevertheless, after some changes, the system became quite favourable to farmers, creating vested interests for this group with regard to social policy. The period was characterised by a number of ad-hoc measures, aimed at the improvement of the situation of certain groups. This approach made matters of social security very complex, with different rules concerning the eligibility and generosity of various benefits of different groups. This is described in more detail below.

\section{THE IMMEDIATE POST-WAR YEARS}

World War II left Poland in a catastrophically bad situation. The level of material destruction and human loss were unprecedented. It is estimated that, compared to 1939, 22\% of the Polish population had been lost in the war, out of which $79 \%$ had been inhabitants of urban areas. With respect to the economic situation, the level of material losses equalled 13 times the national product in 1938, and per capita were the highest in the world. These estimations are even worse if one takes into account that the Red Army confiscated a significant number of former German factories. More than $65 \%$ of factories were destroyed, while in 
agriculture around $22 \%$ of all farms were razed. The stock of animals stood at around $25 \%$ of the 1938 level (Roszkowski 2003).

The economic recovery was a long-term process, but the shift of Poland's borders to west (which was, comparatively speaking, better industrialised) and the engagement of the society resulted in some quite fast economic growth. The state, on the other hand, wanted to achieve its economic aims by extensive planning. It was accompanied by political actions aimed at the possibly of extending the nationalisation of industry. At the beginning of the 1946, all factories employing more than 50 workers were nationalised. Initially after the war, the Polish economy noted growth. The reason for this was the initiative shown by private entities in the economy. Soon, however, with the growing repression of the state, such private activity diminished and the economy started to slow down.

The shortage of basic goods was common and contributed to both a serious decline in the standard of living and development of the black market. The former could most obviously be seen in the serious levels of malnourishment both in general terms and in comparison to the 1930s.

After a short struggle, the communist party defeated its political opposition and started introducing Stalinist order to society, the economy and other spheres of life. Democratic elections became illusory, private economic activity was seen as hostile to socialist ideals and the communist party apparatus took over the governance of the state. One of the main enemies of the state was the underground movement which comprised among others private farmers and members of the pre-war elite such as bureaucrats and private entrepreneurs. Trade unions and NGOs were also seen as the sources of political opposition and were either absorbed by the state or deemed illegal.

Another important group that the state was wary of was the landowners. In the case of big landowners, their land became nationalised. The main policy towards small landowners was collectivisation. However, the success of this programme was very limited because as few as $10 \%$ of all farmers agreed to join cooperatives.

\section{SOCIAL POLICY ORGANIZATION}

As mentioned, World War II had brought about an immense degree of destruction. After the Warsaw Uprising of 1944, the capital of Poland was almost completely destroyed. However, some archives and financial resources were moved to Krakow in 1944, and this created the basis for the continued activity of social security system. The scale of the social need and the resources available 
meant that the job of making the social security system operational was going to be a hard task, especially given the changed territory of the country.

In principle, pre-war solutions were restored with some attempts being made at consolidating them. As early as 1944 in that part of Poland under the Soviet-introduced Polish government, a programme of 'reconstruction and development of self-governed social insurance' was declared (Jacukowicz 1991: 214). This programme proceeded in steps, and was restricted by the impoverishment of the population. Exactly because of this, contributions to sickness insurance (including maternity benefit) were removed in September 1944. Next, a partial unification of the system took place (with the exception of the miners' pension system) that covered the whole territory of Poland.

The organization of the system also resembled the pre-war model. It was based on the principle of self-governing councils, both at the coordinating central level (ZUS) and in each of the social insurance institutions. The councils not only made decisions about financial and budgetary matters, but also elected the directors of the insurance institutions. In the area of sickness and maternity there were 61 separate funds, streaming their contributions to ZUS, which operated health services, related benefits and transferred resources to funds which were in need (Radzimowski 1991). Thus, five separate insurance funds existed under the ZUS umbrella: manual workers' pensions; non-white-collar workers pensions; work accidents; the general fund for sickness and maternity; and the family benefits fund. Each fund was financially independent and calculated its own contribution. However, although formally independent, the manual workers' system was financed from other funds and two unemployment funds became in fact one entity (Radzimowski 1991).

When it came to the scope of the benefits, the early post-war years were very dynamic and moved towards the equalization and extension of coverage for various social groups. The priority was given to short-term benefits (such as sickness benefit), focusing mostly on the working population (Plawucka 1991). Insurance was expanded to agricultural workers, starting from that related to work accidents in 1946, to sickness (and maternity) cover in 1947/1948, and to old-age cover in 1953. These steps saw a doubling in the number of individuals covered. The privileged groups, such as state employees, remained in their own systems. Gradually, however, class differences in the provision and eligibility of benefits, introduced by the dual system (manual vs. non-manual workers), were removed. The purpose here was to attract and sustain the political support of the two groups and so it took the form of upgrading the rights of workers to the level of the more privileged groups. 


\section{OLD-AGE PENSIONS}

Initially, the old-age pensions were paid level at the same level and according to the pre-war rules. However, due to the lack of insurance records from 1945 to 1949 the benefits were flat-rate with a level typical for the non-manual system (with several increases). On the organizational level, the application of complex pre-war rules was difficult in the post-war context. This is why these rules were treated as a point of reference, which could be modified by legal acts of a lower rank (Plawucka 1991).

In 1949 the contribution period and previous income was partially taken into account when calculating the level of benefits. This method went some way to replacing that which was based on class differentiation. A person who worked for at least 18 months was eligible to receive a benefit. The level of benefits was established according to the individual's membership in one of eight income groups and ranged from 20 to 50\% of a salary (Plawucka 1991). The benefits could meet only the very basic needs of the population, as their real value decreased quickly due to rigidity of income categories and increasing income of working population as a whole. Those without a work record received benefits below $20 \%$ of an average salary in their income group. This duality was the starting point of a persistent difference in the pension system in the coming decades.

\section{MATERNITY BENEFITS}

The construction of the maternity benefit remained similar to the pre-war solution. In 1946 the replacement rate of the benefit for manual workers was raised to $100 \%$. It meant that the benefits for manual and non-manual parts of population were equalized as stipulated in the pre-war law in which the latter group had the right to receive an amount equal to that of a salaried worker (Muszalski 1991). In 1948, the length of payment was extended from 8 to 12 weeks. In this way the length of payment was adjusted to the length of leave, which had already been established in 1924. In the following years, regulations concerning maternity benefit were extended to other groups (agricultural workers). The situation concerning this benefit remained unchanged until 1972.

Interestingly, unemployment compensation was not present in the system anymore. There were at least two reasons for this. First, for ideological reasons relating to socialism, unemployment was seen as a purely capitalist phenomenon and, as such, non-existent in socialist society. Second, in times of massive reconstruction, the demand for the labour force was so high that there was no (official) unemployment. 
As far as the financing of social policy was concerned, the authorities were reducing the burden for employees and shifting it to employers. The current contributions paid by employees were the sole source of social security financing: the investment in resources and state subsidies played no role. The financial situation of the system was rather good, as it noted a significant surplus until 1949. The reform of 1949 reduced this surplus significantly.

As shown, this period presented both continuity and change. The continuity was present in the organizational structure of social insurance and in the independence of funds covering different risks and social groups. At the same time, one sees a departure from previous solutions: the class differentiation of benefits provision diminishes while the scope expands; the burden of contributions is moved to employers (soon almost exclusively state-owned enterprises). Also, social insurance was used for other aims, such as the reconstruction of the country: the surplus of the funds had to be moved to the state budget.

\section{PERIOD 1950-67}

The immediate post-war period was a period of domestic political struggle. At the end of the 1940, the communist party (PZPR) successfully dominated the political scene and the process of establishing the Stalinist-type of economy and social organisation - characterised by a high level of political and economic centralization, a virtual lack of private property, and extensive state control - was free to go ahead at full tilt. These changes were visible in the area of social policy as well.

The early 1950s were the peak of Stalinism, a period marked by extensive industrialisation aimed at the development of heavy industry, especially the military sector. The Six Year Plan of Economic Development and Building the Fundamentals of Socialism was a success as industrial production grew by $17 \%$. However, this growth came at price of reduced consumption and common shortage of other goods (Pronobis 1996). The efforts of collectivisation continued, but remained unsuccessful. However, the lack of cooperation between the farmers and the state resulted in other coercive measures such as mandatory deliveries of foodstuffs.

The repressions diminished after the death of Stalin in 1953. The assumptions of the economic plan were modified, with a moderate shift from heavy industry to consumer goods. A consequence of this was that private farming became less oppressed, with the aim of increasing production. 
After 1953, improvements in such things as access to basic goods as well as a liberalization of political rights were expected. However, any such changes proved to be very limited. Popular disappointment with the system occurred for the first time in June 1956. Workers from Poznań called a strike demanding more political freedom and called for a better standard of living. The protest was crushed by the military and a dozen workers were killed. What followed was not only brutal repression but also debates within the communist party concerning the direction it should take. Such debate increasingly attracted the attention of society. After much politicking, including threats from Moscow, the political scene was reshuffled with the victory of seemingly pro-reform wing led by Władysław Gomułka.

Soon, however, it became clear that Gomułka's team was more concerned with preserving the status quo than introducing any serious reforms. The democratising moves at this time, such as workers' councils, were short-lived; however, they did manage to build up unprecedented trust in the ruling party.

Economically speaking, the result of Poznan revolt was another correction of plans aimed at easing the economic situation of Poles. However, as in politics, this did not last long. The focus of planning soon switched to the development of heavy industry, reaching almost half of the total investment made. Thus, the period of improvements was short. The government tried to counteract these negative tendencies by investing in agriculture, but the assumed effects of the plan were limited as production was managed in a typical socialist manner (Pronobis 1996).

Industrialisation changed the social structure of Poland. Between 1950 and 1960 the rural population declined from $61 \%$ to $51.3 \%$, and from the end of the war the urban population almost doubled. At the end of this period, there were 6.4 million industrial workers (without taking into account their families), 1.2 million agricultural workers and 12 million members of families living off cultivating private land. Compared the extent of collectivisation in Poland $(13.2 \%$ of all farmers) with other socialist countries, one sees the outstanding fiasco of this strategy. This is why the policy towards farmers was especially complicated and depended on the militancy of other groups, especially industrial workers. When the militancy grew, the government liberalised the approach towards farmers, so that the needs of other groups could be met.

As mentioned, in the late 1950s and 60s the performance of the economy fluctuated quite often and so too did the standard of living. It is important to note that at that time the Polish labour market was able to absorb any amount of labour 
force, including those of retirement age and especially women (Fallenbuchl 1987). Corrections to the economic plans were always reactions to the problem. It meant that economic difficulties directly affected more and more of the population.

Another important facet of the development of Poland was the popularisation of education, health care and leisure, all of course within the framework of socialist ideology and principles of the so-called 'small stabilisation'. An important part of this development concerned social policy as well (Roszkowski 2003).

\section{FINANCING AND ORGANIZATION OF SOCIAL POLICY}

In the first half of the 1950s, the laws concerning the social security system were introduced, which significantly altered the institutional structure. Two changes seem crucial here. First the social insurance funds and their managing institutions lost their independence and were merged (apart from those related to the railways workers). This move was significant as it signified a break from the tradition of differentiation, pooling 'good' (well-paid) employees of public institutions or well developed industries in separate occupational funds, and the rest in the public scheme.

Second, the single insurance fund became included in the state budget. Therefore, from 1954 on, it was impossible to distinguish streams of contributions covering various kinds or risks, as companies were paying just one contribution, specific for a given occupational group. According to Plawucka, the decree of 1954 was considered complex and unclear due to a lack of sufficient expertise. As a result, there were many amendments and legal acts aimed at clarifying it, but having contradictory effects (Plawucka 1991). The legal acts and internal documents interpreting the decree were barely accessible, and few people knew their content.

Next, as a consequence of subordinating health insurance to the Ministry of Health and Social Care and merging all other insurance institutions, the administration of social security was centralized: there was one fund, managed centrally by the state, with only the delegation of some tasks to lower levels of administration (Borowczyk 1991). The umbrella organization, ZUS, was closed down and its responsibilities were divided between the state apparatus and trade unions (the Centralna Rada Zwiazkow Zawodowych or 'Central Council of Trade Unions' which in fact was directed by the communist party and was part of the state apparatus). The trade unions were responsible for managing short-term benefit, the state administration for old-age and disability pensions. This 
institutional solution proved inefficient and in 1960 ZUS, with its responsibility for both long-and short-term benefits, was restored.

Adding new social groups to the system of social policy was done by creation of specific funds. In 1964 the fund for artisans was established, in 1966 that of the self-employed.

The financial situation of the system was positive and throughout the period it only once noted a loss (in 1959). However, the surplus that had been invested in the state financial instruments, was gone. The same happened to the current surplus; that is to say, it was used for other purposes (Radzimowski 1991).

\section{OLD-AGE PENSIONS}

This period marked important changes in the pension system, including its scope and generosity. The scope was extended to virtually all forms of salaried employment. This had started with the decree in 1954 which introduced universal old-age provision. Further extensions were introduced from the beginning of the 1960s. The reform of 1954 consolidated the system and introduced unified rules for the whole working population with very few exceptions, namely the exclusion of groups such as members of military, the militia and the secret police. Importantly, old-age became a risk in itself, and not an instance of disability.

According to the decree from 1954, a person's age of retirement and the level of benefit they would receive was dependent on the category employment to which they belonged. There were two categories. In category I (for those working under ground and in the steel industry), the retirement was 60/55 for men/women and the level of benefit was set at $60 \%$ of the reference amount; in category II (all other workers) the retirement age was $65 / 60$ and benefits were set at $40 \%$ of the reference amount. The length of work requirement was established at 25 years for men and 20 for women; however, various non-work periods could be included. The amendment of 1958 removed these categories, and raised the benefit level to $75 \%$ of the reference amount, which was capped. This change significantly improved the situation for workers with the lowest salaries.

Going back to 1953, the level of benefits had been raised due to a significant drop in their real value. Nevertheless, the adjusted level was still very low and ranged from 14 to $27 \%$ of an average salary (Plawucka 1991). The decree of 1954 raised benefits again to an average level of 335 zloty. However, the regulation covered only those retiring after July 1954 (about $8 \%$ of all pensioners) 
and heavily conditioned retirement on a person's previous work record. The low level of benefits resulted in the phenomenon of 'working pensioners', a group which comprised half of the beneficiaries at this time. When the categories of employment from the 1954 decree were removed in 1958, differential treatment was eased, but only to some extent however. The problem of a partial (re)valorisation was present during the whole socialist period. In the remaining period the level of pensions was raised twice (in 1963 and 1965) and the level of minimum pensions once (in 1967). Again, these changes were the result of the decrease in the real value of benefits.

The ideological emphasis on the necessity of work and the centrality of work in the social policy system - and the corresponding incentives which were built into the programmes - made the system very complex. As the state treated different occupational groups and sectors of the economy differently, this was mirrored in the construction of benefits. However, it was the period of the 1970s, when the complexity of benefits became a real problem.

\section{PERIOD 1968 TO 86}

The period from 1968 to 1986 was very heterogeneous as far as economic and political developments were concerned. The first half of this period saw a boost in the economy. However, this soon turned into severe economic crisis. Politically, the 1960s was an era of so-called 'small stabilization'. However, various social groups raised a series of protests which took place around this time and which were met with different responses from the authorities, culminating in the introduction of martial law 1981.

As mentioned in the previous section, the Polish economy was developing thanks to the economy's ability to absorb labour. However, the bureaucratic barriers inherent in socialist planning prevented the stipulated investment levels (here with regard to economic planning) from being met. So while industrial production kept up with its increasingly less ambitious targets, the problem that was felt by the majority of Poles concerned the insufficient supply of consumer goods. Such a situation laid the foundations for crisis which appeared inevitable. In the years 1968-1970, the value of real incomes for industrial workers stagnated and, in the case of the agricultural population, dropped by almost $16 \%$ in 1969 . On top of this, another supply-side shortage of food and other goods appeared. Given the fact that prices were controlled centrally, this led to their rise in December 1970.

The reaction of workers to the rise in prices was immediate and they turned against the party and associated trade unions. The workers in the shipyards on the Baltic Sea coast went on strike and demanded not only a reversal of the 
price increases but also systemic changes, including the liberalisation of the press and religion freedom. The strike turned violent and there were clashes with the militia and military on an unprecedented scale. The reaction of the party was extreme: it sent in the military and militia to pacify the striking workers, killing many of them. This escalation of violence inhibited the scope of change among top rank communist party figures and Edward Gierek became new secretary general (Roszkowski 2003).

The Gierek team realised that a the strategy of violence was of limited use in a situation where there was a lack of popular support. Unlike in the case of Gomułka (who used a specific window of opportunity with regard to the popular mood) in this situation popular support had to be acquired through a significant increase in the standard of living similar to that which was achieved in Hungary. This was done by increasing investment in areas which would help achieve this aim (for example, in car manufacture) and increases in the level of nominal salaries (59.4\% between 1970 and 1975). The source of this investment lied abroad. However, a large part of these loans were wasted due to the inability of the administration to use them efficiently, a problem which was typical for socialist management. The other constraint for this improvement was the lack of sustainability, which was especially apparent in the farming sector which was dependent on imports. With loans drying up, the fundamentals of efficient and sustainable agriculture became weak.

Thus, the period of economic improvement was short, but at the same time, it carried a potential for even deeper crisis. The first signs of crisis became apparent in 1976, and Gierek decided to introduce a price increase. In theory, it would be offset by increases in salaries. However, in real terms this meant another drop in the standard of living, especially for the poorest. The reaction on the side of workers was a wave of strikes and riots. Like in 1970, the state replied with repression. But this time the intellectual elite (which was soon to become the political opposition) joined the workers. The involvement of intellectuals took a more organized form than before in respect to support for workers and their families during trials in which people were prosecuted under false charges. The intellectual elite organized legal and financial help. Soon, the activists established an opposition circle, KOR (Komitet Obrony Robotników, or 'Workers' Defence Committee').

A groundbreaking moment in the history of state socialism in Poland (and elsewhere in Eastern Europe) came in 1980. In the preceding years, economic decline combined with exceptional weather conditions showed how clearly the state was unable to cope with basic problems. Another increase in prices was seen 
in 1980, this time brought about by introducing a special category of shops in which prices were much higher than those stipulated. The conciliatory approach of the party was to accept that, although short-sighted, the workers were right to protest these demands on their salaries. However, workers realised the real purpose of this move and called a strike, realizing that this was the only way to achieve their aims. Once again the crucial role here was played by shipyards, whose demands were not limited to economic issues but extended on political ones, such as the establishment of independent trade unions. Soon, the political component of the strikes became a central issue for workers, who gathered in intrafactory strike committees. The scale of strikes forced the government to sign an agreement in September 1980, in which a central point was the recognition of the existence of independent, self-governing trade unions. This was the spark which ignited an historical chain of events: the Solidarność trade union was registered in November of 1980. Soon after it had 10 million members. Subsequently, a number of other independent civil society organizations loomed.

The failure of the party to prevent the establishment of Solidarność led to another reshuffling in the state apparatus. Gierek was replaced by General Wojciech Jaruzelski who, from the beginning of the 1981, started preparing for martial law. The spring and summer of 1981 saw another crisis which resulted from a lack of resources needed to import raw materials and consumer goods. It meant that rationing was necessary, especially with regard to consumer goods. This led to heated conflict. The party reacted with the introduction of the martial law on December 131981 and arresting almost all the leaders of the opposition. The period of martial law that followed crushed popular support and brought apathy to the society. At the same time, the economic problems became even worse.

The social policy developments were therefore a partial reaction to these trends, but also the result of endogenous pressures created by the system itself. The design of social policy financing was therefore changed and the level of benefits was raised. However, the changes shared several important characteristics with economic policy, and proved to be efficient only in a short term.

\section{SOCIAL POLICY ORGANIZATION}

As far as the most important organizational changes were concerned, one may distinguish few important points which are interrelated. 
First, the financing of the social security was changed. The reform introduced a contribution split, with an additional 3\% to be paid by employees. This marked an important point in the development of the social security in Poland during state socialism.

Second, the pension fund was financially detached from the state budget and half of the employers' contributions plus the employees' part was directed there. In this way, the fund gained independence again and established financial flows. All specific funds were included in a single, general fund in 1977. However, with the expansion of cover to farmers in 1978, a separate farmers' pension fund was created in 1978 (later to be replaced by the farmers' social insurance fund). The latter fund was meant to be financially self-sustaining.

In this period the coverage of social security was continually expanded to new beneficiaries, mainly to the self-employed and farmers. Subsequently, in 1971 and 1976 the coverage of workers in state-owned farms was regulated. In 1973 coverage for artists was started and in 1975 the remaining salaried workers were covered. Finally, the biggest group to date, private farmers, was included in the system as of 1977 .

Next, the levels of new and existing pensions were adjusted several times. The adjustment of the latter benefits was done according to more favourable rules. However, the level of both these benefits did not follow the rise of nominal wages and their real value decreased. In 1982 and 1983 the mechanism of automatic adjustment was finally introduced and came into life in 1986, in the middle of a recession which already necessitated another series of adjustments.

In short, the combination of the growing scope of social insurance, various attempts aimed at the de-bureaucratisation of the system, soft-budget constraints on social insurance (the state budged was extensively borrowing from its resources) and many chaotic benefit adjustments led to the growing inability of the system to operate in the long run. A good illustration here might be the situation in 1983 when ZUS could not pay benefits on time (Borowczyk 1991).

A case study from the financial side of the system illustrates this situation. The separate scheme for artisans soon started recording a debt and had to be subsidized from the budget. Before being absorbed, other separate schemes recorded a surplus. After creating of the general pension plan in 1977, its situation worsened, as it had to pay back the subsidy given to the artisan scheme. A surplus was recorded again after raising the level of contributions in 1982 and 1983, and 
allowed for investment (which was not the case before when the surplus was used for operational purposes) (Radzimowski 1991).

The financial situation of the farmers' scheme was different because of its construction. The scheme was subsidized every year from the state budget with a given amount of money, which was the reason for recurring debt in some years. The situation in the two policies of old-age pensions and maternity benefits (remembering of course that unemployment compensation was absent from the 1940s on) are described in more detail below.

\section{OLD-AGE PENSIONS}

In principle, the reforms within the old-age pension system were a continuation of those from the previous period. The reforms were aimed mainly at raising the level of benefits. The Bill of 1968 adopted a parametric approach to change, raising the level of income above which the calculation of benefits was less favourable and increasing the coefficient used for establishing the level of benefits. Accordingly the coefficient for incomes below 1,500 zloty was $80 \%$ (previously 1,200 zloty and 75\%); between 1,500 and 2,000 zloty 55\%; and 25\% above 2,000 zloty. The level of benefits was also linked more closely to the length of employment. This increase was significant. For a person with an average salary and who had a standard length of employment, the increase in the replacement rate was from $53 \%$ to $73 \%$ following the reform. For persons working 40 years the replacement rate was as high as $81 \%$. Additionally, the Council of Minsters now had the right to increase the level of benefits and change the retirement age. Finally, the reform extended the catalogue of activities which could be treated as employment periods and in this way made access to pensions easier (Plawucka 1991).

The 1968 law was amended several times. These changes included mainly raising the level of benefits and a reduction in the number of income levels to two, as in 1974.

The law also gave the Council of Ministers a right to define conditions of early retirement, which was seen as the element of the employment policy rather the pension policy as such. The law of 1977 had three aims: first, it raised the benefits for those who had retired before 1975 and gave the oldest pensioners preferential treatment by raising their benefits the most; second, it regulated the growth of minimum benefits; and third, it adjusted the relation between previous income and the coefficient used for calculating benefits. The reform was 
introduced in steps and it was soon offset by increases in the cost of living. This was repeated several times, peaking at the beginning of 1980s. All the ad-hoc adjustments with all of their inconsistent rules brought about big disparities among benefits, which depended on the moment of retirement. This disparity, in turn, fuelled a debate on the introduction of an automatic mechanism for the adjustment of benefits.

The reform from December 1982 partially tackled the issue. First, the level of benefits granted before 1981 was recalculated incrementally (between 1983 to 1985) according to the growth of salaries in previous years (within certain boundaries). Second, every year the newly granted benefits were to be adjusted to the salaries growth from the previous year (Radziński 1983). However, spreading this operation over three years, where the real value of benefits dropped again, made the impact of the reform rather limited. Subsequently, the differences among newly-granted and currently-paid benefits persisted (for instance, in 1985 newlygranted benefits were $30 \%$ higher than those which were being currently paid). More attempts in the same direction were made in 1987; however, it did not change the situation significantly.

Finally, as mentioned above, the coverage of the system was significantly expanded in 1960s and the 70s. This was especially important when it came to the farmers who made up the second biggest part of the population. The roots of the system dated back to 1962, when a form of old-age benefit was introduced. The benefits were granted in cases when there was a transfer of land ownership to the state. There was no contribution, so there was some heated debate as to whether the system should be interpreted as social insurance (many of the features pointed to this interpretation) (Znyk 1975), or rather as compensation (Plawucka 1991).

However, the inclusion of private farmers' families in 1977 was a groundbreaking moment. Certainly, the reasoning behind this scheme was to decrease the strength of private agriculture because it prevented the land from being inherited. Soon, however, the requirement that land transfer should be loosened as a contribution (to one third of the minimum monthly contribution) was introduced. This decision had some significant unintended consequences. This was because low - but still favourable - benefits (given the level of contribution) were created, favouring those who had vested interests in protecting the status quo. The scheme covered farmers and their spouses. Receiving a benefit was conditional on the transfer of a farm to the state or to children, while the benefits were targeted at the particular farm, rather than the individuals running it. The level of benefit depended on the amount of agricultural produce sold to the state. 
The 1977 regulation was changed in 1982 and the direction of this change followed a similar path to that of the reform of the salaried workers' scheme. The scope of the scheme was also extended to members of a household older than 16 . This construction emphasized the de-facto salaried nature of some agricultural work (Pławucka 1983). It also introduced a differentiation of contributions that depended on not only a farm's size, but also its output. As a consequence, each individual qualified for his or her own benefit, unlike before when it had been granted to a farm (e.g. spouses).

The second important issue arose at the beginning of the 1980s. With the emergence of the first independent trade union in the Eastern Bloc, Solidarność, socialist rule was challenged in several ways. The trade union, among other things, demanded reform of the social insurance system so that it would become more harmonized and transparent. The authorities started working on the reform guidelines. However, with the introduction of martial law in December 1981, the project was abandoned. Martial law brought about complete social distrust of the regime, making people question its very legitimacy. In addition, the regime also saw a decline in its core supporters. In an attempt to regain support in 1982, the authorities extended its catalogue of groups that enjoyed preferential treatment. Not only did miners, railway workers and employees working in difficult conditions or in unusual occupations receive such privileges, but women who fulfilled either certain age or tenure criteria did too (Radziński 1981). With the lasting economic hardship, the approach was continued and preferential treatment was extended to several other groups. The 1982 law made it possible to retire before the stipulated retirement age on the condition that length of employment was met: 35 years for men and 30 for women; or to receive a partial benefit in cases where the tenure requirement was not met (Radziński 1983). As Golinowska and Zukowski (2002) argue, this practice in the Polish social security system meant that the privileged groups in Poland outnumbered those under general rules.

\section{MATERNITY BENEFITS}

The wave of important changes in social policy programmes at this period also saw changes made to maternity benefits, which had previously been reformed at the end of the 1940s. The reforms were profound and included adding a new component: extended maternity leave. In 1972 the length of benefit payment was extended from 12 to 16 weeks for the first birth, and to 18 weeks for the second. When it came to the level of benefits it was $100 \%$, but of a person's net salary 
(previously it had been $100 \%$ of their gross salary, so in fact the benefit had been higher than the salary).

The differentiation between non-manual and manual workers was definitively removed by the Labour Code of 1974, and further regulations were introduced into law regarding sickness and maternity provision in the same year. The bill removed the requirement of work for a person to be eligible for these benefits.

In 1968, non-paid extended leave was introduced. According to the 1974 regulations, a woman qualified for maternity benefit while being on extended leave. The issue of non-paid extended leave became an issue during the wave of strikes in 1980. Those on the independent labour side argued for the introduction of a paid benefit during maternity leave. As a result, the law from July 1981 regulated this problem. Extended maternity leave could be taken for maximum of three years following the expiry of standard maternity leave. This extended leave consisted of a paid component for a period of eighteen months, to be taken immediately after standard maternity leave. The benefit was paid for from the social insurance fund, and means-tested according to a the individual's income. The qualifying income level was $46.8 \%$ of an average salary for one member of a household. A few months later, fathers were granted the right to the extended leave (if agreed by the mother) and the length of payment increased to two years.

With the income thresholds unchanged, fewer and fewer families qualified for the extended leave benefit. Linked to this, the relation between this benefit and the average salary changed so that the value of the benefit was adversely affected.

When it came to other groups in the population, social policy provisions were extended to them as well. A specific and interesting case here concerns private farmers. The law of 1977 did not regulate the issue of maternity benefits, but introduced birth allowances (from 1980) which were seen as a milestone in the development of this kind of provision. Even more so was the 1982 law which introduced maternity benefit. It was regulated differently than in the public scheme. The benefit was paid to an insured woman (or a woman coming from insured household) for 16 weeks at the level of a basic old-age benefit.

To summarise this period, the system had reached its full coverage. Many decisions concerning the inclusion of more social groups into the social security framework were governed by various underlying rationale, not necessarily linked with the idea of securing a certain standard of living in certain risk situations. Perhaps other reasons, directly connected with the specificities of the economic 
and political system were more profound. The examples of such motivations can be seen in the provision of extended leave (seen as an indirect incentive to quit the labour market by women) or in the pension scheme for farmers. However, the adhoc style of these reforms resulted in many unintended consequences. The consequences of the changes in the pension system for farmers have been already mentioned. With regard to childcare policy, the initial level in the take-up of extended leave dropped significantly, as the level of the means-test was not being adjusted to account for any increase in salaries. This approach of 'manual steering' of social policy continued both in the communist era, but also during the transition.

\section{PERIOD 1987-1989}

The years preceding the transition in many respects resembled the previous period. However, the scale and scope of the economic crisis was immense. In these dire conditions, a reform aimed at splitting the insurance fund was conducted. The main task was to improve the quality of benefits and simultaneously, bring financial stability to the system. This aim was to be reached by the separation of the social insurance fund from the state budget, which was to take over the responsibilities of the pension fund. However, the farmers' fund remained a separate entity. The underlying purpose of the new fund was to gather and invest the surplus, guaranteeing long-term sustainability. However, the technical details of these operations were not specified.

\section{SUMMARY OF THE SOCIALIST PERIOD}

The sections above have demonstrated the multifaceted development of social policy in Poland since the end of World War II.

The resources of the social insurance funds were destroyed during the course of the World War II. However, in the immediate war years the funds (whose organization was restored to the pre-war form) displayed a financial surplus. Continuing the pre-war strategy of investment, any surpluses were invested by the funds in a variety of ways which supported the reconstruction of the country. Urszula Prasznic estimates that the guarantees obtained this way amounted to $5 \%$ of the total earmarked expenditures of the state, with the percentage growing in the following years (Prasznic 1989). 
In 1949 the organization of social insurance was changed when it became included in the general economic plan and the investment of financial surplus was abandoned. What followed was the calculation of contributions at a level that met current expenditures, with the surplus located in the state deposits. With the 1951 change, the inclusion of the social insurance funds was finalized. On average, the difference between contributions and expenditure was positive. After 1968, when a separate fund was established, the surplus was located in the central bank (the extent of the surplus ranged from $2.3 \%$ of yearly income in 1971 to $20 \%$ in 1985) (Prasznic 1989).

In the immediate post-war years, the emphasis was put on short-term benefits, such as sickness benefits and upgrading their level to that of privileged groups (state employees). The lack of employment and contribution records in long-term insurance meant that the benefits were calculated according to the white-collar system rules, but this was just a reference point, as eventually benefits became flat rate. Soon however, new rules were introduced that took into account a person's income category. Due to its rigidity, this solution caused a fast deterioration in the levels of pensions. The population coverage increased, as agricultural workers (but not private farmers) became eligible for sickness, maternity and pension benefits between 1946 and 1953.

The immediate post-war years included several measures that were both a continuation and extension of, but which also saw reduction in, social rights. The extension of coverage to the agricultural population was a great step forward. However, In Poland - where private farmers obstructed collectivisation for some time - their risk coverage was smaller than in the case of other major social groups. By the beginning of the 1950s, communist rule had been consolidated and by the middle of the decade Sovietisation had reached its peak. As mentioned above, some of its elements failed in Poland, the most important of which being the collectivisation of agriculture. The direct effects of the worker mobilisation in Poland were less visible than elsewhere. However, in certain areas the break-up with the Soviet dogma and the real increase in benefits were felt. Organizationally, it was the case of social security management by trade unions which appeared to be incapable of performing this function. ZUS took over this responsibility, which at that time was a real deviation from the Soviet model.

In the 1970s, Polish social policy continued to focus on a better link between long-term benefits and a person's previous income and length of employment. Previous employment categories had been removed and a single method for the calculation of benefits' was introduced. This in turn significantly improved benefits to workers with the lowest salaries. Simultaneously, several increases in nominal benefits took place so that their real level could be sustained. 
In order to maintain financial stability, the contribution split was introduced. This was accompanied by the detachment of the pension fund from the state budget. In terms of coverage, more occupational groups became insured, notably private farmers.

It was the mid-1970 that saw a significant reorganization and consolidation of the social security system. Changes seemed inevitable in light of the number of regulations that made the social policy systems very complex, but also in light of the economic crisis in the region.

The developments in Poland were very profound. Continuing a trend from the past, the benefits were raised several times, and the right to increase them was moved to the executive. The increases focused on the oldest pensioners, as it was this group which suffered most because of the deteriorating quality of benefits. One of the most important developments in the whole post-war period concerned the introduction of the full-range social policy coverage for private farmers. This task was accomplished in 1977, with the introduction of a separate old-age pension system for this group. In part, the system was based on the farmers' contributions, but mainly by state subsidies. The level of a benefit depended on the extent of agricultural production and was generally lower than the level of benefit in the general system, but given the low level of contributions, proved attractive for farmers.

The beginning of the 1980s saw the rise of the first independent trade union, which in terms of membership came to outnumber the 'official' unions. The rulers, concerned with losing their legitimacy, decided on a series of policy changes so that the proposals of the opposition would be invalidated. Paid maternity leave was introduced for all, including farmers. In the field of pensions, several privileges were offered to various groups such as miners, railway and steel industry workers, and teachers. The privileges mainly related to early retirement. Simultaneously, the government planned to introduce full financial autonomy of the pension fund from the budget although this aim was not fulfilled. In terms of the levels of benefits, several improvements in the nominal values took place. However, they were valid only for short time because the real value of benefits was decreasing fast due to high level of inflation at the end of the 1980s.

\section{TRANSITION}

\section{TRANSITION: A NEW CONTEXT FOR OLD-POLICY MAKING}

The transition from the planned economy and authoritarian rule to some form of market economy and democracy was - and continues to be - a profound and long-ranging process. 
The transition should not, however, be seen as a replacement of old institutions with the new. Rather, it has been a gradual and, as yet, unfinished process. This section demonstrates that the development of social policy after the breakthrough of 1989 displayed a number of continuities with the previous periods in spite of a completely different political and economic context. Among these factors, unemployment was a new phenomenon even though some authors argued it already existed in the socialist era in a 'hidden' form (Żochowski 2003). It was expected that unemployment was a 'necessary cost' of the transition to a market economy; nevertheless, the speed and scale of unemployment was a shock to many policy makers.

Some authors (cf. Szumlicz 2004) distinguish two waves of reforms: the first focused more on basic economic and political issues, and the second dealt with more detailed issues, such as the pension system. Of course, this does not mean that during the first years of the transformation social policy was not changed. On the contrary, the transition itself brought about a particular risk unknown since the pre-war era and which had to be dealt with: open unemployment. Also, the pension system continued its differential treatment in spite of several amendments that had been introduced in the 1980s and before. This similarity in the response to problems that can be drawn between the transition stage and that of the socialist era is dealt with in more detail below.

The performance of long-term benefits, such as disability and old-age pensions, were the subject of numerous changes which affected almost every aspect of the functioning of the system. As mentioned in the introduction, the developments can be divided tentatively into two major phases. The first one, which lasted until the mid-1990s, was characterised by a number of adjustments within the existing system. The second one, preceded by a number of discussions, focused on the preparations for the reform of the existing system and the implementation of such reforms. The division between these two phases is somewhat blurred, as there had already been discussions (as well as some important measures concerning the conditions of retirement) in the 1980s. For the sake of clarity, this section maintains this rough division between the two phases. As in the previous chapter, the emphasis is put on the parameters of benefits as well as on issues related to the organizational structure, financing and management of the old-age pension scheme.

\section{PERIOD 1989-1991}

Polish social security entered the 1990s as a complex and segmented system, with no checks concerning the level of benefits. Two main schemes existed: 
for salaried workers and for farmers. Within the former scheme for salaried workers, there was a further differentiation of the rules. On top of that, there existed several specific regulations allowing for early retirement that were not stipulated in the general rules. The specific regulations were introduced in the 1980s and it is estimated more than a half of all those who have retired since 1989 have followed this 'specific path' (Wyczańska 1990).

\section{ORGANISATION AND FINANCING}

Organizationally, the Polish social security system entered this period as a complex and fragmented set of institutions as it consisted of 15 segments (Dąbrowska 1991). There was the main fund, the Social Insurance Fund, which was responsible for providing old-age and disability pensions, family and maternity benefits, birth allowances and, at least partially, sickness benefits and funeral aid. The Fund was managed by the Social Insurance Institution and had been detached from the state budget since 1987 (Golinowska 1994).

One important feature which proved essential for the acceptance of system reform was the fact that the Director of ZUS should be a political appointee. In practice, it meant that after every election or nomination of a new prime minister or even minister responsible for social policy, the Director of ZUS was replaced by someone else. Polish politicians perceived ZUS quite traditionally as an essential political resource which could be used without any hindrance from their social partners. In fact, the control of social partners was through political channels (as both major trade unions - Solidarność and the OPZZ (Ogólnopolskie Porozumienie Związków Zawodowych, or 'the All-Poland Alliance of Trade Unions') - were the basis for centre-right wing and post-communist social democratic parties, respectively).

From 1989 to 1992, public spending decreased in real terms. However, in terms of its nominal value it grew proportionally from $15.3 \%$ to $22 \%$ of GDP. The budget subsidies to social security increased almost 4 times between 1988 and 1992 from 7 to 30 per cent. These subsidies were mainly targeted at old-age and disability pensions, not only because of the growth in the number of beneficiaries but also due to the introduction of indexation of benefits. It should be noted, however, that in the mid-1990 the Fund returned a surplus.

Since 1991 a separate fund has existed for the insurance of farmers (the Pension Fund for Farmers). It has been managed by the Management Board of Agricultural Social Insurance. The Farmers' Fund has been heavily subsidised as when in 1992 contributions could finance only $6 \%$ of its expenditure. 
Both funds suffered from growing contribution evasion. In around 1992 the contributions decreased by $7 \%$ in the general workers' fund, while the decrease was double in the case of the farmers insurance.

The issue of the causes that necessitated the budget subsidies for the social security funds is especially important in the light of the facts presented above and this is usually linked to the extraordinary conditions concerning retirement at this time. Some authors (Vanhuysse 2006) argue that it was the lax regulations aimed at easing the social situation (mainly unemployment) which caused the 'abnormal pensioners boom' and, in turn, excessive spending. Stanislawa Golinowska disentangled two aspects of this phenomenon: on one side the 'irregular' early pensioners, and on the other the issue of spending (state subsidies). As the author demonstrates, the number of retiring persons was indeed higher than previously, especially in 1991 (979,000 compared to 494,000 in 1990 and 164,000 in 1989), but after this date the number started to drop (just 251,000 in 1992). More important were the number of early retirees on the basis of special regulations. There were 500,000 new retirees in 1989-1992. However, Golinowska shows that on the basis of the regulations introduced between 1989 and 1991, only 14\% of those benefits granted in cases of disability and old age were related to early retirement provisions (Golinowska 1994). Of more significance were the one million retirees who were granted benefits on the basis of the regulations that had already been introduced in 1982 and 1983.

Golinowska and Zukowski (2002) provide an overview of the financial situation of both the salaried workers fund and that of the farmers. As already mentioned, the fastest growth in subsidies was noted between 1989 and 1993 (when subsidies doubled). What is especially striking is the degree to which the farmers' insurance was subsidized from the budget. After an initial decline, from 1995 the subsidies totalled more than $50 \%$ of all support provided from the budget. One may argue that in structural terms it was this that put the greatest burden on the budget. This became especially visible when measures aimed at 'cleaning' the Social Insurance Fund (reducing its complexity, making its functions more transparent and moving some of its responsibilities to other agencies) were implemented in 1994. From 1995 on, spending on pensions decreased, both because of the growth in the economy and as a result of the reorganisation - the 'cleaning' - of the Social Insurance Fund. 
TABLE 9: EXPENDITURE OF THE SOCIAL INSURANCE FUND (FUNDUSZ UBEZPIECZEŃ SPOŁECZNYCH, FUS) AS A PERCENTAGE OF GDP IN THE 1990S.

\begin{tabular}{|l|l|l|l|l|l|l|l|l|l|l|l|}
\hline $\begin{array}{l}\text { Year/spend } \\
\text { ing item }\end{array}$ & $\mathbf{1 9 9 0}$ & $\mathbf{1 9 9 1}$ & $\mathbf{1 9 9 2}$ & $\mathbf{1 9 9 3}$ & $\mathbf{1 9 9 4}$ & $\mathbf{1 9 9 5}$ & $\mathbf{1 9 9 6}$ & $\mathbf{1 9 9 7}$ & $\mathbf{1 9 9 8}$ & $\mathbf{1 9 9 9}$ & $\mathbf{2 0 0 0}$ \\
\hline $\begin{array}{l}\text { Expenditur } \\
\text { es on cash } \\
\text { transfers, } \\
\text { including: }\end{array}$ & $\begin{array}{l}9.64 \\
\%\end{array}$ & $\begin{array}{l}14.23 \\
\%\end{array}$ & $\begin{array}{l}16.30 \\
\%\end{array}$ & $\begin{array}{l}15.84 \\
\%\end{array}$ & $\begin{array}{l}16.12 \\
\%\end{array}$ & $\begin{array}{l}13.67 \\
\%\end{array}$ & $\begin{array}{l}13.04 \\
\%\end{array}$ & $\begin{array}{l}13.71 \\
\%\end{array}$ & $\begin{array}{l}12.79 \\
\%\end{array}$ & $\begin{array}{l}12.34 \\
\%\end{array}$ & $\begin{array}{l}11.4 \\
5\end{array}$ \\
\hline Old-age & $\begin{array}{l}3.37 \\
\%\end{array}$ & $\begin{array}{l}5.51 \\
\%\end{array}$ & $\begin{array}{l}6.55 \\
\%\end{array}$ & $\begin{array}{l}6.67 \\
\%\end{array}$ & $\begin{array}{l}6.98 \\
\%\end{array}$ & 6.58 & $\begin{array}{l}6.43 \\
\%\end{array}$ & $\begin{array}{l}6.48 \\
\%\end{array}$ & $\begin{array}{l}5.75 \\
\%\end{array}$ & $\begin{array}{l}5.67 \\
\%\end{array}$ & $\begin{array}{l}5.64 \\
\%\end{array}$ \\
\hline Disability & $\begin{array}{l}2.47 \\
\%\end{array}$ & $\begin{array}{l}3.39 \\
\%\end{array}$ & 3.85 & $\begin{array}{l}3.87 \\
\%\end{array}$ & $\begin{array}{l}4.06 \\
\%\end{array}$ & $\begin{array}{l}3.80 \\
\%\end{array}$ & $\begin{array}{l}3.65 \\
\%\end{array}$ & 3.65 & $\begin{array}{l}3.15 \\
\%\end{array}$ & $\begin{array}{l}3.37 \\
\%\end{array}$ & $\begin{array}{l}3.25 \\
\%\end{array}$ \\
\hline Survivors & $\begin{array}{l}1.12 \\
\%\end{array}$ & $\begin{array}{l}1.53 \\
\%\end{array}$ & $\begin{array}{l}1.89 \\
\%\end{array}$ & $\begin{array}{l}1.94 \\
\%\end{array}$ & $\begin{array}{l}2.08 \\
\%\end{array}$ & $\begin{array}{l}1.71 \\
\%\end{array}$ & $\begin{array}{l}1.96 \\
\%\end{array}$ & $\begin{array}{l}1.99 \\
\%\end{array}$ & $\begin{array}{l}1.70 \\
\%\end{array}$ & $\begin{array}{l}1.76 \\
\%\end{array}$ & $\begin{array}{l}1.75 \\
\%\end{array}$ \\
\hline
\end{tabular}

Source: (Chłoń-Domińczak 2002: 105)

\section{PENSION BENEFITS}

The first steps taken by Polish policy makers were aimed at mitigating some political-social assumptions which had laid behind the pension system during socialist era. Accordingly, as early as in October 1989 the government granted a flat-rate ( 30 thousand zloty) supplement to old-age pensions. Simultaneously, there was ongoing work on the issue of decreasing the real level of benefits. The centre of the work laid in the Ministry of Labour and Social Policy, but elements of the bill were proposed by an opposition party, the Alliance of the Democratic Left. From 24 May 1990, work performed before 22 ${ }^{\text {nd }}$ July 1944 (the date when the July Manifesto presenting the blueprints for socialist Poland was announced) became treated as a factor defining the level of benefits. The relation between wages and benefits was established (a minimum benefit was to be equal to $35 \%$ of an average salary) as well as the indexation mechanism for old-age pensions. The benefits were to be indexed four times a year, based on the growth of an average salary, with the increase triggering the indexation no smaller than $5 \%$.

The partial solution to the different 'pockets' problem took place on 14 December 1990 and regulated the level of benefits received by the oldest pensioners ( 80 years or over). This regulation adjusted the level of the benefits in accordance with an average salary. As increases in benefits during the socialist era were based on ad-hoc principles and concerned mainly newly-granted (entry) benefits, there existed a big discrepancy between benefits granted in various years. As a result, the benefits granted a long time ago were disproportionally lower. 
Thanks to the 1990 regulation, the benefits were increased significantly, which for the concerned age group meant levelling the structure of benefits (Rymsza 1998).

In the meantime, due to a defeat in presidential elections, the cabinet of Tadeusz Mazowiecki resigned. The new cabinet, led by Jan Krzysztof Bielecki, in principle continued the activity of predecessor. The new Prime Minister submitted a bill that was intended to simplify and put the social security system in order, with the underlying long-term aim of reducing the level of social security contributions. The bill was suspended by the parliamentary commission, which ultimately gave the green light to a version limited only by the question of benefits valorisation.

This is one of the most important changes in the early period of transformation as it moved the formula of benefits closer towards the insurance principle. The law of October 1991 strengthened the link between the length of contributory period and (partially) the level of contributions. The role of the noncontributory periods was diminished and the level of the highest benefits was capped. After this regulation, the basis used for the calculation of a benefit could not exceed $250 \%$ of an average salary. The law distinguished between the flat rate amount common for all benefits and a variable part dependent on employment history. The flat rate equalled $24 \%$ of an average salary in the quarter preceding a quarter when the last indexation of benefits took place. With regard to the variable component, it depended on the length of contributory period and level of income. The reference income was capped at $250 \%$ of an average salary, as mentioned, while the reference period used for the calculation of benefits was to be gradually extended to 10 years until 1999 (Golinowska and Ochocki 1994). Finally, the law regulated the question of work activity during retirement. Work activity resulted in decreasing the level of a benefit when the income coming from this source exceeded $60 \%$ of a base amount, while if reaching $120 \%$, resulted in the suspension of a benefit.

Once again, the political scene of Poland was reshuffled at the end of 1991. On 27 October 1991, the second set of elections took place that year. Due to the electoral rules, the new Parliament was very fragmented as it consisted of almost 30 parties. The fragmentation of the political based contributed to the volatility of governments. In terms of social policy, the short-lived right-wing government of Jan Olszewski aimed at restricting access to benefits; however, a bill was not sent to parliament. This was due to opposition in parliament, both from the opposition parties and from the pensioners' lobby. The government was also opposed to the law from October 1991. 
Due to the worsening economic situation and the budget crisis following, the government decided to undercompensate benefits. The first step in this direction involved rising the threshold triggering indexation from $5 \%$ to $10 \%$ in February 1992. In the budget bill for 1993, the indexation coefficient was decreased from 100 to $91 \%$. This decision led to fierce protests from the trade unions. One of them, Solidarność, being part of the coalition platform demanded a non-confidence vote and contributed to the collapse of the government (Golinowska 1996). Importantly, the reduced base was also used for calculating newly-granted benefits (as the calculation base had been reduced to $91 \%$ of an average wage) (ChłonDomińczak, Góra et al. 1999).

Also in 1992, pensions became subject to Personal Income Tax in line with taxing wages. The level of benefits was raised accordingly so that their real level would remain unchanged. As a result, the nominal spending on pensions increased from 14 to 16\% from 1991 to 1994 (Chłoń-Domińczak 2002).

From 1993 on, the situation of the economy slowly improved. This structural condition - combined with the victory of the post-socialist party (the SLD) which entered into a coalition with the agrarian party (PSL) - made it possible for an expansion of the Polish welfare state to be reconsidered. The policies were not restricted only to the regulations of benefits but, according to the ruling parties, they also included organizational changes and brought more cohesion to the social security budget. In line with the coalition agreement, the Ministry of Labour was taken by SLD.

In the first months in power the Minister of Social Policy, Leszek Miller, returned to the 'manual steering' tradition. This took the form of ad-hoc adjustments of policy parameters. In order to appeal to state employees in the police and the military, the ministry introduced more favourable principles of benefits valorisation. This meant a clear break with the principle of horizontal solidarity (Rymsza 1998).

Because of electoral promises made from the beginning of 1994, the level of minimum benefits was raised from 35 to 39 percent of an average salary. The increase was reinforced by the full indexation of this group of benefits, while for other provisions the indexation basis equalled 93 percent. For the budgetary year 1996 , the government decided to introduce indexation based on a changed rule: a $2.5 \%$ growth in a real wages was assumed, which resulted in the lack of indexation in the last quarter of 1995. The Constitutional Tribunal questioned this move, and ordered an increase of benefits. Also, in 1997 a new mechanism of indexation, based on price changes, was planned for the future. In 1994 the government 
increased the reference amount used for calculating new pensions from 91 to $93 \%$. The shift to another mechanism of indexation was questioned by President Lech Walesa. The President had issued an official query by the Constitutional Tribunal, which confirmed the necessity of changes: 'Taking legislative action leading to radical restructuring of the pension system, and carrying out social consultation on the proposed changes sufficiently justifies the introduction of the special indexation mechanism in 1996' (in Chłoń-Domińczak 2002, p. 104).

Starting from 1994, the so-called 'uniform' benefits were removed from the Social Insurance Fund. It was a part of a bigger process of 'cleaning' the social insurance system. The payment of benefits to military personnel became the responsibility of the Ministry of Defence in 1994, while the Ministry of Interior was responsible for those of police. This change made the Social Insurance Fund smaller, but at the same time, more transparent (Czepulis-Rutkowska 1996). In 1994, more generous regulation concerning benefits for miners was introduced. Other aspects of 'cleaning' the social insurance system included moving family allowances to social assistance.

Another step in this direction concerned pre-retirement benefits. Early retirement benefits, the argument went, were a functional equivalent of compensation for middle-age unemployed. Therefore, with the regulation from 14 December 1994, the payment of pre-retirement benefits was moved to the Employment Fund budget (Jędrasik-Janowska 1997).

I should mention that the Polish Constitutional Tribunal played an important role in the early transition with respect to shaping social policy. However, its rulings have not followed a consistent pattern. One the one hand, the Tribunal emphasized the protection of acquired social rights, which was applied for example in the case of indexation ruling (that forced the government to restore the $100 \%$ basis) or branch privileges. On the other hand, in other rulings the Tribunal emphasized the need for social policy adjustments in tough economic situations in which the quality of social policy was at risk of deterioration, and even went so far as to point out the necessity of a fundamental reform of the social security system in Poland (Oniszczuk 1999).

\section{DISCUSSION CONCERNING REFORM AND EARLY PROPOSALS}

The discussion concerning the need of more fundamental reform started as early as the beginning of the 1980s. As mentioned earlier in this chapter, some changes did take place in that period although they should be seen more as corrections to the existing system rather than as part of a fundamental change. As Tadeusz Szumlicz argues, the debate concerning a more profound change was 
launched in 1991 when the recalculation of benefits mentioned above took place. According to Aleksandra Wiktorow, who was then the deputy minister responsible for the pension affairs, the reforms of 1991 laid down the fundaments for further action (Szumlicz 1999).

With the publication of another programmatic document The Reform of Social Insurance. Opportunities and Threats. Building a system in May 1993, the Ministry of Labour and Social Policy presented a strategic document outlining the threats concerning the social security system. The document presented the issue of demographic ageing as the main problem the Polish pension system would have to face. As Rymsza stresses, this publication marked a shift in thinking about social policy reform from that which concentrated on difficulties rooted in the socialist past to the threats and challenges of the future. However, this does not mean that the difficulties and the policymaking style rooted in past would not continue to have a heavy influence on future reforms.

The discussion gained momentum in 1995 during SLD-PSL coalition government. In the remainder of its term in office, the government presented parliament with three reform proposals. These started with the proposal put forward by Miller. A second, widely-consulted proposal was presented by Andrzej Baczkowski in January 1996. The third proposal, accompanied by three bills, was presented in May 1997. The 1997 reform document was produced in a relative isolation, especially compared to the 1996 document (Rymsza 1998). This section outlines the main features of several of these presented proposals and traces the processes that contributed to the selection of proposal that was ultimately implemented.

A number of pension reform proposals appeared from the beginning of the 1990s. Some of them focused on a radical change of the pension system that would significantly alter the financing and organization of the system and influence its redistributional characteristics while others were more concerned with modest reform attempts. In principle, the proposals developed by, on one hand, the Ministry of Finance and, on the other, by the Ministry of Labour and Social Policy represent these very different positions.

Chronologically, one of the first proposals calling for reform of the pension system was presented by Marian Winiewski, a scholar affiliated with the Institute of Labour and Social Affairs, in 1991. The reform proposal, rooted deeply in the social democratic tradition, stressed the role of state in the redistribution of wealth and outlined a three-tier organization of social insurance. According to the author, the first component was seen as a flat rate citizenship income available to every 
retiree, equal to the cost of living. This benefit was expected to replace income from social assistance and the minimum pension for both farmers and salaried workers. The second tier was to provide a tenure-based component, calculated as a percentage of a person's last pre-retirement salary $(20 \%)$ and length of service $(2 \%$ for each year in employment). The last element was voluntary, contribution-based tier. The level of combined benefit from the system was proposed to reach $90 \%$ of a previous salary and to be achieved through significant subsidies from the state budget (Rymsza 1998).

Diametrically opposed to this was another proposal from 1991 prepared by two high-level ZUS officials, W. Topinski and M. Wisniewski. The authors, inspired by the experience of Chilean pension system, maintained that the primary aim of any pension system reform is the financial stability of that system, but also that the existence of a social security net should not harm the self-initiative of citizens. In their opinion, the feasibility of the PAYG systems in ECE should be questioned.

The basic assumptions of the reform concerned the partial privatisation of the Social Insurance Fund, its self-financing and consequently a lowering of the level of benefits. The proposed organisation of the system was as follows: the first tier would provide retirees with a basic benefit but which would be much lower than the social minimum level, while the second voluntary tier would be responsible for any additional income. Following this logic, the redistributory role of the pension system would be limited to a minimum. This proposal was heavily criticised exactly because of the lack of any mechanism enhancing social solidarity. However, some aspects of this proposal (e.g. the separation of funds and some aspects of the administrative framework) were used in a governmental proposal implemented few years later.

The third proposal was worked out jointly by the Social Policy and Health Committee and the National Economy Committee of the higher chamber of parliament, the Senat. Work on the reform proposal started as early as 1991, but gained momentum from mid-1992. The proposal assumed a structural reform of the social security system through the creation of three separate insurance funds for different risks (disability/retirement, accidents and sickness) and related reserve funds. Each fund would be earmarked with the Social Insurance Institution being the self-governing body supervised by the Ministry of Labour. The proposal was submitted as a bill so that it would be open to consultation with experts, the Social Insurance Institution and other relevant ministries. The project, however, lacked the impact assessment of the proposed reform, and was considered as more of a impetus for more thorough governmental engagement in reforming social 
security. Altogether, further development of the proposal was cancelled in 1993 when Parliament was dissolved (Rymsza 1998).

It was two years after that election that the government came up with its own policy proposals. Due to the political conditions at that time (the ruling SLD party had a majority in both chambers of the Parliament and, soon afterwards, a sitting president who also came from the SLD), the government had exceptional freedom when it came to pursuing its own political and social goals. It was therefore the government which took the initiative and presented several policy proposals. As mentioned, the beginning of the term was characterised by several ad-hoc measures, resulting in a partial reversal of the 1991 regulations. Only after this ad-hoc period did the government begin more conceptual work on the reform.

The first proposal was issued by the Ministry of Labour and Social Policy in April 1995. Importantly, at that time the Minister of Social Policy was the leader of the SLD, Leszek Miller. This situation put Miller in a favourable position in relation the second important player, the Ministry of Finance, led by Grzegorz Kołodko. From the beginning, the project had been the subject of conflict between Ministries of Labour and of Finance. This conflict concerned the mechanism of valorisation and expected budgetary effects. However, the project was accepted by the Council of Ministers and was then subjected to consultation by social partners. The project assumed the introduction of a social security benefit granted to every citizen older than 65 years, the separation of three distinct funds for different social risks, PAYG financing with any surplus invested in the capital market, and the financing of benefits (which up to then had been financed from the Social Insurance Fund) from the state budget. The system would consist of four elements: the flat rate social benefit, basic insurance, additional voluntary insurance and some form of family benefits. Importantly, the social benefit would be equal to the lowest possible standard of living, with a possibility of further lowering its quality.

The second version of the proposal was published in December 1995. This version was submitted to and debated by Parliament in April 1996. Compared to the previous version, the social benefit component had been removed. According to this proposal the system comprised three elements: basic state insurance, private saving funds and commercial programmes offered by life insurance companies. This proposal clearly was born of a individualistic and privatised approach to social security. The proposed system would offer benefits determined solely by the period and level of contributions paid. For retirees in dire financial need, the project proposed the provision of complementary resources from the social assistance scheme. As several observers noticed, the second proposal was rather eclectic because, while drawing on the previous draft, it also made several links to 
a similar document proposed by the Ministry of Finance. This latter proposal is presented below.

The existence of two strong centres of influence led to a stalemate for a considerable period of time. This lasted until February 1996 when the balance of power changed as a result of political change. With a new Prime Minister, Włodzimierz Cimoszewicz, Miller was moved to the Ministry of Interior, and Andrzej Bączkowski became Minister of Labour. In order to streamline the work on the pension reform, a new office was created. The Plenipotentiary for Social Security Reform was responsible for drafting the governmental version of a proposal. It was the Minister of Labour, Andrzej Bączkowski, who became the first plenipotentiary. Bączkowski was central in the early phase of the pension reform: he was an apolitical bureaucrat who had been involved in the 'early' Solidarność (in the 1980s), but also became renowned for his negotiation skills (Hausner 2001). He appointed several bureaucrats who had also had a background with Solidarity and who at this time aligned themselves with the Christian democratic Unia Wolności - the 'Union of Freedom' Party (Mueller 1999). Following Bacczowski's sudden death the office was taken by Jerzy Hausner, chief advisor to the Minister of Finance, Kolodko. There was a series of negotiations between him and Tadeusz Zieliński, who strongly opposed the privatisation of pensions.

Bączkowski had negotiated several issues with major trade unions in the Tripartite Commission, established in 1994. However in order to avoid political pressures exerted by different parties (being closely linked to trade unions), Bączkowski proposed establishing an informal working group within the Commission. The group consisted of social policy experts from all three sides and screened proposals to be sent to the Commission for deliberation (Nelson 2001).

The Ministry of Finance organized its own team to work on the pension reform, the Social Insurance Reform Group, led by the neoliberal economist Marek Mazur, who was Kołodko's advisor (Orenstein 2008). The agenda of the Group was driven more by the fiscal (budget stability) and macroeconomic (economic growth, fighting inflation) considerations than anything else. Indeed, it was economic growth that was perceived to be the sole factor which contributed to a high level of social benefits. The proposal mainly consisted of a critique of existing social insurance schemes. As Rymsza notices, the proposal was less a policy document concerned with the question of how to reform Polish insurance and more of a programmatic document disseminating the privatisation approach (Rymsza 1998). The proposal diagnosed the problems of the existing social insurance system: branch privileges, early retirement, lax guidelines concerning invalidity, how invalidity benefits were too high compared to the level of old-age 
pensions, and the approaching unfavourable demographic situation. At the same time, possible solutions to these problems were put forward: the introduction of an elastic retirement age, a change of the multiplier of non-contributory periods, making early retirement rules stricter, switching to price valorisation, and a change in the rules guiding the granting of invalidity benefits.

According to the authors, after these stabilisation measures the system would be ready for a more profound reform. As Rymsza argues, the measures proposed for the first stage would be sufficient for providing the system's longterm sustainable operations and had been raised several times by number of social security experts. The proposal went further, however, and advised separating the old-age pension scheme from social security so that it could be privatised. The new scheme would consist of three tiers, with the first tier being basic insurance (initially $35 \%$ but later $20 \%$ of an average wage) and contributions paid by employers. The second tier would be organised as mandatory additional insurance, with contributions paid by employees. The insurance would be provided by a variety of entities. These two tiers would be complemented by a third, voluntary insurance tier. With the pension scheme constructed in this way, the first tier would be burdened with redistributional tasks, while private companies would be expected to invest the remainder of contributions with no such responsibility.

However, in parallel to governmental and parliamentary studies, some non-governmental bodies created their own proposals. In May 1996 the trade union Solidarność presented its own reform document. It stood in opposition to the proposals of both the Ministry of Finance and that of the Ministry of Labour and Social Policy. The proposal followed a classical Bismarckian approach to social insurance with some market elements. Again the system would have three tiers. The first one would be defined as a mandatory social insurance benefit based on the principle of repartition with an initial 50/50 split in contributions between employer and employee (later the employee's contribution would diminish). The benefit would consist of a flat rate component and a dynamic one, depending on the level of an individual's salary and length of contributory period. The second tier would be operated as an additional, funded scheme co-financed from the resources coming from privatisation. Finally, the possibility of additional, voluntary schemes would be left open. It is important to reiterate here that in this project a significant role was attached to privatisation as a way of financing the transitory period.

Two other proposals were presented when the government was already advanced with its own work. First, one came in spring of 1997 from the opposition 
Unia Wolności party. This project went furthest when it came to the privatisation and individualisation of pensions: it assumed a strong link between contributions and benefits, even in the first tier. The second tier would be based on mandatory private pension funds, while the third tier would be of a complementary and voluntary character. It was assumed that total contributions would decrease by $10 \%$, which was in line with general principles of the reform: lessening the tax burden should contribute to economic growth and thus, increased welfare. The second proposal came from the independent think tank CASE (Centrum Analiz Społeczno-Ekonomicznych) and assumed a multitier structure of the system, with a voluntary second tier however.

Stanisława Golinowska (Golinowska 1999) summarizes the different initiatives by grouping them into three trends. The first trend was based on sociopolitical considerations and was typical for early period of transformation in Poland and focused on the situation of retirees. The draft presented by the Ministry of Labour and Social Policy in 1995 reflected such values. The second trend emphasized the fiscal and cost issues the pension system was causing. These considerations could be seen the publication of the 1993 programmatic document by the Ministry of Labour and Social Policy. Such calls became even stronger after increases to minimum pensions in 1994, which in turn triggered the growth of other benefits as their level was linked to the minimum pension benefits. Finally, the third trend focused on financial and capital questions. One the earliest proposals along these lines was that presented by Topinski (the president of ZUS in 1991-1992) and Wisniewski in 1992, following the Latin American model. As already discussed above, the idea of a fully-funded system was criticised on several grounds such as its lack of a solidarity principle, the high operational costs, and significant transition costs. The last problem became the main brake, especially when combined with the protection of acquired rights which was stressed several times by the Constitutional Tribunal. Therefore, the existing mutually reinforcing system prevented the pension system from being radically changed: radical reform which assumed a shift to full funding was not possible because of property rights, but also the costs it would impose on the state budget. Such a shift would mean additional costs of an extra $5 \%$ of GDP for several years.

However, the idea of switching gradually to private funding gained acceptance in spite of the high budgetary costs. The growth in the acceptance for such funding coincided with the World Bank's publication 'Averting Old Age Crisis' (World Bank. 1994). The proposal of Mazur of 1995 reflected the World Bank's approach, but at the same time raised controversies (Golinowska 1999). First, several experts (who were in accord with public opinion) opposed the idea of 
the first tier providing a flat-rate civic pension with a replacement rate of $20 \%$. Second, the obligation of payment contributions to the second tier was questioned. Golinowska explains these objections: when it came to the provision first point, opinion polls showed that Polish society was more in favour of principles of insurance (or the Bismarckian model), than equal provision for everybody (as in the Beveridgean model). The second point was criticised by several commentators as it would lead to the introduction of too much state involvement necessary for its regulation, supervision and control.

Interestingly, support for the reform came from the Solidarnośc trade union. As outlined above, the trade union supported the introduction of a mandatory funded element and presented its own way of financing the transition. According to Golinowska, Solidarność was acting strategically so as to diminish the role of the post-communist government. Another factor was the possibility that trade unions would establish their own pension funds. These factors also explain why the reform was continued after the elections in 1997 when Solidarność was one of the parties in the new government.

What is essential to highlight here is the complete neglect of the farmers' scheme. After clearing the salaried workers' scheme from auxiliary tasks which had contributed to the financial imbalance of social security, the main part of the budget subsidies went to the farmers' scheme. Given the difference in scale, the relative subsidies to the farmers' scheme outnumbered the general workers scheme a few times over.

\section{THE IMPLEMENTATION OF THE “SECURITY THROUGH DIVERSITY”}

\section{REFORM PROPOSAL.}

The first consistent version of the 'Security through Diversity' proposal was presented in February 1997. The proposal was changed several times (in May and June the same year). The project was first presented to a public audience (consisting of mainly experts) in May 1997 during the Institute of Public Affairs conference. The proposal was outlined by the main figures of the Plenipotentiary Office, Michal Rutkowski (Director of the Office and the World Bank expert on leave) and Marek Góra. The authors maintained that their reform proposal included elements from the projects presented by the Ministry of Labour and Social Policy, the Ministry of Finance, the Solidarność trade union, and the Institute of Labour and Social Affairs. However, reference to the abovementioned proposals was restricted to the multiplier construction of the scheme, rather than concrete solutions. The proposal was finally sent to Parliament that was hurried by the coming elections (September 1997). 
As mentioned, the proposal was discussed and accepted in the tripartite negotiations in April 1997. Interestingly, both the main trade unions, Solidarność and the OPZZ, accepted the proposed bill, a fact which might be striking given its redistributional consequences. The standpoint of Solidarność seems clearer as it had made its own reform proposal which also opted for partial privatisation. Within the OPZZ, however, there was a clash between supporters and opponents of the governmental proposal. The supporters of the reform ultimately won, convinced by some open-ended solutions introduced in the proposal (such as further negotiation of retirement conditions for certain groups in the Tripartite Commission). In the case of OPZZ it is also important not to overlook its very close links to the ruling party at that time, the SLD. There did not appear to be any resistance on the side of ZUS either. This had to do with the practice of making political appointments for the post of Director of ZUS. Under the rule of the leftagrarian coalition, the post was held by Anna Bańkowska, a prominent politician of the SLD (Hausner 2001). This coalition in a way weakened the opposition of the more conservatively oriented Ministry of Labour.

The proposal outlined a three-tier structure of the pension scheme. The first tier is based on the reformed ZUS. Generally, the eligibility criteria became stricter, and the scheme moved from a 'defined benefit' to 'defined contribution' formula. The stipulated minimum retirement age is 62 for both sexes, with no indication of retirement age in general. The new system covers individuals born after December 1968. The split in contributions between the first and the second tier is $80 \%$ and $20 \%$, respectively. Employers and employees participate equally in the payment of contributions. The contribution base is limited: the minimum base cannot be lower than a minimum wage, while the upper level is capped at $250 \%$ of the average salary. The contributions to both tiers are not taxed, while the benefit from the third tier is.

The benefit formula is as follows. In the first tier, the benefit is a function of the sum of contributions paid throughout career divided by life expectancy at the age of retiring. The latter factor is equal for women and men. The system guarantees a minimum benefit financed from the state budget if the collected contributions are not sufficient. The minimum benefit is equal to approximately $28 \%$ of the average wage and can be granted at the age of 65 if a person contributed to the system for at least 25 years. With such a construction of this benefit, one should agree with Żukowski (Żukowski 1999) who prefers to call it a guarantee of minimum benefits, rather than a minimum benefit as such.

The reform of pension system materialised in three legal acts that were accepted by the lower chamber of the parliament, the Sejm. The legal acts dealt 
with: pension funds that comprise the second tier; occupational programmes that constituted the third tier; and financing the transition through privatisation (Golinowska and Zukowski 2002). The regulations of the legal acts were as follows.

The Act relating to the organisation and financing of pension funds accepted on 28 August regulated the functioning of the second tier, including relations between funds and individuals, setting up a fund, and the management and supervision of a fund. Participation in a pension fund is mandatory; however, an individual can move to another fund. The capital located in a fund can be inherited. The contributions are managed by pension funds or companies, and when a person retires, she buys her annuity from an annuity company.

In order to establish a pension fund, the minimum capital requirement (4 million ecu) must be met and permission from the Pension Funds Supervisory issued. The assets of a fund or company must be located in a depositary with no links to them. The law specifies the minimal rate of return: it cannot be lower than half of the mean for all funds or 4 percent, whichever is lower. If the rate of return is lower, the company must compensate for it from its own reserve fund. In case of insolvency of a fund, the company running it is closed and the difference is made up from the Guarantee Fund. In such a case, the largest fund takes over and manages the assets. The investment portfolio is regulated: the company is not allowed to invest more than 5\% of the assets in one company (Żukowski 1999).

The activity of the third tier is regulated by the Act relating to employee pension programmes. Such programmes are not mandatory and may take the form of occupational schemes, but also individual insurance and life insurance. When it comes to the occupational programmes, they can be set up in companies with at least five employees and at least half of whom should have the possibility to participate. Contributions to third-tier programmes are taxable; however, the benefits are not. The contributions are subject to the regulations relating to social contributions unless they do not reach $7 \%$ of the contributory basis (Żukowski 1999).

Finally, the last law - the Act relating to the use of funds generated from the privatisation of state assets for social insurance reform - was accepted on 25 June 1997. This Act regulates the way in which any deficit in the first tier is financed. A deficit may occur because of the split in contributions. Contributions to the second pillar should be replaced from another source. The act specifies that the deficit should be covered from the income following privatisation. If this source is insufficient, the state is obliged to issue privatisation bonds that can be used for buying shares of privatised companies. The 'Security Thr ough Diversity' 
document estimated the necessary revenue from privatisation at the level of $2 \%$ of GDP for ten years starting from the introduction of the reform.

In terms of systematic reform, the most important bill (the one just outlined concerning changes to the first tier) was not passed by Parliament. The reason for this was the complicated nature of the bill and a number controversial regulations dealing with raising the retirement age, changing the rules of indexation, and abolishing special treatment of some groups or lowering minimum benefits.

The coalition of 1997 consisted of two centre-right parties, the Solidarity Electoral Actions party (Akcja Wyborcza Solidarnosc AWS) and the Freedom Union (Unia Wolnosci UW). The coalition committed itself to four major reforms, among them pension reform. The person who was appointed responsible for the pension reform was Ewa Lewicka from AWS. A notable appointment for the lack of resistance on the side of ZUS was that of the new director linked to AWS, Stanisław Alot (Orenstein 2008).

The government introduced some changes to the proposal left by the previous coalition. Instead of the equalised retirement age for both genders, the Plenipotentiary maintained the traditionally lower retirement age for women (at 60 years). Also, a new, general law on the framework was proposed that could by an umbrella for the three separate legal acts but also provide regulations for all workers, independent of their sector.

The bill was subjected to the deliberations of the Tripartite Commission in March 1998. However, no consensus was reached on several issues (retirement age, benefit indexation and occupational privileges for young workers). The last issue became especially important on the side of the trade unions which expressed their discontent in the opinion they sent to Parliament.

The proposal was sent to Parliament at the end of April 1998. Unlike with the previous batch of bills, the government did not ask the commission dealing with the reform for it to be fast-tracked. The commission started its proceedings the following month, first concerning the appointment of the commission's leader. It was Jan Lityński, an MP from Unia Wolności. However, work in the commission progressed very slowly as the opposition was very detailed in its analysis of the draft. Also, another vulnerable point was the relationship between Plenipotentiary and the supervisory body of the second tier, the UNFE. There was an apparent conflict as to what the reformed system should look like. The head of the UNFE, Cezary Mech, promoted the Latin American type of system, which stood in 
opposition to the proposal worked out by the previous and incumbent government. After some time, the relationship improved, and the UNFE started licensing the insurance companies of the second tier. These two factors slowed down the pace of the reform, and so the government decided to work on the socalled 'mother law' (Orenstein 2008).

Accordingly, before the law relating to the functioning of the first tier was accepted, the Act on the social insurance system that outlines the overall framework for social insurance was introduced on 13 October 1998. Importantly, the reform did not deal with the farmers' scheme and focused instead on salaried workers. The Act deals with the regulation of four types of social risk: retirement, permanent incapacity to work, disease and maternity, and work accidents and occupational diseases. Contrary to the 'Security Through Diversity' proposal, here the provision of social insurance also covered judges and all uniformed groups starting their employment career as from the beginning of 1999.

Within the Act, social insurance is mandatory for all employed people, but is not restricted only to them as it concerns unemployed persons receiving unemployed compensation, those eligible to permanent social assistance benefits and those caring for handicapped family members (Źukowski 1999). There exists a split in a between people's contributions, respectively for each fund as well as a ceiling for the contribution base, as it cannot exceed 30 average monthly wages. In order to maintain the real level of salaries after the introduction of employee's contribution, the wages had to be 'grossed up' so that the net income was not affected. After this manoeuvre, the contribution for the purpose of old-age pension equals to $19.52 \%$ of the contribution base.

From the organizational perspective, the Social Insurance Institution gained a legal identity and at the same time ceased to be an organ of central administration. Moreover, the self-governance of ZUS became centralised with the abolition of branch boards, whose tasks were moved to the central board. At the same time ZUS was tasked, among other things, with running the register of insured, of contribution payers, and most importantly running individual accounts which are essential for the NDC system (Chłoń-Domińczak 2002). Its responsibilities also came to include the activities related to the functioning of the second tier which among many other things include transferring contributions to this tier and keeping a register of the insured.

Parliament returned to the bill dealing with first tier in October 1998. Work on this regulation was surrounded by a number of protests organized by workers employed in sectors of the economy enjoying occupational privileges. 
Interestingly, among the protesters were activists from Solidarność. The protest became serious in December, when the Ministry of Labour and Social Policy was occupied by the miners' trade unions for a couple of days. The unions opposed the phasing-out of occupational privileges in those sectors of the economy that were shrinking, especially coal mining. The union activists demanded the introduction of the so-called bridging arrangements that would provide security in the condition of layoffs. The tripartite negotiations resulted in the inclusion of this solution in the first-tier bill regulation and the cost-sharing of this solution by employers from some sectors (Orenstein 2008).

The amendments did not stop there. In the course of parliamentary procedures, special regulations were included concerning the early retirement age for those who had accrued the stipulated work requirement, but who did not meet the retirement age requirement. Another change concerned the regulations related to benefit indexation in the first tier. Here, instead of the initial 'Swiss indexation' as proposed, it was based on $75 \%$ of total wage fund increase. The bill with these amendments was voted for on December 17 and was signed by President Aleksander Kwaśniewski on December 29 (Orenstein 2008).

With the four legal acts accepted, the Polish social security system gained a new shape. The Act on pensions from the Social Insurance Fund has been one of the most extensive in the field of social policy in Poland, as it deals with pensions of all social groups except farmers. As Maciej Żukowski argues, the Act had been a modified government project, reflecting the assumptions of the 'Security through Diversity' proposal. It should be noted however that the reformed system included several amendments that increased the distance between the World Bank's 'Averting the Old-Age Crisis' blueprints and what was indeed introduced.

The financing of the first tier is based on the Notional Defined Capital principle. It means that financing remains PAYG, yet the mechanism of calculating benefits is the same as in the funded defined contribution systems. In practice, it means registering social security contributions in individual virtual accounts (virtual, as the contributions are not located there). The process of determining the level of benefits is similar to a funded system: contributions are turned into annuities and based on the tables of expected longevity, the benefit is established. The difference to a funded system, though, lies in its financing: in the NDC system, the benefits are financed from the contributions of current working populations, as in the PAYG system. Participation in the new system depended on the age of an individual: it was mandatory for those younger than 30 years of age, individuals between 30 and 50 could join the new system or remain in the old, while those older than 50 years remained in the old scheme. 
For those aged 30-50 who decided to move to the new system, a 'starting capital' had to be calculated so that the contributions already paid could be used for establishing the level of benefit in the NDC system. The amount of capital was calculated as follows: a hypothetical pension was calculated according to the old rules, including the length of the contributory period. The capital equals to the hypothetical monthly pension multiplied by the expected length of life (Skoczyński 2001).

One of the deviations from the original proposal was the question of retirement age. The proposed age of 62 years was not accepted and instead the old regulation remained: 60 years for women and 65 for men. Another important deviation of the reform was its failure to incorporate the 'uniformed groups'. The reformed system covers only those who started their career after 1 January 1999. With regard to the privileges (such as early retirement, or higher benefits) enjoyed by some groups including miners or railways workers, the reform did not abandon them altogether. The regulations from 1998 state that privileges do not apply to those who do not qualify for them. For the older workers however, the transitory rules were to be established within the Tripartite Commission. This clearly opens the possibility for further manoeuvres on the side of the previously privileged groups (Nelson 2001).

At the beginning of 1999, the second tier began its operations. However, this was hampered by serious problems for ZUS in transferring respective contributions. The source of the problems was the flawed IT system of ZUS which was not able to cope with transfers. When it came to the financial side of the funds' activities, they did not yield the surplus. Quite on the contrary, they closed the period January 2000 to June 2001 with loss ranging from $3.54 \%$ to $13.76 \%$ (Orenstein 2008). Membership in the private funds was rather concentrated as $60 \%$ of all the insured and $65 \%$ of all assets belonged to the three biggest funds (ChłonDomińczak 2002).

Generally, there was an immediate expectation for ZUS to perform several functions from the outset. This proved to be too ambitious and ZUS developed severe and overlapping problems. Chłoń-Domińczak (2002) pointed out some of these. First, the legislation did not specify several important aspects of the functioning of ZUS, especially with respect to collecting and processing contributions. Second, the implementation of the IT system was delayed. This was due to the wrong specifications being given at first and then the new system not being ready. Third, ZUS discontinued the old system while the new one was not ready. All these factors were reinforced by the dysfunctional structure of ZUS as institution: it was not capable of adapting to change. The problems with the 
implementation of changes in the first tier led to 17 amendments of the legal acts so that the reform could proceed.

The amendments included the organizational merger of UNFE (Urząd Nazdoru nad Funduszami Emerytalnymi, the Supervisory Body of Pension Funds) and State Office for Insurance Supervision into one body: the Insurance and Pension Funds Supervisory Commission (2002). Several other proposals dealt with solving the issue of the 'bridging pensions'. Another issue which remained unsettled for several years concerned the companies which provide annuities in exchange for retirement savings.

Parallel to the regulations affecting those who joined the new system, several amendments took effect in the old one. In 1995, the base used for calculating benefits was raised to $100 \%$ systematically with each indexation, accompanied by a rise in benefits by at least $2.5 \%$. One year later, in October 1996, the rules regarding indexation were changed once more: it was based on the CPI change plus the $50 \%$ of the difference between inflation and wage growth. Again in 1996, the new rules concerning pre-retirement benefits were established. Generally, until the mid-2000s, the vast majority of law changes with regard to the 'old' system dealt with the general category of early pensions (whether pre-retirement benefits or 'bridging' benefits) for selected categories (miners, steel workers, teachers, and so on).

In 2004, the third pillar of the reform was extended to the so-called Open Pension Accounts (Otwarte Konta Emerytalne). This was done in order to diversify the third tier and due to the fact that, up until this time, the Occupational Pension Programmes (Pracownicze Programy Emerytalne) that had been on offer had only been used to a very limited degree. Participation in the Occupational Programmes turned out to be very limited, with 10 times fewer individuals than expected subscribing to them in spite of the introduction of tax deductions (Jończyk 2005). In 2005, further exemptions were gained by miners. This occupational group demanded (and obtained) a separate law that regulates their retirement. As a result, miners can retire having met the minimum work period, regardless of the age (Jończyk 2005).

\section{PENSION REFORM IN POLAND: CONCLUSIONS}

What follows from this section is that Poland entered the 1990s in a complex situation with regard to its pension system. First, the credit-seeking communist authorities had eased the entrance conditions for several categories of workers as early as in the 1980s. With such regulation, the potential for a fast increase in the number of pensioners and related social spending at the beginning 
of the 1990s was very high. Second, the pension branch of the social security system was burdened with other tasks which hampered its financial condition. Third, in the socialist period the efforts that were made to separate the old-age pension fund from the state budget were only partial and generally unsuccessful. This meant that in this period which enjoyed some favourable conditions (many workers, few pensioners), no reserves were made which could ease the situation of growing financial pressure stemming from the increasing numbers of pensioners. Fourth, the farmers' scheme depended on state subsidies, which could then grow even if there was a decrease in the contribution base. Finally, the level of benefits was rather low and prone to further deterioration due to the lack of an indexation mechanism.

The economic change which took place after 1989 resulted in a number of threats to the system. The decline in output contributed to unemployment that affected the pension systems in two ways: it diminished the contribution base and increased the incidence of retirement of those eligible to do. Other important factors affecting the pension scheme were tax evasion (including social contributions) and the taxation of social benefits which was not compensated for from the state budget. The workers' system was characterised by several preferential regulations for various groups (e.g. miners, teachers) who retired in growing numbers. Skyrocketing inflation levels meant that the nominal levels of spending grew on an unprecedented scale so that the real value of benefits could be increased. As a result, in the first 5 years of the transformation the autonomous social security budget (including that of the farmers) displayed a severe but declining deficit. At the same time, the system provided exceptionally high benefits (compared with previous decades).

The situation became more and more of an issue in governmental circles and among experts. The first pressing task that needed to be addressed concerned the stabilisation of the pension system and to some extent this was achieved quite fast. The second step concerned more profound reform. Several proposals were put forward, ranging from parametrical reform to full privatisation. However, it was the proposal by World Bank outlining a multitier construction of pensions - its partial privatisation and less redistribution - that attracted the special attention of the government. Such solutions were nothing new in Poland and had already been proposed at the end of the 1980s, hence the acceptance of Bank's initial project.

The reform plans concerned only the scheme related to industrial workers, as the opposition of farmers was seen as too strong. Notwithstanding this proviso, the new system was proposed to operate on equal rules for everybody, so that branch privileges would cease to exist. The new system involved three tiers: the 
first public tier being NDC; the second tier based on funding and run by private companies; and a third, voluntary funded tier to accompany and complement the others.

The reforms spanned over the rule of two governments, a left-agrarian alliance followed by a right wing-centre coalition. Both governments were strongly supported by different trade unions, left-wing and Christian-democrat respectively. As such, the unions were much involved in the political games, following more their political divisions than seriously protecting the social rights of citizens. The remarkable continuation of the reforms across these different governments can also be explained by the fact that its thrust was sustained by several individuals. They occupied governmental offices responsible for the reform, but also other units created in the early phase of the reform such as the regulatory body for the pension funds' market.

Importantly, while the privatisation component of the reform was accepted quite easily, the establishment of equal principles for all workers did not follow so smoothly. Several occupational groups safeguarded their preferential treatment which made the universal character of the reform questionable. In terms of benefits, the new system offered considerably lower pensions, especially for those with an atypical work history and employment breaks. The lack of inclusion of non-work periods in the insurance will affect especially women with childrearing periods.

Finally, it is important to understand the role and position of ZUS, the social insurance company, with regard to the reform. ZUS did not oppose the reform for two major reasons. One concerned the extended role ZUS was to be given in the new system: operational control of the first tier was to be much more complicated than before reform. The second reason for the lack of opposition is the fact that since the late 1960s the directors of ZUS have been appointed by the ruling party. Unlike in several other socialist and post-socialist countries, the Polish social insurance institution is not governed by social partners who could have institutional leverage relating to protecting the status quo.

To summarise the reform of old-age pensions in Poland, one can see elements of both continuity and change. The organization and financing of this aspect of social security have only partially been changed. In terms of change, the role of private funding is essential in the new pensions arrangement. On the other hand and in terms of continuity, ZUS is still the central actor of the new system, the pension scheme for farmers remains intact and several other occupational groups continue to safeguard their privileges. It is also important to acknowledge the 
historical context in which the reforms took place: several conditions affecting the output of the reform were rooted in previous decades, when several seemingly unimportant decisions took place. Examples of such decisions are when the government took over direct management of social security, the creation of several occupational privileges, and when a separate scheme for farmers was set up. These decisions became institutionalised and several years later enabled some policy options during the reform while constraining others.

\section{A CENTURY OF SOCIAL POLICY IN POLAND: A SUMMARY}

The aim of this chapter has been to present the context of the pension reform which took place in Poland at the end of the 1990s. As outlined in the opening chapters of this dissertation, arguing from historical institutionalist approach the reform process should be analysed in a long-term perspective. In methodological terms this has meant going back to the roots of a given policy and following it over time. In order to do so, I started my analysis at the end of the $19^{\text {th }}$ century and went through its history up until the recent date. The development of social policy in Poland was embedded in the political economy of the country, and as such, mutually interwoven with political, social and economic context.

The chapter started with the introduction of policies in the partitioned lands of Poland before World War I. That era was characterised by segmentation, as the scope and logic of social policy with regard to its role in social and economic life differed across the territories, reflecting the uneven stance of the three partitioning countries (Prussia, Russia and the Austrian-Hungarian Empire). Poland therefore entered independence in 1918 with three different systems of social policy. Policy making took place in the context of continual economic crises, international threats and having to deal with the aftermath of the war destruction. In spite of these difficulties, Poland managed to introduce quite a modern set of policies that were democratically governed. The shift to authoritarian rule put an end to this particular development; however, in terms of policy development, the country took a major leap.

World War II brought another wave of destruction and losses, not only in human terms but also economically and politically. The imposition of communist rule in the late 1940s was in many ways a clear break from the past. Financing based on funding was replaced by a PAYG principle and some programmes were abandoned (for example, unemployment compensation). On the other hand, one 
could see a number of continuities with the pre-war era, the majority of these developments being continuous additions to social policy in terms of coverage and its quality. Following the logic of socialist economic management, the governance of social security became centralised and included in the state budget. This had important consequences as the financial surplus of social security was not accumulated and instead, used for economic investment.

The development of social security in Poland was closely linked with the economic, social and political situation. During the socialist period this relationship became especially apparent. The country was experiencing recurring political and economic problems. With each shock, the political conflicts were growing in scale. Similarly, the economic downturns were longer and deeper. The industrialisation of economy meant if not the creation then at least the rapid expansion of the industrial working class. However, this process was limited by the existence of private farmers, who together constituted a large part of the society. Due to the resistance of the latter group to join state farming, the state remained hostile towards farmers until it realised that only with the help of this group would it be able to satisfy the basic needs of industrial workers. Only then was social policy extended on private farmers, guaranteeing them rather low, but easily accessible benefits. A similar method of gaining legitimacy could be observed in the case of industrial workers. In the situation of growing opposition (the Solidarnośc trade movement), the government aimed at restoring social trust by introducing preferential treatment to several such social groups.

Even though the overall shape of social policy development was imposed by the Soviet Union, the specific characteristics of each country played a role as well. Thus, Poland followed its own particular national path of socialist development, marked by extreme war losses, extensive private farming, social militancy and repeating economic crises. The economic factors, such as the war destruction and cyclical downturns combined with an unfavourable social structure (the farmers) were serious constraints on social policy development. Given an unfavourable starting point, the country developed social policy only in periods of relative growth. As a result, the coverage of social policy was extensive, but the quality of benefits was rather low and - in times of crisis - maintained by ad-hoc measures.

The 1980s saw another economic crisis, followed by the most serious decline in the level of benefits which negatively affected the lives of hundreds of thousands of Poles. At the same time, the state introduced preferential treatment for several categories of workers. In this way the system became fragmented and the strong self-interest of certain social groups to defend particular benefit 
solutions appeared. A series of decisions that raised the level of benefits starting in the 1980s and continuing into the early 1990s made pensioners one of the bestprotected groups against the economic problems. Also, the self-interest to protect their social rights remained among those treated preferentially.

In this light, the Polish pension reform should be seen as only partial change of the existing system: continuity can be seen in the fact that the farmers' system was successfully defended as was the preferential treatment of some other groups. In terms of level of benefits that are expected from the new system, the reform returned to the philosophy of lean benefits which was present before 1989 . In other words, from this perspective, the transition period was a rather extraordinary time with a comparatively generous provision for elderly. On the other hand, aspects of change are visible as well. Of special note here are such things as the increased uncertainty concerning future benefits, reduced redistribution, and the privatisation of part of the Polish social security.

To sum up, the role of domestic actors was essential for the outcome of the reform after the transition in 1989. Even though the initial reform proposal came from the World Bank, it has been modified in subsequent stages of reform discussion, legislation and implementation - in accordance with the interest of various groups. 


\section{CHAPTER 5: SOCIAL POLICY IN HUNGARY}

\section{INTRODUCTION}

The second country case used in this study for comparison is Hungary. As mentioned in Chapters 3, this country shared several features with Poland regarding economic and social characteristics. However, what we observe in terms of social policy is that current outputs differ significantly. As I am interested in the politics of pension reform in Hungary that took place in the mid-1990s, and the conditions which contributed to the reform observable outcomes, I will explore these questions following the methodological framework which I outlined in Chapters 1 and 2. There I argued that in order to understand current politics of social policy reform, one needs to understand the historical development of social policy programmes since their establishment. In this way, one can better understand from which quarters the impetus for various reform proposals came and from whom as well as for what reasons such policy reforms were resisted; in other words, the sources of policy change and stability over time can be mapped. Stepping back from this to a longer term theoretical perspective, one can see that social policy reform is not random choice but rather that it can be traced back in a country's social, economic and political history (which one could call its political economy).

Therefore, in this chapter my aim is to present the evolution of social policy in Hungary since the beginning of the $20^{\text {th }}$ century. The chapter has an analogical structure to the previous one and follows policy development in chronological order. It does not deal with Hungarian social policy in a narrow sense, but aims at presenting the possibly exhaustive social, economic and political context. The following paragraphs give a brief overview the chapter's content.

The roots of Hungarian social policy can be found at the end of the $19^{\text {th }}$ century and which are strongly reflected in developments that took place in Austria, with which Hungary created the Dual Monarchy in 1867. From this period came the first regulations regarding sickness insurance and work safety. However, given the fact that the vast majority of Hungarians worked in agriculture, the regulations concerning industrial workers had limited impact. Quite typically, the first policies aimed at mitigating old-age were targeted at civil servants and were strongly subsidized by the state.

The end of the First World War brought social and political upheaval to the country. Defeat in the war weakened the state, which in turn created ground for 
the communists linked to Bolshevik Russia. This peaked in the short-lived Bolshevik Republic of 1919 which is well-remembered for its cruelty towards political opponents. Simultaneously, because of the international settlements following the War, Hungary lost the majority of its territory. These two events shifted the political scene to the right in terms of nationalist attitude on one hand, and anti-left wing measures on the other. Such a shift meant that in a country needing a universal and encompassing policy, the social problems of only selected social groups were addressed.

Subsequently, in terms of social policy only limited progress was brought about during the inter-war period. Due to the anti-labour attitudes of the following governments, unemployment compensation was not introduced at all. The left, the only political power trying to represent the wider social spectrum (including the rural population) was bearing the legacy of its involvement with the Bolsheviks and was restricted in its progressive agenda. As a result, only industrial workers were covered by old-age pensions.

The 1930s saw even further nationalistic radicalisation of political climate, which led to restrictions in the self-governance of social insurance institutions and the abolition of the Ministry of Labour and Welfare. At the very end of the 1930s however, old-age pensions were introduced for the rural population, but were never fully implemented due to World War II.

Hungary entered the post-war era as a defeated country once again. It carried a heavy burden of social problems and the legacy of anti-labour ideology. Such a combination made the new communist rulers act very extensively: Hungary embarked on a path of extensive industrialisation, seen as a means of achieving the goal of a universal high-standard of living and equality. As it turned out, however, this programme of industrialisation was implemented at the cost of the standard of living. In organizational terms, the leading role in social security management was handed to the communist trade unions, linked to the government.

The anti-communist revolution of 1956 shifted the political climate once again. After the revolt had been put down and a period of retribution, the communists led by Janos Kadar came up with the idea of the renegotiation of the social contract. In nutshell, it meant quieting Hungarian society with a number of economic and social concessions which previously were seen as impossible. This meant a shift from investment in heavy industry towards consumption, resulting in a quick improvement in standards of living. The shift affected social policy as well: social security was extended to the rural population and the level of benefits 
subsequently grew. Such changes affected social security management which, at least in principle, gained some independence from the government.

The mid-1970 saw even further efforts towards improving the standard of living of Hungarians. The new benefit formula assumed a high level of benefits for which only a moderate contributory period was required. Simultaneously, current benefits (i.e. those already being paid to pensioners) were significantly indexed. At the same time however (and in parallel to the general economic situation), the Hungarian pension system started displaying signs of crisis. These problems multiplied in the late 1980s.

The Hungarian pension system entered the 1990s as a unified system offering relatively generous benefits. However, the lack of financial autonomy (which meant the surplus was used by the state for other purposes) and a series of organizational manoeuvres further undermined the financial situation. This led to a revival of the debates relating to the necessity of reform. One of the most important players in this game was the World Bank which continually proposed a multi-tier solution involving partial privatisation.

The proposal of the World Bank found support in the Ministry of Finance which, after a number of struggles with the Ministry of Welfare, achieved a superior position. However, other actors stepped in to counteract: it was mainly the trade unions which had been running social security since the 1960s and which had hedged the original proposal that sought to remove the most drastic of the proposed changes. After a number of negotiation meetings, the role of the private component was reduced, the role of public provision increased, and guarantees regarding level of benefits were introduced. Therefore, the outcome of the reforms is a multi-tier pension system, with first mandatory tier being PAYG, the second mandatory tier being fully funded with several exemptions regarding contributory periods, and the third a fully voluntary funded tier. It should be emphasized that the new system shows significant continuities with the previous one: moderate entry conditions, high level of benefits, involvement of the state, but at the same time, financial instability.

In this chapter I argue that the reform process should be understood through the lens of the historical development of Hungarian social policy. Legacies of the inter-war era regarding lagged modernization and right-wing political orientation were altered through extensive Stalinist industrialisation which resulted in a complete change of the social structure. Granting trade unions extensive responsibility over social security and the changes made to the social contract following the events of 1956 led to an improvement in the standard of 
living which became the universal right of Hungarian society. At the same time, the unions became important stakeholders in social security which, because of its universal character, did not allow for particularistic actions. As a result, the universal system underwent change, but the extent of this change is much smaller than assumed. Such a sequence, outlined in more detail later in this chapter, points to the role of domestic actors as being the key players in shaping social policy reform. The impact of external actors, such as international institutions, is limited in the face of such a well-entrenched domestic opposition. This chapter demonstrates how social policy was created under such conditions, the way in which such conditions informed actors interested in maintaining existing social policy, and the process of policy reconfiguration under severe external pressure.

\section{HUNGARIAN SOCIAL POLICY BEFORE 1918}

Hungarian politics was very strongly interwoven with that of Austria. It was the experience of the Habsburg-Hungarian Dual Monarchy (1867-1918) which shaped perceptions concerning national identity and the role of the Hungarian government in the first decades of the $20^{\text {th }}$ century.

The act of 1867 was a ground-breaking moment in Austro-Hungarian relations. It regulated the previously tense relationship between the Austrian emperor and the Hungarian government. In accordance with this document, Hungary gained control over its domestic issues, and autonomous bodies such as parliament were created. International affairs and defence were financed jointly. The compromise of 1867 steered the political agenda on several issues which had not been discussed before, such as ethnic minority rights and education.

Soon after the Austro-Hungarian compromise, even stronger centrifugal forces appeared. One of the facets of this movement was the increased Magyarization and structural exclusion of the ethnic minorities. Simultaneously, their national consciousness started growing. Below, the impact of this context on social policy features will be elaborated.

It is necessary to reiterate that before 1918 Hungary was the part of the Austro-Hungarian Empire. As such, the social policy developments up until the end of the World War I reflected those of the political centre of the Empire. As in other countries, the first measures after the war and the fall of the Empire concerned working conditions and were aimed at industrial workers without, however, the direct involvement of the state (Gyáni 2004). It was at the end of the $19^{\text {th }}$ century that more substantial interventions of the state in the social conditions of the industrial masses were seen: in 1891 compulsory sickness insurance of 
workers in industry and commerce was introduced. In addition, in 1893 the law concerning work safety was passed. In fact, the scope of the protection was limited, as the vast majority of society worked outside industrialised manufacturing and only sickness insurance was available to those in the manufactories. It is estimated that around the year 1900 approximately half of those entitled were covered by the sickness insurance (Romsics 1999).

The reform of 1907 amended this regulation by adding accident insurance. The coverage of this and previous insurance was extended on miners, yet omitted other social groups. This accident insurance was financed solely by employers; also, the reform increased the proportion of their contributions to the sickness insurance. The schemes were managed by self-governing bodies, consisting of employers and representatives of the insured workers. It is worth noting that the trade unions, traditionally linked to the Social Democrats, were significantly involved in establishing and running the schemes (Bod 1995). In 1911 the programmes covered the majority of industrial workers.

As Szikra (2004) argues, these early policies (being directly copied from Austrian and German solutions) were the result of a specific attitude of the government referring to the trade competition (against Czech and Austria). The social legislation was closely related to the general political and economic aims of that time: the promotion of industry and trade and the importance of the agricultural population in politics.

With this in mind, the Hungarian government aimed to subsidise the implementation of modern technologies by way of tax exemptions. Clearly, the aim of social policy programmes was not only the improvement workers' security, but also attracting well-qualified labour from Hungary's main competitors and perhaps, most importantly, reducing their militancy. We can see the results of these pacifying efforts in two related issues. First was the increased control over workers in the boards of mandatory social insurance. Second was the lack of insurance for agricultural workers, who did not rise up against the semi-feudal regime as they had been suppressed already (Janos 1982).

With regard to the policies which are the focus of this study, only old-age pensions for a small group where considered. The first old-age pension provision in Hungary was introduced in 1912. It covered nominated civil servants, of both central and local authorities and offered generous benefits according to the individual's status category. The provision was heavily subsidized from the central budget and thus did not display features typical for social insurance (the link between contributions and a level of future benefits was rather loose). Szikra (2007) 
provides some data on the scheme at the time of its establishment (1912). The yearly contribution was 1 to 1.5 percent of a salary, in absolute amount around 60 Koronas and an individual had to pay contributions for at least 5 years. The benefits were generous for that time, being around 40 percent of the individual's salary, ranging from 800 to 16000 Koronas per year.

Simultaneously, a voluntary system for agricultural workers was introduced, but its coverage and generosity was significantly lower. An agricultural labourer wishing to benefit from the system had to pay around 10 Koronas annually for a minimum period of 10 years. The benefits ranged from 60 to 240 Koronas per year.

The policies concerning families with small children were organized mainly by charity organizations. One of them was the Stefania clinics, aiming at improvement of health conditions of mothers and children: they established the socalled 'milk-kitchens' which distributed mother's milk (Ormos 2007). Apart from this, the only state support families could receive was a scheme of family allowances for civil servants. The policy regarding unemployment compensation had been on the agenda of trade unions from at least the 1913 joint congress of various Hungarian trade unions, whose leading theme was a fight against unemployment (Baxandall 2004). However, no policy was introduced until 1918.

\section{THE INTER-WAR PERIOD}

\section{THE BETHLEN ERA: INTRODUCTION}

Having lost World War I and having to deal with a turbulent domestic situation (the socialist revolution in 1919, coming to terms with the Treaty of Trianon of 1920 and the subsequent strong anti-socialist, nationalist stance of following governments), social policy issues in the country were taken off the agenda until the end of 1920s. As these conditions are of special significance for understanding the inter-war context with regard to social policy-making, some basic facts about them are outlined below.

The context of social policy in Hungary was strongly influenced by and somehow tied up with the political legacy of the short-lived Hungarian Soviet Republic and the impact of the Trianon peace treaty. The political legacy of the short-lived Hungarian Soviet Republic created a specific anti-left climate which led to negligence in respect to social policy as this was seen as empowering the working class. The Trianon peace treaty, which decreased Hungarian territory by two thirds and which severely changed the structure of the Hungarian economy, 
caused nationalist sentiments to swell among both political elites and the wider population.

October of 1918 saw the emergence of the bourgeois democratic People's Republic, which was, however, incapable of resolving the acute political, economic and social challenges set against the backdrop of revolutionary fervour. Land reform was postponed and soon abandoned completely, unemployment was rocketing and the administration was incapable of fulfilling its tasks. As a result, the first government (consisting of representatives of the National Bourgeois Radical Party and Social Democrats and which was led by Mihaly Karolyi) soon lost public support. In the meantime, due to negotiations between countries neighbouring Hungary and which occupied its territory, the country significantly shrunk geographically. As a result a huge inflow of displaced people including prisoners of war, refugees from the occupied areas, public servants who had been made redundant and landowners who had lost their property was seen in the bigger cities of Hungary, mainly Budapest (Ormos 2007). Karolyi, in the meantime, had already proclaimed himself president in November 1918 in the face of strong opposition from the communists. The new governmental coalition, consisting of Social Democrats and Smallholders (representing the agricultural population) together with organizations aimed at introducing dictatorship, strongly opposed the communist movement which was supported by Moscow's Bolsheviks. As a result of the communist's violent reaction, they were repressed, which in turn lead to the growth of their popularity.

On the eve of changes to Hungary's territory in March 1919 which had been brought about by international pressure, a sudden shift occurred. It was the Social Democrats who joined the Communists party with the aim of protecting the country's integrity and in doing so established the Hungarian Soviet Republic. Every big company was nationalised, and many spheres of social life were put under state control. However, the issue of land reform was solved only partially and provoked the hostility of rural population. Some welfare improvements (mandatory insurance for both the industrial and agricultural population) were introduced, but to an insufficient extent (Ormos 2007). Hungary, run according to the Bolshevik principles, was not able to defend its territory. Help from Lenin's Russia did not arrive and the country ended up occupied by the Romanian and Czechoslovak armies in August of the same year.

Later after the Czechoslovak forces had been removed from the Hungarian territory, the Romanian army was still in occupation. Meanwhile, support for the revolutionary government declined and political alternatives emerged, strongly supported by the Great Powers. Nevertheless, the condition of the state both 
domestically and internationally remained dire. To deal with the domestic problem, the restoration of a solid legal and political system was necessary, to solve the international challenge a peace treaty was needed. Both issues were tackled step by step and their impact on the context of policy-making was profound.

The domestic political stabilization involved abandoning the plans of the Dual Habsburg Monarchy restoration, elections to the National Assembly and land reform, and this was soon to be achieved. Parallel to this was the creation of a stable position for Hungary in the international arena, which took place in France on June $4,1920$.

All in all, Hungary became a completely different country. The restoration was formally rejected, but strong conservative and authoritarian attitudes remained present among the political elite. The role of parliament was significant, but representation was not complete as many politicians (both bourgeois- and social-democrats) fled the country and, in light of co-operation with the communists, the Social Democracy had a limited scope of action (especially excluding social insurance). Moreover, in 1922, bya decree following consultation with Horthy and other representatives of aristocrats, new electoral rules had been introduced, changing the law from 1919. In principle, tightening the requirements entitling people to vote (such as finishing some elementary education, a person's minimum age and residence record) diminished the number of citizens who could vote significantly. It is estimated that the proportion of the total population eligible to vote decreased from 40 to 28 percent, which affected mainly poorly educated women (Romsics 1999).

Also, one of the strongest proponent groups of democratic order, namely Jews, became discriminated against as a number of laws, including the infamous numerus clausus were passed. One of the most acute social problems, land reform, was solved but involved only $10 \%$ percent of overall arable land.

The peace treaty regulated the borders of the country and provided some favourable trading conditions with its neighbours. More importantly, however, the country lost two thirds of its territory and half of its population ( $30 \%$ percent of ethnic Hungarians lived in other countries). Major economic centres, infrastructure and resources were lost, not to mention the links with Austria. In this way, the treaty contributed to the conservative climate of the following years, emphasizing the golden era of Greater Hungary on the one hand and downplaying progressive social ideas which were cast as the causes of the country's downfall. 
In economic terms, Hungary also did not perform well. In fact, the years after the Trianon treaty were marked by a constant struggle to balance the budget. As mentioned, Hungary had lost most of its raw material supplies. Another problem was the need to pay war reparations, starting in 1927-8. In order to cope with these challenges, the government introduced a series of moves. Among others, these included: taking out international loans (on very unfavourable conditions, however), the reduction of the civil service by half, the introduction of a central bank running monetary policy, and an increase in the level of taxes. All this led to the stabilisation of the budget and a gradual improvement of the economic situation towards the end of the 1920s. Agriculture remained the biggest sector of economy (the second biggest being industry). The success of the 1920s saw Hungary surpassing its pre-First World War economic performance (according to different estimations by 13 to 30 percent). This situation did not last long, though, as already by 1929 the first signs of a significant crisis occurred.

These were the reasons in this period for the relative selectivity when it came to social policy programmes and their target groups. In spite of the international drive towards basic security rights (fuelled mainly by the International Labour Organization, of which Hungary became a member in 1922) and their expression in the Trianon Treaty, their implementation in Hungary was rather slow. As Maria Ormos states,

"Such social questions affected not only the urban working class, but also clerical employees and the rural masses, but the demands came mainly from the Social Democrats, who represented the urban working class. So many came to see social policy as something to do with the workers, to whom there was widespread antipathy in the aftermath of Bela Kun's Hungarian Soviet Republic. This social psychosis impeded the introduction of welfare measures" (Ormos 2007: 194)

This statement stands in a stark contrast with the social situation of Hungary, which was affected by the post-war crisis combined with the inflow of displaced people into a reduced territory. The overall decline in production immediately after the war (when compared to the pre-war levels, a decline estimated to be approximately $50 \%$ for industrial and $35 \%$ for agricultural production), combined with high inflation induced an increase in unemployment. Those who did not lose their jobs saw a marked drop in their salaries. Accordingly, the standard of living dropped as well: when compared to the immediate pre-war years, in 1919 an average day worker's salary was 70\% lower, an industrial worker's salary was $60-71 \%$ lower and a civil servant's or army officer's was $82 \%$ lower (Romsics 1999). Nevertheless, the dire situation of those affected by the crisis was not eased in any systematic way. As mentioned, due to the legacy of the short- 
lived Soviet Republic, the Communist party was abandoned and the Social Democrats had to give up their social demands.

The general attitude towards social policy changed from 1922 when Jozsef Vass, who was a member of the governments led by Istvan Bethlen, gave a new direction to Hungarian social policy. The shift was from one focused solely on the social issues of industrial workers (and in this way, empowering them, as proposed by the left wing) to a more encompassing approach, including other social groups (and focusing more on the nation-building too). To accomplish this aim, Vass pursued a conservative policy with a Christian ingredient. Leaving aside the ideological connotations, the Bethlen era (c.1921 - 1931) was one in which social policy changes were profound.

From the administrative point of view, it was the Ministry of Labour and Welfare that supervised the institutions dealing with an expanding portfolio of social matters. Along with the introduction of new social benefits, several social insurance institutions dealing with the administration of such were created. The law of 1927 which introduced sickness and accident insurance also created the National Social Insurance Institution (OTI) to deal with financial and organizational issues. At the same time, the Insurance Institution for Private Employees (MABI) was established.

Interestingly enough, the establishment of the new supervisory institutions, especially OTI, created a new balance of power. Before, it was formally the representatives of employers and employees (in equal numbers) who supervised the social insurance institutions. In fact, it was the workers' representatives (closely related to the Social Democrats) who were more influential in the supervision of these organizations. The reform of 1927 altered this situation, as the employees, including the directors who sat on boards the of the social insurance institutions, were hired by the Ministry of Work and Welfare, and their supervision by workers became limited (Romsics 1995). This facet of the reform meant a significant involvement of the state in previously self-governing institutions.

The sections below describe the developments with respect to unemployment compensation, old-age pensions, and support for families with very small children.

\section{UNEMPLOYMENT COMPENSATION}

Unemployment compensation had been one of the most hotly-debated, but at the same time most unsuccessfully implemented areas of Hungarian social 
policy between the wars. This policy area had been shaped on one hand by the limited pressure exercised by the constrained left and on the other by the strong anti-labour attitude of the conservative governments. As a result, several attempts to establish a modern universal system of protection against the deprivations wrought by unemployment failed. The only period when there was more unemployment compensation was during the Soviet Republic. There existed some form of financial relief administered by the trade unions and the unemployed were directed to the army (Baxandall 2004).

As mentioned above, international organizations held strong influence over the Hungarian government, and they promoted institutionalised development of social rights, especially the ILO. One of the most pronounced initiatives by the ILO was to promote compensation against loss of work and this was included in the Convention 2 of 1919. The first attempts to introduce such a scheme in Hungary took place in 1922. It was planned the scheme would take the form of a fund with contributions from the employers. However, due to the opposition of the employers who did not want to finance the scheme in addition to a the lack of financial resources in the state budget, this project was abandoned. Instead, the idea of public works was proposed, which also failed to be implemented (Ormos 2007).

Another attempt to introduce a scheme to insure workers against loss of work took place in 1926. In contrast to the previous attempt, the benefits were to be financed by all three parties: insured workers, employers (at a maximum 4 percent of the payroll) and the state. The proposed length of payment was up to 13 weeks. The project was consulted with several bodies and received mixed feedback. Generally, it lacked comprehensive political support, given the fact that the parliamentary opposition consisted of the liberal party. Also, the strong opposition of the industrial elite who argued that another burden would diminish international competitiveness contributed not only to this particular project being abandoned but also the whole idea in the inter-war period. It is even more paradoxical if one considers the fact that Bethlen's ideas concerning workers protection changed from the classical liberal point of view (they are the cause of unemployment) to one which was more sympathetic around the mid-1920s (Romsics 1995).

Even in the period of the Great Crisis of the 1930s that affected the country, the government downplayed the issue of unemployed without financial support. In spite of some attempts by the Social Democrats and the trade unions, this problem was not solved comprehensively, with only short-lived measures introduced in 1931. 
As has already been seen, the climate for new policy enactment was rather unfavourable. This was especially true in the first half of the 1920s when the general economic and social situation was dire and at which time the lack of oldage pension provision affected a number of different social groups which were all in need. One manifestation of the hardship was not only the reduction in the number of civil servants, but also in cutbacks to their privileges. Given the fact that many redundant state employees became pensioners, the expected savings were offset. While about 60,000 people lost their jobs between 1922 and 1926, the number of pensioners increased by 70 percent (from 63,000 in 1913 to 101,000 in 1926). Therefore, in order to reduce this growing pressure on the budget, the benefits were reduced by 40 percent in 1924 (Romsics 1999).

A major expansion of the pension system took place in 1928 and was closely related to the policy regarding unemployment. The government reached an agreement with the industrial circles that it would not put forward plans for introducing unemployment benefits in return for the industrialists' support relating to old-age pensions. The introduction of the system was preceded by debates, both by the National Federation of Industrialists and the National Social Insurance Institution (OTI) and finally in Parliament. OTI highlighted the narrow scope of coverage (which excluded agricultural workers, farm servants, retail traders and unemployed) and the rudimentary involvement of the state in the scheme. Nevertheless, neither OTI, nor parliamentary opposition were able to change the draft proposed by the government.

The old-age pensions scheme was mandatory for all workers but again still excluded those from the agricultural sector. It was based on occupational differentiation, resulting in higher contributions (and benefits) for the white collars. There was an equal split in contributions between employer and employee totalling $4-5 \%$ of the payroll depending on the white/blue collar worker status. Both sides, with a participation of the National Social Insurance Institution, managed the programme.

In principle, the retirement age was 65 and a person was eligible after contributing to the system for 10 years. The benefit consisted of two components: a flat rate and a dynamic element which was a percentage of the contribution, depending on occupational group. Generally, the flat rate component was 120 Pengo annually and $19-24 \%$ of the previously paid contribution. The level of benefits for persons with 30 years of work was comparable to that of living in Austria (Tomka 2004). 
The construction of the benefit was based on the principle of a 'benefitdefined, fully-funded system'. Therefore, it did not pay the benefits in the first four years of its activity, but only cumulated contributions. Generally, due to its construction (length of the contributory period), the system did not operate in full.

\section{CHILDCARE POLICY}

Just one year before the establishment of old-age pensions in 1927, more childcare policy was introduced. It consisted of three types of allowances: pregnancy, breast-feeding and child-bed. The length of the first two allowances was six weeks before and after labour. It was very generous as they equalled to $100 \%$ of a previous salary (Szikra 2007). The scheme was based on the principle of insurance, so that in order to qualify a woman had to work at least 10 months within 2 years preceding a confinement. The child-bed benefit was available to mothers after expiration of the two previous allowances and lasted for twelve weeks. Its value was low and equalled to 18 pengo a month.

\section{THE 1930S}

The 1930s brought about the conditions that radicalised the political climate in Hungary, which inevitably influenced the context of policy-making as well. The two main issues were 1) the prolonged impact of the Great Crisis on the overall economic performance and international position of the country in the international economy, and 2) the political shift towards authoritarian rule.

\section{SOCIO-ECONOMIC CONDITIONS}

The Great Depression affected two areas on which Hungary heavily relied: agriculture and the international financial markets. From 1929 the prices of Hungarian agricultural goods, its main export commodity at the time, declined sharply by between 50 and 70 percent. This in turn created a big disparity between agricultural and industrial product prices, inducing even greater problems for this sector (Romsics 1999). The crisis in the industrial sector did not last as long as for agriculture and touched only selected branches, especially those relying on agricultural products.

The second factor having an impact on the domestic situation in the country was the crisis in the international money markets, which started in mid1932. The fact that Hungary was to a certain degree dependent on the loans offered by other countries also undergoing crisis meant that the measures to contain the 
problems abroad would be echoed at home. This was the case, and all donors that could cancel their loans did so.

It should be stated however that, comparatively speaking, the impact of crisis on the Hungarian economy was rather modest; Hungary was located in the lower ranks of the national per capita income drop with its 7 percent decline (between 1929 and 1933).

Another factor that eased the situation in the period of crisis was Hungary's closer economic cooperation with Germany. Starting from 1931, a series of trade treaties had been signed, and Hungary was allowed to sell its products, mainly agricultural ones, on the German market in exchange for importing manufactured goods. Soon, a similar type of trade had been established with Italy and Austria. At the end of the 1930s Germany (and Austria after the Anschluss) was the recipient of half of the total of Hungary's exports.

An intense programme of heavy industrial development accompanied the extensive international exchange. It focused on the development of infrastructure mainly through armaments. 60 percent of the five-year plan which was launched in 1938 was directed towards the military sector (Romsics 1999).

When it came to the structure of society, it was typical for a moderately developed agrarian industrial economy (and in this respect, comparable with Poland and the countries of Southern Europe). At the beginning of the 1930s, half of the population (51.8\%) worked in some form of agricultural activity. The second biggest group (32.3\%) was employed in industry. The structure of the society was hierarchical and polarized, which was reflected in a variety of lifestyles and standards of living. Romsics provides an illustration of this situation from 1930-1, in the middle of the depression. The concentration of wealth was quite extreme, with $0.6 \%$ of population owing $20 \%$ of private wealth. If one takes a national average income (534 pengos) as the benchmark, the differences become stark. The income of great landowners and bourgeoisie ( $0.6 \%$ of population) was 33 times higher than this benchmark, the middle class $(18.2 \%$ of population) enjoyed an income 2 times higher, while other social groups scored below. Peasants with medium crop area (8.6\%) and workers in mining and metallurgy $(1.3 \%)$ received around $80 \%(0.8)$ of the average income, while urban workers $(22 \%$ percent of the population) only around $70 \%$. The owners of small plots of land, estate servants and agricultural workers (together representing some $40 \%$ of the population) occupied the worst position with an income only ranging from $43 \%$ to $34 \%$ of the average wage. 
Hungarian politics for the first two years of the 1930s were very volatile as the economic crisis reached its peak, creating general political instability which was hard to contain. Both left and right wing movements threatened the government of Karoly. At the peak of the crisis a wave of strikes hit the country and was radically pacified.

It was the government of Gyula Gombos which radicalised the politics and started introducing openly fascist structures (or at least strongly authoritarian with Italy as a benchmark). Gombos in the preceding decade was known for his rightwing radicalism, when he led the Racial Defence Party, which accused Bethlen of depending too much on international help and Jewish circles. At the end of the 1920s, however, he re-joined the Unity Party (later Party of National Unity), strengthening its right wing. However, the right-wing ideas did not take an extreme form as the Party of National Unity had become quite fragmented and had entered into several mergers with other parties, thus being constrained by the conditional support of various factions. As Romsics argues, it is exactly this internal diversity of the party which allowed it to hold a parliamentary majority for several years. (Romsics 1999).

As in the previous decade, the activity of left-wing parties was significantly suppressed, but it should be mentioned that the extremist right party was also affected by the state apparatus, albeit to a lesser degree). Still, the rightwing Party of National Will (soon to become the infamous Arrow-Cross Party) was elected to Parliament. At the same time, the prerogatives of the Regency were extended. Therefore, it seems correct to call Hungary an authoritarian regime with a hegemonic role of one party (Romsics 1999). The most striking example of the right-wing domestic policy was a series of anti-Jewish Acts, introduced in 1938-42.

\section{ORGANIZATION OF SOCIAL POLICY TOWARDS CENTRALIZATION}

From the perspective of social policy developments, the 1920s were fundamental as the frames of reference were created. After the era of Bethlen, a more radical policy context occurred: a shift towards a nationalist, corporatist state a la fascist Italy. One of the components of this shift was the increased control of over various spheres of the 'planned society'. A series of changes in the administrative layer of the social insurance took place. First, in 1932, the autonomy of social insurance organizations was limited by denying their right for insurance arbitration. Next, in 1933 the Ministry of Labour and Welfare was abolished and its tasks were scattered around in six other ministries. It was argued that this manoeuvre would allow for more 'socialisation' of other government departments. Finally, the National Social Policy Council was established which in terms of its 
organization was supervised directly by the prime minister. Clearly, these changes were heading towards increased centralisation, so that the sole interests of the government could be pursued. Another attempt was taken during elections at MABI and OTI when the ruling party tried to get a majority in their boards. However, in both cases it failed.

Another interesting facet of pursuing a comprehensive, planned social policy was the investment policy of social insurance funds. A proportion of the available resources since 1930 had been invested in housing bonds, guaranteed by the state. In this way, the resources of one social institution were used to finance others (Kovrig 1940). This institutional interdependence would ultimately impact social insurance with the arrival of war.

When it came to the policy developments, the expansion of coverage of existing schemes took place, combined with some parametric changes of their generosity. Until 1938, when a partial extension of social insurance for agricultural population took place, the disparity between this group and industrial workers was extensive. While the social rights (including regulation of minimum wage and work conditions) of the latter group had been extended, those living from agriculture had been neglected. An example of this differentiation was demonstrated in the per capita social benefit paid in 1938 to various occupational groups. While the industrial employees received on average 27 pengos, the agricultural workers received as little as 0.36 pengo (Romsics 1999). However, these differences were eased by some partial measures introduced in the remaining years of the 1930s.

The first, important reform here concerned the old-age pension scheme. Its coverage was partially extended to the agricultural population in 1938-9. The qualifying conditions were stricter and combined with lower level of benefits when compared to the workers' system. Accordingly, all male agricultural workers without land ownership (or having only a small plot of land) over 18 years old were included in the system and eligible for the benefit after reaching the age of 65 . The benefit was established at 60 pengo a year. It is estimated that about $25 \%$ of the paid agricultural labourers was covered by this scheme.

As for childcare policy, no big changes were introduced. However, as mention in the introduction, the policy became more driven by nationalist, and especially anti-Jewish sentiments. In practice, it took two forms. First, the aim was to weaken the economic and social position of Jews. In order to do so, in many cases the Jews were very highly taxed and their property nationalised. The tax revenues were used, among other things, for financing social policy and especially 
family policy targeted at the 'core' Hungarian families. The confiscated goods were distributed among 'deserving' Hungarian citizens, mainly Christians (Szikra 2007).

Finally, as previously mentioned, there was no notable success in the field of unemployment provision. The policies aiming at easing the conditions for the unemployed remained organized, delivered and financed by the local authorities. At the peak of the depression, the trade unions threatened the government with a strike, demanding the introduction of an unemployment protection scheme. Such calls were however unsuccessful.

\section{WORLD WAR II}

The active involvement of Hungary as a war actor started as late as 1944. In part, this was a consequence of a close political and economic alliance with the Nazi Germany, accompanied by the announcement of neutrality. However, the close links with Germany were strongly supported by domestic actors, and, in fact, were a declaration of alliance with this country. The position of 'the unwilling satellite' (as the Horthy Regency was called) towards Germany shifted from what had already been seen in the 1930s towards more open co-operation. Its aim, among other things, was the restoration of the pre-Trianon borders, which to a certain extent was achieved (Berend 2001).

As mentioned, in 1938 Hungary adopted a 5-year plan aiming at the fast industrialization of the country, mainly through armaments. This shift to a war economy (especially from the autumn of 1939, when cooperation with the Nazi Germany became even closer), boosted production and hence, the standard of living. As the country was not directly involved in the war activities, it did not suffer (until 1944) from the destruction of production infrastructure. With time, the burden of work imposed on workers was increased and the cost of living grew. This was, however offset by the increase of nominal salaries. Even though the consumption needs could not be met via the official economy and that, especially from 1942, the role of food stamps had been decreasing, the situation did not change dramatically. The reason for this was that there had been just a slight drop of the real income as compared to pre-war times, combined with the labour shortage induced by the war economy which opened new employment opportunities. As Ivan Berend estimates, accounting for the role of the black market in both foodstuffs and labour, the real wages of workers at the end of 1943 were at the level of $91 \%$ of those in 1938 (Berend 1993).

The only significant change of social policy arrangements concerned lowering the retirement age. It was decreased from 65 to 60 years (Czucz and Pinter 2002). 
Due to a complicated series of political manoeuvres in both the domestic and international arenas, Hungary engaged fully in the war in 1944 on the Nazi side. As a result, the territory of the country became a battlefield, which in turn brought about significant human losses and destruction of infrastructure. Hungary's human war losses were among greatest in the war (after Poland and the Soviet Union), equalling to $6.2 \%$ of the population. The material losses were estimated at $40 \%$ of the national wealth. As an ally of Nazi Germany, Hungary lost the war.

\section{SUMMARY OF THE PRE-SOCIALIST PERIOD}

The Hungarian social policy in the inter-war period was marked by several changes and gradual improvements. However, it should be noted that these improvements followed the logic of selectivity, and concerned mainly the industrial working population, aiming at improvement of productivity. Other groups, such as small land-owners, remained in the margins of social policymakers interests for a long time, and it was only just before the war that a residual pension coverage was extended on them.

Therefore, it seems justified to emphasize that the inter-war Hungarian social policy lagged behind other European countries of both similar and higher economic levels. As Ferge (1987) stresses, very few policy innovations which were developed in Austria (of which Hungary was part for several decades, and thus inherited several institutional structures) were incorporated in the country after gaining full sovereignty. Also the impact of international institutions, such as International Labour Office, was marginal. As a result, the country was lagging behind several western and eastern nations not only in terms of social policy coverage but also in terms of risk coverage.

This striking underdevelopment was the result of an amalgam of economic, ideological and political factors. Especially important factors here were the post-war (i.e. post-1918) economic crisis stemming from both the shift from a military to a peaceful pattern of production, and the loss of two thirds of the country's territory. This structural crisis was later reinforced by the Great Crisis. Ideological and political factors hampered the modernization of Hungary in a sense that after the experience of Bolshevik Republic, the socialist progressive proposals were removed from official political discourse.

Interestingly, it was not the industrial working class which suffered most from the lack of political representation. In the conditions of rebuilding the country and regaining its strength, industrial labour was more at the centre of attention of state-led policies (excluding trade unions from management, however). It was 
rather the rural population which suffered most from the traditional social structure, a lack of land and exclusion from democratic processes. This differentiation became even stronger when Hungary embarked on the path of military development and a close alliance with Germany.

\section{THE POST-WAR PERIOD}

\section{FROM 1944/5 to 1956}

Due to the agreements between the Great Powers and Hungary's policy during the last year of the war, the country found itself under occupation from the Soviet Union. As in other countries of the region, the role of the communists supported by Moscow had been steadily growing, ultimately aiming at a power takeover. Importantly, the takeover was not achieved at once, but rather took the form of a staged weakening of parties reluctant to accept domination of the communists supported by Moscow. This systematic approach became known as the 'salami tactics'. As the immediate post-war (1945) elections showed, it was rather clear that the Hungarian communists had scarce support from society; their main opponent, the Smallholders Party, gained the majority of seats in parliament. Nevertheless, the Soviets insisted on the co-optation of communists in government and the latter gained control over crucial ministries (mainly the Ministry of the Interior). Therefore, one may talk about a decreasing degree of democratization in the immediate post-war period (1945-8), followed by one-party rule. The process of the sovietisation of Hungary speeded up in 1947, when the leadership of the main anti-communist party, the Smallholders, were either charged for virtual crimes or forced to leave the country. The following year the Social Democrats were made to merge with the Communist party. As a result, from 1948 on the communist party ruled without visible opposition.

A number of changes in the economy accompanied the political developments. One of first was that of land reform, introduced in 1945. Overall, one third of Hungary's land was expropriated from the owners and was either distributed or nationalised in the first wave.

In addition, the reconstruction of the economy was started. This included mainly transport infrastructure, vital for the development of other branches of economy. The process of reconstruction was constrained by two factors: war reparations imposed on Hungary and the post-war crisis. The latter were to be paid to the Soviet Union, Czechoslovakia and Yugoslavia. For the destructed 
economy, the burden was even harder as the exchange rates were unrealistic, and the real value of reparations doubled.

This unfavourable economic situation had a direct impact on the social situation. Rocketing inflation (12\% an hour in the end of 1946!) diminished real wages by $40-60 \%$ in mid-1945 and 1946, while people's typical caloric intake was half of the international standard. With paper money swept away from the market, the main mode of economic exchange even for salaries was barter, being paid in kind (Berend 2001).

Hungary was looking for financial assistance from the West, but the communists - who acted on behalf of Moscow - wanted to preserve their exclusive influence on Hungarian affairs and so opposed this attempt. This policy was reinforced in two ways. First, from the moment of the occupation, the Hungarian economy had been run by Soviet advisers (Kovrig 1979). Second, international cooperation within the Eastern Bloc and especially with the USSR had been institutionalised in 1949 by the establishment of the Council for Mutual Economic Assistance (COMECON) (Berend 2001). Hence, the reform came to rely on domestic resources only.

The Stalinist style reforms were not restricted to the economy and polity, however. They aimed at the complete dismantlement of the old, bourgeois order and the introduction of a new, socialist one. In the period analysed the emphasis was placed on the removal of the 'old' social structure. This aim had several aspects: abandoning private ownership (including that of land), the removal of the pre-war 'reactionary' elites, and the establishment of new ones which were to come from the 'oppressed' classes.

As mentioned above, the gentry landowners had their land confiscated step by step and distributed among landless population. The aim of this action was not only to punish the pre-war elites, but also to gain the support of the general population, which under the conditions of constrained pluralism, did show enthusiasm for the communists.

The Stalinisation of Hungary also meant the replacement of the pre-war bureaucratic apparatus with the new elites, recruited mainly from the working class. This also meant the removal of the privileges enjoyed by old elites up to that moment. Not only did the vast majority of the pre-war bureaucrats lose their employment, but they also lost their favourable social insurance entitlements (the so-called B-listing). 
In addition, the nationalisation of industry took place under the manifest flag of preventing further shortages. To begin with, it was concerned with only the largest enterprises which had been abandoned and which were of strategic importance, but soon nationalisation affected virtually all private companies. While the idea of more state control of the economy held sway across Europe, in Hungary it was taken to the extreme.

A second facet of the economic intervention was the introduction of planning in the Soviet style. The first plan, concerned mainly with the issue of post-war reconstruction, was introduced in the autumn 1947. Thirty per cent of the investment was directed to agriculture, $26 \%$ to heavy industry, and $25 \%$ to infrastructure.

To summarize, after the war Hungary was operating under significantly altered conditions, both domestically and internationally. Accompanied by the impact of the war losses, the change of the mode of production and the induced social transformation contributed to the grand change.

This significant shift, as Szalai states in a broader context, was not welcome with regard to its method, driven as it was by communist ideology. However, in assessing its aims it could be seen as '[...] an attempt to respond to two major problems which had plagued the country for at least a century: social disintegration (or, more aptly, the lack of social integration) on the one hand and on the other the lack of success in closing the modernization gap' (Szalai 1992). One of the starkest examples of the 'modernization gap' was the partial and selective nature of social policy. Social policy, as part of a wider concept of 'societal policy' (Ferge 1979), was seen as a tool of social transformation leading to a more egalitarian society.

Therefore, the wider aims of social policy (even though it was seen as a component of capitalist systems and as such redundant in socialism) were considered as indispensable. The eradication of poverty and misery of the working class were to become a part of a more general social programme: the industrialisation of the country. As some authors (Ferge 1979; Baxandall 2004) show, the social aims were subordinated to this general aim, to be achieved almost automatically through industrialisation. It should be stated, though, that such a programme assumed the deprivation of other social groups, those who had been better-off before the war.

Clearly, the aims of some social policy reforms were not only to increase the security of the most deprived groups. In some cases, social policy was seen as 
the instrument of shaping the behaviour of individuals in accordance with the guidelines of the state-communist ideology. During the first post-war decade, characterised by hard-core Stalinism, the motives underlying the incentives were quite straightforward. If one considers the typical 'enemies of the people' (private landowners both large and small, private entrepreneurs and state bureaucrats of the former regime) it can be seen that they were deprived of their property, status and privileges. What is more, the new social policy regulations were not extended to them. On the other hand, there existed a strong push towards collective (or state-owned) farming and production, supported by the state apparatus. By promoting these types of collective activity, workers in these groups were covered (to a varying degree) from early on (Insurance 1968).

The first post-war decade was a period when the economy and polity was shaped according to the guidelines provided by the hard-core Moscow Stalinists. In this decade, the close resemblance of the state-socialist regime to the Stalinist ideal could be seen, accompanied by the elimination of both intra-party opposition ('nationalists') and other centrifugal movements. At the same time, following the death of Stalin in 1953 and with some critical assessment of his era within the Communist party in the Soviet Union, some signs of liberalization began to appear in the satellite countries. In practice, this meant that 'the only way to communism' idea was abandoned and some country variations were allowed. The hardliner Rakosi was condemned for the blind loyalty to Moscow and Imre Nagy became the head of government from 1953 to 1955. With his change in leadership came a gradual liberalization of the regime. The extensive investment in industrialization was slowed and more attention was given to the level of people's general level of consumption through increased investment in agriculture. With this increased input into agriculture came a softening of the repression of private owners. At the same time one third of those working in cooperatives left them. Several increases of wages took place with a simultaneous decline of prices.

\section{CENTRALIZATION OF ORGANIZATION AND FINANCING}

Most of the financial resources available around this time had been diminished due to the war, post-war inflation and destruction of physical infrastructure which had to be rebuilt. The inflation that started with the Great Crisis had greatly sped up during the World War II. The decline in asset values was compounded by post-war hyperinflation and the Hungarian Monetary Reform of 1946, which ate up many of the cash reserves and investments. Investments in real estate (via housing bonds) also proved unsatisfactory: during 
the war many properties had been destroyed, and instead of profiting from them, the social insurance institutions were mandated to reconstruct them (Bod 1995).

The immediate post-war period also saw multifaceted developments in organizational issues. The short-lived democratic rule resulted in debates concerning social policy development but without visible effects, however. With the communist take-over, the discussion was stopped and from that moment on the political centre of the country developed and controlled policy decisions. Social insurance organization was reformed so that the Stalinist-socialist principles were promoted and behaviour which did not comply to them was discouraged (Baxandall 2004). An example of this practice was the expansion of the old-age pensions' coverage, which affected the 'core' (from the planners view) groups of workers which had not been covered up until then.

Such a situation made the operation of the pre-war system almost impossible

given the loss of financial resources combined with the growing numbers of those who were entitled to a benefit. From 1949, the funded systems (for several occupational groups, most generally white-collar workers, manual workers from various sectors and civil servants) were turned into one Pay-As-You-Go scheme, which to some degree meant sustaining the social rights already earned.

As for the financing and organization of the system, it was as follows. Until 1949 the elected insurance boards, although gradually disappearing, continued to exist. Afterwards, in order to facilitate the control over the funds, management of social insurance institutions by the state was introduced and hence centralised. The National Institute of Social Insurance took over responsibilities of sector-based institutes (except for the railways). It did not last long, however, as in 1950 the National Institute of Social Insurance was shut down and the Central Council of Trade Unions (Szakszervezetek Orszagos Tanacsa - SZOT) started management of social security under the direct supervision of the Council of Ministers. The Trade Unions' Social Security Centre managed the central office and overlooked regional and plant-based units dealing with social security (Gabor and Gyorki 1973).

While in the immediate post-war years it had been the employers who had had sole responsibility for contributions, from the beginning the 1950s the contributions from employees were restored. The latter group's share varied from 1 to 15 percent of salary (Inglot 2008). The overall level of contributions was raised several times after the war in order to finance the growing needs of social security 
system. Importantly, the system became an integral part of the state budget, with no possibility of accumulating financial surplus.

\section{PENSION BENEFITS}

The leading political rule of thumb in Hungary following the war was the differentiation of entitlements of social groups according to their importance for the socialist state. Therefore, the preferential treatment of the functionaries of the pre-war state apparatus was removed. At the same time, coverage of pension benefits was extended to the agricultural population (salaried agricultural workers, members of agricultural co-operatives) from 1945 and on, reaching $97.7 \%$ by the mid-1960s (Tomka 2004). It was from 1951 that the system started to gradually increase its coverage, especially to the agricultural population. Nonetheless, that system offered reduced entitlements and generosity when compared with that of the industrial workers, where an internal differentiation existed as well (preferential treatment of miners, for example). This situation lasted until the mid1970s when the general rules were equalized for all social groups. This is described in detail in the next section.

As far as eligibility to old-age pension benefits is concerned, the retirement age varied according to the occupational group, as mentioned above. Generally, the qualifying age for a minimum benefit was 60/55 years for men/women, and limited to 65/60. The minimum period in employment qualifying for a benefit was 10 years. There were exemptions from this rule: those working underground or in severe conditions could retire after 25 years of work at the age of 55 (Mamrotowa 1952).

How the level of benefits was determined was subject to several changes. From 1951, the level of benefits was defined according to a person's participation in one of six contributory groups (depending on sector and type of work, resulting in the preferential retirement age, for example miners could retire at age of 50), with a loose link to previous contributions. The contribution was set at the level of 4 percent, and was paid only by employers (Gabor and Gyorki 1973). The level of benefits granted before 1952 was significantly raised, by up to 50\% (Mamrotowa 1952).

Roughly, the benefit was determined for each contributory group and consisted of a base amount and the supplement. The base amount was dependent on the retirement age ( $15 \%$ of a pre-pension salary for a minimum retirement age 
to 30 percent for the maximum retirement age, with a 3 percent increase for each year within these limits). The reference salary was the last 12 months before retirement. The supplement depended on the length in employment counted from 1945 on. For each year of service the benefit was raised by 2 percent of the reference amount (Bod 1995). After the introduction of the PAYG scheme, the average level of benefits decreased. It had to deal not only with the limited capacities of the new system, but also a significant reduction (or in some cases, the deprivation) of privileges of some groups (mainly civil servants) which was a part of the so-called B-listing.

In 1954 the law brought about another set of changes aimed mainly at raising the relative level of pensions. In March the benefit formula was modified. The base amount had been raised to 50 percent of a pre-retirement salary for 'regular workers', and thereafter $1 \%$ was added to the benefit each year, an incremental increase that was less than that seen previously (Czucz and Pinter 2002). Again, especially for those working in the heavy industry the increase was more preferential, while for workers in agriculture it was less so. Importantly, the contribution split was restored: the contribution from employers remained unchanged but a contribution of 3 percent on the employees was introduced. In September the retirement age was unified and set for 60 years for men and 55 for women, except for some special provisions mentioned above (Gabor and Gyorki 1973).

\section{6 то 1975}

The years 1953-55 saw a gradual liberalization of political and social life. The oppressive measures aimed at the 'enemies of the people' were relaxed. The departure from the ideology and practice of Stalinism became visible in several areas of social and economic life. However, a series of power shifts occurred in the Kremlin and, consequently, the group led by Nagy lost its support from Moscow. With the official critique of the Stalinist era in 1956, a revival of the Nagy group took place embodying a reformist approach and it was opposed to the dictatorial rule of Rakosi (again in power). Under these conditions, the revolution of 1956 came about. Given that the demands made were mainly of a political and civic character (and did not refer to restoring the pre-war order), the revolution was gaining considerable support, perhaps surpassing any other mobilisation up to then. 
The revolution of 1956 left an enduring legacy which was to influence Hungarian politics, economy and society for several decades. The brutal put-down of the revolution itself followed by the subsequent wave of repression significantly worsened the public mood and created a long-standing distrust of the state. While acknowledging the cruelty of the repression that took place, it should be stated it was much more focused when compared to the 1940s' blind terror. At the same time, the opposition of society to the apparatus which was clearly collaborating with Soviets in restoring order was the biggest since the end of the war. Again, however, the post-revolution period was not homogenous.

Under the rule of Kadar, the regime evolved from the repression and the restoration of the dictatorship to a gradual liberalisation and introduction of some elements typical for market economies. One of the most significant aspects of this transformation was the emphasis on the standard of living. It was exactly this rise in quality of life with which Kadar legitimized his rule: 'For a substantial portion of the working masses what primarily interests them is not the general issues of politics but proper solutions to the economic and cultural issues that shape their daily lives' (Romsics 1999: 321).

In other words, Kadar's approach was still one that aimed to transform Hungarian society in line with socialist ideals (although more loosely defined than before), but with less repression and with more freedom to win popular support. It should be noted here that the attempts to introduce a more encompassing and generous policy did not start with the introduction of the New Economic Mechanism of 1968 (directly aimed at improving the standard of living and followed by major social policy reforms), but earlier. It was as early as in 1957 when a set of proposals regarding lessening the role of detailed planning was raised, aimed at increasing the economy's efficiency by way of a more rational use of resources.

The consequence of such an approach was the gradual increase of tolerance for the 'second economy' in industry and agriculture, which complemented the official one. At the same time, as in the previous period, the new policies were not only used to please the population, but also to induce certain behaviour in accordance with the principles of the socialist state.

Examples of the former facet of the transformation might be the rises in real salaries in the public sector and agricultural products bought from private farmers by the state, lessening the tax burden for small private companies, which all had already started in 1956. An example of the latter might be the push towards 
collectivisation, through the creation of the social security system for the individuals in this sector.

Economic liberalization was boosted in a systemic way at the end of the 1960s with the so-called New Economic Mechanism. The 1968 Mechanism broke up several dogmas of the socialist economy. Some of the most important aspects of the new policy direction were: allowing management more autonomy and control over their enterprises (at the expense of central planners), the introduction of market rules in the pricing system of some goods, and more flexibility in pay determination (which, however, did not result in the increase of unemployment). This shift led to increased investment in the infrastructure and services.

As a result of the layering of different, often contradictory policies, the Hungarian economic system was a hybrid of several socialist features combined with some market mechanisms. Because of these different rationales, the period under analysis should be seen as very heterogeneous in terms of social policy developments. The sections below describe these early attempts.

\section{ORGANIZATIONAL STRUCTURE OF SOCIAL POLICY}

The managerial changes, profound in the economic sector, also affected the social security administration. As Ferge (1988) states, with the economic reform aiming at more autonomy from the state, in the social security field a similar step was taken. Importantly, the autonomy of social policy organization was of a twofold character. First, the aims of social policy became disconnected from economic policy so that the research and expertise concerning the previous regained the right of existence. Second, the management of social security institutions had won, if only virtually, independence from the state in 1964. From then on, a specialized unit of the trade unions became responsible for day-to-day management and the drafting social security law (Tomka 2004). One caveat applies with respect to these changes: the financial autonomy of the social security did not exist. Therefore, while these changes were not of importance at that point in time, they marked a significant opening. Social policy became a separate item on the agenda, and some more independent research and policy planning started to be conducted.

\section{OLD-AGE PENSIONS}

As for the parameters of the old-age pensions benefits, significant changes took place as well. As mentioned above, the immediate post-war period was 
characterised by a departure from the pre-war solutions, combined with the extension of coverage. However, it soon became clear that the existing formula was rather impossible to maintain and should be more closely linked to the benefit with contributions.

One of the most important developments was the extension of coverage to the agricultural population. The law of 1961 had been a central piece of the legislation, as it opened the system to the members of co-operatives (and their families) who were at that time the majority of the agricultural population. The system did not cover only new entrants, but also individuals of retirement age with a limited insurance history. From 1960 to 1965, approximately 400,000 new retirees started withdrawing their pensions. As Maria Augusztinovics (1993) states, such a wide opening of the system would not have been possible under the previous social insurance system, given the amount of beneficiaries.

In the following years this formula was changed so that the link between the years in employment and level of benefits could be closer (Tomka 2004). An increase in the required years of employment was introduced. In order to qualify for a full pension in 1958, it was necessary to be employed for at least 14 years. Ultimately, the qualifying length of service was to become 25 in 1970. The age qualifying for minimum benefit remained 10 years. Those in between received a partial pension. Another dimension of more strictly linking benefits with previous employment was the change in defining the supplement. It was calculated at 1 percent for each year from 1929.

The law of 1961 distinguished two groups of retirees depending on the conditions of employment: the first group contained those working in severe conditions, while the second group comprised the rest of salaried employees. The benefit consisted of two components, the so-called basic benefit combined with another dependent on the length of employment. The basic component was calculated as $50 \%$ of the basis, which was the average monthly income from the 4 years preceding retirement (and from 1962, 5 years). The second component increased the level of benefit by $0.5 \%$ of the basis for each year of employment. The basis was capped on the level of 4720 forint.

The system allowed for a partial benefit, which reduced the basis by $2 \%$ for every year of difference between the actual length of employment and the stipulated one. The law specified a minimum level (500 forint or, if the basis was lower, the amount equalling to it) and a maximum level of benefit (3500 forint). The law made the income from other sources possible, unless it exceeded 500 forint (Radzimowski 1963). 
Importantly, in 1971 Hungary became the first country in the socialist bloc to introduce the mechanism of pension indexing. Every year the benefit was raised by 2 percent, with a minimum amount established. This mechanism enabled a systematic growth of nominal pension levels, in turn protecting their real value from dramatic declines, which was a typical occurrence in other socialist welfare states.

Summarising the period from mid-1940s to the mid-1970s, several changes to the old-age pensions were made. The system was expanding its coverage by including new social groups (mainly the agricultural population), although offering these groups worse conditions, however. At the same time, the extensive entitlements of the pre-war state apparatus operatives were significantly reduced. Thus, the underlying logic of entitlements was based on differentiation of rights among social groups. As in the larger part of the pre-war period, the planning of social policy was the domain of the Ministry of Finance (as the Ministry of Welfare did not exist) resulting in the neglect of long-term planning and coordination. The administration of pensions was run by the trade unions which were, however, politically subordinate to the communist party. The pre-war principle of joint financing of benefits was kept.

As the system remained a part of the state budget, it was not able to accumulate any surplus, especially in conditions of growing coverage. Thus, no favourable financial conditions were created for the extraction of surplus.

\section{FROM THE MID-1970 TO 1989}

The decade following the introduction of the New Economic Mechanism was characterized by a sharp increase of standard of living and economic growth. The growth of real salaries, combined with several reductions in working time, induced a growth in the standard of living: a smaller and smaller proportion of income was devoted to foodstuffs. More and more of personal income went on savings. As Romsics states, incomes became flattened, with a decreasing (15 times) share of the lowest income in society in the period 1962-77. Also, the income differential between the top and bottom deciles fell in this period, but grew again from the beginning of the 1980s.

This situation was to some extent affected by the oil shocks of the mid1970. As the Hungarian economy was dependent on the import of raw materials, any significant fluctuation in prices in the world market markedly affected the country. While most economies responded to the crisis by cutting pay and phasing out energy-demanding branches of economy, in Hungary such a scenario was impossible for political reasons. Measures aimed at reducing employment and/or 
the standard of living would undermine the very legitimacy of the system; therefore, Kadar turned to the West with a loan request. In the period 1970-1980 foreign debt increased 12-fold.

The postponed results of the crisis and the growing foreign debt forced the Kadar group to seek another set of solutions which would not undermine the legitimacy of the system. The reform followed the principles of that of 1968. The government expanded the field of economic freedom by allowing farmers to keep animals and increase their plots of land. Also, private entrepreneurship was less heavily taxed. Finally, the pricing mechanism of $70 \%$ of consumer goods was relaxed, and only a few basic goods had their prices regulated. Given the high level of inflation, the regulated prices grew steadily anyway. The efforts to create more space for faster-responding economic actors succeeded and dozens of thousands of new small companies were established. Finally, in 1982 Hungary was admitted to the International Monetary Fund and the World Bank.

These social and economic developments were the background for social policy reform, one of the most important in the post-war era. Again it can be seen that the period under analysis is not homogenous as several, often contradictory, processes were in place. The section below maps out these processes.

\section{ORGANIZATIONAL ISSUES}

The government, in order to gain more control over the system, took over control of social security from the trade unions in 1984. The National Central Administration of Social Security was established which was subordinated to the Council of Ministers. At the end of 1988 the Social Insurance Fund was established, but without its own budget : the cash flows were included in a separate chapter of the annual state budget. The income of the SIF came from three sources: contributions, state subsidies and gains from business activities. As Mate (2004) emphasises, the outflows of the SIF were less specified. It included pensions, but also several pension-like benefits such as special benefits for miners and those related to earlier retirement. A law passed in 1988 required the SIF to establish the liquidity and reserve funds, to be funded initially from the state budget, and to establish the Central Administration of National Social Insurance Fund to which would report to Parliament on an annual basis.

Before 1988, the total contribution paid by employers could mount to 43 percent, but in principle their level differed depending on the sector of economy (as some of them were treated preferentially) and the level of salary (Mate 2004). In practice, it was a kind of a progressive tax on wages. With the introduction of 
personal income tax in 1988, the progressivity on the employees part was cancelled, as everybody paid $10 \%$ of their income to the social security.

\section{OLD-AGE PENSIONS}

The reform of 1975 was one of the most important points in the development of social policy in Hungary. In principle, the differentiation of entitlements was removed and all social groups were treated equally. Also, the benefit determination formula was modified.

Accordingly, the qualifying age was $60 / 55$ for men/women. The minimum employment period was established at 10 years (and extended in steps to 20, which was to be achieved in 1990). The minimum level of benefit for the shortest period of employment was raised from 22 to 33 percent of a former salary (with a reference period of the three best out of five recent years of employment). The level grew with the employment length (2 percent until 25 years, 1 percent from 26 to 32, and 0.5 percent for more than 33 years). The level of benefit was established at the level of 75 percent of a former salary. This formula focused on an individuals' level and length of contributions, making the link between the contributions and benefits even stronger.

The economic crisis that started at the end of 1970s influenced the pensions system during the 1980s as well. The changes affected both, newly-granted and extant benefits. The first group of reforms concerned the lack of inflation adjustment of income brackets taken into account while determining the level of a benefit, resulting in a more digressive formula. The latter changes were the consequences of the inefficiency of the automatic system; hence, many ad-hoc measures were implemented. The main direction of the reforms was to ease the pressure of the system on the budget by reducing the level of highest benefits; however, this also affected the middle income group. At the same time, those with the lowest benefits received full compensation (or were even overcompensated) (Augusztinovics 1993). The effect of this action was that the level of newly-granted benefits (entry pensions) were still quite high but which, over time and due to undercompensation, deteriorated (Antal, Reti et al. 1995)

Additionally, in 1986 the indexation formula was raised from two to five percent per year in 1987, 8 percent in 1988 to reach 10 percent in 1989 for pensioners older than 70 years. The systemic indexation of benefits was accompanied by several ad-hoc adjustments. In 1989 the indexation was suspended because of the lack of resources: at the beginning every beneficiary received an additional flat rate payment of 360 Forint which compensated for the 
growth in the cost of living by $45 \%$. For those older than 70 years (but also disabled and women on maternity leave) an increase of 1000 Forint was granted (ZUS 1989).

Already at that time, several issues regarding the sustainability of the pension scheme emerged. Due to rising inflation, only the pensions at the lowest level were fully compensated, while other benefits remained undercompensated. However, in 1988 the lowest old-age benefit did not meet the social minimum level (reaching $83 \%$ of the minimum) while it amounted to $96 \%$ of the biological minimum. For an average benefit the values equalled 119 and $136 \%$, respectively.

The second important issue noticed by policymakers concerned the increase of the old-age dependency ratio starting from the beginning of the 1970s. Nevertheless, this was not caused by any exceptionally relaxed retirement rules, but as Augustinovics emphasises, the declining population: '[...] the 1970s added only 79,000 and the 1980s 93,000 persons' to the retired cohorts (Augusztinovics 1993: 306). She continues: 'On average 9,300 persons added annually over the last ten years to an army of 2.2 million can hardly be blamed for a severe social security crisis. The percentage increase from 1980 to 1990 was due less to this real increase than to the decrease of population' (Augusztinovics 1993: 306-307)

TABLE 10: PERCENT OF INSURED ACQUIRING ENTITLEMENT FOR PENSION AMONG ECONOMICALLY ACTIVE IN HUNGARY 1950-1990.

\begin{tabular}{|l|l|l|l|l|l|l|l|l|l|}
\hline Year & $\mathbf{1 9 5 0}$ & $\mathbf{1 9 5 5}$ & $\mathbf{1 9 6 0}$ & $\mathbf{1 9 6 5}$ & $\mathbf{1 9 7 0}$ & $\mathbf{1 9 7 5}$ & $\mathbf{1 9 8 0}$ & $\mathbf{1 9 8 5}$ & $\mathbf{1 9 9 0}$ \\
\hline$\%$ & 37 & 52 & 65 & 76 & 82 & 84 & 85 & 85 & 84 \\
\hline
\end{tabular}

Source: (Bod 1995: 178)

TABLE 11: PERCENT OF INDIVIDUALS RECEIVING PENSIONS TO THE GROUP OF PENSIONABLE AGE IN HUNGARY 1950-1990

\begin{tabular}{|l|l|l|l|l|l|l|l|l|l|}
\hline Year & 1950 & 1955 & 1960 & 1965 & 1970 & 1975 & 1980 & 1985 & 1990 \\
\hline$\%$ & 39 & 38 & 43 & 59 & 56 & 71 & 83 & 93 & 105 \\
\hline
\end{tabular}

Source: (Bod 1995: 178) 


\section{CONCLUSIONS}

The worsening economic situation had been affecting the pension system since the beginning of the 1980s, which caused a deterioration in what had initially been very generous benefits. Simultaneously, more pluralism in the analysis of social policy resulted in a variety of critical accounts regarding the Hungarian welfare state. Bob Deacon studied these accounts, which ranged from proposals for introducing pure market mechanisms, through pluralisation of welfare state, to more emphasis on social planning, and finally to the need for social revolutionary strategy (Deacon 1990).

While several adjustments took place in the period analysed, simultaneously a proposal for a systemic reform was raised. The proposal was developed by a prominent figure in social policy circles, Zsuzsa Ferge, who proposed a return to the principles of insurance in social policy programmes. In the words of the author, the proposal included,

'a clearer relationship between insurance and solidaristic principles; the return to the independence of the pension fund under a board, the introduction of a universal minimum income scheme for elderly who lacked (sufficient) pension coverage; and a three- tier scheme composed of a universal, budget-financed minimum pension, a pay-as-you-go scheme and a voluntary private (or mutual) scheme' (Ferge 2003: 132).

According to Ferge, the Hungarian pension system was blurred and characterised by several inequalities which had resulted from a layering of several reforms, and which was also too parsimonious. This comprehensive programme did not see its full implementation in the 1980s, but some elements were introduced in early 1989. More importantly, however, was the fact that awareness as to the presence of difficulties in the system was raised among several policymakers and experts. In consequence, the issue of the reform and the direction the system should follow had been present since mid-1980s.

\section{TRANSITION}

Hungary is exemplary of those countries undergoing a gradualist type of transition. Basically, this means a step-by-step switch to a form of a market economy and democratic political system, opposed to the 'big bang' strategy which for example took place in Poland (Roland 2000). It is worth noting that these categories are only approximate, as various political and economic processes 
differed with respect to their dynamics. Accordingly, in the case of Hungary it is hard to establish a departure point for the transformation; nevertheless, one could argue it was around 1988, when taxation of personal income of the population was introduced.

\section{ORGANIZATION AND FINANCING}

Organizationally, this period brought several changes aimed mainly at making the system more financially sustainable, but also at reducing the involvement of the state so that social security did not add to an already dire situation for the budget. First, in 1989a separate financial entity, the Social Insurance Fund, was established. The Fund was partially independent from the budget and was managed by the National Social Insurance Administration. However, the influence of central government was continued from the 1980s, with a strong involvement of the Ministry of Social Affairs and Health which included strategic planning. Both the head of the social insurance entity and the Council of Ministers used their discretionary powers to influence the parameters of the benefits. The relative dependence of the Fund on central government was the result of a postponement in the introduction of an independent self-government. The postponement, in turn, resulted from a fear that only post-socialist trade unions could dominate the management of social insurance given the lack of strong independent trade unions (Ferge 2003). Therefore, Supervisory Committees proposed by Parliament temporarily oversaw the funds.

In line with the changes described above and in order to leave the fund in a sound financial condition, 300 billion forint was promised to it. However, only a fraction of this amount was transferred to the found (of which a big part was in housing assets).

One of the most important organizational changes in the social security system was the unification of the Social Insurance Fund and the Health Fund. The unification of the funds worsened the financial situation of the social policy finances, as expenditure on health exceeded the contributions collected. The deficit was financed from the old-age pensions side of the unified funds, but this also coincided with a growing level of inflation.

In November 1990 the government sent Parliament a document that outlined the financial situation of the Social Insurance Fund in the previous year. The Fund entered 1990 with a 10\% surplus; the vast majority of its income (98\%) came from contributions (Mate 2004). 
Although the Social Insurance Fund closed the 1980s with a surplus, by 1990 this surplus was already gone. In the following years the budget was characterised by a growing deficit. Maria Augusztinovics provides the explanation for the occurrence of this deficit. In the process of gaining independence from the state budget (and the ministry responsible for social security), the traditional focus for cash transfers (both long and short-term) had been extended to the health services. It began in 1988 with transferring the responsibility for pharmaceutical subsidies (i.e. subsidies for pharmaceutical drugs for consumers at the point of purchase) to the social security organization without any required compensation from the state budget, and in 1990 the entire financing of health services was moved to social security. At the same time the ministry responsible for social policy took over payment of child allowances. In 1990, the losses and gains balanced for both sides, so this action was called the exchange of equal burdens. However, in the coming years the burden of expenditure on the health service grew significantly (by a third), while general expenditure on child allowances decreased (at the same time, the social security organization still had to contribute financially to their payment in form of a loan to the government). As a result, potential savings were consumed by indirect financing of government spending (Augusztinovics 1993).

A significant part of this expenditure in the first half of the 1990s was of an inflationary character. As Czucz and Pinter show, the expenditure growth was lower in 1990s (that is, during the 'pension crisis') than in the 1970s and 80s. On the other hand, as in all the economies of the region, tax evasion and the extent of the grey economy made the tax (and contribution) base smaller. Altogether, this complex situation contributed to the impression shared by several politicians for the need to reform the excessive and indebted social security system.

One of the most important political declarations concerning the reform of the pension system was Resolution 60/199, issued on October 29 1991. The document was a call for pension system reform and provided some blueprints as to how to achieve it. The resolution proposed adjustments to the system, but without removing its essential institutional framework. The system was to remain PAYG, but under certain conditions: nothing else should be able to draw on its budget, the link between contributions and benefits should be closer (although child-rearing should be included into a period of service), and the case for adding new tiers was set out. The Resolution outlined the measures to achieve these aims: raising the retirement age, making the Social Insurance Fund budget independent from the general budget, and a separation of health services financing from the financing of other benefits amongst others (Mate 2004). 
The separation of the funds took longer than expected, and instead of in 1992 it was finalised in 1994. It left, however, a significant financial loss in the oldage pensions' fund. As Ferge argues, the Health Board was not as successful in managing the health part of the fund and earned a bad reputation, as did the Pensions Board. The financial and organizational split into two separate selfgoverning funds was followed by the split in contributions and the raise in its total level. Accordingly, out of a combined total $54 \%, 44 \%$ was paid by employers and the remainder by employees. The contribution of the employers was divided between health insurance $(19.5 \%)$ and pensions $(24.5 \%)$, and in the case of employees it was $4 \%$ and $6 \%$ respectively. At the same time, the cap on contributions from employees grew to a high level of 900 thousand forint (Czucz and Pinter 2002).

During the process of separation, further decisions towards selfgovernance were taken. In 1993, elections to the Pension Insurance General Assembly were held. The assembly comprised 36 insuree representatives (including 4 pensioners) and 24 employers' representatives. The actions of the Assembly were supervised by the State Audit Office and the government, which could in case of unlawful action make their case in the Parliament and cancel the decisions concerned (Czucz and Pinter 2002).

The role of parliament was also essential when it came to the pension system budget: the Insurance Assembly drafted it, but Parliament was in a position to debate and accept the final version. The role of the executive branch had been strengthened by parliamentary decision in 1995, so that the Assembly had to comply with the deadline every year (July 31). If this was not the case or the government opposed the proposed budget, it could submit its own for the coming year and parliament could work with this version. In this way, the government took over a significant part of the power from the previously quite independent Assembly.

An essential addition to the system took place in 1993, when voluntary pension funds were established. From a policy point of view, it was aimed at diversifying the pensions' portfolio, but another important aim was to strengthen Hungarian civil society. The latter idea is reflected in the organization of this voluntary scheme: it was composed of a number of small mutual benefit societies. The participants in the voluntary funds were eligible for significant tax exemptions (50\% of contributions paid to private voluntary funds was tax deductible) (Matits 2008). This incentive did not prove strong enough, as the inflow of members was rather limited. 


\section{PENSION BENEFITS}

One of the most essential changes regarding the level of benefits took place in 1992, when the indexation of benefits was introduced. The benefits were indexed according to the change of net wages. However, different sets of rules relating to how newly-granted pensions were calculated and the indexation of those pensions already in place resulted in the differences between age cohorts.

As far as the eligibility is concerned, some additional parts of legislation were created. First, in 1990, the condition of the retirement age was loosened. A person who might possibly be made redundant within five years or less to the stipulated retirement age could obtain a benefit conditional upon the agreement with his/her employer. In such case, employers were obliged to pay the equivalent of a benefit every six months until that person's official retirement age. As this solution faced several problems due to the instability of the economy, another preretirement formula was legislated in 1991. The rules became stricter as it was now stipulated that a person had to have been made redundant within three years of their retirement age. What is also worth noting is that this benefit was financed from the Solidarity Fund - the same as for the unemployment compensation jointly by the state budget and by employers. In 1994, the number of persons receiving such benefits was around 100,000 - that is to say, less than $5 \%$ of all pensioners.

When it came to the newly established pension supplements, the biggest group of beneficiaries consisted of the politically rehabilitated who numbered 250,000 (Antal, Reti et al. 1995).

As stipulated in the 1980 regulation, full eligibility to pension rights was to be obtained from 1990 and on, with a record of 20 years of employment. In order to cope with the problem of an interrupted employment record due to the crisis surrounding the transition, the possibility of a partial pension was introduced in 1991. Along a similar line, the imputation of tenure interruptions longer than five years was introduced. Also, from 1992, the period of care for each child born before the introduction of paid care leave is included into tenure.

In 1993, an increase in the retirement age was introduced in line with the 1991 guidelines. The aim was establish this at 62 or 65 before 2003 in order to ease the burden carried by the working population and to reverse the high dependency ratio. This aim was made less ambitious at the parliamentary stage which stipulated an increase in the female retirement age by two years every single year starting from 1995 with the ultimate aim of the official age of 60. However, existing 
rules concerning early retirement made the effective age lower, partially as a result of strong opposition on the part of the trade unions (Ferge 2003).

When it came to the generosity of the benefits, several measures took place as well. In principle, they were of a compensatory character and served different political aims (such as compensating the victims of communist repression, but also countering the effect of high inflation with which the existing mechanism dealt poorly). Accordingly, in 1990 a group of pensioners was given a one-time payout ranging from 2400 to 4000 forint in order to compensate their benefits for the effects of inflation. Of more systemic character were the changes made to degression tables in 1991, which had been originally introduced in 1982. The compression of the upper income bands prevented the occurrence of excessively high benefits, while the increase in the base level raised the level of the benefit ceiling for the calculation of benefits. Thanks to its degressive formula the disparity between the lowest and the highest benefits could be lowered.

From 1992 on, the income reference period used for establishing a level of benefit was extended. In 1992, the period was extended from 3 to 4 years. More importantly, however, Parliament decided in 1991 on the regular indexing of the level of benefits. The reference for an increase in benefits was the expected wage increase for a given year. From 1995 the reference became the wage increase from a previous year (Czucz and Pinter 2002). In 1991 the benefits were increased by 21$29 \%$, to a small degree depending on tenure. From 1992, the link became closer and benefits were adjusted twice a year (by 13 and 6.5\%). In the same year, a corrective adjustment took place concerning pensions granted before 1989 . Here, the adjusted rate of increase ranged from 3 to $18 \%$, depending on the time a benefit was granted and tenure. In 1993, the increase took place three times as the regular increase of $14 \%$ lagged behind the growth of wages (Ministry of Finance 1993).

When it came to establishing the level of entry (i.e. newly-granted) benefits, in 1993 all income as of 1988 became a reference for benefit calculation. The aim of this change was to make the link between previous incomes and expected benefit closer. However, under conditions of persisting economic downturn, reliance on nominal wages endangered the real value of benefits. This problem was tackled with a partial valorisation. However, due to the time lag built into the mechanism, the benefits remained constantly undercompensated, as their reference basis was adjusted to the level of wages growth that took place two years earlier. Accordingly, in 1993 the level of newly-granted benefits was determined on the partially valorised wages (to the level of 1991) from the period 1988-1989; this affected the level of benefits between 1991 and 1993 (Antal, Reti et al. 1995). Both 
newly-granted and existing benefits were affected by either partial compensation or wage valorisation until 1994.

A more organized attempt to curtail social security benefits (mostly family benefits, but also pensions) took place in 1995. As the Constitutional Court questioned it soon after its introduction as not being in line with the Hungarian tradition of social policy provision, I will describe the so-called Bokros reform below. Serious debate concerning the systemic features of the scheme started in the mid-1990s with the establishment of the new government after 1994 elections. The government was a result of a coalition between the Socialist Party and liberal Alliance of Free Democrats, which held the aim of renegotiating the social contract with its social partners. However, due to mounting economic problems, the direction of the government policy changed from reconciliation to that of costcontainment. The Prime Minister of the socialist-liberal coalition, Gyula Horn, gave his minister of finance Lajos Bokros (liberals) the green light for the reform. The aim of Bokros' plan was to curtail public spending by the devaluation of the currency, introducing an $8 \%$ surcharge on imports and several cuts in social expenditure (Cook and Orenstein 1999). The benchmark of the Bokros plan was to reduce public debt from 5.4\% of the GDP (as proposed in the budget outline for $1995)$ to $3 \%$. The measures led to a reduction in real wages by $9 \%$ according to the government, and by as much as $15-20 \%$ according to the trade unions. Apart from the impact resulting from the changes in the macroeconomic situation, the programme focused mainly on two social policy programmes: family and child allowances, and old-age pensions. Family and child allowances became meanstested (at the level of income 25,000 HUF per capita per family), while the pensions were to be affected mostly through the mechanism of adjustment, relying on the growth of real wages. The other aspect included charging social contributions from the self-employed and some wage benefits. Very importantly, the Hungarian Constitutional Court ruled the regulation concerning child allowances unconstitutional one month after its introduction. The ruling was based on the acknowledgment of the existing property rights to social security and that they could not be taken away from the citizens (Cook and Orenstein 1999). As Gero emphasises, 'the Court claimed that as a result of the long history of receiving such services, the beneficiaries had acquired a right to these services' (Gero 1997) This is why the Court mandated 300 days of waiting period, after which some new regulations could be implemented.

The ruling dealt with the issue of old-age pensions along similar lines. As Andras Sajo remarks, '[although] still recognising that past pension contributions were not directly correlated to the current pension benefits, the Court held that 
citizens' expectations of continued benefits were legitimate given their basis in past contributions. Once the contributions were made, according to law the conditions of future or current benefits were to be honoured, irrespective of the value of contribution' (Sajo 2006: 88). In this way, the Court somehow confirmed the specificity of the Hungarian model, characterised by a relatively high level of security for pensioners and their situation.

It should be noted that the 1995 ruling was not the exception in the first half of the 1990s. The Constitutional Court had previously been involved in the process of policy-making in Hungary when it maintained the right of citizens to social protection, either on the basis of property right (pensions, sickness benefits) or as a right in itself (child allowances). Gero concludes that the activity of the Hungarian Constitutional Court established clear standards regarding the rights of population (including social security) and made policy makers aware that activities going against these rights could be judged unconstitutional (Gero 1997).

\section{DEBATES AND POLICY PROPOSALS}

Simultaneous to the changes in the formula of pensions, more strategic decisions were being discussed. They concerned the future of the old-age pensions system and the way it was to adjust to the new situation. In 1991the National Assembly had already discussed this issue and came up with a proposal for reform. The reformed system, according to the parliamentary proposal, was to consist of three parts (or levels), of which two would be mandatory and the third voluntary. The first level was planned to be a basic national pension, but given the economic situation its introduction was to be postponed. Instead, for the transitory period a system of income supplement allowances was to be implemented. The second proposed part was a modification of the existing PAYG system in order that there should be a closer link between income and benefit. The third part included a voluntary insurance scheme. (Czucz and Pinter 2002). Also, as a general principle, it was proposed that the retirement age should be raised. As mentioned above, due to the volatile economic situation, the implementation of this framework for insurance was supposed to take between 10 and 15 years.

In the background there were proposals for more fundamental reform, pushed forward by international organizations such as the IMF and the World Bank. However, they did not bring anything to the table which had not been proposed by Hungarian experts. In addition and what was also important was the fear that such significant changes might lead to delayed and irreversible results which could not be predicted at the time of taking the decisions (Ferge 2003). It was after 1992 when more and more conflict became present regarding the 
direction of reforms. The conflicts revolved around the issues of financing (funding versus PAYG) and the privatisation of the pension scheme.

The shift of the mid-1990s, which affected mostly existing policies, was also present in the pension discussion, as described below.

The debate resulted in a series of competing proposals developed by various government agencies. The proposals can be roughly divided into two groups: the first group of proposals was concerned with maintaining the existing PAYG scheme while introducing some changes aimed at improving its fairness and transparency. The second group of proposals proposed a total or partial privatisation. The proposals belonging to both groups are outlined below.

The institutionalisation of the governmental debates concerning pension reform took place at the end of 1994 . The body facilitating the development of proposals was the Subcommittee on Welfare, working within the frames of the Committee of the Reform of the Treasury. The first proposal developed by the Subcommittee followed the principles presented in the parliamentary resolution of 1991. A three-level system was to be established, with first level being a universal, basic pension, covering either insured (financed by contributions) or all citizens (financed through general taxation). The second level would be a reformed PAYG scheme, whose formula would be linked more closely with paid contributions (their level and length of contributory period) and benefits, so that it would work in more actuarially fair manner. The third level would be an optional additional insurance scheme. This proposal was supported by the macroeconomic simulations delivered by Maria Augusztinovics and the Institute of Economics of the Hungarian Academy of Science (Hasselmann 2006). The proposal was largely neglected, however. While well-received by the Subcommittee on Welfare (and accepted in the summer 1995) it did not reach governmental meetings. Instead, the Committee of the Reform of the Treasury submitted a proposal in the summer 1995 consisting of several points that were not discussed during the meetings of the Subcommittee. The proposal submitted to the government presented a framework rather than concrete solutions, but it attached a significant role to the private, funded level (Ferge 2003). The Ministry of Finance, strongly influenced by the World Bank, took up this framework

Thus, parallel to the proposals giving priority to parametric change, a discussion concerning more fundamental reform surfaced. This debate begun in the circles of the Ministry of Finance sketching a proposal for the reform of public finances and which was fuelled by consultants of international organizations, mainly the World Bank. The inspiration for the actions of the Ministry of Finance 
was foreign (mainly coming from World Bank circles), but it was also Lajos Bokros whose views strongly influenced the shape of the proposal. Numerous versions were presented, starting from late 1995 and were followed by feasibility studies prepared within the ministry. In principle, the aim of the reform was to boost longterm economic growth by increasing participation of Hungarians in the official economy and through the creation of savings in private funds. Next to this was a desire to reduce the burden the pension system was creating for the state budget as well as for an overall increase in the international competitiveness of the economy by a reduction in labour costs. Clearly, the idea of lessening the budgetary pressure the pension system created was linked with reducing the generosity of benefits. Beside the fact the new system would be leaner - due to the phasing-out of both the old system and the double burden carried by the working population - the new system was also expected to be less generous.

However, other proposals were being developed by the PIF and the Ministry of Welfare. The two proposals differed to that developed within the Ministry of Finance in their fundamental logic. While the previous attached importance to the well-being of elderly and securing their situation, the latter focused more on the issues of long-term economic development.

The proposal which was followed was one based on the Parliamentary recommendations of 1991 and which assumed the operation of the pension scheme based on a three-tier architecture and which also focused on sustaining a decent level of living for pensioners without compromising a closer link between contributions and benefits. Accordingly, the basic pension was aimed at needy individuals. In order to increase the transparency of the scheme, a so-called 'points system work-related pension' was proposed. The idea behind this solution was to make the contributions comparable across years in a unified manner. Here, one 'point' referred to the level of contributions paid from national average earnings. The scheme assumes a variation in the level of contributions, hence the increased (or decreased) number of points. The information on points would be collected throughout a person's entire employment career. During the periods of employment inactivity (maternity leave, military service), the contributions would be paid by the state budget. The level of income basis for calculating contributions ranged from the minimum wage to the two and a half to three times an average wage.

The minimum service period was 20 years; however, the full contributory period was to last $42-44$ years. The retirement age for both sexes would be the same and set at 62 years. The average benefits were expected to reach $60-65 \%$ of an average wage, while the benefits after the full contributory period would amount 
to $75-80 \%$. The benefits already paid were to be recalculated according to the point system so there is no discrepancy between the 'new' and 'old' benefits.

The benefits were to be accompanied by income from the third tier - the voluntary pension scheme, treated preferentially by the tax system. The other elements included stricter rules concerning disability benefits, abandoning the regressive formula and reducing the solidarity principle in the system (Szeman 1999).

The second 'modest' proposal was developed the Ministry of Welfare. This proposal referred to the structural changes of the Hungarian economy as the source of pension system problems. In other words, the reform of the pension system was to be a function of the general transformation of the economy and its relation to the system. Again, the parameters of the proposed system (with a replacement rate oscillating around $60-65 \%$ or even $65-70 \%$, with the first level generating $20 \%$ and the second around $40 \%$ and, and with minimum benefits guarantees combined with the PAYG framework) did not aim at changing the system fundamentally (Czucz and Pinter 2002). The proposal assumed only a parametric reform of the system which, combined with the increase of retirement age enacted in 1991, would generate significant savings. However, this proposal was not discussed within the government.

In May 1996, the direction of proposed reform was further confirmed by a government resolution (Czucz and Pinter 2002). The proposal went along with the arguments outlined in the influential the World Bank publication Averting the OldAge Crisis (1994) which stressed the importance of fairness and equity in any new system on the one hand and an increased role of market in provision of benefits on the other. The planned system consisted of two mandatory tiers: the first being a social insurance pension, and the second a private scheme based on private insurance accounts. These mandatory tiers were to be accompanied by a voluntary one. The minimum retirement income was to be guaranteed through a meanstested allowance.

The background and the solutions proposed in the reform blueprints were widely discussed by both the insiders (the Pension Insurance Assembly) and independent actors.

One of the most important bodies in this respect was the Council on Elderly Affairs established in December 1996 by the government. Among its members were not only government representatives but also representatives from other organizations. The members included the three main organizations 
representing pensioners as well as the Health Insurance Board, the Pension Insurance Board, the Hungarian Maltese Charity Service, the Hungarian Federation of Practising Physicians, representatives of the Federation of Local Authorities and several independent experts (Szeman 1999). The Council raised several criticisms that coincided with those pointed out by the Pension Insurance Board.

The new system, according to its critics, put a large groups of citizens especially women - in a comparatively disadvantaged position by tightening the link between contributions and benefits. The new system would not take into account the difference in life expectancy between women and men. The problem of inequality here lies in the fact that initially the estimation formula was based on separate longevity data for each sex. Because of a longer average length of life, the benefit would be lower for women compared to that of men with the same employment and earnings history.

The system openly promoted a male-style of employment (without interruptions related to childbearing) and young individuals starting their careers - it was only these groups for which the generosity of new pensions would be comparable with the old system. The inclusion of periods of childcare leave considered as service years was not proposed in the original reform framework. Additionally, the years spent in higher education were not included in the service period either.

With regard to the problems related to the assumptions underlying the reform, the Council stressed that they painted a very optimistic state of economy. Economic growth was supposed to last for 55 years, combined with a decreasing rate of inflation. The growth was assumed at a pace of $5 \%$ per year until the year 2000 and 3\% thereafter. The running costs of funds were established at the level of 4 to $5 \%$, while in other countries this cost was three times higher. Also, the problem with indexing the benefits of those who would like to remain in the old system was identified: with the changed rules the value of their benefits (expressed in the relation to the average wage) would decrease from 61 to $42 \%$ (Szeman 1999).

The Pension Insurance Assembly pointed out the underestimation of the deficit of the pension fund which would be caused by transferring a part of the contribution going to the funded tier. The discrepancy between the assembly's figure and that of the Ministry of Finance leading the reform was 300\% (90 versus 30 billion forint). Another issue was the underestimation of running costs, of a similar magnitude (Czucz and Pinter 2002). 
Apart from the question of running the system, legal matters were raised. The question of the asymmetrical involvement of the state was raised (the state enforced the contribution payment compliance, but on the other hand, did not guarantee the benefits).

Importantly, the governmental debate and the process of social consultations reduced the importance of the funded component, and more generally, the radical nature of the reform. Initially in the light of the budgetary crisis of the 1995/6, the Ministry of Finance - inspired by the World Bank - pushed for a complete replacement of the existing scheme with private, mandatory pension saving accounts. This option was especially supported by Adam Gere, who was an investment banker involved in voluntary pension insurance. This proposal was opposed, however, within the Ministry working group itself as too radical. As Orenstein states, the members of the group were initially sceptical when it came to the privatisation, but soon changed their mind when they were convinced the funded component would work under the existing regulatory framework (Orenstein 2008). Thus, the working group decided to go for a compromise and proposed 50/50 division between PAYG and the funded component. Given the dire economic condition of the budget, it was also proposed to reduce the level of total contribution from 54 to 44 percent (with $25 \%$ of salary devoted to pension insurance). The split of contribution was to be reinforced, with 15 percent paid by employers via the PAYG system and10 percent paid by employees to the mandatory funded tier.

The next step towards softening the proposal took place because of the discussion between the ministries, with a significant involvement of the Ministry of Welfare. This discussion coincided with the change of the leader of the working group in the Ministry of Finance, who was replaced by a more moderate person (Orenstein 2008). In addition, due to the reversal in social policy changes stipulated in the Bokros plan, Bokros himself resigned (and joined the World Bank). Peter Medguessy from the Socialist Party, who was more conciliatory compared to his predecessor, replaced Bokros.

The discussions between the two ministries were fierce and did not lead to a victory for either side. However, gradually, they led to the hedging of the proposal developed within the Ministry of Finance. The Ministry of Welfare headed by the socialist Szabo had an ally in the Pension Insurance Fund officials who were elected from the trade union activists and who were independent of governmental influence. This coalition stood in opposition to the Ministry of Finance. As the decision paralysis had become more and more obvious, the government decided adopt a reform timeline. The reform proposal was developed 
within less than one month starting from April 1996 (Orenstein 2008). On April 9, 1996 during a meeting organised by the Prime Minister Medgyessy, the ministers of finance and those from welfare reached a preliminary agreement. Szabo, heading the Ministry of Welfare, accepted partial funding of the pension system on the condition of figuring out how to finance it. An important part of the agreement (and a great success for Szabo) concerned the size of the funded component, the acceptance of the points system for social security reform and loosening the qualifying conditions for benefits. Accordingly, the share of the mandatory funded component was decreased from $50 \%$ to $33 \%$, and finally, only 20 years of service instead of 32 or even 35 as proposed by the Ministry of Finance - was accepted.

As a result of the compromise between the two ministries, a joint working group had been established, with on the one hand the representatives of the Ministry of Welfare dealing with changes to the first tier and on the other hand those linked to the Ministry of Finance, the World Bank and financial sector working on the parameters of the funded component of the system. At the same time, the Committee of the Reform of the Treasury with all its subcommittees was dissolved. Thus, the forum for the pension reform debates disappeared and the government working group became a major platform for shaping the reform proposal. The PIF did not join the group in spite of several invitations from its leaders.

The agreement was not accepted by the PIF (as well as other nongovernmental bodies) which held a very radical stance on the issue of (partial) privatisation of pensions.

However, the voice of MSZOSZ trade unions, involved also in the PIF, kept on being heard in the further legislative stages: another set of debates took place in the Interest Reconciliation Council (IRC) rather than Parliament. The split within the Socialist Party did not add to its agenda clarity, as there existed clear water between the IRC which was more modest and the PIF which represented the hardliners (Hasselmann 2006). However, the wing that opposed a radical pension reform channelled and contained the debate to within the IRC as a condition for further cooperation. It was in the IRC where Socialist-affiliated MSZOSZ had an important position.

The reform-oriented wing of the Socialists together with the centrists joined the parliamentary working group with the aim of opening up the discussion to a greater number of interested parties. The group also consisted of members of the Alliance of Free Democrats who strongly supported the reform line outlined by Bokros. Interestingly, several important figures of the group (including Judit 
Csehak, a leading member of the parliamentary social policy committee) were involved in, and benefited from, the voluntary pension schemes. After a short period of hesitation, the parliamentary working group opted to support the reform proposal as outlined by the government. As Orenstein (Orenstein 2008) argues, the debates in the working group replaced the parliamentary discussions and in this way, decreased their public outreach. However, as shown in the following sections, there were other bodies (mainly the IRC), where more profound decisions were being made. The parliamentary debates did not add much to changing the proposal and were reduced to representing the standpoints of various parties on the issue. Once the working group finished drafting the reform proposal, it was subjected to a consultation process with social partners, one of them being the IRC, starting from the beginning of 1997

The debates in the IRC reformed the proposal even further, starting with weakening the funded component. Here, the opponents of a radical reform were more successful than in the Parliament and in principle follow the PIF standpoint. This view was expressed right at the beginning of the negotiations with the IRC by the MSZOSZ leader Laszlo Sandor, who openly dismissed the option of directing a third of contributions to the private sector. On the other hand, the representatives of the employers also did not agree to the reform due to the expected burden it could bring about. More concretely, the discussion revolved around issues of benefit indexation (so-called Swiss, half-price, half-wages), the design of the first tier and the benefit formula, and whether to include childrearing and periods spent in higher education to the years of service. The government side accepted these claims and the following regulations were agreed upon: the formula concerning benefits for the first tier assumed more generous benefits than that proposed by the government, the state guarantee for the private funds, inclusion of childrearing and higher education periods in the qualifying conditions for a minimum benefit and the possibility of contributing to the private tier. In addition, the switch to the Swiss indexation model was postponed until year 2000 with the government committing itself to much more favourable indexation (i.e. above the level of inflation).

The success of the MSZOSZ did not end there. Sandor Nagy, a former head of the union as well as the PIF, organized a conference on February 13 where he expressed his criticisms towards the government concerning the exclusion of the PIF (and trade unions more generally) in the reform process. Nagy received the support from members of the conference, more than a half of whom protested against the privatisation of pensions (Ferge 2003). His idea was to minimise the importance of the funded component; he achieved this aim and negotiated a 
further decrease in the contribution going to the second tier: from 10 to $6 \%$ for two years to be raised to 8 percent. Subsequent IRC meetings resulted in a series of other changes: state guarantees for the private component, change in rates for calculating the contributions in the mixed system, inclusion of the period of maternity leave to the eligibility criteria and the suspension of regulation concerning special groups' transition rules.

The draft which was discussed and significantly changed during the IRC meetings reached the parliamentary stage in May 1997. The ruling coalition wanted the draft to be discussed and voted on immediately; however, the parliamentary opposition did not agree. The parliamentary proceedings took one and a half months (from June 3 to July 13) and the debate revolved around issues already raised during discussions in other bodies: financing the transitional period and the expected benefits the new pension arrangements would bring to the Hungarian economy. Five drafts of legal acts were presented by the government: on the general financing of social insurance, on the public insurance system, on the private funds, on mandatory health insurance and on the modification of the Social Act, which introduced social assistance for the elderly. The length of the debate was limited to 40 hours, and it did not exceed this limit. 400 amendments were submitted, but they did not change the fundamental assumptions of the proposals (Ferge 2003).

\section{POST-REFORM DEVELOPMENTS (IMPLEMENTATION)}

The new system was accepted on July 151997 and was to be implemented from January $1^{\text {st }} 1998$. This section describes the impact of the reform on organizational and financing arrangements and further, regulations concerning eligibility and expected generosity.

Since the beginning of 1998, few important organizational changes have been introduced, some of them being result of the reform itself, others that were decided in the phase of implementation. First, the PIF, previously independent, has been subjected to the control of the Ministry of Finance. The PIF lost the authority to collect contributions, and this responsibility was moved to the State Tax Collection Agency. The transitional rules for older workers had been extended. In 1999 the Swiss type of indexation had been suspended and the old type of indexation had been reintroduced. Also, the transitory level of contributions (6\%) to the private tier was sustained, while the total contributions were reduced from $24 \%$ to $18 \%$.

As to the issue of who was covered by the new system and who belonged to the old one, a mixed approach was adopted. For those newcomers to the labour 
market (after 1 July 1998), who were no older than 42 years, the participation in the new system was mandatory. Participation in the new scheme was voluntary for persons no older than 47 years, which would give them at least 15 years (given a retirement age of 62) of saving accumulation in the second tier.

The features of the new system are as follows. When it came to financing, there existed a split of contribution between employer and employee, with a gradual shift of responsibility to the latter. Accordingly, from 1998 to 2000, the contribution of employers was planned to be decreased from 24 to 22 per cent. Simultaneously, the rate of employees' contribution was to grow from 6 to 8 per cent.

With respect to the new system, its financing would be based on the contribution split between employers and employees. The level of the joint contribution would remain the same as in the old system, so as to facilitate the gradual shift towards more responsibility for employees (the reduction of the contribution level on behalf of employers and increase of contributions paid by employees). In the final model, the employers' share at $22 \%$ of a base income is paid to the first tier (PAYG) while $8 \%$ is paid to the second tier-private funds.

\section{REFORMED PAYG TIER}

The socialist-liberal government which prepared the pension reform did not repeat its success in the election taking place in June 1998. Instead, the conservative government took power. The government immediately proposed the decrease of social security contributions. The plans were introduced, but accompanied by a slower growth of continuing benefits: $14 \%$ instead if $18-20 \%$ as stipulated earlier. Also the process of phasing out regression continued. When it came to the flow of new entrants to the mixed system, this requirement was also suspended until 2002. The plans of the conservative government went as far as to introducing the NDC formula in the first tier and a possibility of return to the 'old' system for persons who entered the new system by mistake (Simonovits 2008).

These plans were not implemented because in the elections of 2002 the leftliberal coalition was returned to power. The changes introduced by the conservative government proved hard to change as they appeared very popular among Hungarians. Indirectly, the coalition influenced the pensions level by way of a $50 \%$ increase of salaries in the public sector, which was followed by an increase in the private sector, and ultimately, the benefits level. Quite contrary to its earlier promises, the coalition wanted to counterbalance the effects of the Swiss indexation, and introduced the $13^{\text {th }}$ month pension, which contributed to the $2 \%$ increase of the benefits' real value. Another two steps of the coalition included 
further changes to the ceiling for employees' contributions and more favourable rules regarding establishing levels of newly-granted benefits. The previous issue resulted in deepening the degressivity of the system: while employers' contributions were not capped, the ceiling for contributions paid by employees increased from 2 to 3 average gross wages. The second change concerned the actuarial adjustment rate, defining the increase of benefit for each year of work beyond the stipulated retirement age. Until 2004 this rate equalled to $3.6 \%$ for each year, which meant that a benefit was increased by this value if someone worked over the official age of 55 . However, with the planned increase of the retirement age to 62 years the coalition changed the adjustment rate to $6 \%$. As a result, the decision about retiring at the beginning of 2004 instead of the end of 2003 changed the level of benefits significantly (Simonovits 2008).

These manoeuvres caused the deficit in the health and social funds which, at the end of 2005, accounted for 5\% of GDP. However, this dire situation did not prevent the ruling party from promising cuts in contributions by $5 \%$, while the opposition party (the conservatives) went even further and proposed a reduction of employers' contributions from 29 to $19 \%$ and the introduction of the $14^{\text {th }}$ month pension. These plans were not implemented as the ruling coalition remained in power and disregarded such proposals. Instead, facing a mounting deficit, the government introduced austerity measures. The actions aimed at reducing the deficit involved an increase in employers' contributions (from 18 to $21 \%$ ) and a change to the rules for calculating newly granted benefits. Compared to the old rules, under the new regulations (which excluded an employee's contribution from the nominal wage used for calculating pensions) the level of benefits was $8 \%$ lower (Simonovits 2008).

The main novelty of the reform system lies in the creation of the second tier, the so-called Mandatory Private Pension Scheme that is based on the dynamics and activities of Mandatory Private Pension Funds. The bodies controlling the funds are the Ministry of Finance and State Financial Supervisory Authority. The latter charges the funds for its supervisory activity.

Mandatory Private Pension Funds are owned by their members, who exercise their power through general assembly. The general assembly appoints a board of directors to deal with the strategic issues of the fund as well as a board of supervisors to overlook and manage its financial affairs. A fund is run by its mandatory employees (managing director, auditor, actuary, lawyer and an internal auditor) but also through outsourcing certain activities (bookkeeping, investment management, etc.) (Iwasaki and Sato 2008). 
Contributions, which are paid by employees and which go to the second tier, are divided into 3 parts: $4-6 \%$ covers operational costs, $1 \%$ is devoted to various guarantee funds, while the rest (that is $93-95 \%$ ) goes to individual saving accounts. Importantly, a fund must demonstrate the rate of return of at least $1-2 \%$ percent after all deductions; otherwise, its role as a pension payment institution is liable of being called into question (Iwasaki and Sato 2008).

When it comes to the investment portfolio, until accession into the European Union it was very precisely defined by the Government Decree No. 171/1997. At least $51 \%$ of the assets were to be invested in domestic financial instruments, with no upper limit. In practice, between 1998 and 2005 the vast majority of assets (approximately 75\%) were located in government securities, $9.6 \%$ in stocks and $2.6 \%$ in corporate bonds (Iwasaki and Sato 2008). While the restrictions concerning investment portfolios have been removed, the investment profiles remain similar.

The annuity return depends on the return rate achieved by a fund. However, the value of assets in individual accounts has been guaranteed by law for individuals being members of funds for more than 15 years. If the capital of a fund member hits a level lower than the stipulated limit, it is topped up from the Guarantee Fund. In case the Fund has insufficient resources, it is subsidized from the state budget.

\section{DEVELOPMENT OF MPPFS}

As mentioned above, the inflow of participants to the new, mixed system exceeded the expectations of policy-makers. After a period of 20 months when workers under age of 42 could decide whether to join the new reformed system, 2 million of them did so (against the 1.5 million expected). However, afterwards some number of them returned to the old system.

Between 1998 and 2005 the SFSA gave licenses to 60 funds irrespective of how their membership is concentrated: the biggest six funds gathered $85 \%$ of total membership and had around $80 \%$ of all assets. The performance of the funds was not successful in the period 1998-2000 where the average annual real yield was $0.73 \%$ on average. The return became even lower between 2001 and 2003 (Iwasaki and Sato 2008). The problem of poor asset management became so acute that the government introduced several measures with the aim of harnessing more control over the activity of funds. The measures included the introduction of a ceiling on the rate concerning an asset management fee, the strengthening of the supervisory power of SFSA over funds and the extension of management asset activities that must be reported to the supervisory body (Iwasaki and Sato 2008). 
The reform meant that voluntary funds, established in 1993, were included into the pension framework. The main feature, the possibility tax deduction both on contributions and benefits paid, remained in place; however, the ceiling for the deduction decreased (from 500,000 HUF between 1993 and 1997 to 200,000 until present). Until 2006 the contributions of employers were not taxed up to the level of minimum level, but afterwards this limit was cut by half. Interestingly enough, in spite of fears that the mandatory private funds (that is the second tier) would crowd out voluntary schemes, this did not happen. Quite the contrary: the introduction of the mandatory schemes coincided with the growth of the third tier (Matits 2008). By 2005 more than 30\% of the economically active population were members of voluntary pension funds. The role of employers is essential when it comes to payment of contributions, though: $70 \%$ of total contributions are paid by them. The level of contributions has been low: only 280 Euro per person in 2005. For the majority of contributions (65\%) the level of contributions is smaller than 250 Euro, while for only $6.5 \%$ is it higher than 500 Euro.

According to Agnes Matits (2008), with a contribution level of 250 Euro per year, a person will accumulate 10,000 Euros after 25 years, an amount which is unsatisfactory.

Following the logic of moderate changes in the 'old' system, the rules concerning calculation of benefits system changed only partially. The basic principle has not been changed: the level of pension is a function of earned income and the length of employment. Nevertheless, the change will take place as far as a base income from which contributions are calculated is concerned. Contributions are to be calculated from a gross income, and in consequence, old-age benefits will be taxed (Czucz and Pinter 2002). The benefit after 20 years of service will be equal to $33 \%$ of income used for calculating contributions. Each additional year of service will add $1.65 \%$ to the base rate. After 40 years of paid employment, the replacement rate reaches $66 \%$.

When it comes to the new system, following the introduction of the multitier organization, the benefits come from the first and the second tier. Accordingly, a person with a 20 -year contribution period can receive a maximum $24.4 \%$ from a first (PAYG) tier, with an increase of 1.22 percentage points for each next year. After having completed 40 years of service a person will have a benefit with a gross replacement rate of $48.8 \%$ (Czucz and Pinter 2002). The benefit will be complemented by the income from the second tier.

The benefits in the new system are indexed according to a mixed principle. More and more weight is attached to the consumer price index growth. While 
previously $70 \%$ of the indexation weight was based on the net salaries growth and $30 \%$ on the consumer price index change, from 2001 the weights are equal.

Maria Augusztinovics and Janos Kollo (2008) presented a simulation regarding the level of old-age pensions calculated according to two sets of rules: concerning the 'old' system and the 'new' one. In order to increase the comparability of the results, the values of wages and benefits are relative; that is, presented as proportion of an average wage in the economy.

There were more proposals aimed at strengthening the intra-family intergenerational transfers. One of them was put forward by FIDESZ (a centreright party), which wanted to channel 1 percent of personal income tax to the parents of a tax-payer. This proposal was further extended to $5 \%$ and even $25 \%$, but has not been implemented, however (Gal, Iwasaki et al. 2008).

\section{PENSION REFORM IN HUNGARY: CONCLUSIONS}

The aim of this section was to present the context and process of old age pensions reform in Hungary. The country entered transition with discussions already quite advanced concerning the poor shape of its pension system. One of the problems was the number of additional tasks that the social security branch responsible for retired Hungarians had to fulfil. This problem drove another one: the financing of additional tasks came from a joint budget, so any increase in the spending on other tasks (such as subsidizing the cost of consumer pharmaceuticals) was at the cost of old-age pensions. Finally, again on the financial side, the old-age pension benefits budget was not autonomous which meant it had hardly any resources to cope with a decrease in the flow of contributions.

Many of the problems just raised were not solved until 1995. This delay had a profound impact on the condition of Hungarian social security. The split and creation of an autonomous Pension Fund took place after a period of financing other tasks. High inflation levels and economic decline leading to unemployment and tax evasion added to the dire situation of the Pension Fund. The situation of the Pension Fund reinvigorated a debate which had started in the 1980s. The debate ranged from suggestions advocating the complete privatisation of pensions to those which championed even further financial engagement of the state in financing benefits. Generally speaking, the most popular solution was thought to be some sort of multitier organization of the pension system, but the specific and more problematic question regarded the method of financing. Following from the fact that Hungary introduced additional private pensions in 1993 which proved to be quite popular, the issue of to what extent the private component should play a 
role in a mandatory scheme was more pertinent than the introduction of a mandatory scheme in itself.

As in other Eastern European countries, the World Bank stepped in with its proposal of a multitier, partially privatised pension system. From the outset, the proposal was criticised by several bodies, including organizations involved in social security, those representing civil society, pensioners and the Pension Insurance Board (governed by unions). As a result, the proposal was hedged in many respects: the role of the private component was significantly reduced, the regulatory role of the state increased, and the service period qualifying for benefit was also amended.

During the negotiations within the Interest Reconciliation Council, further guarantees were secured: a more generous formula of the first tier, the inclusion of childrearing and higher education in the period of service, and state guarantees for the benefits from the second tier. As a result, the bill presented to Parliament looked completely different compared to the original plan that was proposed by the government.

\section{SOCIAL POLICY IN HUNGARY IN THE 20 ${ }^{\mathrm{TH}}$ CENTURY: SUMMARY}

The main ambition of this chapter was to present the conditions which influenced the reform of old-age pensions in Hungary at the end of the 1990s. Following the historical institutionalism framework, this chapter has presented the development of Hungarian social policy and its political, economic and social context following the first regulations that took place at the end of the $19^{\text {th }}$ century.

The pre-World War I regulations were copies of Austrian solutions and concerned industrial workers and state bureaucrats. This meant that the vast majority of Hungarians who worked in agriculture were not insured (which was typical for this period in other countries as well). The split with Austria and defeat in the first World War meant that Hungary had to operate in conditions that had changed considerably. Hungary's links with its major partner became loosened, while its territory and population decreased significantly due to international agreements. At the same time, radical communist ideas found fertile ground in the conditions of the continuing post-war crisis. The legacy of the short-lived but wellremembered Bolshevik experiment combined with a feeling of loss together framed the inter-war period of social policy making. Accordingly, several progressive policy options (especially much needed unemployment compensation) 
were disregarded by the increasingly nationalist governments. On the other hand, old-age pensions were introduced for salaried workers and, in the late 1930s, for the agricultural population as well.

Hungary entered the post-World War II era as a country defeated by Allies and occupied by the Soviets. Hungary's engagement in the war on the side of the Nazis and the crash of the Bolshevik Republic in the early 1920s made the Soviets act very brutally and extensively in political and economic terms. Hungary embarked on a radical path of Stalinist industrialisation. The result was an inflow of the agricultural population to cities and fast modernisation. This also meant a switch to PAYG principles and the centralisation of social security governance (managed by loyalist trade unions). The fast modernization of the country led to an impressive extension of insurance coverage, being especially important to the agricultural population and to the level of benefits.

The 1956 revolution not only changed the political scene, but also affected the Hungarian political economy as a whole. Under the leadership of Kadar, Hungary evolved towards quite a liberal economic system with extended social guarantees. Therefore, Kadar's era was a period when a completely different social contract was proposed. It was a Hungarian version of socialism, searching for more social support which had been lost after the events of 1956. Soon, the standard of living became one of the highest in the soviet-controlled territories of Eastern Europe. A significant part of this improvement was the extensive welfare state, which gained partial autonomy from the state and was governed by trade unions. In this way, one could observe a number of continuities with the interwar period: social security management by unions, planning by government, and the involvement of employees in contribution payments.

By the time of the crisis in the mid-1970s, the universal welfare state had already been established. At the same time, some features of social policy became affected by the crisis. The answer to these economic difficulties was further liberalisation of the regime. In social policy terms, this entailed protecting the lowest benefits from deterioration at the cost of the highest benefits. These measures were accompanied by a number of discussions and even reform proposals so that the negative trends could be reversed.

In fact, in many respects, the Hungarian transformation started a decade earlier than elsewhere, especially in the field of the economy. After a series of changes in the early 1990s aimed at short-term improvements to the welfare state, the debates concerning reform were reinvigorated. The outcome of the reform was quite far from what was proposed by the World Bank and its followers. The old- 
age pension system remained highly redistributive and strongly controlled by the state in spite of its multitier organization. The main source of opposition came from well-entrenched trade unions which had been involved in social security management for several decades.

The Hungarian reform of the pension system demonstrates how well institutionalised actors and rules (as confirmed by Constitutional Court, for example) can significantly alter a reform proposal. In addition, the universal construction of old-age pensions did not encourage any particularistic defence of specific aspects of the welfare state, a reaction which could be seen in countries which did have more of a segmented organization. The sources of actors' power and the strategies they used in defence of the Hungarian welfare state can only be understood by analysing the historical development of social policy. Finally the reform demonstrates how powerful domestic actors can be, if wellinstitutionalised, in the face of pressure from international actors such as the World Bank. 


\section{CHAPTER 6: TRANSFORMATION OF OLD-AGE PENSION SYSTEM IN POLAND AND IN HUNGARY COMPARED.}

\section{INTRODUCTION}

The aim of this chapter is to present the transformation of Polish and Hungarian old-age pension systems in a comparative perspective. The chapter will focus on the most essential moments in the development of the pensions, regarding not only the narrow context of social policy making as such, but also wider socio-political circumstances. The essential message of this chapter is that the policy developments which took place during the political and economic transition of the 1990s were strongly influenced by historically shaped developmental paths. In other words, what was witnessed from the beginning of the 1990s was a continuation of a path taken a long time ago, albeit adjusted to new conditions.

Although the analysis makes use of rough distinctions between historical periods (e.g. 'the interwar years', 'communist rule'), such periodisation should be treated cautiously. As will be demonstrated, there was a multiplicity of political, economic, social and pension policy processes which did not necessarily follow a common pattern. For example, in some cases a particular political mobilisation against the regime resulted in policy expansion, while in others the result was retrenchment. Similarly, economic hardship does not by necessity lead directly to welfare cuts: sometimes it can contribute to a policy development as well. Therefore, the factors that contribute to policy change or stability should be seen as contingent and historically contextual.

After this short summary of the historical background of social policy developments in both countries, I will go on to analyse of such changes with the use of theoretical framework outlined in Chapters 1 and 2. In this study the emphasis is put on the process of pension reform: the way in which the successful proposals came to be developed in Poland and Hungary: the struggles within governments and with interests groups, and the process of policy implementation. Such an analysis is key in understanding not only the nature of change but also the factors that contributed to the policy outputs that were seen. With regard to the first point (the nature of change), the extent of the reforms that were seen is 
assessed in light of the given historical specificities of the respective welfare states. Special attention is paid to the issues surrounding the financing and organizational of such policy outputs, the specific features of pension policy regulation (such as eligibility, generosity) as well as to cases of special or different treatment (such as branch privileges, the different treatment of women and the rules surrounding the transition to a market economy) in both countries. As to the second point (the factors that contributed to the policy outputs), attention is paid to the mobilization of various actors, the roles they played in social policy reforms and ways in which they were able to use their resources. While the reform process should be seen as something that was by-and-large isolated from the public in Hungary and Poland, some actors were nonetheless able to mobilise support and to have a profound impact on the reform. This was seen when trade unions protected universal and redistributive welfare state in Hungary and in Poland when actors such as farmers, trade unions and occupational groups acted in defence of the preferential treatment they received. The differences and similarities with respect to policy reform will close this part of the analysis.

The final section wraps up the main findings of this research project, both empirical and theoretical, and points out possible directions for further research.

\section{DEVELOPMENT AND EVOLUTION OF SOCIAL POLICY IN POLAND AND HUNGARY IN A COMPARATIVE CONTEXT.}

\section{ORIGINS AND THE MID-WAR ERA.}

The origins and early development of social policy in Poland and Hungary strongly depended on the specific characteristics of economic and political contexts. It is a fact that both countries gained independence in 1918. However, the initial conditions that each country inherited differed as did their post-World War I situations. As a part of the Austro-Hungarian Empire Hungary entered the $20^{\text {th }}$ century with a semi-autonomous public administration and a comparatively developed state structure. However, Hungary's engagement in World War I on the side of Austria and the resulting defeat had a long-standing impact of the country. Hungary became a sovereign and independent country in 1918, but participation in the war had brought about massive changes in the economy, polity and social life. The separation from the Empire meant breaking economic links with Austria, traditionally the biggest market for goods produced in Hungary. The defeat made 
the country subject to several measures undertaken by the international community: Hungary's territory and population were severely attenuated. At the same time, the country went through the experience of being the Soviet Republic. This post-war social hardship coupled with the experience of the short-lived but well-remembered communist rule on top of the post-war resentments resulted in a generally conservative-nationalist climate and approach to social policy-making. One of the results was the resistance of several governments to introduce more progressive social measures that would ease the situation of the working class (and the agricultural population whose situation was even more severe). This meant that social policy in the early post-war period did not develop as much as it had during the time of the Austro-Hungarian Empire, despite the need for such mitigating measures. Indeed, pension benefits were limited to one occupation group - civil servants - from 1912 onwards. This was a classical solution in corporatist countries that wanted to secure the loyalty of this group.

The initial situation was quite different in Poland. The country, having been partitioned for 123 years, entered independence in 1918 with hardly any administrative, economic and political structures. The different economic and administrative regimes of the partitioning forces (which were run mainly by those partitioning forces with the proviso of marginal autonomy in the AustrianHungarian part) meant overall underdevelopment and more specific inequalities in the respective parts of newly integrated lands of Poland. Given such a situation, effort was mainly directed at consolidating the country's organizational structures. This task, however, was hampered by the Polish-Bolshevik war of 1920 that required most of the scarce resources of the economy. Thus several social policy programmes continued in their inherited forms (different for each part of Poland) but even such maintenance was a tough task given the social and economic conditions. At the time of independence the most developed social policy existed in the former Prussian part. Social policy was less developed in the territories of the former Austrian-Hungarian part, while the lands ruled by Russia (while being the most populated and biggest area) had the least developed welfare measures. These differences could not be overcome in a short period, and in fact several of them remained until the end of World War II. Therefore, the context for social policy making in Poland in the early period was strongly influenced by the inherited diversity of state functions that coincided with the war effort in the early years of the reunified country's existence. However, it should be noted that the left-leaning political firmament in Poland was rather supportive when it came to social policy development. 
While in the mid-war period Hungary's social policy was constrained by the legacy of the Bolshevik Republic and driven by nation-building, Polish social policy appeared more progressive. However, it was also constrained by the economic and structural conditions. In Hungary, the programme of building the Hungarian nation was to be achieved by Magyarization - the promotion of 'true' Hungarian families and lifestyle. This is why emphasis was placed on the development of policy that could transcend social classes, and not on policies which would empower the working class (such as pensions for blue-collar workers and especially unemployment insurance). The best policy to promote Magyarization was family policy and efforts to develop this policy occupied politicians. A clear indication of the prioritisation of family policy was the fate of the struggle of the working class to introduce unemployment insurance which was both long and completely unsuccessful. Poland pursued a policy of an incremental expansion of coverage in terms of both the provision for different types of social risk and for the various social groups. This started with the introduction of pensions for civil servants, those responsible for state-owned companies and military staff - in other words, the groups most appreciated from the perspective of the state. At the same time, Poland became active on the international scene where it promoted increases to social security standards. Hungary, interestingly, was not active in this field. Moreover, the country did not implement the decrees regarding social issues that had been stipulated in the peace treaty.

The first important social policy measures were introduced in Hungary in the second half of the 1920s and concerned sickness and accident insurance. Alongside these, two social insurance institutions were introduced. These actions were followed by the introduction of old-age pension provision, which was a result of an agreement between the government and those in industrial circles supporting this policy who were promised that unemployment compensation proposals would be abandoned in lieu. The old-age pension programme covered all salaried workers, but excluded the agricultural population. It was managed jointly by employees and employers. In fact, this was the only achievement real in Hungarian social policy at this time, apart from the comparatively well-developed childcare services. Poland's development as already mentioned was more incremental, but simultaneously more extensive. Illustrative examples here might be the unemployment compensation scheme introduced in 1924 for manual workers (one of the first in this part of Europe) as well as the scheme for white collars which followed in 1927. Some years later, the pension scheme for white collars was introduced. In 1933, as part of a bigger consolidation regulation, the old-age insurance for manual workers was enacted. 
As the comparison of two cases demonstrates, Poland and Hungary pursued rather different social policies. Hungary opted for policies that were informed by the growing right-wing and nationalistic stance of incumbent governments: hence the lack of developments that could ease the situation of labour. In addition and in terms of organization, Hungary increasingly limited the involvement of the working class in social insurance management. This limited progress is striking not only when compared to Austria, but also to several countries in East Central Europe. Poland on the contrary pursued policies that stood out in the region. By the outbreak of World War II, it had major social policy schemes covering both white-collar and manual workers with some limited - but real - involvement of workers in their management. What remained the biggest unresolved issue was the participation of the agricultural population in social policy programmes. In both countries, measures aiming at this social stratum remained limited.

\section{POST-WAR SOCIAL POLICY EVOLUTION: DEVELOPMENT,}

\section{CONSOLIDATION AND CRISIS}

The two countries suffered from severe World War II damage. However, the circumstances during the war were very different in each. In Poland, the systematic deprivation of the population started from the very beginning of the occupation, while in Hungary - at least in the initial four years of the war - the social situation actually improved. It was in the last years of the war when Hungary became actively involved in the war that the situation deteriorated there. Having focused these differences, it is important to remember that both countries were the subject of international debate, and both were occupied by the Soviet army.

In Poland in the immediate post-war years, the pre-war social security system was restored in relation to its organization, financing and split for white and blue collars. Soon the system was unified, with the exception of the miners. Organizationally, the system was based on self-government, both at the central (ZUS) and policy branch levels. Five separate funds existed for different social groups and risks. The emphasis was put on short-term benefits - such as sickness benefits - and upgrading their level to that of the privileged groups (e.g. state employees). The lack of employment and contribution records in the long-term insurance system meant that the benefits were calculated according to the (more generous) white-collar system rules. However, this was just a reference point, as in the end the benefits became flat rate. Soon however, new rules were introduced that took into account an individual's income category. This solution caused a fast 
deterioration of pension levels due to its rigidity. Population coverage increased as agricultural workers (but not private farmers) became eligible for sickness, maternity and pension benefits between 1946 and 1953.

Hungary experienced significant post-war depression which, combined with a strong central-planning emphasis on industrialisation, created unfavourable conditions for social policy development. On the other hand, the relative underdevelopment of social policy called for its fast expansion. As was the case in Poland, the organization of the pre-war period lasted for some years after the war. Pension insurance was reconfirmed. However, the loss of resources and - equally as importantly - the expansion of insurance to more social groups (mainly the agricultural population) with the possibility of an immediate payment of benefits led to changes in organization and financing. The process started in 1949 and included consolidation of social insurance into one scheme, run on the PAYG principle. The system became managed by socialist trade unions. The benefits offered to agricultural population were less generous compared to those workers received.

The immediate post-war years saw several measures that represented both a continuation/extension of, as well as a reduction in, social rights in Hungary and Poland. The extension of coverage to the agricultural population was a great step forward, welcomed in both countries. In Hungary especially the situation of the agricultural population was severe, and such a step meant a real extension of the social rights of this group, even though they were less preferentially treated. However, this was achieved at the price of farmers' collectivisation. Quite a different situation was seen in Poland, where private farmers obstructed collectivisation and for some time their risk coverage was smaller than in the case of other major social groups. Another type of specific treatment concerned civil servants in Hungary: those in service before and during the war had been deprived their employment credits and preferential benefits. When it came to financing, in Poland the burden of contributions was put on employers, while in Hungary the employees had to pay their share. Organizationally, the pension systems were turned into PAYG and their finances included into state budgets.

By the beginning of the 1950s, communist rule had been consolidated and by the middle of the decade Sovietisation reached its peak. As mentioned above, some of its elements failed in Poland, the most important of which was that of the collectivisation of agriculture. In Hungary, the process went on full-steam ahead and had various effects: heavy industry burgeoned creating a number of employment opportunities at the price of a relative backwardness in other sectors in the economy. In both countries, the demise of Stalinism led to social upheaval 
that left an enduring legacy. The Hungarian revolution of 1956 was a moment of extraordinary mobilisation, which when crushed created a deep distrust in the state. Therefore after a period of state retribution following the revolution it soon started searching intensively for social support. One of the ways it set about achieving this goal was through a visible increase in the standard of living. In Poland the direct effects of the workers' mobilisation following the demise of Stalinism were less visible; however, in certain areas the break-up with the Soviet dogma and real increase of benefits were felt. Organizationally, the unions were seen to be incapable of managing the social security system effectively. Consequently, ZUS took over this responsibility, which at that time was a real deviation from the Soviet model.

The process of social policy development in Hungary accelerated especially strongly after the introduction of the New Economic Mechanism, which broke away from several dogmas of the socialist planned economy and focused instead on investment in social infrastructure. In social policy terms, one of the most important developments was opening old-age pensions to members of cooperatives and their families (the majority of the rural population) at the beginning of the 1960s. This created a great inflow of insured individuals, but at the same time an increase in the payments of a number of benefits paid out by the government. The pension system was reformed so that the level of benefits reflected the employment length, hence a minimum period of insurance and a stipulated length of insurance to qualify for a full benefit. This was to motivate Hungarians to work longer. This measure was accompanied by relaxed regulations concerning work in the 'second economy'. The emphasis on economic incentives was reflected by the fact that it was the Ministry of Finance which dealt with social policy planning. Importantly, in 1971 the limited indexation of pension benefits was introduced, the first such mechanism in socialist countries.

Polish social policy also focused on a closer link between the level of longterm benefits and an individual's previous income and length of employment. Previous employment categories were removed and a single method to calculate benefits was introduced. This in turn significantly improved benefits of workers with the lowest salaries. Simultaneously, several increases in the nominal levels of benefits took place so that their real level could be sustained. In order to maintain financial stability, the contribution split was introduced. This was accompanied by the detachment of the pension fund from the state budget. In terms of coverage, more occupational groups became insured, including private farmers.

The 1960s and early 70s saw rapid developments in social policy. More and more social groups joined the social insurance programmes, and the average 
level of benefits grew significantly. The benefit formulae linked previous income and work length more closely with the level of benefits. At this stage of development, it was Hungary that moved ahead with its universal welfare state. Virtually the whole population was covered and the benefits were comparatively high given the eligibility criteria. A difference between industrial and agricultural workers' insurance existed, but the fact that the latter had extensive social rights was considered a success all the same. At that time the insurance for private farmers in Poland was in its initial stage.

It was the mid-1970 which saw a significant reorganization and consolidation of the social security systems in the two countries. This was because the number of regulations made the social policy systems complex and, at the same time, signs of economic crisis appeared in the region (more quickly in Hungary than in Poland). Given the political dimension of social policy, the reaction to the crisis could not involve retrenchment. Rather, given the risk that economic hardship would be felt by the population, the governments decided to improve social policy.

In Hungary, the major reform here concerning pensions occurred in 1975. The reform aimed at consolidating and simplifying the system through the application of unified rules to every member of the system. This meant that branch exemptions (i.e. the preferential treatment that certain workers received) were removed almost completely and only very few occupational groups were left to enjoy them. Additionally, the rural population could enjoy the same treatment as others. On top of this, the benefit rules themselves were changed. The change of eligibility rules and issues connected with the calculation of benefits went further in the direction of linking the contributory period as well as the level of contributions with the level of benefits. The minimum contributory was extended, the minimum pension-increased.

The developments in Poland were more profound. Continuing the trend from the past, the benefits were raised several times, and the right to increase them was moved to the executive. The increases focused on the oldest pensioners, as it was this group which suffered most because of the deteriorating quality of benefits. One of the most important developments in the whole post-war period concerned the introduction of the full-range social policy coverage for private farmers. This task was accomplished in 1977 with the introduction of a separate old-age pension system for this group. The system was based on farmers' contributions, but the main source of financing was state subsidies. The level of a benefit depended on the size of agricultural production and was generally lower 
than in the general system, but given the low level of contributions it proved attractive for farmers.

In the mid-1970s the Hungarian and Polish social security systems reached almost full coverage as major occupational and social groups became included. The main difference between two countries was the existence of a single, unitary system in Hungary which served the majority of society, and the existence of two systems in Poland: one for salaried workers and another for farmers. Another important difference concerned the central role of trade unions in the management of old-age pensions in Hungary while in Poland this task belonged to a state institution, ZUS. The difference in the pension policy design will be a lasting legacy, influencing the financial condition of the social security system and any possibilities for reform in the future.

The economic crisis deepened in the 1980s. As a result, the real income of pensioners started decreasing, and previous measures (ad-hoc steering in Poland, and the indexation in Hungary) were not able to reverse this trend. In Poland, the economic slowdown coincided with the biggest social unrest in the post-war era. The beginning of the 1980s saw the rise of the first independent trade union, which in terms of members far outnumbered the 'official' unions. In light of this challenge to its legitimacy, the regime decided to make a series of policy changes so that the momentum of the opposition could be stymied. Paid maternity leave was introduced, inclusive of farmers. In the field of pensions, several privileges were offered to various groups: miners, railway and steel industry workers, and teachers. The privileges related mainly to earlier retirement age. Simultaneously, the government planned to introduce full financial autonomy of the pension fund from the budget; however, this aim was not fulfilled. In terms of benefits levels, several improvements of nominal values took place; however, they were valid only for short time because the real value of benefits was decreasing fast due to high inflation.

Hungary introduced similar measures. First of all, in order to obtain better control of social policy, a governmental management body replaced the trade unions in this role. This organizational change was accompanied by a number of reforms introduced in order to compensate for changes in the real value of benefits with regard to the growing cost of living stemming from the rigid rules used for calculating pensions. Apart from this, the indexation was raised from 5 to 10 percent between 1985 and 1989. The indexation was suspended in1989 and replaced with flat rate payments. 
As this summary of social policy developments demonstrates, the period of state socialism was not homogenous within the so-called 'Eastern Bloc'. Each country had its own policy dynamics, determined not only by particular inherited social, economic and political conditions, but also by the characteristics of social policy system. The following short presentation of some key developments in social policy demonstrates that the historical evolution of pension policy (and social policy in general) was not the same in Hungary and Poland.

The inter-war years were characterised by different political and economic contexts in the different countries, and also by the country-specific priorities as to the role social policy should have. In Hungary, following the harsh experience of experiments with communism just after the First World War, an anti-labour climate persisted. Combined with a nationalistic mood, such a situation led to the neglect of social policy compared to other countries in the region. Poland, which was also going through the experience of nation-building, went for more inclusive measures, such as unemployment compensation and other social policy measures, including pensions.

The periods of social policy expansion were frequently interrupted by economic crises (of the 1920s and the Great Crisis). Under the conditions of a weakened labour lobby in Hungary from 1920s, and in Poland from 1930, this often meant policy reversals or at least a lack of adjustment. However, what one could observe in times of crisis was a series of political manoeuvres aimed at reshaping social policy which did not necessarily lead to retrenchment. Often presented as trade-offs, such moments of reconfiguration led to expansions in social policy areas such as the introduction of old-age pensions in Hungary and in Poland.

The Second World War did not signify a discontinuity in social policy institutions and policies. The immediate post-war years saw an attempt to reestablish the earlier order rather than bring about its replacement. Alongside the consolidation of the communist rule following the war, the countries started enforcing the process of industrialisation which entailed reshaping the social structure according to the Soviet model. Therefore, it was not so much that social policy changed in structural terms, but that society itself changed. One of the clearest cases here concerns private farmers. In both countries, collectivisation was pursued. The underlying aim of this process was to make farming work analogous to industrial labour: the farms were owned by the state or collectives, and the work became waged. In this way, the problem of private farmers' insurance became obsolete, as the group was meant to disappear. The plan was fulfilled only 
partially, especially in Poland, where the vast majority of farmers remained owners of their farms.

The example mentioned above demonstrates that even during the most oppressive period of Stalinization, both countries accommodated differently to this external pressure. Perhaps Hungary went further with this transformation than Poland. In Hungary, Soviet pressure was stronger, given the more pronounced right-leaning nature of the pre-war governments, the crush of the Bolshevik Republic in the 1920s and involvement of the country in the war against the Soviet Republic. In addition, as mentioned in the chapter 5, some argued that there was a need for more profound reform, which was to be achieved through societal policy. In Poland, the tolerance shown towards private farming led to fraction change within the communist party, but with no success in collectivisation however.

The most important change in organisational terms was the process of turning previously funded systems into PAYG. As argued in the country chapters, this would be the only feasibly tool for achieving the social policy aims of societal policy. Also, as several experts in Hungary and Poland noted, abandoning separate book-keeping and merging social policy funds with the state budget made the outflow of money from the system possible. Consequently, it is hard to talk about financial condition of social policy, as little is known about contributions, reserves, subsidies, and payments.

The following decades were characterised by further divergence in the country paths of the two countries as the pressure on the side of the Soviet Union lessened. The Hungarian economy had a decade or so of interrupted economic growth which translated into an increase in the standard of living and social policy reforms. Poland's economic story was not that successful as the economy and the general standard of living fluctuated. One form of dissent by proxy here was the number of major workers' protests that were mainly and ostensibly political demonstrations, but which referred to the worsening economic situation as well and which took place in 1956, 1968, 19701976 and 1980. The last main social group, farmers, became fully included in the welfare state before the biggest crisis broke out and contributed, among other things, to the collapse of the regime. However, compared to Hungary's social policy, from the late 1970s the laggard nature of reform in Poland is apparent.

The two countries left the socialist era with differently institutionalised welfare states and political economies. In both of them experts realised that the crisis of social policy was a real threat. However, when faced by the challenge of the crisis, the two countries responded differently. While in Hungary the crisis 
went comparatively smoothly and the response to it was of the same character, Polish policy makers had to face an economic crisis that mounted up over a comparatively short period of time, combined with growing political opposition. The response was to open the pension system for future pensioners and correct the level of benefits. Another important difference was that while Hungarian social policy was the domain of the Ministry of Finance and trade unions, in Poland there was the specialised state agency, ZUS, which had been established in the first years of independence, and a separate ministry to deal with social policy issues.

These are the main legacies of the pre-transition era. As one can observe, in each country they created a different configuration of policy, institutional and organizational factors. The section below shows how these factors determined social policy during the transition.

\section{POST-SOCIALIST SOCIAL POLICY REFORMS: RECOMBINATION OF INSTITUTIONAL FACTORS}

As the previous sections outlined, some economic reforms started as early as the 1980s. The same situation happened with social security, where a move towards financial autonomy and more expertise-based management took place. The transformation from socialism to a new system involved several parallel processes: regulation of the economy according to free market principles, privatisation, the creation of new political parties, independent trade unions and the mobilisation of civil society to name but a few. These parallel processes had different dynamics, and sometimes contradictory aims (Stark and Bruszt 1998). Nonetheless, what is essential here is that these processes did not take place in a vacuum, and were embedded in the existing environment. This was the case of social security as well.

The post-1989 developments which took place in the field of social policy can be roughly divided into two periods: before and after 1995. However, this division should be taken cautiously as one may find roots of the developments that occurred after 1995 well before this year, while at the same time the impact of the pre-1995 regulations were to be felt for several years after.

The reforms that were introduced will be analysed with respect to continuities and innovations in the pension systems in Poland and Hungary. The 
aim of this exercise is to identify the evolution of the post-socialist social policy and the factors that contributed to this evolution. The theoretical discussion outlined at the beginning of this dissertation points to the possibility that institutional settings (including pensions systems) may simultaneously change and be stable. The second message of the theoretical discussion is that the stability of any given institutional setting has to be actively sustained. It stems from the fact that regulations and rules are implemented as institutions in an imperfect way. These imperfections and contestation of institutions by various actors make them prone to change (Streeck and Thelen 2005).

This section focuses on the features of benefits such as eligibility, generosity and the preferential treatment of some groups as well as the organization, operation and financing of the schemes.

\section{OLD-AGE PENSIONS DURING EARLY TRANSITION}

Poland entered 1989 with a differentiated system that consisted of two major pension systems, several smaller ones (for the military, militia and secret service for example) and a number of branch privileges. The social security fund was separated from the state budget and managed by ZUS. A separate fund and managing institution scheme was established for the purpose of farmers' insurance. This fund, in contrast to the main one, was heavily subsidized. With mushrooming unemployment many Poles chose to retire, making spending on pensions rise to an unprecedented level. It should be clarified, however, that the growth of spending caused by the 'abnormal pensioners boom' (Vanhuysse 2006) should not be allied with extraordinary governmental actions. The early retirement possibilities introduced after 1989 constituted less than $15 \%$ of all retirements and disability pensions between 1989 and 1991 (Golinowska 1994). The opportunities to retire earlier used by hundreds thousands of Poles were introduced in the early 1980s. Therefore, it was not excessively lax regulations or preferential treatment pursued by the first transition governments, but the inherited socialist regulation that contributed to the financial crisis in the old-age scheme.

Another factor that contributed to the dire situation of the pension fund was indexation of benefits in conditions of high inflation, but also the recalculation of benefits whose real value dropped significantly during the 1980s crisis. The existence of different 'pockets' (benefits significantly varying in value due to the ad-hoc criteria of granting) became a severe problem, especially for the oldest pensioners.

In 1991 a change of pension formula took place, linking the level of benefits with contributions paid: the benefits consisted of a flat rate part and a 
variable component depending on the period and level of contributions. However, for running benefits the key issue was keeping their real value.

This task was achieved and Poland was among very few transition countries which protected the standard of living of their pensioners. In fact, as several research studies suggest, in this transition period characterised by poverty, pensioners were one of the better-off groups, especially when compared to families with small children (cf. Golinowska 1996).

The financial stress of the social insurance system induced efforts to 'clean' it of tasks not being covered by contributions. This involved the benefits for military and other 'uniformed' services, but also family allowances and preretirement benefits, to be financed from the Employment Fund.

Hungary followed a similar path of development. One of the first actions was the establishment of a separate social insurance fund, the SIF. The SIF, like the Polish ZUS, was in the short-term partially independent from the executive, but in the long-term it was to be governed by an independent board. Importantly, in the initial phase of transition the merger of SIF and the Health Fund took place. This step had long-term consequences as the clearing between two pension components and additional ones (pharmaceuticals, healthcare, child allowances) added to the debt present which appeared 1990. A significant part of the growth in expenditure was incurred by anti-inflationary measures aimed at sustaining the real level of benefits, as the beneficiaries' growth was lower than in the preceding decades. Combined with contribution evasion, the overall social security situation was seen by many as one of severe crisis.

This concern was expressed by Parliament, which outlined a way out of the crisis. This aim was to be achieved by closely linking benefits and contributions, separating social security funds from the budget, and the establishment of new risk-based funds. The separation of funds took place in 1994 and resulted in the bad reputation the fund gained.

In terms of pension benefits, as early as 1990 the condition of retirement age had been loosened for persons who were possibly made redundant and this regulation changed several times. The economic situation and growing unemployment caused discontinuities in work careers. This became a critical issue given the requirement that 20 years of work was to be meet as of 1990. In order to overcome this problem, the partial pension option, imputations in career interruption and the equalisation of the period of childcare with work were introduced. The other problem policy makers faced was the low retirement age. Therefore, the retirement age for both sexes was increased. 
The changes in the retirement age were coupled with a change of digression tables, used for calculating benefits, which made the benefit structure more compressed. Apart from one-off increases, the more systematic indexation of benefits was announced and introduced. The next couple of years were characterised by further measures linking benefits with work performance by extending the reference period length.

The profound economic and political changes of the early transition did not lead to fundamental restructuring in the Polish and Hungarian welfare states. The old-age pension schemes were 'cleaned up' and separated from the tasks which were foreign to them and did not follow the insurance principle. The pension funds became separate entities with their own budgets and bookkeeping. The financing of social security became more dependent on state subsidies. The difference between the two countries laid in how they accommodated increases in the cost of living. While in Poland the real level of benefits was well protected, in Hungary the decrease of the real value was quite significant. Also, the up-take of retirement differed: while in Poland the numbers of individuals claiming benefits were the highest ever, in Hungary in contrast the number of benefits claimed was lower than before. Consequently, the patterns of the pension expenditures were different: while in Hungary it was centred around maintaining the level of benefits, in Poland the growth was caused by the inflow of new pensioners. What stems from this discussion is that in the first 5-6 years of transition, the changes in the pension schemes were rather tactical adjustments which did not change the strategic principles of the systems and displayed several similarities with the changes that were introduced during the socialist period. One should also emphasize that several of the difficulties were the result of the schemes' designs that had already become well-institutionalised in the previous era. Certainly the starkest example is the regulation concerning early retirement, introduced in Poland at the beginning of the 1980s that was so eagerly exploited by Poles. Other cases of long-term unintended consequences might be the merger of pension and healthcare funds in Hungary or the existence of a separate scheme for farmers in Poland. Finally, there were lot of continuities in the style of policy- making: the adhoc approach to policy making persisted, especially in Poland, where the policy was characterised by a number of mounting contradictions.

\section{PROPOSALS, DEBATES AND REFORMS OF OLD-AGE PENSION SYSTEMS}

The situation of exceptionally high spending on old-age pensions led to debates on the necessity of more systemic changes to the system. In fact, the debates concerning the financial sustainability of the systems were taking place as 
early as the 1980s in expert circles. However, neither in Hungary nor in Poland had such proposals gone beyond a narrow circle of social policy specialists.

In Poland, the debates surrounding pension changes began in 1991. The proposals differed significantly in their visions of pensions organization, financing, redistributive effects and the overall extent of change. Therefore, there were proposals coming from a social democratic tradition which argued for more redistribution, a multitier structure of the system and subsidies from the state budget. At the other pole were proposals which questioned completely the viability of the existing system and instead argued for the introduction of a fullyfunded, Chilean type of pension system. Apart from the expert proposals, programmatic documents were issued by parliamentary bodies which assumed the creation of risk-based funds and earmarking of contributions, so that the social security resources are not hijacked by the state. Although the proposal was not even voted on, it did however encourage the government to consider a more substantial reform of pensions. In the initial phase, governmental debate was led by the Ministry of Social Policy and three policy reform proposals were issued between 1995 and 1997. The proposals of the Ministry evolved over time. They started from a four-tier structure, granting every elderly citizen a social component of pension, topped up with the benefits from the PAYG tier, a voluntary scheme and additional benefits. The second proposal removed the social component and called for the determination of pension benefits based on the pure insurance principle. Simultaneously, a reform proposal was issued by the Ministry of Finance. This proposal was mainly concerned with the macroeconomic effects of the pension system and strongly promoted its detachment from the social security structure and further, full privatisation. The system would again be based on the multitier structure.

These competing proposals resulted in the clash between the ministries. In order to overcome the deadlock, the post of Social Security Reform Plenipotentiary was created so that the work on reform could be streamlined. Work on the reform accelerated in the Plenipotentiary office and gained external support from the World Bank. Discussion centred mostly on issues concerning financing the transition to a new system and the importance of the second tier.

The proposal developed by the Plenipotentiary and submitted to Parliament in 1997 once again outlined a multitier structure of the pension scheme. The first tier was based on the reformed ZUS, and was designed to operate as a Notionally Defined Contribution (NDC) plan. The second tier was a fully-funded mandatory scheme, operated by private insurance companies. The proposal sent to Parliament included several important changes including the elimination of branch 
privileges and the equalisation of the retirement age between sexes (62 years). The first round of laws was accepted by Parliament before the elections in October 1997 and concerned the introduction of the second tier, the third tier (voluntary pension schemes) and the financing of the transition (through the means generated from the privatisation of state-owned companies).

The process of reform was then interrupted by the elections in 1997 as mentioned above. However, the reform was continued by the next government which did however introduce some changes (lowering the pension age for women to 60 years) and which also negotiated the scheme's assumptions with trade unions. It soon became apparent that the unions would defend some of the privileges present in the old system. The second batch of government proposals was sent to Parliament the following year and dealt with the overall structure and organization of the first tier; that is, the reform of ZUS. However, due to a clash between the newly-established supervisory body for the second tier which promoted full privatisation of the pension scheme and the parliamentary commission dealing with bills, the work on the first tier was postponed. Instead, work on completing the 'mother law' was accomplished. Importantly, the farmers' provisions remained outside this regulation. Soon work on the first tier was accomplished as well, which in principle meant the finalization of the reform. However, the deliberations concerning the first tier did not go as smoothly as previously. Trade unions, including those associated with the governing party, demanded the withdrawal of the phasing-out of branch privileges. In the negotiations, the unions achieved the inclusion in the bill of bridging benefits which provided income between earlier retirement and the stipulated retirement age. The bill consisted of new regulations concerning early retirement and more favourable indexation formula.

The reformed system was mandatory for new entrants to the labour market, those between 30 and 50 in 1999 could voluntarily join it, while older workers remained in the old system. The system, as organized at the end of the 1990s, comprised elements that were not included in the original proposal. In addition, the performance of ZUS as contributions collector and transmitter to the second tier was sluggish. As a result, a significant part of the contributions did not reach the personal accounts in the second tier. This in turn led to several law amendments.

The negative atmosphere surrounding the pension reform and the experience of having already achieved success elsewhere led to the further mobilization of some occupational groups. The miners' occupational group was 
successful in its goal of achieving partial exclusion from the new system and so separate retirement rules were introduced.

In Hungary, the discussions concerning reforming the pension scheme started as early as the 1980s when doubts concerning the sustainability of the scheme were raised. Some proposals were raised at the end of the socialist era, but the collapse of the regime meant that they were disregarded. The political importance of reform was confirmed in 1991 with the parliamentary decree emphasizing the need for structural change. The decree specified a multitier structure of the system: the first tier being a flat rate benefit, the second a reformed PAYG scheme and the third a voluntary component. In the background, there were policy proposals put forward by international actors, but they did not differ from those of domestic experts.

The debate was institutionalised at the end of 1994 with the establishment of a special government body dealing with, among others things, social policy reform. The proposed system would be based on the guidelines from 1991: a social benefit component, a more actuarially fair PAYG scheme, and a voluntary component. In spite of strong analytical backing and the support of the Subcommittee on Welfare, the proposal was neglected in the governmental circles. Instead, a proposal that was developed by another unit, and which was not discussed with the one that was ultimately responsible, was pushed forward. Importantly, the reform document considered a funded element in the multitier structure, and consequently attracted the attention of the Ministry of Finance.

Simultaneously two other proposals were developed by the social security institution and the Ministry of Welfare. The document issued by the social security institution was another version of the 1991 guidelines but which placed special attention to the transparency of the system. The proposal of the Ministry of Welfare opted for a modest reform of the pension system, but again also the introduction of multilayer organization. The Ministry argued that the increase of the retirement age as stipulated in 1991 combined with parametric reform was sufficient for saving the long-term prospects of old-age pensions.

The Ministry of Finance continued to work on reform and in 1996 presented another proposal. Consistent with the previous one, this plan for reform outlined a multitier organization with the first component being mandatory social insurance and second mandatory private insurance. The proposal became the official government document and, as such, was extensively discussed by various bodies. The assumptions of the reform raised criticism and a number of doubts as to its impact on the situation of the elderly. Several organizations pointed to the gender inequality present in the proposed reform - where the male-norm was 
treated as the work-norm (all non-work activities such as childcare or higher education would be treated as inactivity periods) - and to the overly optimistic assumptions concerning the situation of the economy in the future and the efficiency of the system.

The debates led to significant hedging of the reform proposal. It should be noted that the most radical proposal of the Ministry of Finance (substitutive full funding) was deemed unrealistic by the working group of the Ministry itself. The first step included giving equal importance to the public and private tiers, which coincided with the resignation of several most radical policy makers within the Ministry of Finance. However, the conflict with the Ministry of Welfare continued over the details of the proposal. As deadlock seemed unavoidable and more and more opposition appeared on the side of trade unions, social security and other actors, the Prime Minister intervened and this led to preliminary agreement, which further reduced the importance of funded component. Even though the parliamentary debate took place in isolation, there were other platforms where discussions of the proposal were channelled. It was in the Hungarian tripartite commission Interest Reconciliation Council and the board of social insurance where the softening of the proposal took place: a further reduction in the funded component, return guarantees in the funded tier, and the inclusion of maternity leave in the work period. As a result, the proposal that was sent to Parliament for approval was completely different from the one that left the Ministry of Finance. Proceedings at the parliamentary stage did not take long and the pension reform was voted on and accepted.

The new system started at the beginning of 1998. It changed the organization of social security, as Pension Insurance Fund became subordinated to the Ministry of Finance and the task of contribution collection was moved to the tax authorities. The system was mandatory for those entering the labour market, provided they were no older than 42 years. Those no older than 47 could join the scheme on voluntary basis, while the rest of the workers remained in the old system.

The years following the introduction of the reform were full of policy reversals and changes that contributed to the dire financial situation of the pension system. Subsequent governments increased benefits, reduced contributions, and allowed for some returns to the old system that brought into question the sustainability of the reformed pension system. 


\section{CONCLUSIONS: CONTINUITY AND CHANGE IN OLD-AGE}

\section{PENSIONS}

From a comparative point of view, there are several differences between the processes and the outcomes of pension reforms in Poland and Hungary. As the summary of the reforms shows, they were pursued by different actors. After a common period characterised by a clash between the ministry responsible for social issues and the Ministry of Finance ending up in a stalemate, in Poland one strong centre responsible for reform emerged while in Hungary it was as a joint ministerial committee. In Poland, it was the Plenipotentiary for the Pension Reform, while in Hungary this was achieved jointly by the Ministry of Finance and the Ministry of Welfare. The Polish Office of Plenipotentiary was responsible for drafting proposals, information campaigns, analyses and other actions related to the reform, and in principle, should cooperate with the Ministry of Labour and Social Policy. However, the Office often acted on its own. In the case of Hungary it was the Ministry of Finance and the Ministry of Welfare who divided responsibility for components of the reform.

The position of social security institutions was different in two countries as well. This difference might be attributed to the relative independence of PIF and the political dependence of Polish ZUS on the current political situation. Comparatively, PIF enjoyed more freedom and was able to comment negatively on the reform proposals prepared by the Hungarian government. In Poland, on the other hand, the President of ZUS is a political appointee and is replaced at least after each parliamentary election. Given such conditions, ZUS acted as a strategic ally of the government while in Hungary post-socialist trade unions involved in the management of the pensions fund could strategically oppose the reforms.

Critically for the output of the reform, the involvement of civil society differed. As argued in theoretical part of this dissertation, it has to do with the structure and organization of the pension schemes. Hungary inherited a unified, universal, generous and accessible social policy from the socialist era. There were not many branch privileges and the system differentiated more on the basis of previous income (which is the legacy of the economic policy pursued in the 1970s), rather than by occupational category. As such, the pension system did not have many loopholes and exceptions that would be worth defending at the price of other members of the system. Therefore, such universalistic organization determined the fact that several actors involved in the process of reform defended the system as a whole, and not particularistic solutions. 
In Poland on the contrary, the pension system inherited from socialism was in fact a collection of more than dozen separate regulations for specific occupational groups. These included the main general scheme, the private farmers' scheme and a number of branch privileges, being de facto separate schemes. The farmers' scheme remained completely unchanged in spite of a number of political declarations to do so. The scheme offers comparatively high benefits, given a minimal level of contributions, but at the same time puts a heavy burden of the state budget. Without discussing the feasibility of such a solution, it must be mentioned that any attempt to introduce income-based differentiation of contribution meets with fierce opposition from the farmers. Therefore, there has not been a real attempt to reform this scheme. Finally, several occupational groups (often the core professions from the perspective of a socialist economy) had specific privileges, mainly concerning lower retirement age and more favourable benefit formulae. In fact, after 1989 consecutive governments negotiated the regulations introduced earlier rather than innovating completely new rules. Both during socialism and in democratic Poland, these groups were highly unionized and were focused on protecting their privileges under conditions that saw their importance to the economy drop. Therefore, it does not come as surprise that these groups were able to mobilize and defend their privileges.

However, the overall impression of the reform is that it took place in isolation from societal actors. It was the insider process, where early debates took place in governmental circles or in a small group of experts. In neither of the countries have non-governmental actors been able to pursue their own proposals and push them to the top of the reform agenda. Rather, it was the ministries responsible for the reform which selectively picked reform components from other actors (as was the case of financing the transition to reformed system). The bargaining related to fundamental features such as the financing, organization or the role of the funded component took place between government units or even party factions. Even the debates in Parliaments mainly concerned reform technicalities and did not publicise the viable alternatives. All this does not mean that the drafting, negotiating, legislating and implementing took place in a total vacuum. As was illustrated above, there were situations in which social actors became involved in certain stages of this process and successfully modified its outputs.

Finally, the role of international actors, especially the World Bank, should be assessed. The Bank has been very active in the region, including in the field of social policy. The World Bank provided technical assistance, financial support and ready-made policy guidelines in its influential publications. Its experts were present while drafting various versions of proposals opting for partial 
privatisation. However, as mentioned, the ideas promoting multitier pension systems existed well before the involvement of the Bank. The same is true for ideas concerning funded components, especially in Poland. Finally, the countries had a short-lived, but real experience of funded systems operating before World War II. 


\section{CONCLUSIONS}

The aim of this concluding chapter is to draw together the key questions of the dissertation as well as to recall the methodology and theoretical approaches applied to answer them. The chapter presents them main research findings of the dissertation and locates them in the wider context of comparative welfare state analysis. Finally, I present a possible future research agenda which can be a continuation of the current project.

The dissertation started with an empirical puzzle: the observed diversity of social policy arrangements in East Central Europe. The major question was the following: why is there such noticeably striking diversity of social policy between states in the region which seemingly not only share similar social, political and economic conditions, but which also went through a period of state socialism together?

To answer these questions, the dissertation focused on the characteristics of social policy programmes, their dynamics over time, and the processes which contributed - and continue to contribute - to these policies' institutional development. In order to analyse these issues, the dissertation sought to answer the following key questions: what are the characteristics, the logic and the dynamics of social policy change after the collapse of communism; and what are the processes which have contributed to observed social policy features?

The overall strategy of the analysis was to follow a two-stage approach, which would correspond to the two sets of questions just raised. In the first stage of my research, I identified basic relationships in post-socialist social policy, while in the second I outlined the mechanisms which contribute to processes of institutional reproduction with respect to social policy. These two stages are not foreign to each other; on the contrary, I argued they have a commonality which is at the heart of policy sequencing, dynamics and the temporal dimension.

The first part of the analysis was covered in Chapter 3. In this chapter I applied an innovative research tool - fuzzy sets ideal-types analysis. I studied the main institutional characteristics of three social policy areas: unemployment benefits, family policy (maternity and parental leave benefits, childcare) and pensions in the group of eight countries which joined the European Union in 2004: the Czech Republic, Estonia, Hungary, Latvia, Lithuania, Poland, Slovakia and Slovenia. The chapter looked at the relation between the institutional logics of social policy programmes expressed by the principles guiding eligibility, generosity and quality, from which we can deduct the relations between state, 
market and family in welfare provision. If one underlying logic would be the case, it might mean there exists one 'post-communist' model of social policy, as suggested by the 'one Eastern European regime' thesis. If this is not the case, and the region of Central Europe is characterised by internal divergence of policies, then the analysis should go beyond the 'common experience' approach and focus more on the specific country developments and reasons which stand behind them.

The comparison conducted showed a wide spectrum of policy mixes, which provided a rich illustration of the empirical puzzle that was the starting point of this dissertation and at the same time answered the research question about the characteristics of main social policy programmes in these eight countries. It was hard to find single underlying logic for each policy and combinations of them. Rather, there were different logics which underlie each specific policy mix. Accordingly, at the beginning of transition period all three policy areas were characterized by some variation across countries (to a different extent, of course). This observation led to three conclusions. First, that the policies inherited from the socialist past were already varied. Assuming some degree of continuity and stability, it meant that social policies already had different shapes in the pretransition era. This argument goes against the assumption of communist social policy as a single regime. Second, the variation in unemployment compensation points to the existence of multiple designs being in place in the early phase of this policy development. Finally, the countries which conducted radical reforms to their pension systems did not necessarily implement the same type of reform in other fields of social policy. This diversity leads to the idea that the transformation of social policy has been a multifaceted process from the very beginning and there did not exist one template of the policy design and implementation.

The second stage of the research involved a comparative historical analysis of old-age pension policies in two countries with strikingly different pension policy reform outcome: Hungary and Poland. Informed by the historical institutionalism approach I argued that in order to understand current politics of social policy reform, one needs to understand the historical development of social policy programmes since their establishment. In this way, one can better understand from which quarters and for whom the impetus for various reform proposals came as well as for what reasons such policy reforms were resisted; in other words, the sources of policy change and stability over time can be mapped. Stepping back from this to a longer term theoretical perspective, one can see that social policy reforms are historically traceable political tensions and power struggles within specific institutions, deeply embedded in a country's social, economic and political history. 
Chapters 4 and 5 described and compared the contexts in which social policy making took place in the $20^{\text {th }}$ century as well as the changes to particular regulations regarding old-age pensions. Special attention was paid to institutional continuities and changes. The analysis demonstrated that from a historical point of view, the old-age pension programmes display a great degree of continuity.

The notion of continuity was understood in this dissertation as a persistence of particular social policy characteristics rather than unconditional stability. Therefore, the building blocks of social policy can themselves create the context for the policy developments. The chapters focused on the organization, financing and regulations concerning old-age programmes in a comparative perspective to show how these factors - if institutionalised - influence social policy reform.

The comparative historical view gave a unique opportunity to observe how various building blocks of social policy layers can co-exist and can crowd each other out. By this, I have provided an answer for the main research question about the sources of the present institutional shape of the policies under analysis. The historical development of social policy, as the case studies show, is not always a linear and intended process. A similar observation can be made about institutional innovation: it is rare and requires a specific set of conditions. Instead, policy makers work with material they have at hand and which by its very nature is historically contextualised and linked to other elements of social systems. The unitary nature of Hungarian welfare system and its high quality contributed to the preservation of Hungarian social policy, as the system itself did not give many opportunities for the particularistic behaviour of agents. However, such a conclusion can only be reached when the history of Hungarian political economy, society and social policy in known: of how social structure has been changed, what kind of political context surrounded the changes, and how these factors interacted with the existing social policy institutions. Another instance of this relational and contingent nature of welfare state is the reform of the Polish pension system. Here, the policy makers had to deal with a situation in which there were de facto several systems. Unlike in Hungary, the general system was not historically recognized as generous, while it offered privileges to certain social and occupational groups. As a result, the reform of pensions significantly modified the general scheme, while it left intact the scheme for farmers and other occupational privileges.

Apart from the theoretical considerations, the chapters illustrated several cases in which social policy regulations created in one context were sustained over time, in spite of pressures to alter them. One such case is that of the Polish 
occupational privileges, which although introduced under a previous regime largely contributed to the crisis of the pension system.

This dissertation corroborates findings presented by the scholars studying the sources and mechanisms of the reproduction of diversity in political economies of post-socialist societies. There is a growing body of research literature (Ekiert 1996; Inglot 2003; Seleny 2006; Inglot 2008) which argues that the sources of the current diversity lie in the past and are the result of the historically distant political events. The contribution that this dissertation makes to this body of research is, as I have argued, that the diversity of post-socialist social policy and its differentiated reform strategies is the result of a chain of processes, of institutional evolution, which finds its sources in the early stages of social policy making. The postsocialist welfare states, therefore, are the effect of distant compromises and conflicts that took place during socialist era, which in turn, were conditioned on processes preceding them.

This research has demonstrated the importance of history for understanding the present and future. This link is not straightforward and has to be established separately in each and every case. The analysis I conducted focuses on the relations between society, the political sphere and the economy, and the evolution of these interdependencies. Coming back to the Polanyian metaphor, the dissertation demonstrated that the double movement is a process, where these relations are constantly shaped and reshaped by structural constraints and openings, the agendas of various organizations' and collective mobilizations as well the behaviour of single individuals who replicate these mechanisms at the micro level.

As to the limitations of the current research, one should point out that the mechanisms identified cannot be automatically transposed to other cases, both in terms of policy domains and countries. Such a warning is not a weakness of the historical approach itself, rather its peculiar characteristic, emphasizing the importance of a historical context. In research terms it means that the historical framework should be carefully filled with building blocks which are relevant for a given case (policy or country) and reflect a specific context.

To conclude, the dissertation contributed to the understanding of welfare reform in East Central Europe - and especially Hungary and Poland - on three fronts: in terms of policy analysis, methodology and social theory. In terms of policy analysis, the study demonstrated that different social policy domains (such as old-age pensions, unemployment compensation and childcare) have varying dynamics, both with regard to inter- and intra-country comparisons. On the 
methodological front, a renewed focus on the temporal dimension of policy making and its dynamics revealed the importance of historical political and economic processes' sequences for understanding current policy developments. Finally, when it comes to the theoretical contribution of this study, the dissertation elucidated a process - institutional reconfiguration - that offers a richer and more rigorous explanation of social policy evolution in East Central Europe. 


\section{APPENDIX 1: ADDITIONAL TABLES AND FIGURES.}

TABLE 12: FUZZY MEMBERSHIP SCORES IN UNIVERSALITY OF THE OLD-AGE PENSIONS IN EIGHT POST-SOCIALIST COUNTRIES FOR YEARS 1989-2004

\begin{tabular}{|l|l|l|l|l|l|l|l|l|}
\hline $\begin{array}{l}\text { Country/ } \\
\text { Year }\end{array}$ & 1989 & 1991 & 1993 & 1995 & 1997 & 1999 & 2002 & 2004 \\
\hline Czech & 0.30 & 0.30 & 0.30 & 0.30 & 0.30 & 0.30 & 0.60 & 0.60 \\
\hline Estonia & 0.50 & 0.70 & 0.70 & 0.70 & 0.70 & 0.70 & 0.70 & 0.35 \\
\hline Hungary & 0.70 & 0.70 & 0.70 & 0.70 & 0.70 & 0.70 & 0.35 & 0.35 \\
\hline Latvia & 0.50 & 0.40 & 0.25 & 0.25 & 0.25 & 0.25 & 0.25 & 0.25 \\
\hline Lithuania & 0.60 & 0.60 & 0.60 & 0.60 & 0.75 & 0.75 & 0.75 & 0.40 \\
\hline Poland & 0.60 & 0.60 & 0.60 & 0.60 & 0.60 & 0.60 & 0.25 & 0.25 \\
\hline Slovakia & 0.30 & 0.30 & 0.60 & 0.60 & 0.60 & 0.60 & 0.60 & 0.60 \\
\hline Slovenia & 0.60 & 0.60 & 0.60 & 0.60 & 0.60 & 0.60 & 0.60 & 0.60 \\
\hline
\end{tabular}

TABLE 13: FUZZY MEMBERSHIP SCORES IN GENEROSITY OF THE OLD-AGE PENSIONS IN EIGHT POST-SOCIALIST COUNTRIES FOR YEARS 1989-2004

\begin{tabular}{|l|l|l|l|l|l|l|l|l|}
\hline $\begin{array}{l}\text { Country/ } \\
\text { Year }\end{array}$ & 1989 & 1991 & 1993 & 1995 & 1997 & 1999 & 2002 & 2004 \\
\hline Czech & 0.55 & 0.80 & 0.51 & 0.42 & 0.47 & 0.47 & 0.40 & 0.36 \\
\hline Estonia & 0 & 0 & 0 & 0.04 & 0.12 & 0.30 & 0.12 & 0 \\
\hline Hungary & 0.72 & 0.60 & 0.60 & 0.53 & 0.50 & 0.48 & 1 & 1 \\
\hline Latvia & 0 & 0 & 0.05 & 0.12 & 0.28 & 0.45 & 0.25 & 0 \\
\hline Lithuania & 0 & 0 & 0 & 0 & 0.18 & 0 & 0 & 0 \\
\hline Poland & 0.45 & 0.95 & 0.92 & 0.98 & 0.8 & 0.42 & 0 & 0 \\
\hline Slovakia & 0.55 & 1 & 0.47 & 0.46 & 0.51 & 0.49 & 0.20 & 0.40 \\
\hline Slovenia & 1 & 0.94 & 0.97 & 1 & 1 & 1 & 0.83 & 0.89 \\
\hline
\end{tabular}


TABLE 14: FUZZY MEMBERSHIP SCORES IN PRIVATE/PUBLIC MIX OF THE OLD-AGE PENSIONS IN EIGHT POST-SOCIALIST COUNTRIES FOR YEARS 1989-2004

\begin{tabular}{|l|l|l|l|l|l|l|l|l|}
\hline $\begin{array}{l}\text { Country/ } \\
\text { Year }\end{array}$ & 1989 & 1991 & 1993 & 1995 & 1997 & 1999 & 2002 & 2004 \\
\hline Czech & 0 & 0 & 0 & 0 & 0 & 0 & 0 & 0 \\
\hline Estonia & 0 & 0 & 0 & 0 & 0 & 0 & 0 & 0.82 \\
\hline Hungary & 0 & 0 & 0 & 0 & 0 & 0 & 0.78 & 0.78 \\
\hline Latvia & 0 & 0 & 0 & 0 & 0 & 0 & 0 & 0.78 \\
\hline Lithuania & 0 & 0 & 0 & 0 & 0 & 0 & 0 & 0 \\
\hline Poland & 0 & 0 & 0 & 0 & 0 & 0 & 0.76 & 0.76 \\
\hline Slovakia & 0 & 0 & 0 & 0 & 0 & 0 & 0 & 0 \\
\hline Slovenia & 0 & 0 & 0 & 0 & 0 & 0 & 0 & 0 \\
\hline
\end{tabular}

TABLE 15: FUZZY MEMBERSHIP SCORES IN ACCESSIBILITY OF THE UNEMPLOYMENT COMPENSATION IN EIGHT POST-SOCIALIST COUNTRIES FOR YEARS 1989-2004

\begin{tabular}{|l|l|l|l|l|l|l|l|l|}
\hline Country/Year & 1989 & 1991 & 1993 & 1995 & 1997 & 1999 & 2002 & 2004 \\
\hline Czech Rep. & NS & 0.77 & 0.94 & 0.80 & 0.80 & 0.80 & 0.80 & 0.80 \\
\hline Estonia & NS & 1 & 0.60 & 0.60 & 0.60 & 0.85 & 0.85 & 0.85 \\
\hline Hungary & 0.67 & 0.75 & 0.75 & 0.77 & 0.75 & 0.75 & 0.86 & 0.75 \\
\hline Latvia & NS & 1 & 0.10 & 0.10 & 0.10 & 0.10 & 0.25 & 0.25 \\
\hline Lithuania & NS & 1 & 0.34 & 0.34 & 0.60 & 0.60 & 0.60 & 0.60 \\
\hline Poland & NS & 1 & 0.60 & 0.10 & 0.10 & 0.10 & 0.10 & 0.10 \\
\hline Slovakia & NS & 0.77 & 0.94 & 0.67 & 0.67 & 0.67 & 0.67 & 0.25 \\
\hline Slovenia & 0.10 & 0.33 & 0.33 & 0.33 & 0.33 & 0.33 & 0.33 & 0.33 \\
\hline
\end{tabular}

${ }^{*}$ No scheme existing 
TABLE 16: FUZZY MEMBERSHIP SCORES IN GENEROSITY OF THE UNEMPLOYMENT COMPENSATION IN EIGHT POST-SOCIALIST COUNTRIES FOR YEARS 1989-2004

\begin{tabular}{|l|l|l|l|l|l|l|l|l|}
\hline Country/Year & 1989 & 1991 & 1993 & 1995 & 1997 & 1999 & 2002 & 2004 \\
\hline Czech Rep. & NS & 1 & 0.83 & 0.83 & 0.83 & 0.50 & 0.50 & 0.50 \\
\hline Estonia & NS & 0.67 & 0.67 & 0 & 0 & 0 & 0.50 & 0.50 \\
\hline Hungary & 0.91 & 1 & 1 & 1 & 1 & 1 & 1 & 1 \\
\hline Latvia & NS & 0.67 & 0 & 0 & 0.67 & 0.67 & 0.67 & 0.67 \\
\hline Lithuania & NS & 0.67 & 0.97 & 0.97 & 0.07 & 0.07 & 0 & 0 \\
\hline Poland & NS & 0.73 & 0.20 & 0.20 & 0.07 & 0 & 0 & 0 \\
\hline Slovakia & NS & 1 & 0.83 & 0.83 & 0.83 & 0.83 & 0.50 & 0.67 \\
\hline Slovenia & 0.67 & 0.67 & 0.67 & 0.67 & 0.67 & 0.67 & 1 & 1 \\
\hline
\end{tabular}

TABLE 17: FUZZY MEMBERSHIP SCORES IN DURATION OF THE UNEMPLOYMENT COMPENSATION IN EIGHT POST-SOCIALIST COUNTRIES FOR YEARS 1989-2004

\begin{tabular}{|l|l|l|l|l|l|l|l|l|}
\hline Country/Year 1989 & 1991 & 1993 & 1995 & 1997 & 1999 & 2002 & 2004 \\
\hline Czech Rep. & NS & 0.67 & 0.27 & 0.27 & 0.27 & 0.27 & 0.27 & 0.27 \\
\hline Estonia & NS & 0.27 & 0.27 & 0.27 & 0.27 & 0.27 & 0.27 & 0.27 \\
\hline Hungary & 0.67 & 1 & 0.67 & 0.67 & 0.67 & 0.67 & 0.50 & 0.50 \\
\hline Latvia & NS & 0.27 & 0.27 & 0.27 & 0.50 & 0.50 & 0.50 & 0.50 \\
\hline Lithuania & NS & 0.27 & 0.27 & 0.27 & 0.27 & 0.27 & 0.27 & 0.27 \\
\hline Poland & NS & 1 & 0.67 & 0.67 & 0.67 & 0.67 & 0.67 & 0.67 \\
\hline Slovakia & NS & 0.67 & 0.27 & 0.27 & 0.46 & 0.27 & 0.27 & 0.27 \\
\hline Slovenia & 0.67 & 0.67 & 0.27 & 0.27 & 0.27 & 0.27 & 0.27 & 0.27 \\
\hline
\end{tabular}


TABLE 18: FUZZY MEMBERSHIP SCORES IN OBLIGATION DIMENSION OF THE UNEMPLOYMENT COMPENSATION IN EIGHT POST-SOCIALIST COUNTRIES FOR YEARS 1989-2004

\begin{tabular}{|l|l|l|l|l|l|l|l|l|}
\hline Country/Year & 1989 & 1991 & 1993 & 1995 & 1997 & 1999 & 2002 & 2004 \\
\hline Czech Rep. & NS & 0.70 & 0.70 & 0.70 & 0.70 & 0.70 & 0.70 & 0.70 \\
\hline Estonia & NS & NA & 0.30 & 0.30 & 0.30 & 0.30 & 0.25 & 0.25 \\
\hline Hungary & 0.60 & 0.60 & 0.60 & 0.60 & 0.80 & 0.80 & 0.80 & 0.80 \\
\hline Latvia & NS & NA & NA & NA & NA & NA & 0.30 & 0.30 \\
\hline Lithuania & NS & NA & 0.30 & 0.30 & 0.60 & 0.60 & 0.60 & 0.60 \\
\hline Poland & NS & 0.65 & 0.50 & 0.25 & 0.30 & 0.30 & 0.30 & 0.30 \\
\hline Slovakia & NS & 0.70 & 0.70 & 0.30 & 0.30 & 0.30 & 0.30 & 0.30 \\
\hline Slovenia & 0.60 & 0.60 & 0.60 & 0.60 & 0.60 & 0.60 & 0.60 & 0.60 \\
\hline
\end{tabular}

TABLE 19: EXTENSIVENESS OF CHILDCARE SERVICES: FUZZY-SET MEMBERSHIP SCORES FOR YEARS 1989-2004.

\begin{tabular}{|l|l|l|l|l|l|l|l|l|}
\hline Country/Year & 1989 & 1991 & 1993 & 1995 & 1997 & 1999 & 2002 & 2004 \\
\hline Czech Rep. & 1.00 & 0.76 & 0.87 & 0.93 & 0.97 & 1.00 & 1.00 & 1.00 \\
\hline Estonia & 0.56 & 0.52 & 0.41 & 0.62 & 0.81 & 0.90 & 1.00 & 1.00 \\
\hline Hungary & 1.00 & 1.00 & 1.00 & 1.00 & 1.00 & 1.00 & 1.00 & 1.00 \\
\hline Latvia & 0.34 & 0.00 & 0.00 & 0.18 & 0.32 & 0.56 & 0.94 & 0.98 \\
\hline Lithuania & 0.34 & 0.20 & 0.00 & 0.00 & 0.08 & 0.25 & 0.32 & 0.58 \\
\hline Poland & 0.21 & 0.08 & 0.07 & 0.13 & 0.19 & 0.24 & 0.28 & 0.33 \\
\hline Slovakia & 0.93 & 0.81 & 0.58 & 0.43 & 0.63 & 0.74 & 0.77 & 0.71 \\
\hline Slovenia & 0.40 & 0.39 & 0.52 & 0.63 & 0.66 & 0.75 & 0.61 & 0.54 \\
\hline
\end{tabular}


TABLE 20: QUALITY OF THE CHILDCARE SERVICES: FUZZY-SET MEMBERSHIP SCORES FOR YEARS 1989-2004.

\begin{tabular}{|l|l|l|l|l|l|l|l|l|}
\hline Country/Year & 1989 & 1991 & 1993 & 1995 & 1997 & 1999 & 2002 & 2004 \\
\hline Czech Rep. & 0.00 & 0.28 & 0.00 & 0.08 & 0.11 & 0.00 & 0.00 & 0.00 \\
\hline Estonia & 0.71 & 0.94 & 0.84 & 0.89 & 0.94 & 0.71 & 0.71 & 0.71 \\
\hline Hungary & 0.08 & 0.02 & 0.00 & 0.00 & 0.00 & 0.00 & 0.49 & 0.49 \\
\hline Latvia & 0.71 & 0.72 & 0.82 & 0.73 & 0.73 & 0.74 & 0.61 & 0.23 \\
\hline Lithuania & 0.71 & 0.99 & 1.00 & 0.84 & 0.84 & 0.84 & 0.71 & 0.71 \\
\hline Poland & 0.00 & 0.00 & 0.00 & 0.00 & 0.00 & 0.00 & 0.00 & 0.00 \\
\hline Slovakia & 0.00 & 0.25 & 0.80 & 0.30 & 0.30 & 0.48 & 0.48 & 0.00 \\
\hline Slovenia & 0.55 & 0.46 & 1.00 & 0.25 & 0.52 & 0.00 & 0.00 & 0.00 \\
\hline
\end{tabular}

TABLE 21: GENEROSITY OF PARENTAL LEAVE PROVISION: FUZZY-SET MEMBERSHIP SCORES FOR YEARS 1989-2004.

\begin{tabular}{|l|l|l|l|l|l|l|l|l|}
\hline Country/Year & $\mathbf{1 9 8 9}$ & $\mathbf{1 9 9 1}$ & $\mathbf{1 9 9 3}$ & $\mathbf{1 9 9 5}$ & $\mathbf{1 9 9 7}$ & $\mathbf{1 9 9 9}$ & $\mathbf{2 0 0 2}$ & $\mathbf{2 0 0 4}$ \\
\hline Czech Rep & 0.62 & 0.67 & 0.57 & 0.60 & 0.79 & 0.70 & 0.78 & 0.87 \\
\hline Estonia & 0.29 & 0.59 & 0.47 & 0.35 & 0.35 & 0.42 & 0.43 & 0.41 \\
\hline Hungary & 1.00 & 1.00 & 1.00 & 1.00 & 0.94 & 1.00 & 1.00 & 1.00 \\
\hline Latvia & 0.29 & 0.44 & 0.56 & 0.41 & 0.37 & 0.34 & 0.32 & 0.30 \\
\hline Lithuania & 0.29 & 0.54 & 0.89 & 0.67 & 0.72 & 0.70 & 0.69 & 0.71 \\
\hline Poland & 0.26 & 0.49 & 0.48 & 0.43 & 0.46 & 0.49 & 0.49 & 0.52 \\
\hline Slovakia & 0.62 & 0.63 & 0.62 & 0.55 & 0.66 & 0.65 & 0.59 & 0.60 \\
\hline Slovenia & 0.15 & 0.15 & 0.73 & 0.74 & 0.72 & 0.74 & 0.69 & 0.68 \\
\hline
\end{tabular}

TABLE 22: UNIVERSALITY OF PARENTAL LEAVE PROVISION: FUZZY-SET MEMBERSHIP SCORES FOR YEARS 1989-2004.

\begin{tabular}{|l|l|l|l|l|l|l|l|l|}
\hline Country/Year & 1989 & 1991 & 1993 & 1995 & 1997 & 1999 & 2002 & 2004 \\
\hline Czech Rep & 0.40 & 0.40 & 0.40 & 0.40 & 1.00 & 1.00 & 1.00 & 1.00 \\
\hline Estonia & 0.30 & 0.55 & 0.80 & 0.80 & 0.75 & 0.85 & 0.85 & 1.00 \\
\hline Hungary & 0.85 & 1.00 & 1.00 & 1.00 & 0.30 & 1.00 & 1.00 & 1.00 \\
\hline Latvia & 0.30 & 0.40 & 1.00 & 1.00 & 1.00 & 1.00 & 1.00 & 1.00 \\
\hline Lithuania & 0.35 & 0.35 & 0.40 & 1.00 & 1.00 & 1.00 & 1.00 & 1.00 \\
\hline Poland & 0.20 & 0.20 & 0.20 & 0.20 & 0.20 & 0.20 & 0.20 & 0.20 \\
\hline Slovakia & 0.40 & 0.40 & 0.40 & 0.40 & 1.00 & 1.00 & 1.00 & 1.00 \\
\hline Slovenia & 0.40 & 0.40 & 1.00 & 1.00 & 1.00 & 1.00 & 1.00 & 1.00 \\
\hline
\end{tabular}


TABLE 23: RESPONSES TO WELFARE POLICY QUESTIONS, 1992-94 (PERCENT AGREE/STRONGLY AGREE).

\begin{tabular}{|c|c|c|c|c|c|c|}
\hline \multirow[t]{2}{*}{ Question } & \multicolumn{3}{|c|}{ Poland } & \multicolumn{3}{|c|}{ Hungary } \\
\hline & 1992 & 1993 & 1994 & 1992 & 1993 & 1994 \\
\hline $\begin{array}{l}\text { It should be the } \\
\text { government's } \\
\text { responsibility to } \\
\text { provide a job for } \\
\text { everybody who } \\
\text { wants one }\end{array}$ & 85 & 91 & 89 & 88 & 84 & 89 \\
\hline $\begin{array}{l}\text { Unprofitable } \\
\text { factories and } \\
\text { mines should be } \\
\text { closed, even if } \\
\text { this leads to } \\
\text { unemployment * }\end{array}$ & 62 & 75 & 72 & 59 & 67 & 65 \\
\hline $\begin{array}{l}\text { Goal: Guarantee } \\
\text { that less } \\
\text { economic burden } \\
\text { is put on the } \\
\text { shoulder of } \\
\text { people during } \\
\text { the } \\
\text { transformation } \\
\text { of our economy }\end{array}$ & 88 & 86 & 88 & 92 & 92 & 92 \\
\hline $\begin{array}{l}\text { Goal: Increase } \\
\text { pensions and } \\
\text { social benefits }\end{array}$ & 88 & 92 & 91 & 89 & 93 & 92 \\
\hline
\end{tabular}

*Percentage of respondents who disagree with the statement Source: (Tworzecki 2006)

TABLE 24: EMPLOYMENT RATES IN HUNGARY AND POLAND, 1992-2000, SELECTED YEARS

\begin{tabular}{|l|l|l|l|l|l|l|}
\hline \multirow{2}{*}{$\begin{array}{l}\text { Country/ } \\
\text { Year }\end{array}$} & \multicolumn{3}{|c|}{ Hungary } & \multicolumn{3}{c|}{ Poland } \\
\cline { 2 - 7 } & Males & Females & Total & Males & Females & Total \\
\hline $\mathbf{1 9 9 2}$ & $64.6 \%$ & $52.3 \%$ & $58.3 \%$ & $61.4 \%$ & $46 \%$ & $53.3 \%$ \\
\hline $\mathbf{1 9 9 5}$ & $60.2 \%$ & 45.9 & 52.9 & 58.5 & 43.7 & 50.7 \\
\hline $\mathbf{1 9 9 8}$ & $60.6 \%$ & $47.3 \%$ & $53.9 \%$ & 58.9 & $43.9 \%$ & $51.0 \%$ \\
\hline $\mathbf{1 9 9 9}$ & $62.6 \%$ & $49.0 \%$ & 55.7 & 55.9 & $40.7 \%$ & $48 \%$ \\
\hline $\mathbf{2 0 0 0}$ & $63.3 \%$ & $49.7 \%$ & 56.4 & $55.2 \%$ & $40.3 \%$ & $47.4 \%$ \\
\hline
\end{tabular}

Source: (Balcerzak-Paradowska, Chłoń-Domińczak et al. 2003; Lukacs and Frey 2003) 
TABLE 25: PROPORTION OF NEWLY GRANTED PENSION/AVERAGE WAGE, PROPORTION OF RUNNING PENSION/AVERAGE WAGE, RELATION BETWEEN RUNNING AND NEWLY GRANTED PENSION IN POLAND, 1961-1978

\begin{tabular}{|l|l|l|l|}
\hline Year & $\begin{array}{l}\text { \% of average newly } \\
\text { granted } \\
\text { pension/average wage }\end{array}$ & $\begin{array}{l}\text { \% of average running } \\
\text { pension/average wage }\end{array}$ & $\begin{array}{l}\text { \%f average running } \\
\text { pension/average } \\
\text { newly granted } \\
\text { pension }\end{array}$ \\
\hline $\mathbf{1 9 6 1}$ & 57.2 & 54.9 & 96.1 \\
\hline $\mathbf{1 9 6 2}$ & 57.1 & 55.7 & 97.5 \\
\hline $\mathbf{1 9 6 3}$ & 56.7 & 55.9 & 98.7 \\
\hline $\mathbf{1 9 6 4}$ & 56.4 & 56.1 & 99.4 \\
\hline $\mathbf{1 9 6 5}$ & 53.8 & 52.9 & 98.4 \\
\hline $\mathbf{1 9 6 6}$ & 53.3 & 52.8 & 99.1 \\
\hline $\mathbf{1 9 6 7}$ & 52.0 & 52.2 & 100.5 \\
\hline $\mathbf{1 9 6 8}$ & 61.6 & 55.6 & 90.1 \\
\hline $\mathbf{1 9 6 9}$ & 63.1 & 60.8 & 96.4 \\
\hline $\mathbf{1 9 7 0}$ & 72.3 & 65.3 & 90.3 \\
\hline $\mathbf{1 9 7 1}$ & 71.9 & 66.2 & 92.0 \\
\hline $\mathbf{1 9 7 2}$ & 73.8 & 64.4 & 87.3 \\
\hline $\mathbf{1 9 7 3}$ & 68.0 & 59.8 & 87.8 \\
\hline $\mathbf{1 9 7 4}$ & 64.1 & 54.9 & 86.8 \\
\hline $\mathbf{1 9 7 5}$ & 60.1 & 50.2 & 83.7 \\
\hline $\mathbf{1 9 7 6}$ & 63.7 & 50.1 & 78.7 \\
\hline $\mathbf{1 9 7 7}$ & 69.9 & 53.9 & 77.1 \\
\hline $\mathbf{1 9 7 8}$ & 74.4 & 57.7 & 77.5 \\
\hline
\end{tabular}

Source: (Wiktorow 1980: 59) 
TABLE 26: FARMERS' SCHEME: PENSIONERS, BENEFITS AND RELATIONS BETWEEN BENEFITS FROM FARMERS AND GENERAL SCHEME IN POLAND, 1963-81

\begin{tabular}{|l|l|l|l|}
\hline Year & $\begin{array}{l}\text { Number of pensioners } \\
\text { (thousands) }\end{array}$ & $\begin{array}{l}\text { Average benefit of } \\
\text { individual farmers (in } \\
\text { zl) }\end{array}$ & $\begin{array}{l}\text { Average running } \\
\text { benefit of individual } \\
\text { farmers/general } \\
\text { average benefit (\%) }\end{array}$ \\
\hline $\mathbf{1 9 6 3}$ & 0.2 & 589 & 83.5 \\
\hline $\mathbf{1 9 6 4}$ & 1.5 & 590 & 79.8 \\
\hline $\mathbf{1 9 6 5}$ & 3.1 & 489 & 62.6 \\
\hline $\mathbf{1 9 6 6}$ & 4.8 & 594 & 73.4 \\
\hline $\mathbf{1 9 6 7}$ & 6.7 & 596 & 70.3 \\
\hline $\mathbf{1 9 6 8}$ & 8.9 & 612 & 64.2 \\
\hline $\mathbf{1 9 6 9}$ & 15.3 & 702 & 66.3 \\
\hline $\mathbf{1 9 7 0}$ & 25.1 & 683 & 59.7 \\
\hline $\mathbf{1 9 7 1}$ & 36.0 & 708 & 58.3 \\
\hline $\mathbf{1 9 7 2}$ & 45.5 & 726 & 57.6 \\
\hline $\mathbf{1 9 7 3}$ & 54.3 & 716 & 54.7 \\
\hline $\mathbf{1 9 7 4}$ & 64.2 & 850 & 61.2 \\
\hline $\mathbf{1 9 7 5}$ & 93.7 & 1119 & 72.4 \\
\hline $\mathbf{1 9 7 6}$ & 133.2 & 1176 & 70.0 \\
\hline $\mathbf{1 9 7 7}$ & 164.3 & 1210 & 62.5 \\
\hline $\mathbf{1 9 7 8}$ & 194.2 & 1409 & 64.5 \\
\hline $\mathbf{1 9 7 9}$ & 289.4 & 1772 & 72.0 \\
\hline $\mathbf{1 9 8 0}$ & 422.9 & 1999 & 74.6 \\
\hline $\mathbf{1 9 8 1}$ & 549.7 & 2304 & 71.1 \\
\hline
\end{tabular}

Source: (Łopacińska and Wiktorow 1984: 24) 
FIGURE 1: RELATION BETWEEN AVERAGE PENSION AND WAGES AND NEWLY GRANTED PENSION AND WAGES IN HUNGARY, 1970-1993

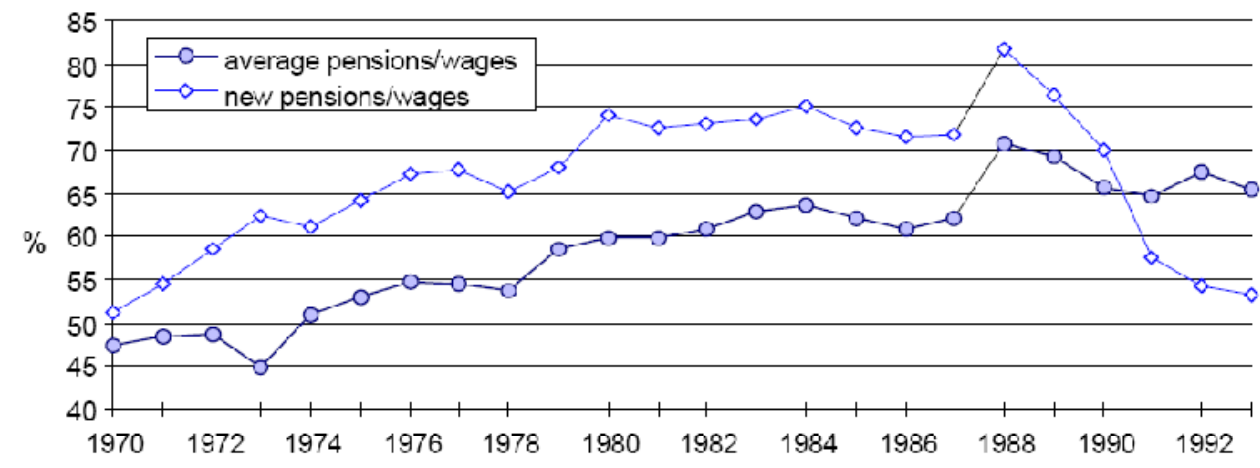

Source: (Antal, Reti et al. 1995: 188)

Note: The significant jump in $1987 / 8$ is the result of referring to net wages after introduction of a personal income tax 


\section{REFERENCES}

Adcock, R. and D. Collier (2001). "Measurement Validity: A Shared Standard for Qualitative and Quantitative Research." The American Political Science Review 95(3): 529-546.

Albert, A. (1989). Najnowsza Historia Polski. Londond, Polonia Book Fund

Anderson, E. A., R. C. Hula, et al. (1991). The Reconstruction of family policy. New York, Greenwood Press.

Antal, K., J. Reti, et al. (1995). Pension Outlay and Changes in the Pension System in the Nineties The Economy, Human Resources and Social Stability During the Transition in Hungary. E. Ehrlich and G. Revesz. Budapest, International Center for Economic Growth.

Antal, K., J. Reti, et al. (1995). Loss of Value and Distortions in the Hungarian Pension System. The Economy, Human Resources and Social Stability During the Transition in Hungary. E. Ehrlich and G. Revesz. Budapest, International Center for Economic Growth.

Arts, W. and J. Gelissen (2002). "Three worlds of welfare capitalism or more? A state-of-theart report." Journal of European Social Policy 12(2): 137-158.

Atkinson, A. B. (1999). The economic consequences of rolling back the welfare state. Cambridge, Mass., MIT Press.

Augustinovics, M. and J. Kollo (2008). Pension System and Fragmented Labor Market Careers. Assessing Intergenerational Equity. An Interdisciplinary Study of Agin and Pension Reform in Hungary. R. I. Gal, I. Iwasaki and Z. Szeman. Budapest, Akademiai Kiado.

Augusztinovics, M. (1993). The Social Security Crisis in Hungary. Hungary: An Economy in Transition. I. Szekely and D. Newbery. Cambridge, Cambrideg University Press.

Balcerzak-Paradowska, B., A. Chłoń-Domińczak, et al. (2003). The Gender Dimensions Of Social Security Reform in Poland. The Gender Dimensions of Social Security Reform in Central and Eastern Europe: Case Studies of the Czech Republic, Hungary and Poland E. Fultz, M. Ruck and S. Steinhilber. Budapest, International Labour Organization.

Baldwin, P. (1990). The politics of social solidarity : class bases in the European welfare state, 1875-1975. Cambridge [England] ; New York, Cambridge University Press.

Barany, Z. D. and I. Völgyes (1995). The legacies of communism in Eastern Europe. Baltimore, Johns Hopkins University Press.

Barr, N. A. (1994). Labor markets and social policy in Central and Eastern Europe : the transition and beyond. New York, N.Y., Oxford Univerersity Press.

Baxandall, P. (2004). Constructing unemployment : the politics of joblessness in East and West. Aldershot, Ashgate. 
Berend, I. (1993). The Composition and Position of the Working Class During the War.

Hungarian Economy and Society During World War II. G. Lengyel. New York, Columbia University Press.

Berend, I. (2001). The Changed Post-War Conditions for Development Evolution of the Hungarian Economy 1848-1998. One-and-a-Half Centuries of Semi-Successful Modernization 1848-1998. I. Berend and T. Csato. Colorado, Columbia University Press. I.

Berend, I. (2001). The Changed Post-War Conditions for Development.

Bleses, P. and M. Seeleib-Kaiser (2004). The dual transformation of the German welfare state. Houndmills [England] ; New York, Palgrave Macmillan.

Bod, P. (1995). Formation of the Hungarian social insurance pension system. Human

Resources and Social Stability during Transition in Hungary. I. o. W. E. o. t. H. A. o. Science. San Francisco, International Center for Economic Growth.

Bohle, D. and B. Greskovits (2007). "Neoliberalism, Embedded Neoliberalism, and Neocorporatism: TowardsTransnational Capitalism in Central-Eastern Europe." West European Politics 30(3): 443 - 466.

Bonoli, G., V. George, et al. (2000). European welfare futures : towards a theory of retrenchment. Cambridge, U.K.

Malden, MA, Polity Press ;

Blackwell.

Bornstein-Łychowska, M. (1928). 10 Lat Polityki Społecznej Państwa Polskiego 1918-1928. Warszawa, Ministerstwo Pracy i Opieki Społecznej.

Borowczyk, E. (1991). Organizacja Ubezpieczen Spolecznych. Rozwoj Ubezpieczen Spolecznych w Polsce. C. Jackowiack. Wroclaw, Ossolineum.

Bridgen, P. and T. Mayer (2007). Private pensions versus social inclusion? Citizens at risk and the new pensions orthodoxy. Private Pensions versus Social Inclusion? NonState Provision for Citizens at Risk in Europe. T. Mayer, P. Bridgen and B. Riedmueller. Cheltenham, Edward Elgar.

Bruszt, L. (1993). Transformative Politics: Social Costs and Social Peace in East Central Europe. Transforming Economic Systems in East Central Europe. R. Schonfel. Munchen, Sudosteuropa-Gesellschaft.

Bürger, T. (1987). Max Weber's theory of concept formation : history, laws, and ideal types. Durham [N.C.], Duke University Press.

Castles, F. G. (2004). The future of the welfare state : crisis myths and crisis realities. Oxford, Oxford University Press.

Castles, F. G. and D. Mitchell (1993). Worlds of Welfare and Families of Nations. Families of Nations: Patterns of Public Policy in Western Democracies. F. G. Castles. Aldershot:, Dartmouth Publishing Company. 
Cerami, A. (2003). "The Impact of Social Transfers in Central and Eastern Europe." Luxemburg Income Studies Working Paper Series 356.

Chłoń-Domińczak, A. (2002). The Polish Pension Reform of 1999. Pension Reform in Central and Eastern Europe Volume 1. Restructuring with Privatisation: Case Studies of Hungary and Poland. E. Fultz. Budapest, International Labour Organization.

Chłoń-Domińczak, A., M. Góra, et al. (1999). Shaping Pension Refom in Poland: Security through Diversity Washington, DC, World Bank.

Clasen, J. (2001). What future for social security? : debates and reforms in national and crossnational perspective. The Hague ; Boston, Kluwer Law International.

Clasen, J. and N. A. Siegel (2007). Investigating Welfare State Change. The 'Dependent Variable Problem' in Comparative Analysis. Cheltenham, Edward Elgar.

Clasen, J. and W. van-Oorshot (2002). "Changing Principles in European Social Security." European Journal of Social Security 4(2): 89-114.

Clegg, D. and J. Clasen (2003). Conceptualising and measuring the changing principles of social security in Europe: Reflections from a five-country study. 1st ESPAnet annual conference "Changing European Societies-the role of social policy" Copenhagen.

Cook, L. and M. A. Orenstein (1999). The Return of the Left and Its Impact on the Welfare State in Poland, Hungary and Russia. Left Parties and Social Policy in Postcommunist Europe. L. Cook, M. A. Orenstein and M. Rueschmeyer. Boulder, Westwiew Press.

Cook, L. J., M. A. Orenstein, et al. (1999). Left parties and social policy in postcommunist Europe. Boulder, Colo., Westview Press.

Crowley, S. (2004). "Explaining Labor Weakness in Post-Communist Europe: Historical Legacies and Comparative Perspective." East European Politics and Society 18(3): 394-429.

Czepulis-Rutkowska, Z. (1996). Zmiany w Systemie Emerytalno-Rentowym. Polityka Społeczna w Latach 1994-1996. Procesy Regulacyjne i Ich Skutki. S. Golinowska. Warszawa, IPiSS.

Czucz, O. and M. Pinter (2002). Transformation of old-age security in Hungary. Transformation of Pension Systems in Central and Eastern Europe. W. Schmahl and S. Horstmann. Cheltenham, Edward Elgar: 277-304.

Daly, M. and K. Rake (2004). Gender and the Welfare State Cambridge, Polity Press.

Dąbrowska, E. (1991). "Źródła niektórych prawidłowości w funkcjonowaniu ubezpieczeń społecznych." Praca i Zabezpieczenie Społeczne(10): 27-35.

Deacon, B. (1990). Introduction: The Significance of Recent Social Policy Developments in Central and Eastern Europe Social Policy in the New Eastern Europe. What Future for Socialist Welfare. B. Deacon and J. Szalai. Aldershot, Avebury. 
Deacon, B. (1992b). The New Eastern Europe : social policy past, present and future. London ; Newbury Park, Sage Publications.

Deacon, B. (2000). "Eastern European Welfare States: the Impact of the Politics of Globalization." Journal of European Social Policy 10(2): 146-161.

Deacon, B., M. Hulse, et al. (1997). Global social policy: international organizations and the future of welfare. London ; Thousand Oaks, Calif., SAGE.

Deacon, B. and J. Szalai (1990). Social policy in the new Eastern Europe : what future for socialist welfare? Aldershot, Hants, England ; Brookfield, Vt., USA, Avebury.

Ekiert, G. (1996). The state against society : political crises and their aftermath in East Central Europe. Princeton, N.J, Princeton University Press.

Esping-Andersen, G. (1985). Politics against markets. The Social Ddemocratic Road to Power. Princeton, Princeton University Press.

Esping-Andersen, G. (1990). The three worlds of welfare capitalism. Cambridge, England, Polity.

Esping-Andersen, G. (1990). The Three Worlds of Welfare Capitalism,. London, Polity Press. Esping-Andersen, G., M. Regini, et al. (2000). "Why deregulate labour markets?", from Fallenbuchl, Z. M. (1987). Empolyment Policies in Poland. Employment Policies in the Soviet Union and Eastern Europe. J. Adam. Basingstoke, Macmillan Press.

Ferge, Z. (1979). A Society in the Making. Hungarian Social and Societal Policy 1945-1975. Middlesex, New York, Penguin Books.

Ferge, Z. (1987). The Impact of the Present Crisis on Social Policy from a Comparative European Perspective. The Changing Face of Welfare. A. Evers, H. Nowotny and H. Wintersberger. Aldershot, Gower Publishing Company.

Ferge, Z. (1988). Plan Perspektywicznego Rozwoju Polityki Socjalnej na Wegrzech. Warszawa, ZUS.

Ferge, Z. (1995). Social Policy Reform in Post-Communist Countries: Various Reform Strategies. Social Reform in East-Central Europe: New Trends in Transition. S. Ringen and C. Wallace. Prague, Trevor Top.

Ferge, Z. (2003).

Ferge, Z. (2003). The Actors in Hungarian Pension Reform. Small Transformations. The Politics of Welfare Reform-East and West. J. M. Kovacs. Munster-HamburgLondon, LIT.

Ferrera, M. (1996). "The "Southern" Model of Welfare in Social Europe." Journal of European Social Policy 6(1): 17-37.

Flora, P. and J. Alber (1981). Modernization, Democratization, and the Development of Welfare States in Western Europe. The Development of Welfare States in Europe and America. P. Flora and A. J. Heidenheimer. New Brunswick, Transaction Books 37-80. 
Fultz, E., Ed. (2006). Pension Reform in the Baltic States. Budapest, International Labour Organization.

Gabor, R. and B. Gyorki (1973). Public Health and Social Security. Hungary. E. C. Helmrich. Westport, Conn, Greenwood Press.

Gal, R. I., I. Iwasaki, et al. (2008). Conclusions and Agenda for Further Reseach. Assessing Intergenerational Equity. An Interdisciplinary Study of Aging and Pension Reform in Hungary. R. I. Gal, I. Iwasaki and Z. Szeman. Budapest, Akademiai Kiado.

Gál. Róbert, I., I. Iwasaki, et al. (2008). Assessing intergenerational equity : an interdisciplinary study of aging and pension reform in Hungary. Budapest, Akadémiai Kiadó.

Gero, B. (1997). The Role of the Hungarian Constitutional Court CIAO Working Papers.

Golinowska, S. (1994). Publiczne wydatki społeczne. Polityka Społeczna i Warunki Społeczne w Polsce w latach 1989-1993. IPiSS. Warszawa, IPiSS.

Golinowska, S. (1996). Publiczne Wydatki Społeczne. Polityka Społeczna w Latach 19941996. Procesy Regulacyjne i Ich Potencjalne Skutki. S. Golinowska. Warszawa, IPiSS.

Golinowska, S. (1996). Ubóstwo w Polsce w pierwszej połowie lat dziewięćdziesiątych. Synteza wyników badań. Polska Bieda. Kryteria. Ocena. Przeciwdziałanie. S. Golinowska. Warszawa, IPiSS.

Golinowska, S. (1997). Polityka Spoleczna w Gospodarce Rynkowej Warszawa PWN.

Golinowska, S. (1999). Ochrona Socjalna Bezrobotnych w Polsce i Innych Krajach. Warszawa, CASE.

Golinowska, S. (1999). Political Actors and Reform Paradigms in Old-Age Security in Poland. Transformation of Social Security: Pensions in Central-Eastern Europe $M$. K., R. A. and W. H.-J. Hedielberg, New York, Physica-Verlag.

Golinowska, S. and A. Ochocki (1994). Polityka spoleczna i warunki spoleczne w Polsce w latach1989-1993. Polityka Spoleczna i Warunki Spoleczne w Polsce w latach 19891993. IPiSS. Warszawa, IPiSS.

Golinowska, S. and M. Zukowski (2002). Transformation of old-age security in Poland. Transformation of Pension Systems in Central and Eastern Europe. W. Schmahl and S. Horstmann. Cheltenham, Northampton, Edward Elgar.

Gornick, J. C. and M. K. Meyers (2003). Families that Work. Policies for Reconciling Parenthood and Employment, Russel Sage Foundation.

Green-Pedersen, C. (2004). "The dependent variable problem within the study of welfare state retrenchment: defining the problem and looking for solutions." Journal of Comparative Policy Analysis 6(1): 3-14.

Guardiancich, I. (2007) Intitutional Degeneration of Multipillar Pension Systems. The Case of Croatia. EUI Working Papers Volume, DOI: 
Guardiancich, I. (2009). "The New Pension Orthodoxy in Central, Eastern and South Eastern Europe: Lessons for Perspective Reformers." Rivista Italiana di Politiche Pubbliche(1): 5-31.

Gyáni, G. (2004). Social History of Hungary in the Horthy Era. Social History of Hungary from the Reform Era to the End of the Twentieth Century. G. Gyáni, G. Kover and T. Valuch. Colorado, Boulder, Colorado University Press. 113.

Hacker, J. S. (2002). The divided welfare state : the battle over public and private social benefits in the United States. New York, Cambridge University Press.

Hall, P. and D. Soskice, Eds. (2001). Varieties of Capitalism. Oxford, Oxford University Press.

Haney, L. (2002). Inventing the Needy: Gender and the Politics of Welfare in Hungary. Berkley, University of California Press.

Hantrais, L. (2004). Family policy matters : responding to family change in Europe. Bristol, Policy.

Hasselmann, C. (2006). Policy reform and the development of democracy in Eastern Europe. Aldershot, England ; Burlington, VT, Ashgate.

Hausner, J. (2001). Security through Diversity: Conditions for the Successful Reform of the Pension System in Poland. Reforming The State. Fiscal and Welfare Reform in PostSocialist Countries. J. Kornai, S. Haggard and R. Kaufman. Cambridge, Cambridge University Press.

Heclo, H. (1974). Modern social politics in Britain and Sweden : from relief to income maintenance. New Haven, Yale University Press.

Holzmann, R. and U. Guven (2009). Adequacy of Retirement Income after Pension Reforms in Central, Eastern, and Southern Europe Eight Country Studies. Washington, World Bank.

Howlett, M. and B. Cashore (2009 ). "The Dependent Variable Problem in the Study of Policy Change: Understanding Policy Change as a Methodological Problem." Journal of Comparative Policy Analysis 11(1): 33-46.

Huber, E. and J. D. Stephens (2001). Development and crisis of the welfare state : parties and policies in global markets. Chicago, The University of Chicago Press.

ILO (1995). Reforming wage policy in Central and Eastern Europe. Budapest, ILO.

Inglot, T. (2003). Historical Legacies, Institutions, and the Politics of Social Policy in Hungary and Poland, 1989-1999. Capitalism and Democray in Central and Eastern Europe. G. Ekiert and S. E. Hanson, Cambridge University Press: 210-247.

Inglot, T. (2008). Welfare states in East Central Europe, 1919-2004. Cambridge ; New York, Cambridge University Press.

Insurance, H. D. o. S. (1968). Social Insurance of Agricultural Workers in Hungary Central Council of Hungarian Trade Unions Head Department of Social Insurance. 
Iwasaki, I. and K. Sato (2008). Mandatory Pension Funds: The Second Pillar. Assessing Intergenerational Equity. An Interdisciplinary Study of Aging and Pension Reform in Hungary. R. I. Gal, I. Iwasaki and Z. Szeman. Budapest, Akademiai Kiado.

Jackowiak, C. (1991). Kierunki rozwoju ubepieczen spolecznych. Rozwoj ubezpieczen spolecznych w Polsce. C. Jackowiak. Wroclaw, Ossolineum.

Janos, A. C. (1982). The politics of backwardness in Hungary, 1825-1945. Princeton, N.J, Princeton University Press.

Janoski, T. and A. Hicks (1994). The comparative political economy of the welfare state. Cambridge, UK ; New York, NY, USA, Cambridge University Press.

Jędrasik-Janowska, I. (1997). "Zasiłki i świadczenia przedemerytalne." Praca i Zabezpieczenie Społeczne(7-8): 37-40.

Jończyk, J. (2005). "Ubezpieczenie emerytalne-stan obecny i widoki na przyszłość." Praca i Zabezpieczenie Społeczne(9): 2-8.

Kersbergen, K. v. (1995). Social Capitalism. A Study of Christian Democracy and the Welfare State. London/New Yor, Routledge.

Kersbergen, K. v. and U. Becker (2001). Comparative Politics and the Welfare State. Comparative Democratic Politics. H. Keman, Routledge: 185-214.

Keune, M. and European University Institute. Dept. of Political and Social Sciences. (2006). Creating capitalist labour markets : a comparative-institutionalist analysis of labour market reform in the Czech Republic and Hungary, 1989-2002. Florence, European University Institute.

Kornai, J. (1980). Economics of shortage. Amsterdam ; New York

New York, North-Holland Pub. Co. ;

Kornai, J. (1992). The Socialist System: The Political Economy of Communism. Oxford, Oxford University Press.

Korpi, W. (1980). "Social policy strategies and distributional conflict in capitalist democracies." West European Politics 3(3): 296-316.

Korpi, W. (1989). "Power, politics, and state autonomy in the development of social citizenship: Social rights during sickness in eighteen OECD countries since 1930." American Sociological Review 54: 309-328.

Kovrig, B. (1940). Hungarian Social Policy since the World War. The Hungarian Economic Yearbook. G. Gratz. London

Kovrig, B. (1979). Communism in Hungary : from Kun to Kádár. Stanford, Calif, Hoover Institution Press.

Ksiezopolski, M. (1999). Polityka spoleczna. Wybrane problemy porownan miedzynarodowych. Katowice, Slask.

Kurowski, P. (2002). Koszyki minimum socjalnego i minimum egzystencji - dotychczasowe podejscie. www.ipiss.com.pl Warszawa, IPiSS. 
Kvist, J. (1999). "Welfare reform in the Nordic countries in the 1990s: using fuzzy-set theory to assess conformity to ideal types." Journal of European Social Policy 9(3): 231-252.

Kvist, J. (2003). Conceptualization, Configuration, and Categorization- Diversity, Ideal Types and Fuzzy Sets in comparative Welfare State Research. COMPASSS Launching Conference 16-17 September 2003, Louvain-la-Nouve and Leuven, Belgium.

Kvist, J. (2006). Diversity, ideal types and fuzzy sets in comparative welfare state research. Innovative Comparative Methods for Policy Analysis: Beyond the quantitativequalitative divide. B. Rihoux and H. Grimm. New York, Springer: 167-184.

Landau, Z. (1991). Podstawowe Kierunki Rozwoju Ubezpieczen Spolecznych. Rozwoj Ubezpieczen Spolecznych w Polsce. C. Jackowiack. Wroclaw, Ossolineum. Landau, Z. (1992). The Economic Integration of Poland, 1918-1923. The Reconstruction of Poland 1914-1923. P. Latawski. London, Macmillan Press.

Lazarsfeld, P. (1937). "Some Remarks on Typological Procedures in Social Sciences." Zeitschrift fur Socialforschung(6): 119-139.

Leibfried, S. (1992). Towards a European welfare state? On Integrating Poverty Regimes into the European Community. Social Policy in a Changing Europe. Z. Ferge and J. Kolberg. Frankfurt am Main, Campus Verlag.

Leitner, S. and S. Lessenich (2005). (In-)Dependence and Dependent Variable: conceptualising and measuring 'de-familisation'. Exploring the Dynamics of Reform: the dependetn variable problem in comparative welfare state analysis. University of Stirling, 13-14 May 2005

Lieberman, E. S. (2005). "Nested Analysis as a Mixed-Method Strategy for Comparative Research." American Political Science Review 99(3): 435-452.

Lipsmeyer, C. S. (2000). "Reading Between the Welfare Lines: Politics and Policy Structure in Post-Communist Europe." Europe-Asia Studies 52(7): 1191-1211.

Lukacs, E. and M. Frey (2003). The Gender Dimensions of Social Security Reform in Hungary. The Gender Dimensions of Social Security Reforms in Central and Eastern Europe: case studies of teh Czech Republic, Hungary and Poland. E. Fultz, M. Ruck and S. Steinhilber. Budapest, International Labour Office: 43-108.

Łopacińska, E. and A. Wiktorow (1984). Ubezpieczenia Emerytalne Rolników Indywidualnych. Warszawa, Instytut Pracy i Spraw Społecznych.

Mamrotowa, M. (1952). "Węgierska Ustawa o Świadczeniach Emerytalnych." Przegląd Zagadnień Socjalnych(9): 40-41.

Marshall, T. H. (1950). Citizenship and social class, and other essays. Cambridge [Eng.], University Press.

Mate, L. (2004). The Collection of Pension Contributions in Hungary. The Collection of Pension Contributions: Trends, Issues, and Problems in Central and Eastern Europe. . E. Fultz and T. Stanovnik. Budapest, International Labour Organization. 
Matits, A. (2008). Voluntary Pension Funds: The Third Pillar. Assessing Intergenerational Equity. An Interdisciplinary Study of Aging and Pension Reform in Hungary. R. I. Gal, I. Iwasaki and Z. Szeman. Budapest, Akademiai Kiado.

Milanović, B. and World Bank. Development Research Group. (1995). Poverty, inequality, and social policy in transition economies. Washington, D.C., World Bank, Policy Research Dept., Transition Economics Division.

Ministry of Finance (1993). New Regulations On Social Insurance and Other Benefits. Budapest, PERFEKT.

MPiOS (1923). "Sprawozdanie z dzialalnosci Ministerstwa Pracy i Opieki Spolecznej " Praca i opieka spoleczna 2.

Mueller, K. (1999). The Polital Economy of Pension Reforms in Central Eastern Europe. Cheltenham, UK; Northampton, MA, USA, Edward Elgar.

Mueller, K. (1999). The Political Economy of Pension Reforms in Central Eastern Europe. Cheltenham, UK; Northampton, MA, USA, Edward Elgar.

Muszalski, W. (1991). Swiadczenia Rodzinne. Rozwoj Ubezpieczen Spolecznych w Polsce. C. Jackowiak. Wroclaw, Ossolineum.

Neale, W. C. (1991). "Society, State and Market: A Polanyian View of Current Change and Turmoil in Eastern Europe " Journal of Economic Issues XXV(2): 467-473.

Nelson, J. (2001). The politics of pension and health care reforms in Hungary and Poland. Reforming the state: fiscal and welfare reform in post-socialist countries. K. J., H. S. and K. R. New York, Cambridge University Press.

Offe, C. and U. K. Preuss (1998). Institutional design in post-communist societies : rebuilding the ship at sea. Cambridge, U.K. ; New York, Cambridge University Press.

Oniszczuk, J. (1999). "Reforma świadczeń emerytalno-rentowych w świetle wyroku Trybunału Konstytucyjnego." Praca i Zabezpieczenie Społeczne(10): 29-34.

Orenstein, M. A. (2008). Privatizing pensions : the transnational campaign for social security reform. Princeton, Princeton University Press.

Orenstein, M. A., S. R. Bloom, et al. (2008). Transnational actors in Central and East European transitions. Pittsburgh, Pa., University of Pittsburgh Press.

Organisation for Economic Co-operation and Development. (2009). Pensions at a glance : retirement -income systems in OECD countries. Paris, Organisation for Economic Co-operation and Development.

Orloff, A. S. (1993). The politics of pensions : a comparative analysis of Britain, Canada, and the United States, 1880-1940. Madison, University of Wisconsin Press.

Orlowski, A. (1912). Ubezpieczenia Robotnicze w Dumie Panstwowej. Warszawa, Ksiegarnia G. Centnerszwera i S-ka.

Ormos, M. (2007). Hungary in the age of the two World Wars, 1914-1945. Boulder, Colo. 
Ost, D. (2005). The defeat of solidarity: anger and politics in postcommunist Europe. Ithaca, N.Y., Cornell University Press.

Palier, B. and C. Martin (2007). "Editorial introduction - From a 'frozen landscape' to structural reforms: The sequential transformation of bismarckian welfare systems " Social Policy \& Administration 41: 535-554.

Palme, J. (1990). Pension Rights in Welfare Capitalism. Stockholm, Swedish Institute for Social Research.

Pasternak, J. (1926). "Ubezpieczenie Pracownikow Umyslowych." Praca i Opieka Spoleczna 5(1): 54-66.

Pierson, P. (1994). New politics of the welfare state. Cambridge, Center for Euripean Studies.

Pierson, P. (2000). "Increasing returns, path dependence, and the study of politics."

American Political Science Review 94(6-7): 251-267.

Pierson, P. (2001). The new politics of the welfare state. Oxford ; New York, Oxford University Press.

Pierson, P. (2001). Post-Industrial Pressures on the Mature Welfare States. The New Politics of Welfare States. P. Pierson. Cambridge, Cambridge University Press.

Pierson, P. (2004). Politics in time : history, institutions, and social analysis. Princeton, N.J. ; Oxford, Princeton University Press.

Pilichowska, H. (1931). "Ubezpieczenie Pracownikow Umyslowych na Wypadek Braku Pracy." Praca i Opieka Spoleczna XI(3): 345-348.

Plawucka, H. (1991). Swiadczenia Emerytalne i Rentowe. Rozwoj Ubezpieczen Spolecznych w Polsce. C. Jackowiack. Wroclaw, Ossolineum.

Pławucka, H. (1983). "Ubezpieczenie społeczne indywidualnych rolników." Praca i Zabezpieczenie Społeczne(4): 11-26.

Polakowski, M. and D. Szelewa (2008). "Zasiłki dla osób bezrobotnych w Europie Środkowo-Wschodniej - analiza konfiguracyjna." Problemy Polityki Społecznej(11).

Polanyi, K. (1957). The great transformation. Boston,, Beacon Press.

Prasznic, U. (1989). "Fundusze ubezpieczeń społecznych a budżet państwa." Praca i Zabezpieczenie Społeczne(11/12): 18-22.

Pronobis, W. (1996). Polska i świat w XX wieku. Warszawa, Editions Spotkania.

Radzimowski, Z. (1963). "Świadczenia pieniężne w węgierskim ubezpieczeniu społecznym." Praca i Zabezpieczenie Społeczne(8/9): 48-52.

Radzimowski, Z. (1991). System Finansowy Ubezpieczen Spolecznych. Rozwoj Ubezpieczen Spolczncyh w Polsce. C. Jackowiack. Wroclaw, Ossolineum.

Radziński, T. (1981). "Kierunki dalszego rozwoju systemu zaopatrzenia emerytalnego (propozycje zmian i uzupełnień)." Praca i Zabezpieczenie Społeczne(3): 2-6.

Radziński, T. (1983). "Nowa ustawa emerytalna." Praca i Zabezpieczenie Społeczne(1): 1-14. 
Ragin, C. (1994). A Quantitative comparative Analysis of Pension Systems. The Political Economy of the Welfare State. T. Janoski and A. Hicks. Cambridge, Cambridge University Press.

Ragin, C. (2000). Fuzzy-set social science. Chicago and London, The University of Chicago Press.

Ragin, C. C. (1987). The comparative method : moving beyond qualitative and quantitative strategies. Berkeley, University of California Press.

Ragin, C. C. (2008). Redesigning social inquiry : fuzzy sets and beyond. Chicago, University of Chicago Press.

Rayner, J. (2009). "Understanding Policy Change as a Historical Problem." Journal of Comparative Policy Analysis 11(1): 83-96.

Rhodes, M. and M. Keune (2006). EMU and Welfare State Adjustement in Central and Eastern Europe. Enlarging the Euro Area. External Empowerment and Domestic Transformation in East Central Europe. K. Dyson. Oxford, New York, Oxford University Press.

Riboud, M., C. Sánchez-Páramo, et al. (2002). Does eurosclerosis matter? : institutional reform and labor market performance in Central and Eastern Europe. Washington, DC, World Bank.

Rihoux, B. and H. M. Grimm (2006). Innovative comparative methods for policy analysis : beyond the quantitative-qualitative divide. New York, NY, Springer.

Rimlinger, G. V. (1971). Welfare policy and industrialization in Europe, America, and Russia. New York,, Wiley.

Roland, G. (2000). Transition and economics : politics, markets, and firms. Cambridge, Mass., MIT Press.

Romsics, I. (1995). István Bethlen : a great conservative statesman of Hungary, 1874-1946. Boulder, Colo.

Highland Lakes, N.J.

Romsics, I. (1999). Hungary in the twentieth century. Budapest, Corvina : Osiris.

Rostgaard, T. (2000a). Recommendations for data and indicator development for ECEC systems. Paris, OECD.

Roszkowski, W. (2003). Najnowsza Historia Polski 1914-1945. Warszawa, Świat Książki. Roszkowski, W. (2003). Najnowsza Historia Polski 1945-1980. Warszawa, Świat Książki.

Rozniewicz, K. (1931). "Fundusz Bezrobocia i Jego Dzialalnosc." Praca i Opieka Spoleczna XI(3): 340-345.

Rymsza, M. (1998). Urynkowienie Panstwa czy Uspolecznienie Rynku? Kwestia Socjalna w Trzeciej Rzeczypospolitej na Przykladzie Ubezpieczen Spolecznych. Warszawa, TEPIS.

Sajo, A. (2006). Social Rights as Middle-Class Entitlements in Hungary: The Role of the Constitutional Court. Courts and Social Transformation in New Domocracies: An 
Institutional Voice for the Poor? R. Gargarella, P. Domingo and T. Roux. Aldershot, Ashgate.

Schmitter, P. C. and G. Lehmbruch (1979). Trends toward corporatist intermediation.

London ; Beverly Hills, SAGE.

Schwartz, H. (2001). Round Up the Usual Suspects! Globalization, Domestic Politics and Welfare State Change. The New Politics of Welfare State. P. Pierson. Cambridge, Cambridge University Press.

Seeleib-Kaiser, M. (2008). Welfare State Transformation in Comparative Perspective: Shifting Boundaries of 'Public' and 'Private' Social Policy? Welfare State Transformations. Comparative Perspectives. M. Seeleib-Kaiser. Basingstoke, Palgrave Macmillan.

Seleny, A. (2006). The political economy of state-society relations in Hungary and Poland: from communism to the European Union. Cambridge ; New York, Cambridge University Press.

Simon, G. (1928). Zagadnienie Społeczne w Konstytucji Polskiej. Warszawa, Skład Główny Księgarni F. Hoesicka.

Simonovits, A. (2008). The Pay-As-You-Go System and Permanent Reform: The First Pillar. Assessin Intergenerational Equity. An Interdisciplinary Study of Agin and Pension Reform in Hungary. R. I. Gal, I. Iwasaki and Z. Szeman. Budapest, Akademiai Kiado.

Sissenich, B. (2007). Building states without society: European Union enlargement and the transfer of EU social policy to Poland and Hungary. Lanham, MD, Lexington Books.

Skocpol, T. (1992). Protecting soldiers and mothers : the political origins of social policy in the United States. Cambridge, Mass., Belknap Press of Harvard University Press.

Skoczyński, J. (2001). "Ustalanie kapitału początkowego ubezpieczonego w ubezpieczniu emerytalnym." Praca i Zabezpieczenie Społeczne(1): 31-35.

Stark, D. and L. Bruszt (1998). Postsocialist Pathways. Transforming Politics and Property in East Central Europe. Cambridge, Cambridge University Press.

Starke, P. (2006). "The Politics of Welfare State Retrenchment: A Literature Review." Social Policy \& Administration 40(1): 104-120.

Starke, P. (2008). Radical welfare state retrenchment : a comparative analysis. Basingstoke [England] ; New York, Palgrave Macmillan.

Steinmo, S. (1993). Taxation and democracy : Swedish, British, and American approaches to financing the modern state. New Haven, Yale University Press.

Streeck, W. (2009). Re-Forming Capitalism. Institutional Change in the German Political Economy. Oxford, Oxford University Press.

Streeck, W. and K. Thelen (2005). Introduction: Institutional Change in Advanced Political Economies. Beyond Continuity. Institutional Change in Advanced Political Economies. W. Streeck and K. Thelen. Oxford, Oxford University Press. 
Streeck, W. and K. A. Thelen (2005). Beyond continuity : institutional change in advanced political economies. Oxford ; New York, Oxford University Press.

Szalai, J. (1992). Social policy and child poverty: Hungary since 1945. Florence, UNICEF.

Szelewa, D. and M. Polakowski (2006). Who cares? Patterns of Care in Central and Eastern Europe the 4th Annual ESPAnet Conference 2006, Transformation of the Welfare State: Political Regulation and Social Inequality, 21-23 September 2006 Bremen, Germany.

Szelewa, D. and M. Polakowski (2008). "Who Cares? Changing Patterns of Childcare in Central and Eastern Europe " Journal of European Social Policy 18(2): 115-131.

Szeman, Z. (1999). The politics of old age in Hungary. The politics of old age in Europe. A. Walker and G. Naegele. Buckingham, Open University Press.

Szikra, D. (2004). "The Thorny Path to Implementation: Bismarckian Social Insurance in Hungary in the Late 19th Century." European Journal of Social Security 6(3): 255272.

Szikra, D. (2005). Family and Child Support in a Post-Communist Society - Origins of the Mixed Hungarian Welfare Capitalism. Third Annual ESPAnet Conference "Making Social Policy in the Postindustrial Age" September 22-24, 2005. University of Freiburg, Switzerland.

Szikra, D. (2007). Family and Child Support in a Postcommunist Society: Origins of the Mixed Hungarian Welfare Capitalism. Fighting Poverty and Reforming Social Security: What Can Post-Soviet States Learn from the New Democracies of Central Europe? EES Special Report M. Cain, N. Gelazis and T. Inglot. Washington, Woodrow Wilson International Center for Scholars. East European Studies.

Szikra, D. (2007). From Bismarck to the New Pension Orthodoxy. The Historical

Development of the Pension System in Hungary. Institutions, Knowledge and Change. The Danish Pension System in International Comparison. Odense, University of Southern Denmark.

Szumlicz, T. (1999). Reforma zabezpieczenia emerytalno-rentowego. Druga Fala Polskich

Reform. L. Kolarska-Bobińska. Warszawa, Instytut Spraw Publicznych.

Szumlicz, T. (2004). Reforma Systemu Zabezpieczenia Spolecznego: ku Rozwiazaniom

Ubezpieczeniowym. Reforrmy Spoleczne. Biland Dekady. M. Rymsza. Warszawa, Instytut Spraw Publicznych.

Taylor-Gooby, P. (2004). New Risks, New Welfare. The Transformation of the European Welfare State. Oxford, Oxford University Press: 280 p.

Thelen, K. (2004). How institutions evolve : the political economy of skills in Germany, Britain, the United States, and Japan. Cambridge ; New York, Cambridge University Press.

Tomka, B. (2004). Welfare in East and West : Hungarian social security in an international comparison, 1918-1990. Berlin, Akademie-Verlag. 
Tworzecki, H. (2006). "Welfare-State Attitudes and Electoral Outcomes in Poland and Hungary." Problems of Post-Communism 47(6): 17-28.

Vanhuysse, P. (2006). Divide and pacify : strategic social policies and political protests in post-communist democracies. Budapest ; New York, Central European University Press.

Vaughan-Whitehead, D. (1995). Minimum Wages in Central and Eastern Europe: Slippage of the Anchor Minimum Wages in Central and Eastern Europe: From Protection to Destitution. G. Standing and D. Vaughan-Whitehad. Budapest, ILO and CEU.

Whiteside, N. (2003). Historical Perspective and the Politics of Pension Reform. Pension Security in the 21st Century. Redrawing the Public-Private Debate. G. L. Clark and N. Whiteside. Oxford, Oxford University Press.

Wiktorow, A. (1980). Zmiany Poziomu i Struktury Rent Emerytur. Warszawa, Instytut Pracy i Spraw Socjalnych.

Wilensky, H. L. (1975). The welfare state and equality : structural and ideological roots of public expenditures. Berkeley ; London, University of California Press.

Williamson, J. (1990). What Washington Means by Policy Reform. Latin American Adjustment: How Much Has Happened? J. Williamson. Washington, Institute for International Economics.

World Bank. (1994). Averting the old age crisis : policies to protect the old and promote growth. Oxford; New York, Published for the World Bank [by] Oxford University Press.

Wyczańska, B. (1990). "Zmiany w przepisach emerytalno-rentowych w 1990 roku." Praca i Zabezpieczenie Społeczne(7-9): 60-64.

Znyk, W. (1975). "Renta za Ziemię-Świadczeniem Socjalnym?" Polityka Spoleczna 19(6): 2427.

ZUS (1989). Niektóre Aspekty Reformy Ubezpieczeń Społecznych na Wegrzech. Warszawa, Zakład Ubezpieczeń Społecznych.

ZUS (2005). 70 Lat Ubezpieczen Spolecznych w Polsce (1934-2004). Warszawa, ZUS.

Żochowski, D. (2003). Falowanie aktywności gospodarczej. Polska Gospodarka w XX Wieku. Eseje historyczno-ekonomiczne. J. Beksiak, T. Gruszecki, U. Grzelońska, J. Papuzińska and D. Żochowski. Warszawa, Wydawnictwo Literatura.

Żukowski, M. (1999). The New Polish Pension Laws. Transformation of Social Security: Pensions in Central-Eastern Europe. K. Muller, A. Ryll and H.-J. Wagener. Heidelberg, Physica-Verlag. 


\section{SAMENVATTING}

\section{DE INSTITUTIONELE TRANSFORMATIE VAN HET SOCIALE BELEID IN OOST- CENTRAAL-EUROPA:}

\section{POLEN EN HONGARIJE IN VERGELIJKEND EN HISTORISCH PERSPECTIEF}

Dit proefschrift begon met een empirische puzzel: de waargenomen diversiteit van sociale beleidsafspraken in Oost-Centraal-Europa. De hoofdvraag luidde: waarom bestaat er zo'n zichtbaar opvallende diversiteit in sociaal beleid tussen de staten in deze regio die uiterlijk niet alleen dezelfde sociale, politieke en economische omstandigheden delen, maar die ook samen een staatssocialistische periode doormaakten?

Om deze vragen te kunnen beantwoorden richtte ik mijn proefschrift op de kenmerken van sociale beleidsprogramma's, de dynamiek daarvan na verloop van tijd en de processen die hebben bijgedragen - en nog steeds bijdragen - aan de institutionele ontwikkeling van deze beleidslijnen. Om deze punten te kunnen analyseren probeerde ik in mijn proefschrift met antwoorden te komen op de volgende sleutelvragen: wat zijn de kenmerken, de logica en de dynamiek van de sociale beleidsverandering na de val van het communisme; en wat zijn de processen die hebben bijgedragen aan de waargenomen sociale beleidskenmerken?

De globale strategie voor de analyse bestond uit een tweefasenbenadering, die zou corresponderen met de twee vragen die net gesteld zijn. In de eerste fase van mijn onderzoek heb ik de hoofdrelaties in het postsocialistische sociale beleid geïdentificeerd. In de tweede fase heb ik juist de grove lijnen geschetst van de mechanismen die bijdragen aan processen van institutionele reproductie met betrekking tot sociaal beleid. Deze twee fasen zijn elkaar niet vreemd; integendeel, ik stel dat ze een gemeenschappelijkheid hebben die aan de kern ligt van beleidsopeenvolging, dynamiek en de temporele dimensie.

In het eerste deel van het proefschrift heb ik een innovatief onderzoeksinstrument toegepast - de fuzzy sets ideal-types-analyse. Ik heb de belangrijkste institutionele kenmerken onderzocht van drie terreinen binnen 
sociaal beleid: werkloosheidsuitkeringen, gezinsbeleid (zwangerschaps- en ouderschapsverlof, kinderopvang) en pensioenen in de groep van acht landen die in 2004 is toegetreden tot de Europese Unie: Tsjechië, Estland, Hongarije, Letland, Litouwen, Polen, Slowakije en Slovenië. Ik heb gekeken naar de relatie tussen de verschillende institutionele logica van sociale beleidsprogramma's uitgedrukt in de beginsels die ontvankelijkheid, vrijgevigheid en kwaliteit bepalen. Hieruit kunnen we de relaties tussen staat, markt en gezinnen met een uitkeringsvoorziening concluderen. Indien er sprake zou zijn van één enkele onderliggende logica, dan zou het kunnen zijn dat er één 'postcommunistisch' model van sociaal beleid bestaat, zoals gesuggereerd door de stelling 'één Oost-Europees regime'. Indien dit niet het geval is en de regio Centraal-Europa wordt gekenmerkt door intern uiteenlopend beleid, dan zou de analyse verder moeten gaan dan de benadering van 'gemeenschappelijke ervaring' en zich meer moeten richten op de specifieke ontwikkelingen van een land en de redenen daarvoor.

De uitgevoerde vergelijking liet een breed spectrum aan beleidsmixen zien. Dit vormde een rijke illustratie van het empirische probleem dat het beginpunt van dit proefschrift was en gaf tegelijkertijd antwoord op de onderzoeksvraag over de kenmerken van de belangrijkste sociale beleidsprogramma's in deze acht landen. De tweede fase van het onderzoek omvatte een vergelijkend historische analyse van ouderdomspensioenregelingen in twee landen met een opvallend afwijkend resultaat na pensioenbeleidshervorming: Hongarije en Polen. Door de informatie van de historisch institutionalistische benadering stelde ik dat je eerst inzicht moet hebben in de historische ontwikkeling van sociale beleidsprogramma's na de oprichting om het huidige sociale hervormingsbeleid te begrijpen.

Met de vergelijkend historische overtuiging creëerde ik een unieke mogelijkheid om waar te nemen hoe verschillende bouwstenen van sociale beleidslagen naast elkaar kunnen bestaan en elkaar kunnen verdringen. De historische ontwikkeling van sociaal beleid is niet altijd een lineair en gepland proces, zoals blijkt uit de casestudies. Voor institutionele innovatie geldt een soortgelijke waarneming: het gebeurt zelden en een specifiek aantal voorwaarden is hiervoor vereist. In plaats daarvan werken beleidsmakers met materiaal dat ze voorhanden hebben en dat uit de aard der zaak historisch in zijn context is geplaatst en gekoppeld aan andere elementen van sociale systemen.

Het proefschrift heeft op drie fronten bijgedragen aan het begrijpen van welvaartshervorming in Oost-Centraal-Europa - en dan in het bijzonder in Hongarije en Polen: met betrekking tot beleidsanalyse, methodologie en sociale theorie. Ten opzichte van de beleidsanalyse heeft het onderzoek aangetoond dat verschillende sociale beleidsdomeinen wisselende dynamieken hebben, zowel met het oog op de inter- als op de intralandelijke vergelijkingen. Op het punt van 
methodologie toonde een vernieuwde focus op de temporale dimensie van beleid maken en haar dynamiek aan dat historisch politieke en economische procesopeenvolging van belang zijn voor het begrijpen van de huidige beleidsontwikkelingen. Ten slotte wat betreft de theoretische bijdrage van dit onderzoek, heeft het proefschrift een proces verhelderd - institutionele herconfiguratie - dat een rijkere en rigoureuzere verklaring biedt van de evolutie van het sociale beleid in Oost-Centraal-Europa. 


\section{CURriculum VitaE}

Michal Polakowski was born in 1979 in Częstochowa, Poland. Michal started his university education at Warsaw University, Institute of Social Policy, where he obtained MA degree in 2003. He also holds MA degree in political sociology from Dalarna University, Sweden (2003) and MA degree in political science from Central European University, Hungary (2005).

Michal started his PhD in the Maastricht Graduate School of Governance in 2005. He was a visiting researcher at European University Institute, Florence, University of Bath, Danish National Institute for Social Research and University of Southern Denmark.

Michal is a winner of the 2007 edition of the ESPAnet/Journal of European Social Policy doctoral researcher prize. He is a co-founder of the International Centre for Research and Analysis, an independent Warsaw-based think-tank engaged in public policy research. 


\section{MGSOG DISSERTATION SERIES}

Florian Tomini

Between Family and Friends. Understanding the interdependency of private transfers

MGSoG Dissertation Series, nr 15 (2010)

Michał Polakowski

The Institutional Transformation of Social Policy in East Central Europe: Poland and Hungary in comparative and historical perspective

MGSoG Dissertation Series, nr 14 (2010)

Maha Ahmed

Defining, Measuring and Adressing Vulnerability: The Case of Post Conflict Environments

MGSoG Dissertation Series, nr 13 (2010)

Pascal Beckers

Local Space and Economic Success. The role of spatial segregation of migrants in the Netherlands

MGSoG Dissertation Series, nr 12 (2011)

Victor Cebotari

Conflicting Demands in Ethnically Diverse Societies Ethnopolitical Contention and Identity Values in Europe

MGSoG Dissertation Series, nr 11 (2010)

Dennis Gyllensporre

Competing and Complementary Perspectives on the EU as a Crisis Management Actor: An Examination of the Common Security and Defence Policy through the Lenses of Idealism and Realism MGSoG Dissertation Series, nr 10 (2010)

Judit Vall Castello

Business Cycle and Policy Effects on Labour Market Transitions of Older and Disabled Workers in Spain

MGSoG Dissertation Series, nr. 9 (2010)

Keetie Roelen

False Positives or Hidden Dimentions: The definition and measurement of child poverty

MGSoG Dissertation Series, nr. 8 (2010) 
Denisa Maria Sologon

Earning Dynamics in Europe

MGSoG Dissertation Series, nr. 7 (2010)

Melissa Siegel

Money and Mobility: Migration and Remittances

MGSoG Dissertation Series, nr. 6 (2010)

Jessica S. Hagen-Zanker

Modest Expectations: Causes and effects of migration on migrant households in source countries

MGSoG Dissertation Series, nr. 5 (2010)

Mirtha R. Muniz Castillo

Human Development and Autonomy in Project Aid: Experiences from four bilateral projects in Nigaragua and El Salvador

MGSoG Dissertation Series, nr. 4 (2009)

Christiane Arndt

Governance Indicators

MGSoG Dissertation Series, nr. 3 (2009)

Britta Augsburg

Microfinance - Greater Good or Lesser Evil?

MGSoG Dissertation Series, nr. 2 (2009)

Geranda Notten

Measuring and Managing Poverty Risks

MGSoG Dissertation Series, nr. 1 (2008) 